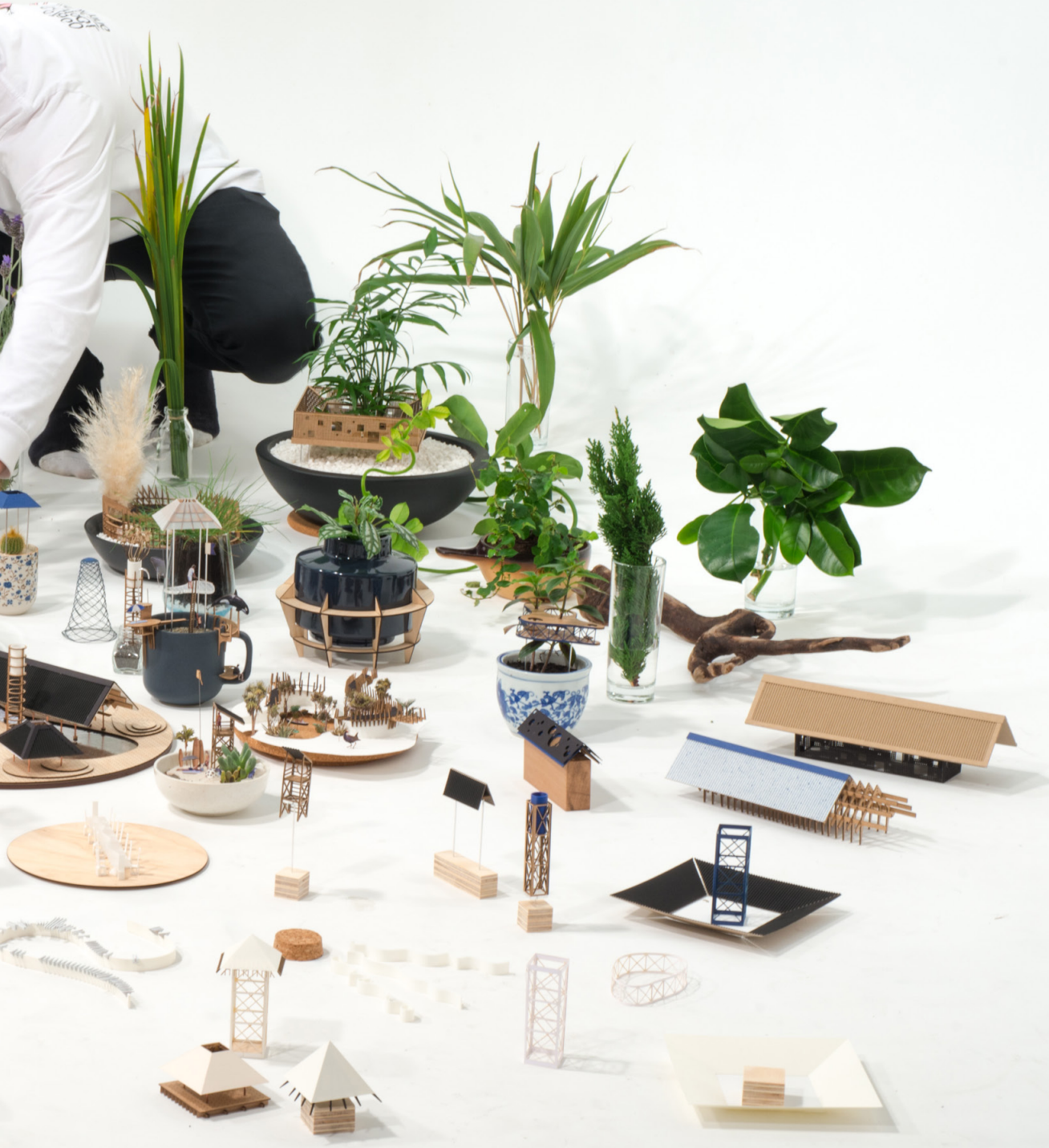




\section{Spatializing the Image}

Joe Batchelor

A 120-point thesis submitted to the Victoria University of Wellington in partial fulfilment of the requirements for the degree of Master of Architecture (Professional)

Victoria University of Wellington School of Architecture

2020

Note: All images within this document were presented at the $75 \%$ final visual presentation and are part of this document for the purpose of clarification. 


\section{Abstract}

Modern society has become ocular-centric as a result of technological development making the production and distribution of images easier than ever before. This ocular bias extends to architecture. Rather than resisting the increasingly ocular-centric nature of our social-media driven culture, this research aims to find new methods for designing space which incorporate a tactile process. This process simultaneously focuses on the creation of marketable perspectives. Through this research I advocate for tactility in the design process to evoke spatial awareness of the image.

This research portfolio operates through a design-led research methodology where knowledge is uncovered by designing. Hundreds of models were produced and critically reflected upon in terms of both their process and outcome. The research culminates with the development of a design process centred on using architectural models as design tools. Referred to as devices, these models are spatial systems that are able to be manipulated by hand to alter the composition of a perspective view. Although focusing on the image, the physicality of the devices implicate spatial awareness in the design process ensuring the design is considered in both two and three dimensions.

A design for the proposed Kapiti Island Biosecurity Gateway Centre formed an architectual testing ground which was used to evalute the design process developed in this research. Influenced by the design process the architecture itself also became an optical device. The resulting design controls and composes views through concealing, revealing, superimposing, aligning and framing particular elements. The final outcome provides visitors with a choreographed journey of highly considered perspective compositions. 


\section{Proposition}

How can the design process spatialize the image?

\section{Acknowledgements}

My supervisior Sam Kebbell.

Jaimee, family \& classmates.

Thank you, without you this would not have been possible.

Note: All images within this document were presented at the $75 \%$ final visual presentation and are part of this document for the purpose of clarification. 


\section{Introduction}

Study One. Spatializing an Idea

Spatial design

Study Four: Framing the Shot

\section{Design Vehicle}

Study Five: Setting the Scene

\section{Developed Process}

Tourism and the image

Architectural Model As a Device

Kapiti Island Tourism

Material Swatch Device

Dune Superimposition Device

Boatshed Viewing Device

Kapiti Island Gateway Centre Feasibility Study

Island Aperture Device

Two-way Landscape Mock-up

Site: Paraparaumu Beach

Site: Kapiti Boating Club

Pier Devices

Fernery Composition Diorama

Design Response

\section{Context}

Smout Allen

Nat Chard

Georges Rousse

\section{Conclusion}

Device Based Process

Architectural result

Critical Reflections

Kapiti Island Biosecurity Gateway

Beach Art: Doing What You Love

Mediums

Physical Models

Models as Machines 
Chapter One

INTRODUCTION 


\section{Society of the Spectacle}

Technological developments has made the production and distribution of images easier than ever before. Juhani Pallasmaa states that as a result of this, "Vison and hearing are now the privileged sociable senses" $(2015$, p. 15). Over eighty percent of everything we learn today comes through our eyes (Fox, 2013, p. 13). Life on Earth in the twenty-first century can be characterized by the near inability to avoid being constantly bombarded by images, described by Italo Calvino as an "unending rainfall of images" (1988, p. 57). This ocular bias extends to architecture. C.J. Lim suggests that "architectural production has moved from the built environment to other media such as film, photography and journalism, and the new sense of space is defined by images rather than walls" (2013, p. 104). Pallasmaa states that as a result of this bias, contemporary architecture has "adopted the psychological strategy of advertising and instant persuasion; buildings have turned into image products detached from existential depth and sincerity" $(2015$, p. 30$)$. Focusing too heavily on vison when designing can risk architecture becoming 'two-dimensional'.

Leon van Schaik describes Henri Lefebvre's remarks on modern technology and its effects on the spatial perception of those around him:

Penetratingly he remarked on the flattening out of our spatial awareness by the combined effects of traveling at speed and of seeing the world, not with our heads free in the air, but with them poised in a capsule of space, shielded by screens from the effects of moving. He thought this flattening of our awareness in time and spatial duration was compounded by the way in which we have become accustomed to receive information from screens, whether through movies, TV or terminals and monitors (2008, p.10).

\section{Spatial Design}

Hand drawing, digital drawing and even three-dimensional digital modelling all involve a two-dimensional visual interface with the architect. Tactile design processes in architecture are becoming increasingly less common. Physical models are being supplemented for a more time efficient option, digital modelling software. Models are often used only for communication purposes. While architects design space, few operate with space as a design medium. Using physical models as design tools is one possible method for introducing tactile three-dimensionality to the design process. This research portfolio advocates for the use of physical models, proposing that using them to design will allow the architect to cater for the ocular-centric society without losing touch of spatial quality. 
Chapter Two

DESIGN VEHICLE 


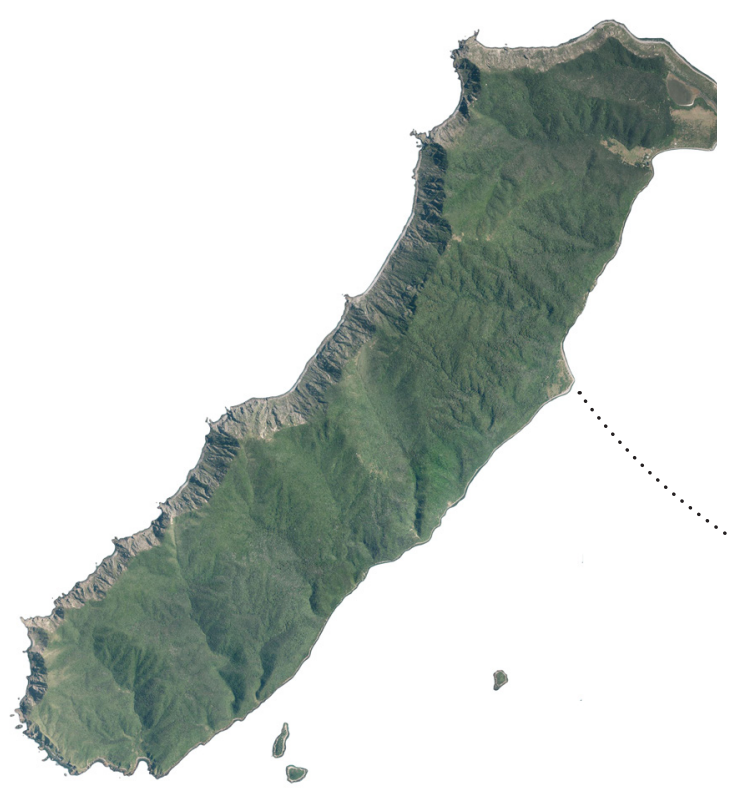

\section{$40^{\circ} 53^{\prime} 27.1^{\prime \prime} \mathrm{S} 174^{\circ} 58^{\prime} 50.2$ "E}

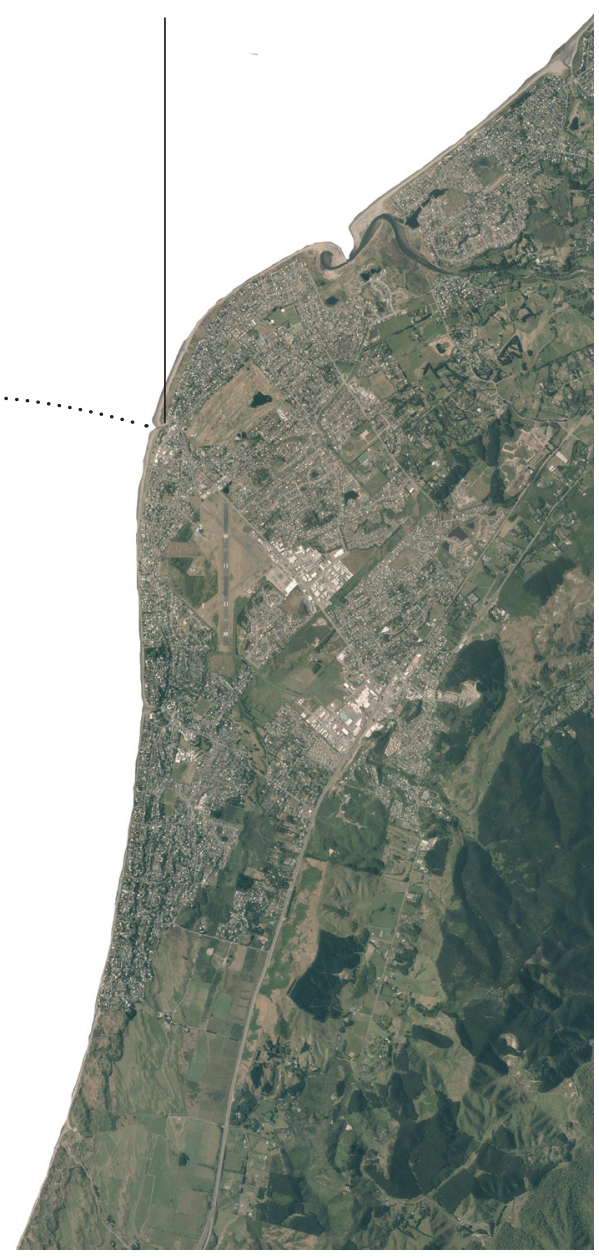

02. 1:100000 Kapiti Coast aerial. (LINZ, 2017) 


\section{Introduction}

The Kapiti Island Biosecurity Gateway project was selected to be the design vehicle of this research portfolio. Increased biosecurity procedures are necessary to cope with thousands of tourists visiting Kapiti Island each year. This forms an architectural opportunity to design a landmark building on Paraparaumu Beach for both tourists and locals.

\section{Tourism and the Image}

Tourism is about the gaze, it's about looking at things, and with the development of camera technology it's more and more about taking photos. Thanks to the instant results and embedded software of SLR, DSLR and smartphone cameras, photography today seems to neither require skill nor practice (Frazier, 2015). Modern tourists have a desire after viewing an image of an attraction, to visit the attraction and take their own image of it, often with themselves standing in the foreground.

Because of its relationship to the photograph, the tourism based programme of the Kapiti Biosecurity Gateway project was selected as the testing ground for this research. Tourists are likely to perceive in two-dimensions as they look for photo opportunities, and look through the camera lens. Because of this, it is appropriate to design architecture which responds to this type of perception. As Joan Ockman states "whether received in a mode of distraction or attention, perceived as background or foreground, architecture has always been an integral part of the tourist's experience" (2005, p. 35). There is potential for the design of the building to direct and assist tourists with their photography, and if the architecture supports well composed photographs it is likely tourists will be drawn there. 


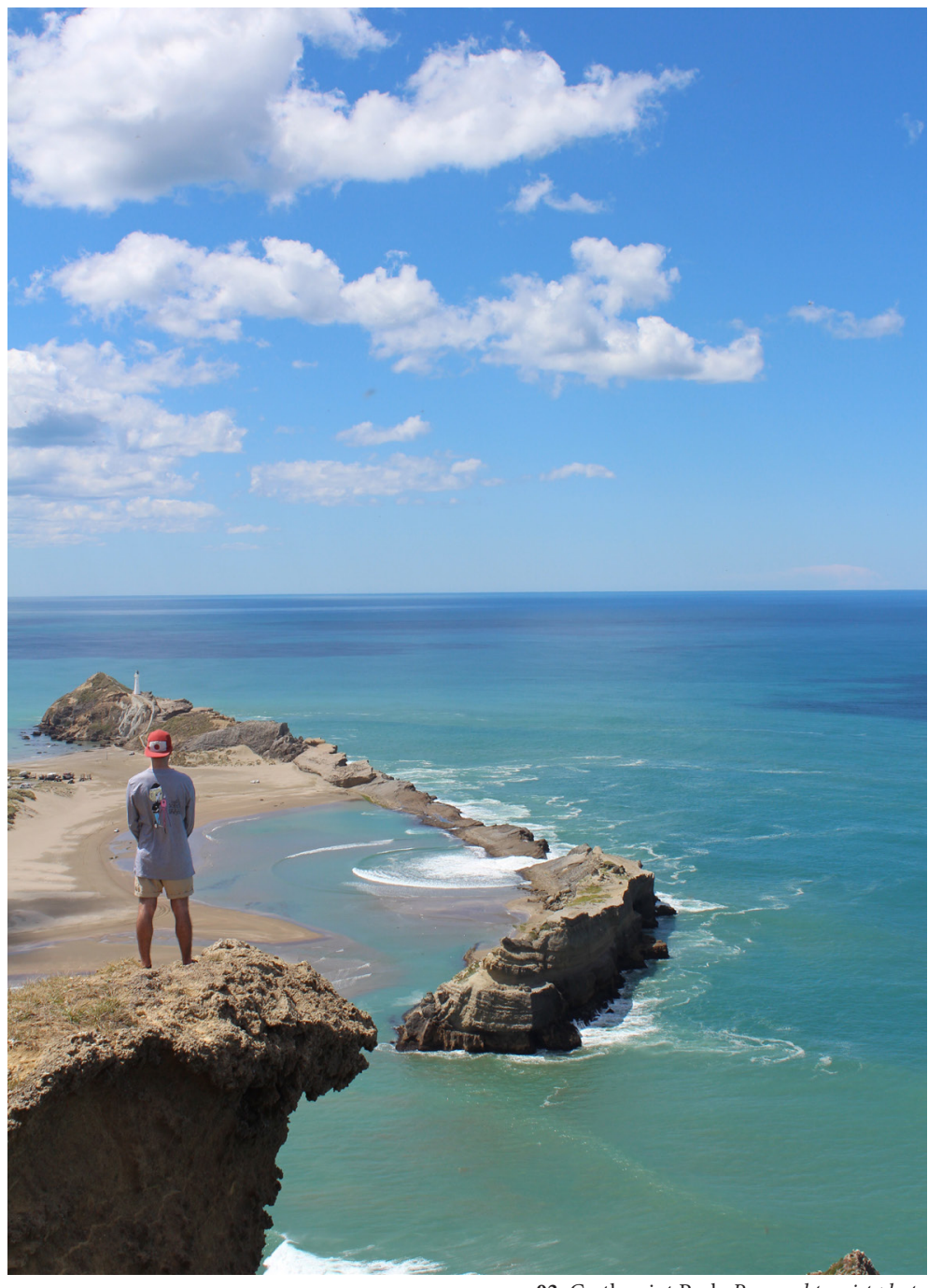

03. Castlepoint Peak. Personal tourist photo

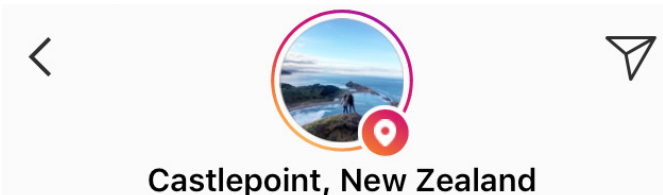

Castlepoint, New Zealand

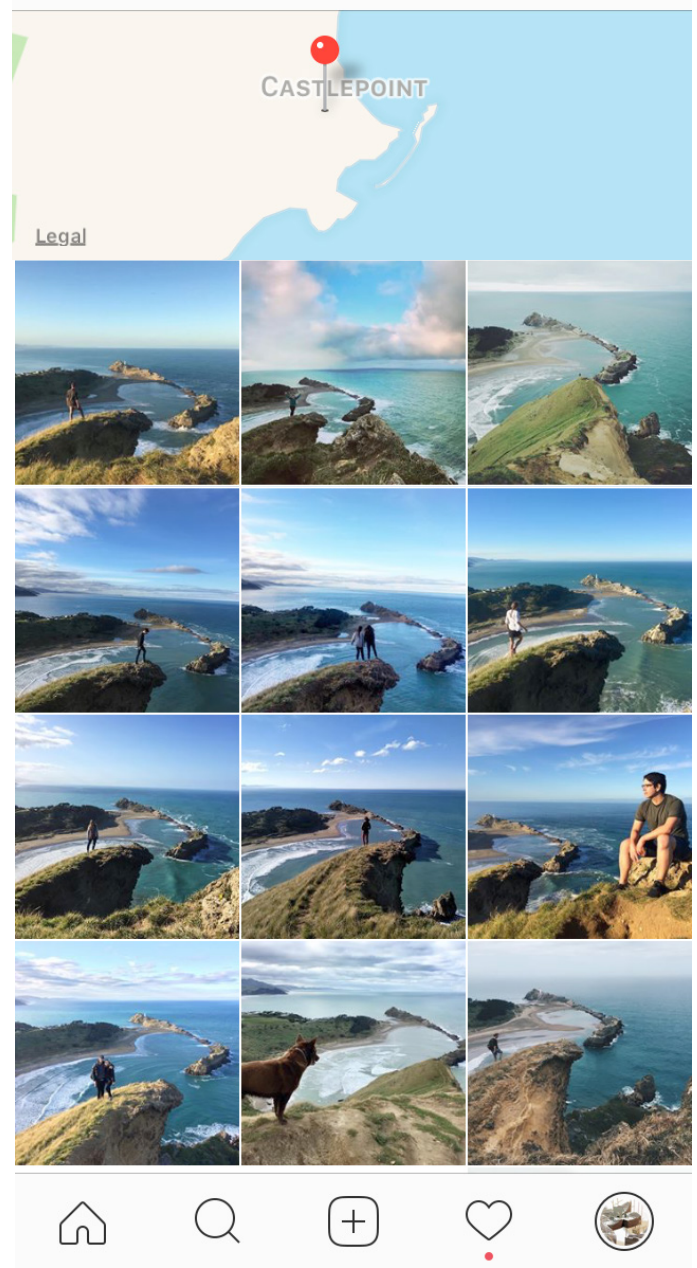

04. Generic tourist photo \#Castlepoint. (Instagram, 2017) 


\section{Kapiti Island Tourism}

Located $5 \mathrm{~km}$ off the west coast of New Zealand's North Island, Kapiti Island is a refuge from the mainland. Once used by Te Rauparaha and the Ngati Toa during the Maori Land Wars, the island is now a sanctuary for endangered native flora and fauna. Ten kilometres long and two kilometres wide Kapiti Island is a 1,965 ha sanctuary that has been predator-free since 1998. Takahē, kākā, kōkako and the little spotted kiwi are just some of the rare species which struggle on the mainland but flourish on the island (Department of Conservation, 2017, p. 2).

The unique ecosystem of Kapiti draws thousands of tourists to explore its rugged landscape every year. Jenny Fraser, the local tour boat operator stated that the island receives "roughly 12,000 people annually" and has a permit for 100 people per day (2017). There are a number of walks on the island and a few cabins for overnight stays. Due to the rugged terrain the majority of the activities require a good level of fitness such as tramping, bird watching, and snorkelling. 

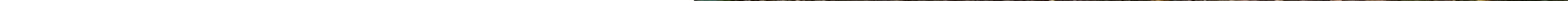


\section{Current Arrangement}

Biosecurity checking processes are required for everything departing to the island. Currently, tour boat companies run makeshift operations out of the boot of a car using trestle tables, and if raining, a flimsy fold-out pagoda. The current procedure involves a self-check process guided by the operator where visitors check their equipment for any invasive species and scrub their boots prior to boarding the boat. The current mayor of the Kapiti Coast district Krishnasami Gurunathan argues for the development of a hub including a best-practice security process rather than, "this shameful disgrace where visitors to our island are forced to undergo biosecurity checks on the tarmac in open weather" (quoted in Haxton, 2016, np). Former mayor Ross Church suggested that the island needs more visitors. Church stated, "we want more people to go there; we want to make more of a visual effort on the waterfront to help people get to the island" (Maxwell, 2014). The development of a biosecurity building has the potential to both ensure the environmental protection of the island and become a beacon to draw tourists to the island and wider region.
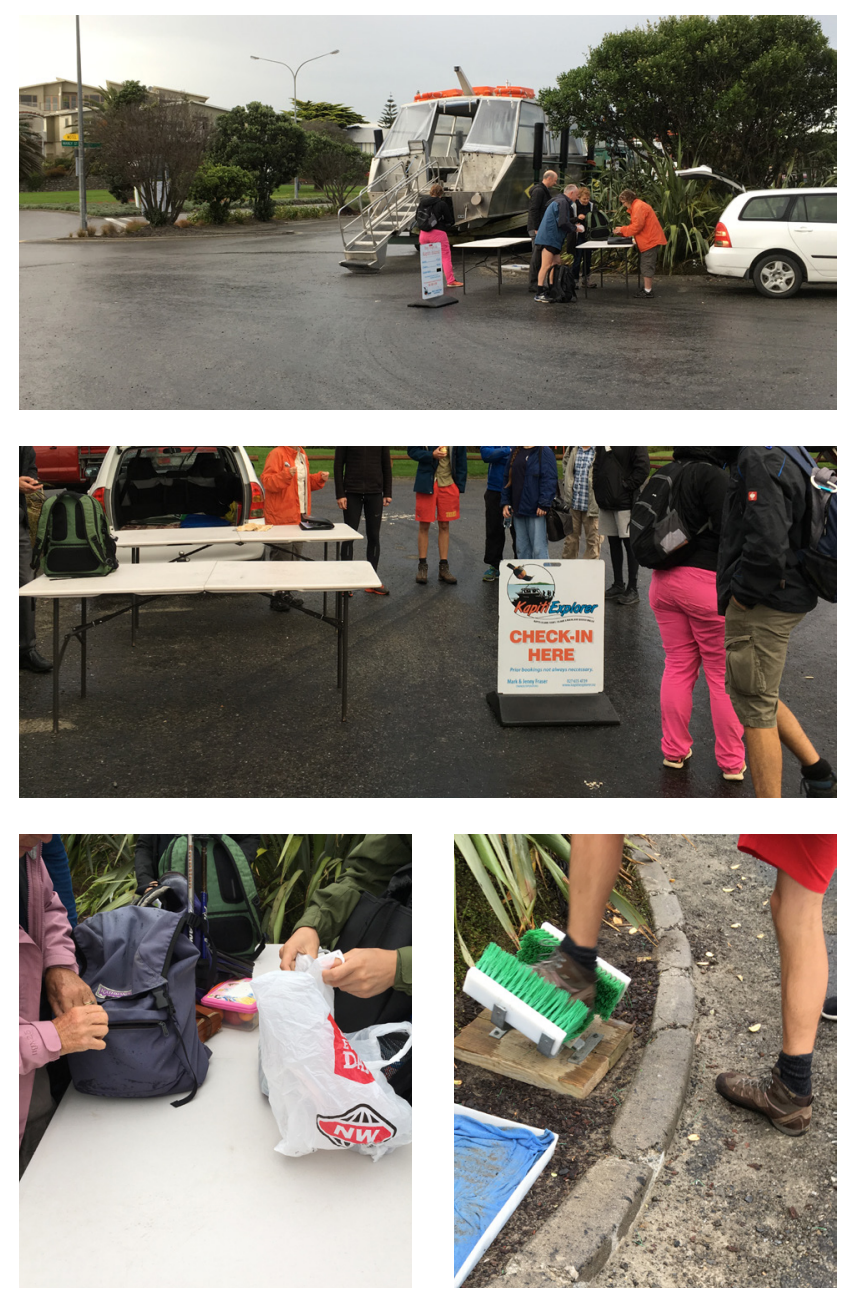

08. Current biosecurity process (28.02.17). Kapiti Boat Club carpark 


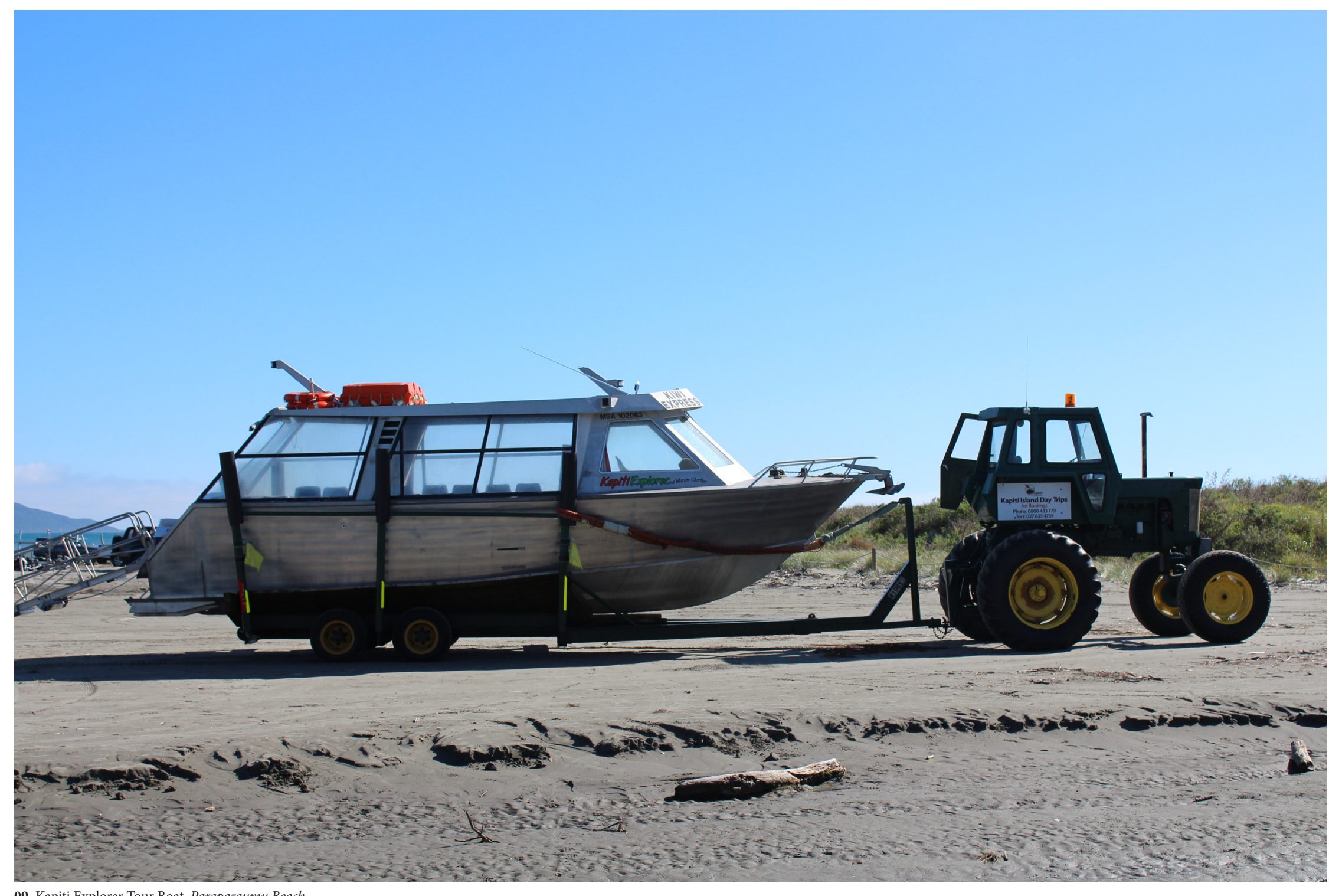



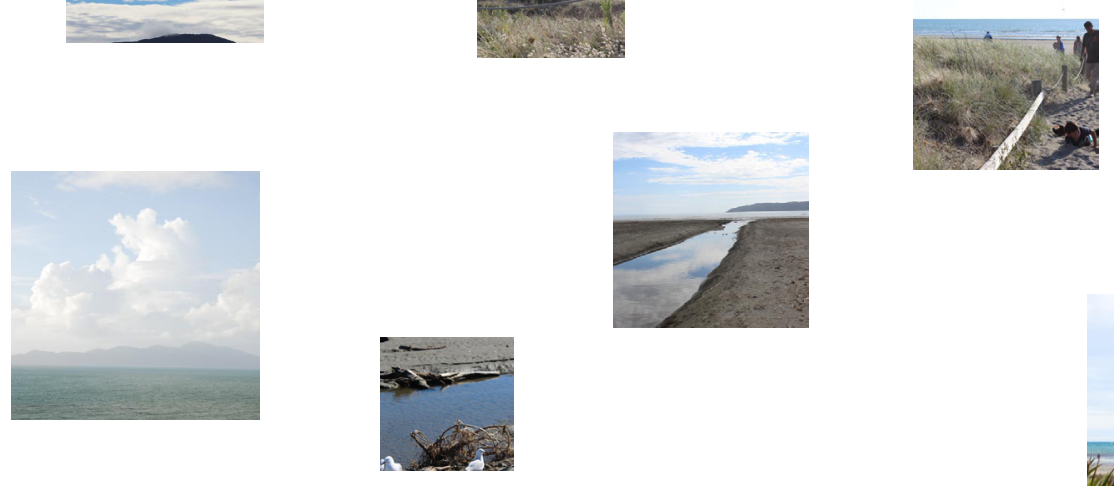

(1) ${ }^{n}{ }^{-1}$

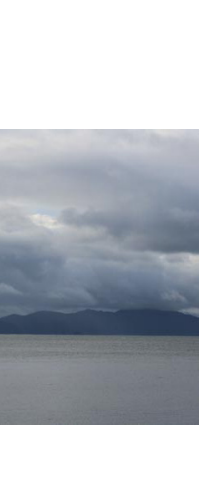

$x$
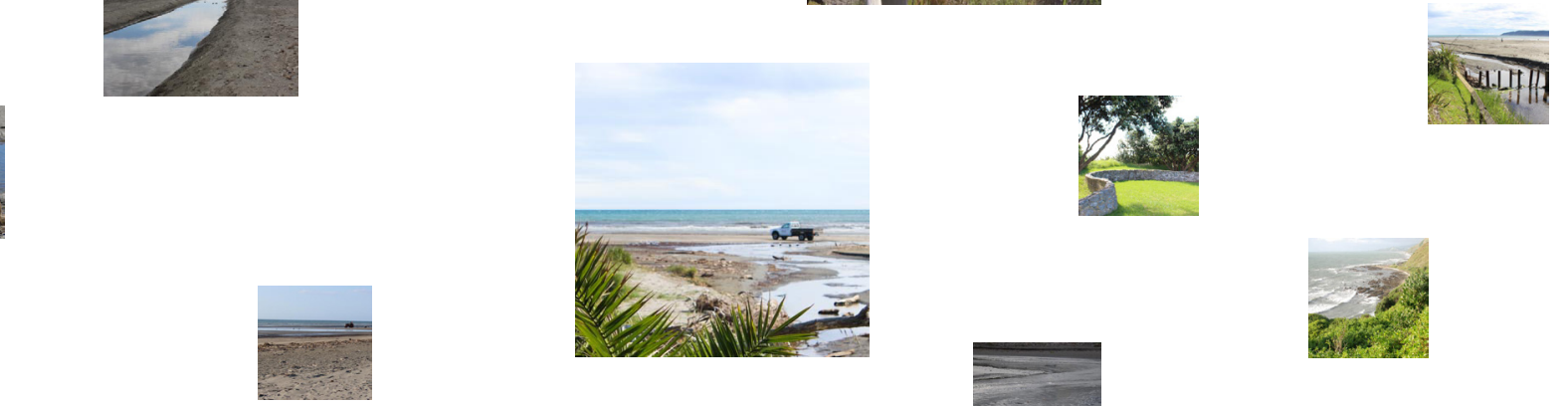

2.
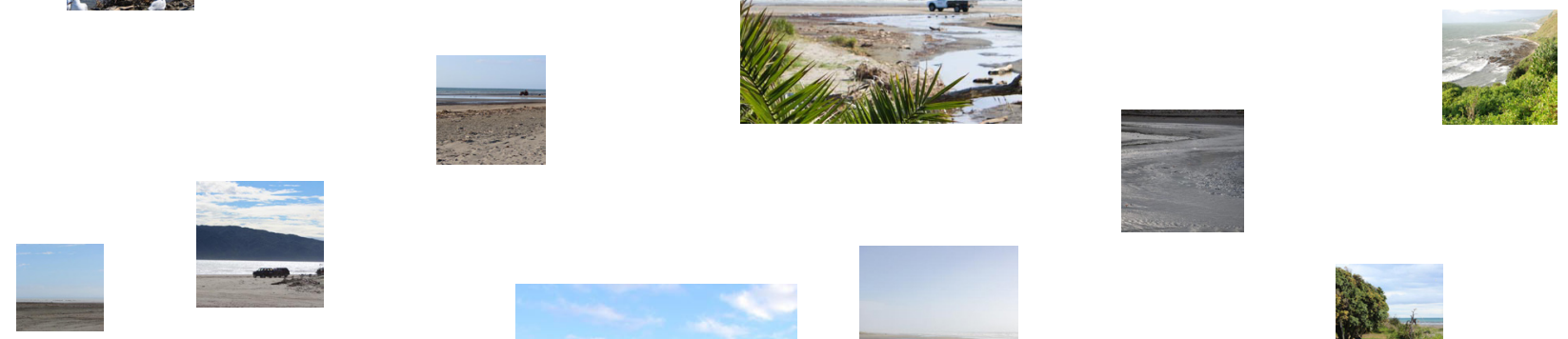

risey

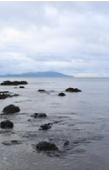

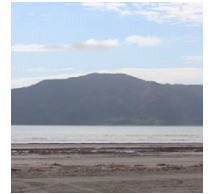
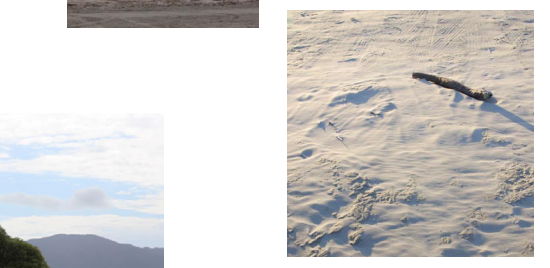

2

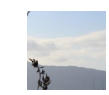
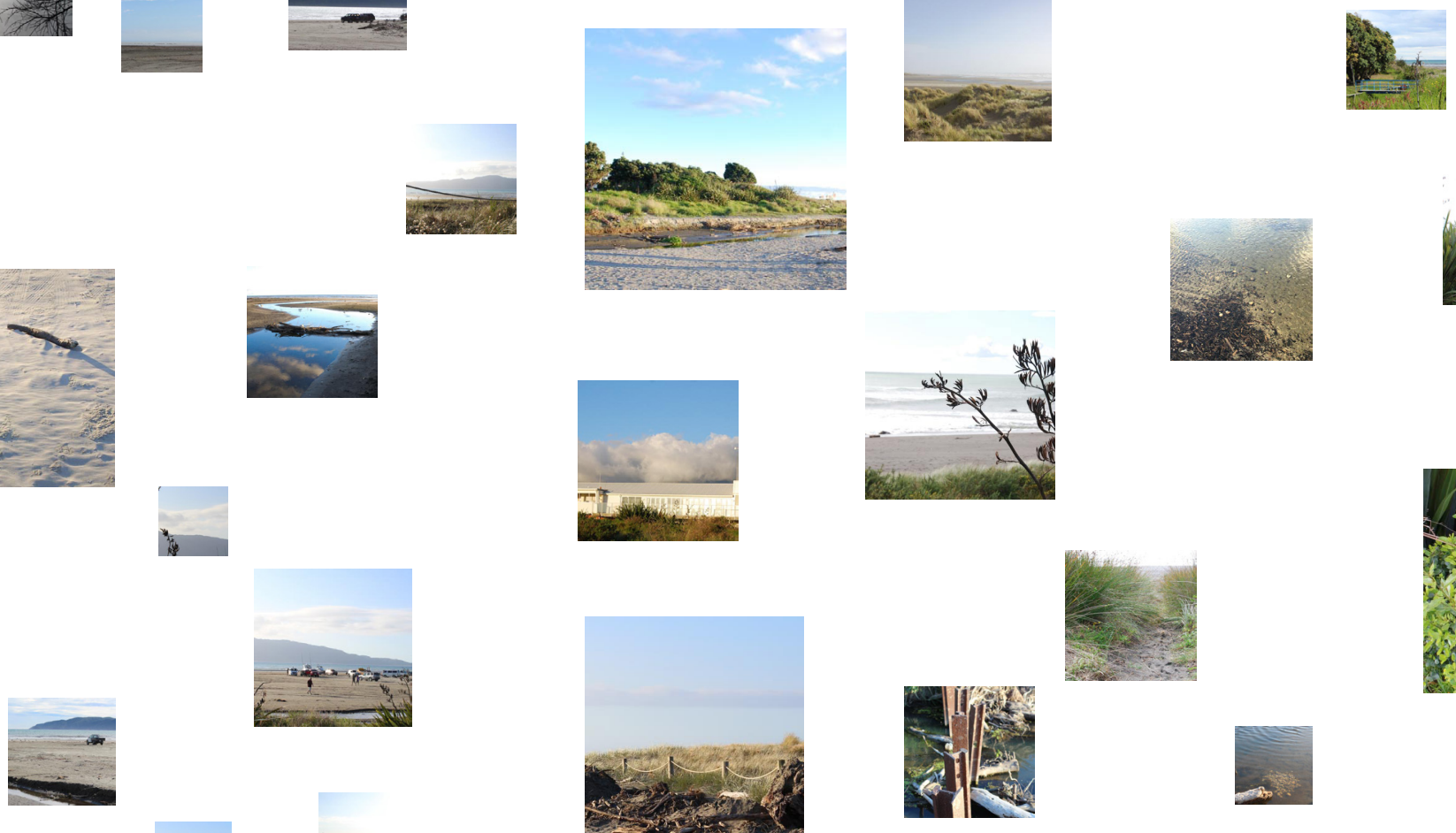

觜

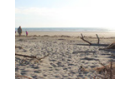

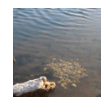

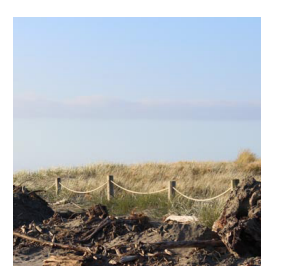

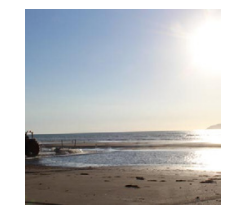

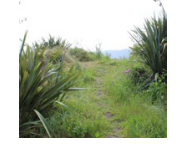
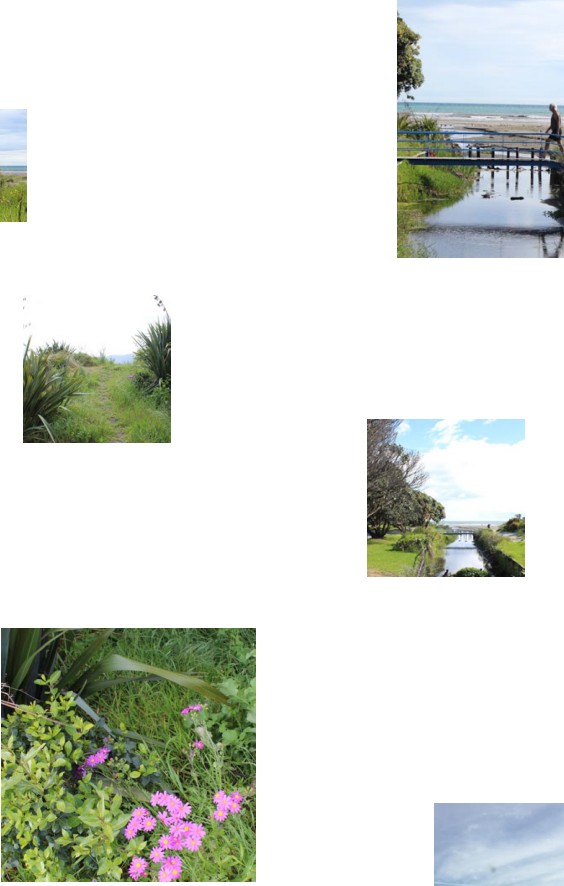

$$
x^{-x}
$$

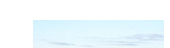


은 $\frac{1}{-15}$
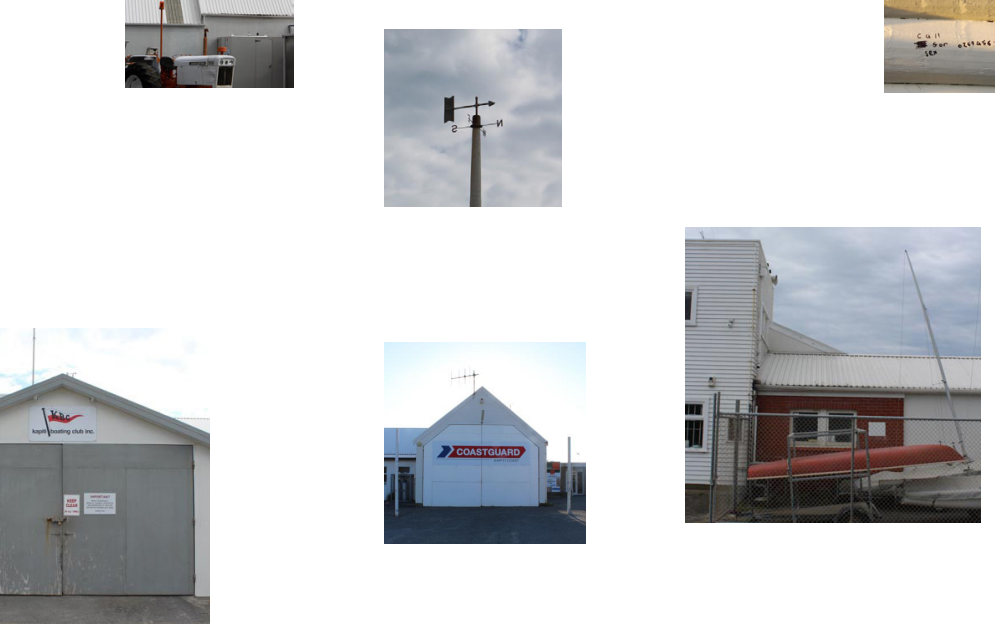

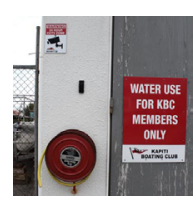
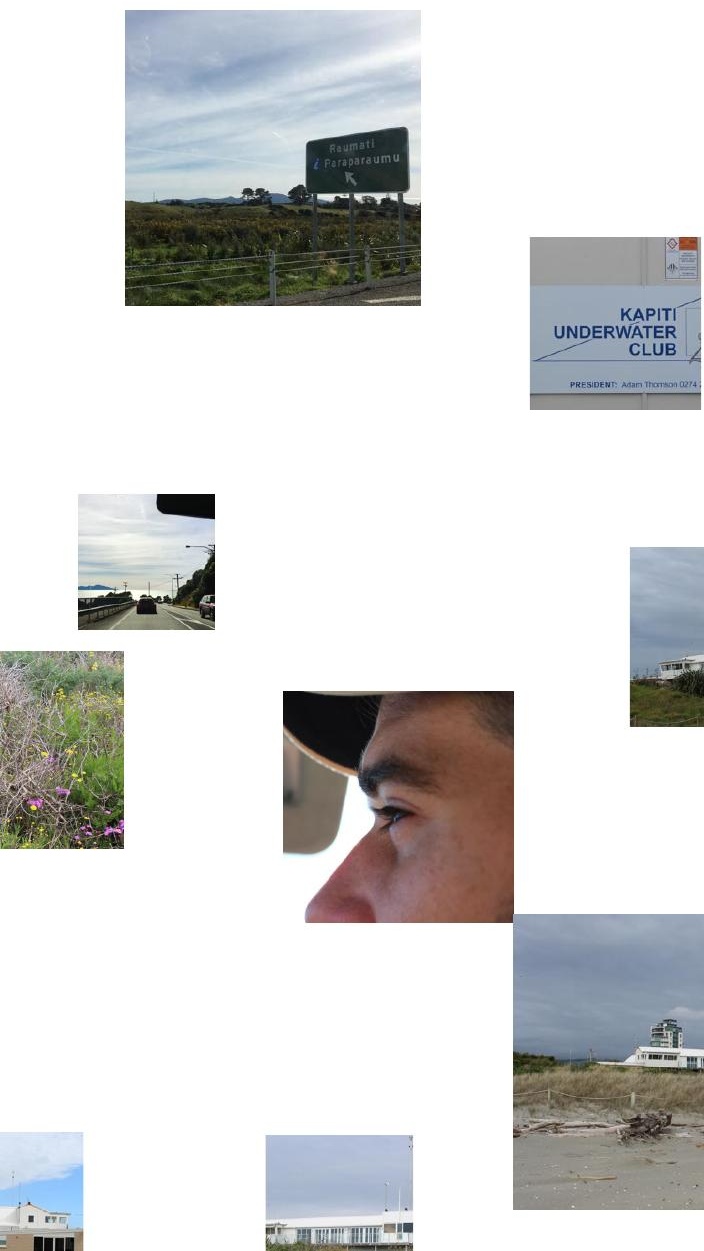

$\sin$

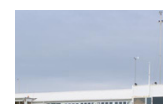

F
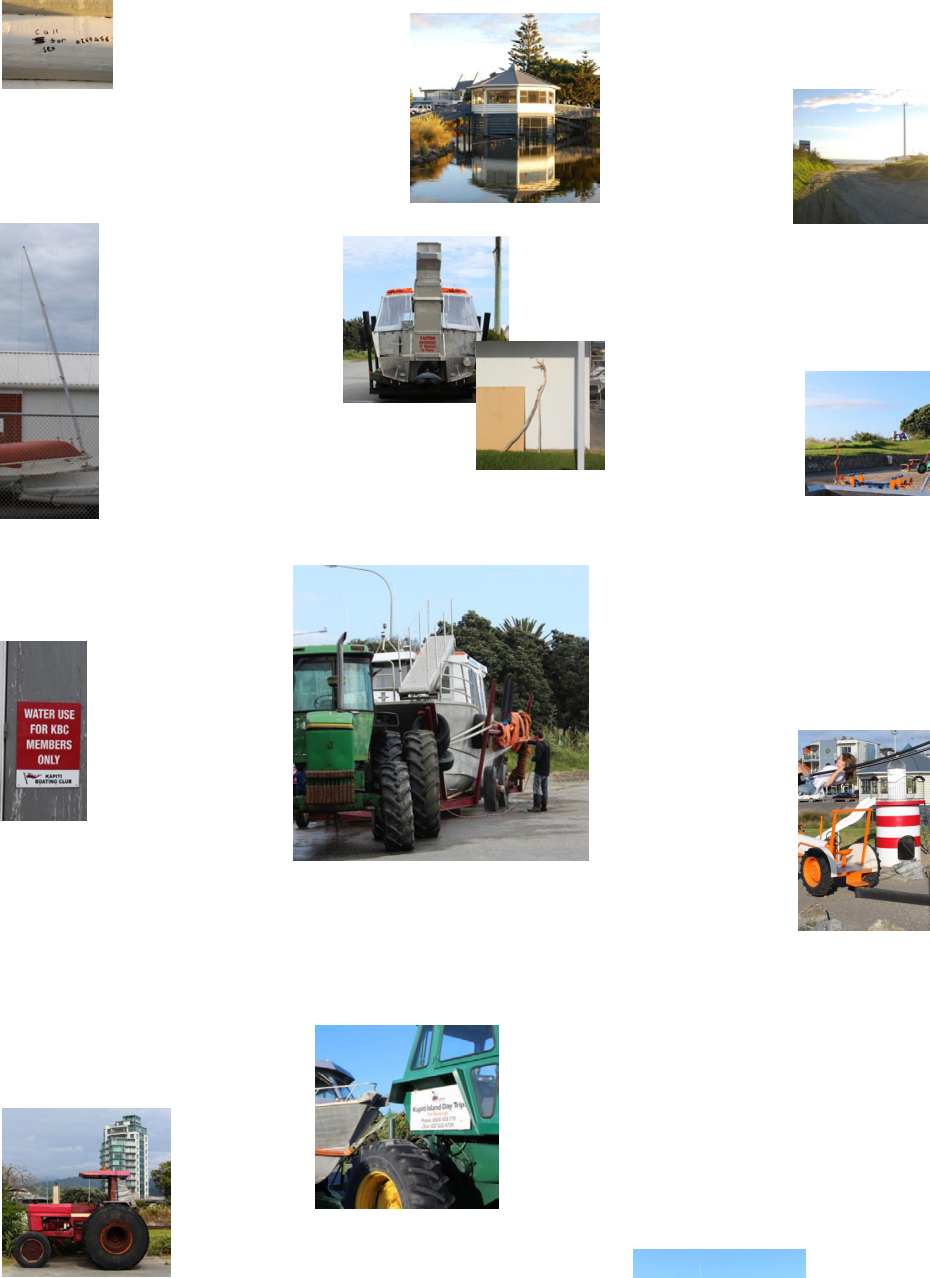

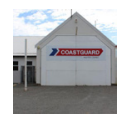
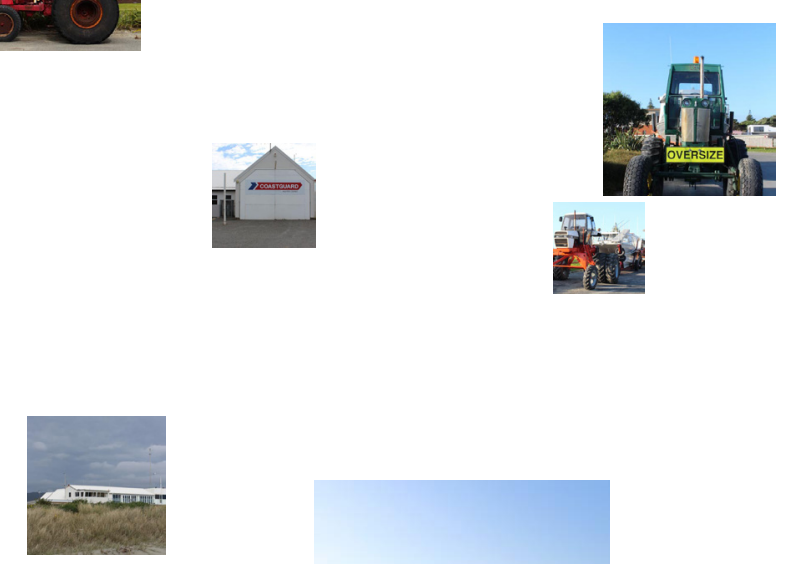

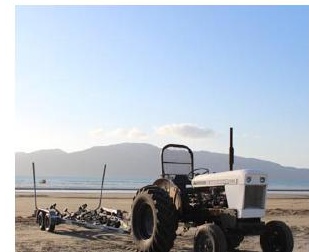

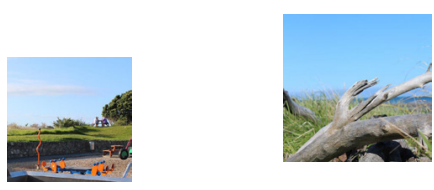
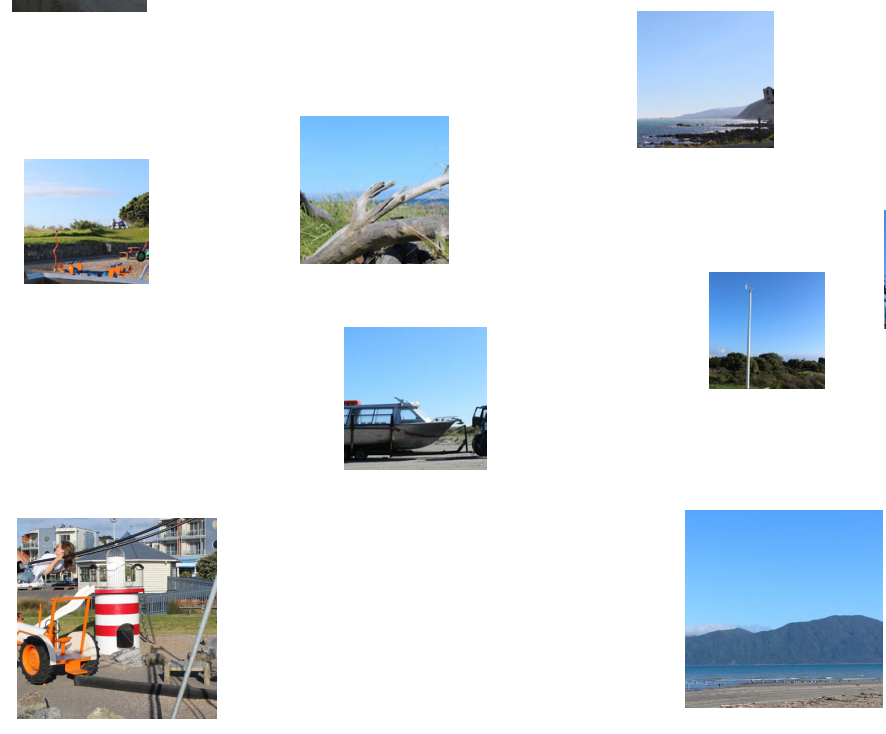

$$
\text { I- }
$$
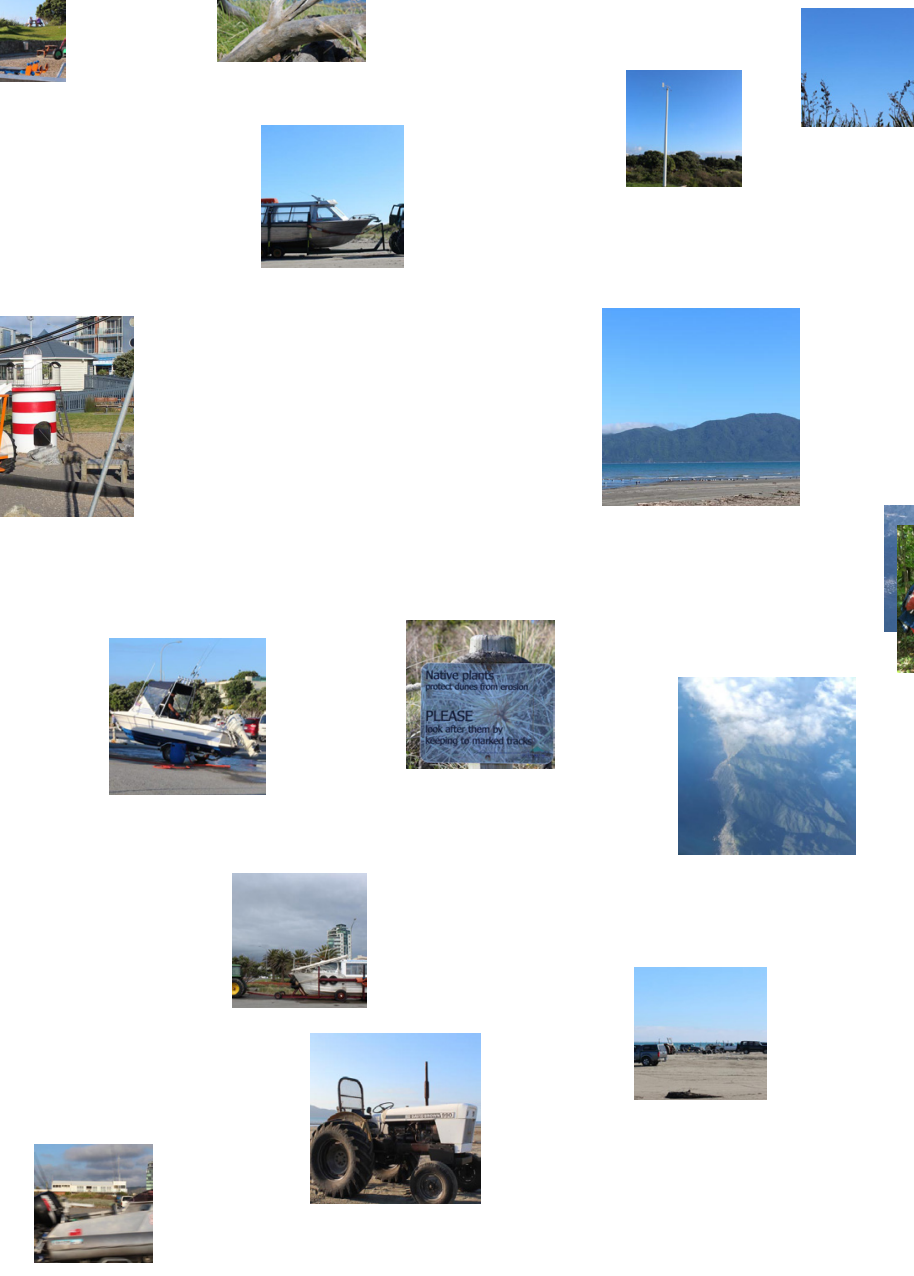

11. Arrival, Kapiti Boating Club. Site photo composition

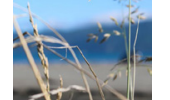

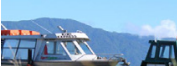



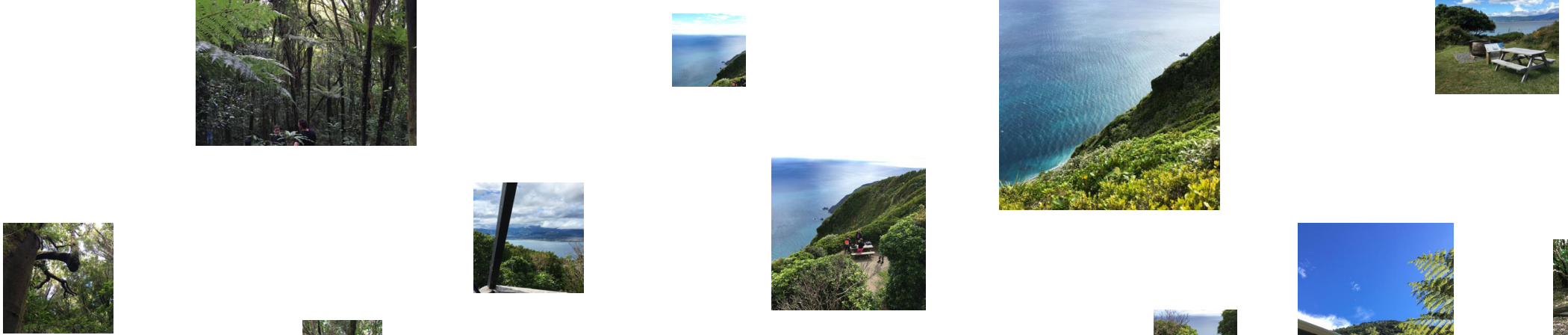

딘
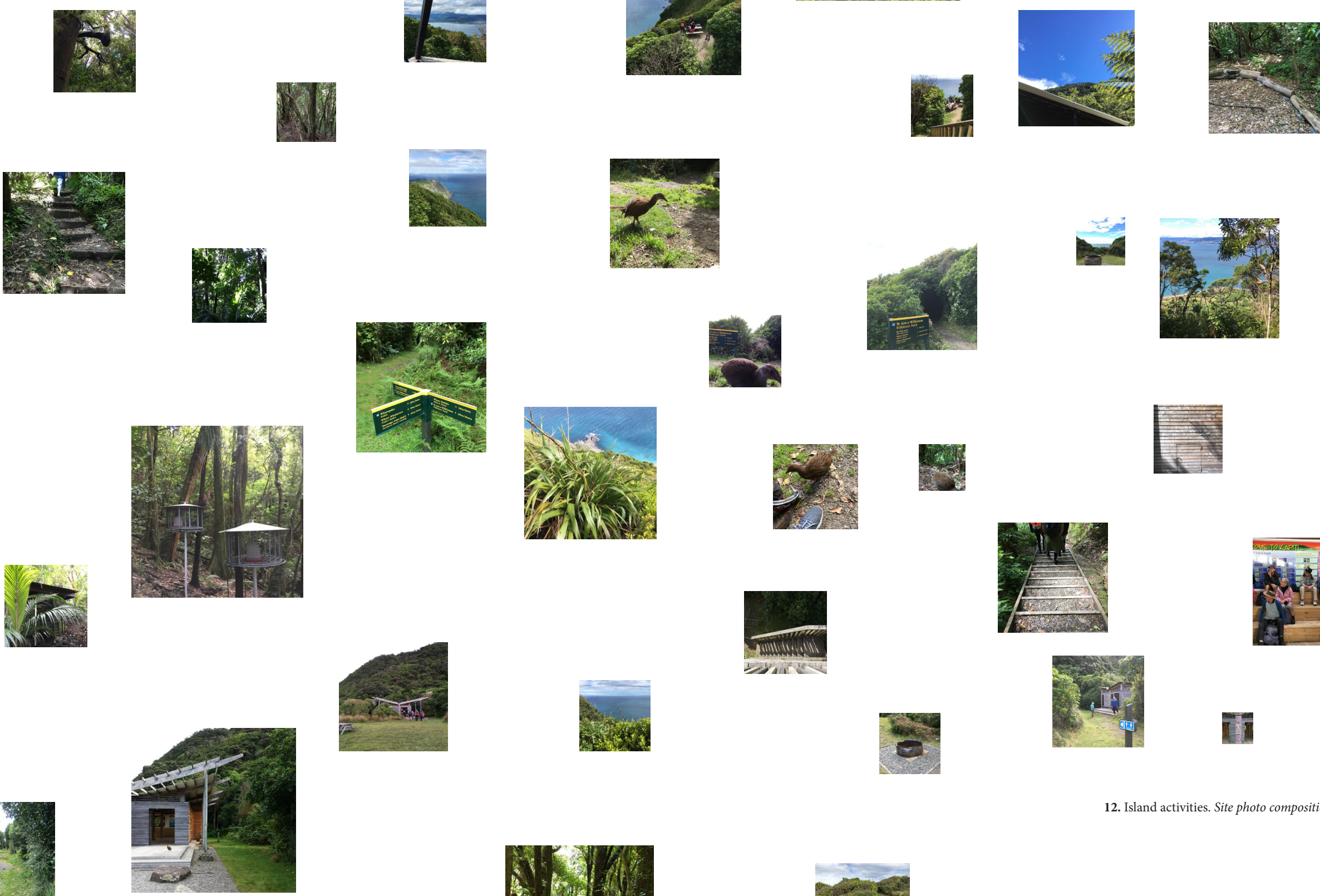

$-$
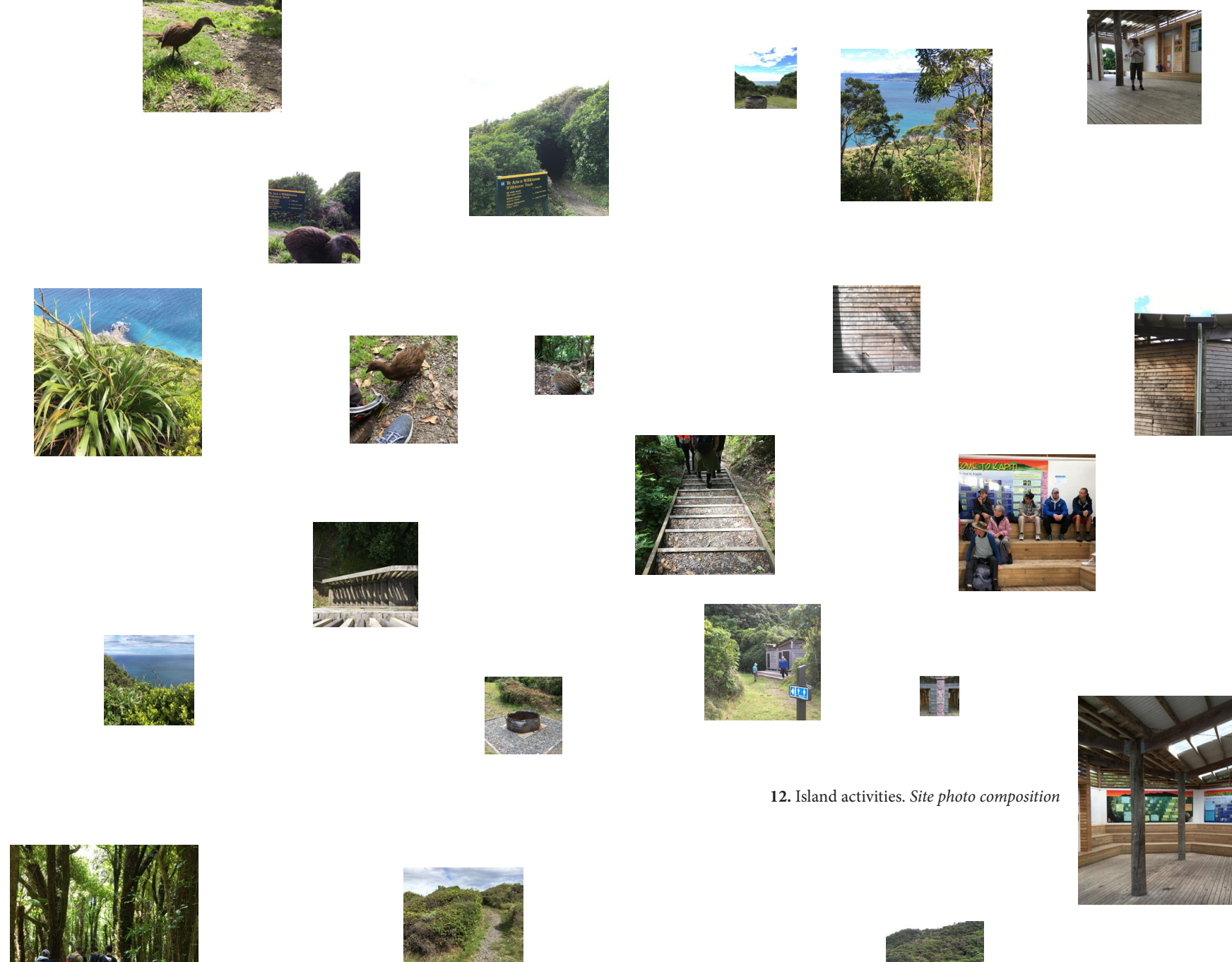

12. Island activities. Site photo composition

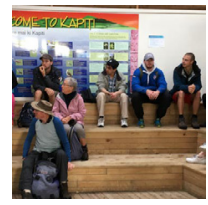

EI
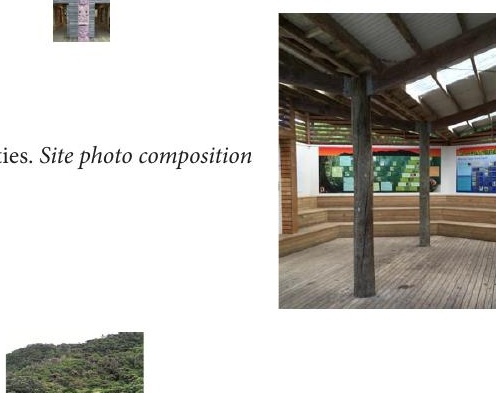

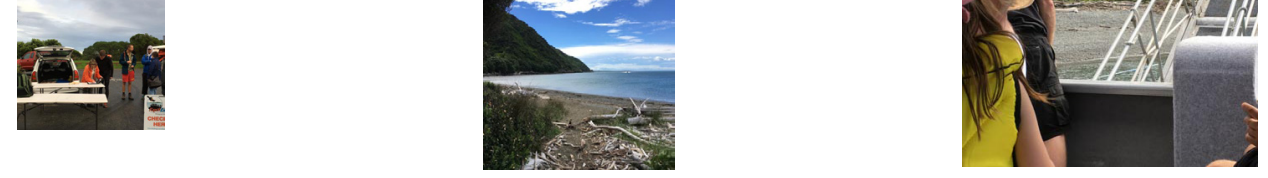

and

늘 글
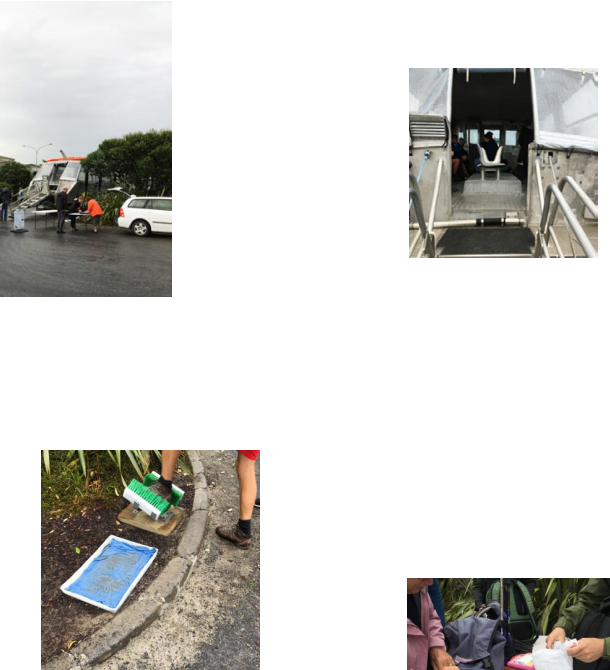

$7 \frac{1}{2}$

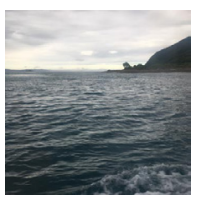

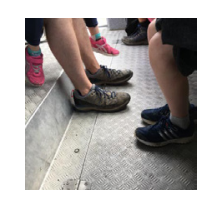
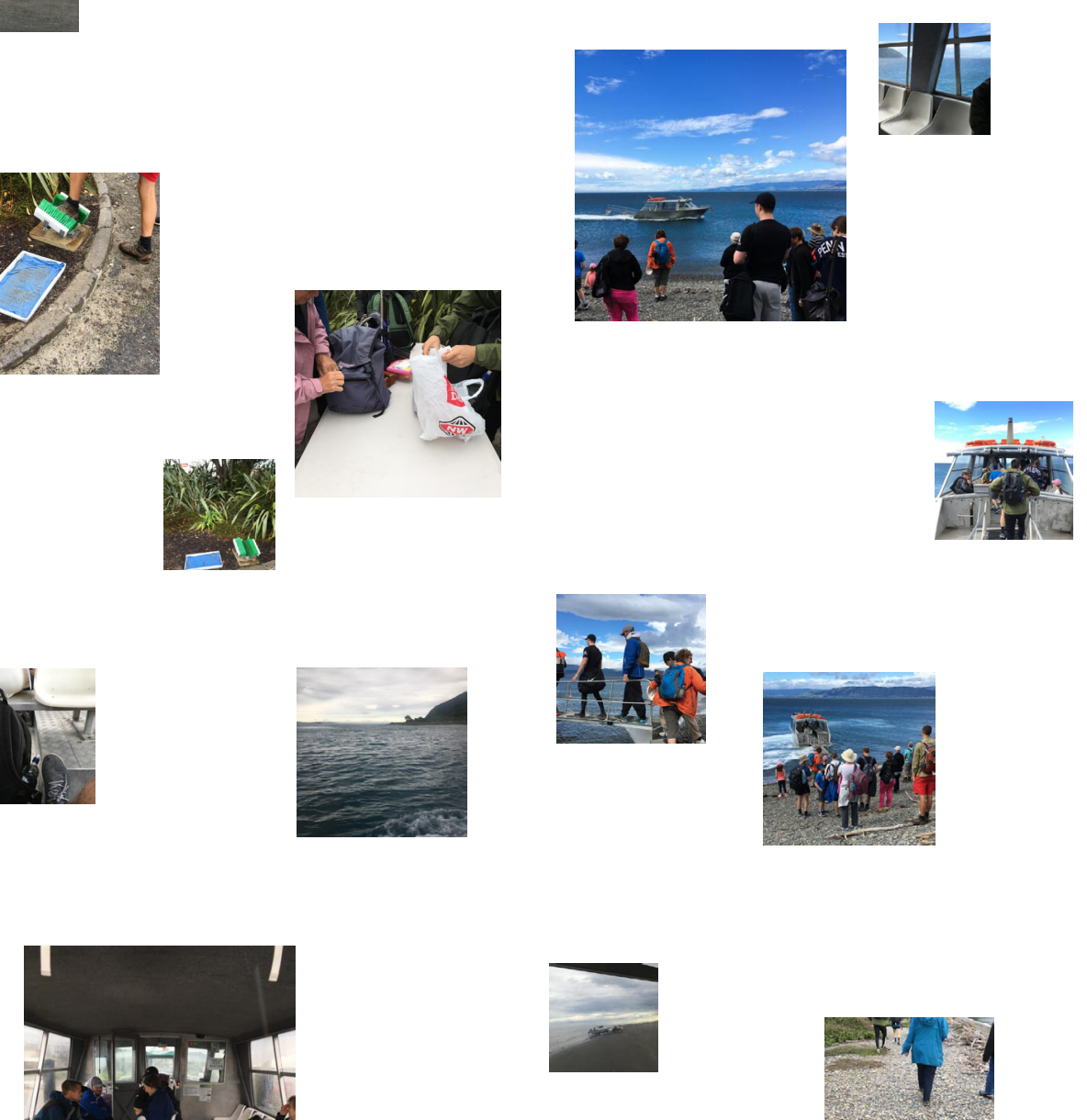
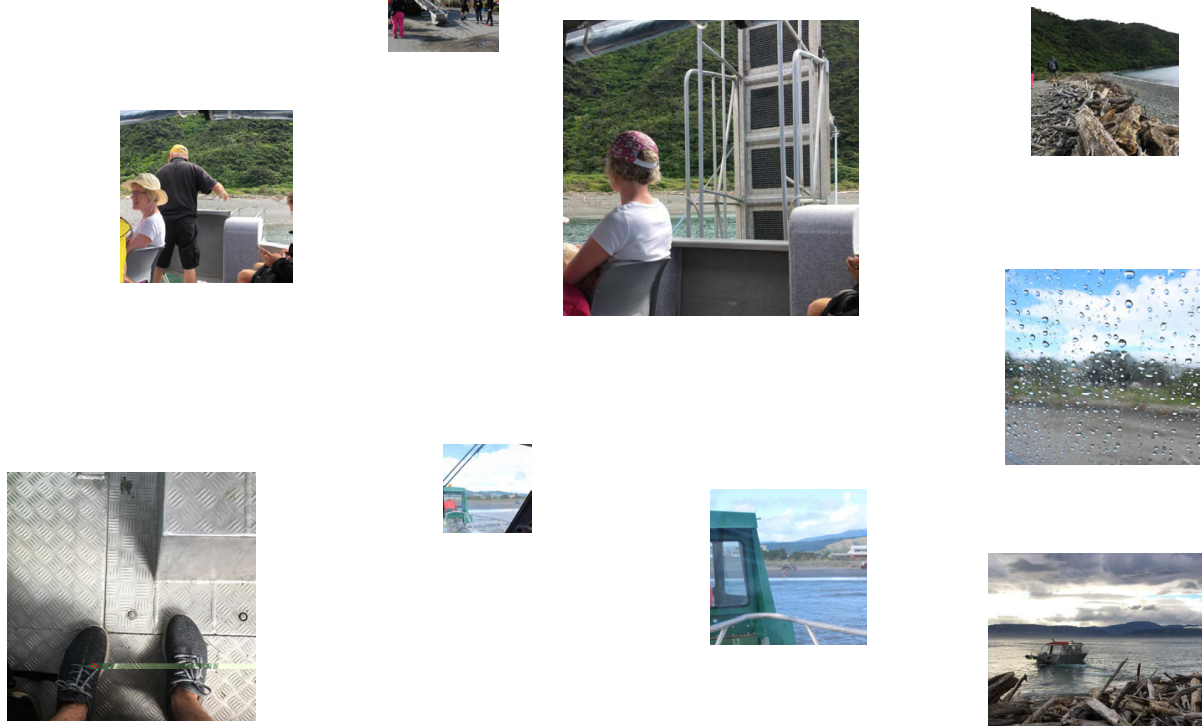

-
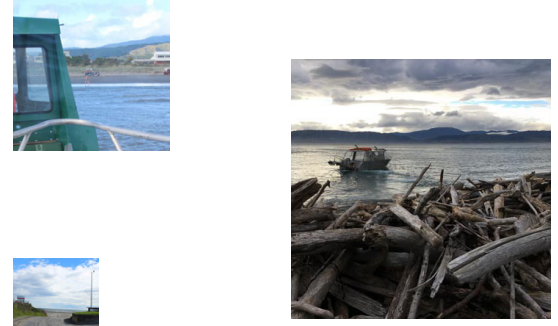

i)

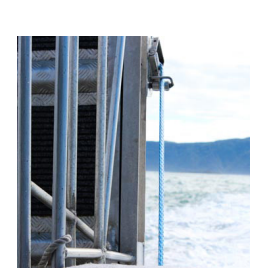

1
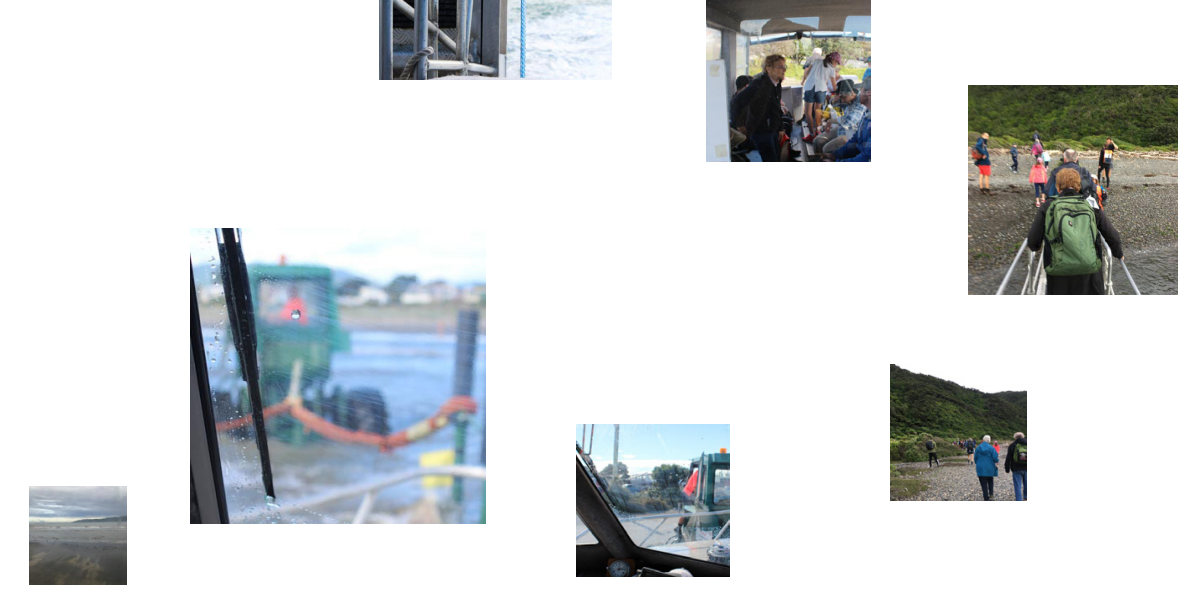

13. Tour boat. Site photo compositio
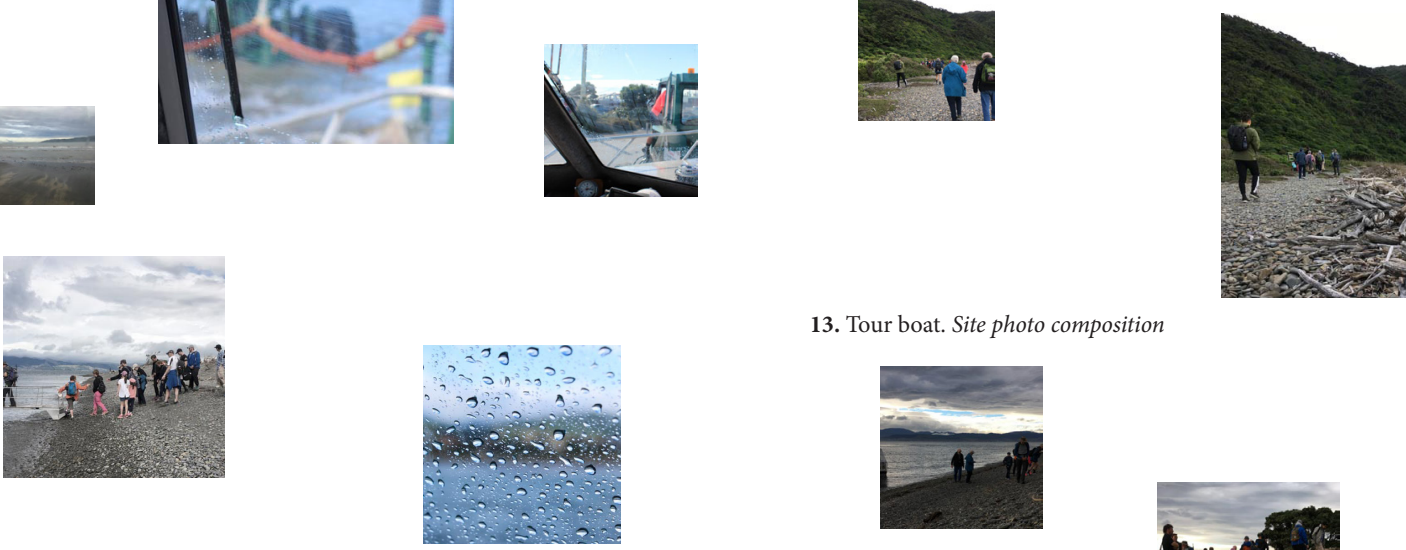
-

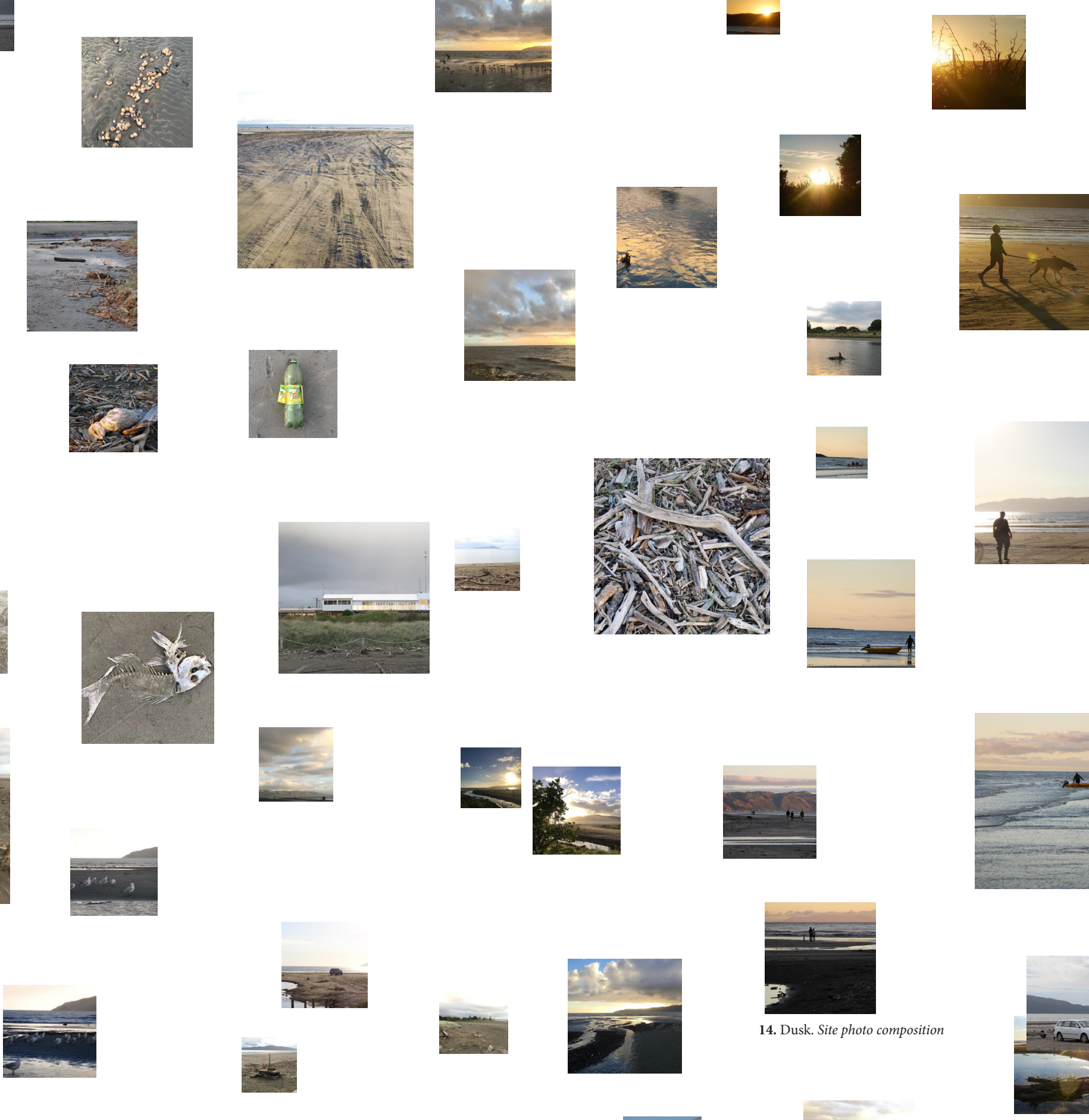




\section{Kāpiti Island Gateway Centre Feasibility Study}

The Kāpiti Island Gateway Centre Feasibility Study 2013 is used in this research portfolio to determine the programmatic requirements of the design. The Study recommends a "\$15 million-plus facility" including "Improved Boating Club, Coastguard and Underwater Club facilities, Biosecurity and departure lounge facilities for Kapiti Island tourism ventures and the Department of Conservation" (Maxwell, 2014). The key points outlined in the study are as follows.

The main aims of this project are to:

1. Significantly enhance the experience of visitors going to Kapiti Island by providing ease of access, information and education about the island

2. Increase the number of visitors to the island while ensuring ongoing protection

3. Increase the profile of Kapiti Island nationally in order to attract more visitors to the Kapiti district as a whole.

The centre should accommodate the following functions:

- Relocatable building positioned on the site of the existing boating club which contains and reflects the following four key relationships:

- Boating Club/ Coast Guard/ Underwater Club - improved facilities with new income stream to off-set maintenance costs
- DOC / Concessionaries - excellent bio-security and a smooth departure sequence for island visitors.

- DOC / Iwi - Telling the stories of Kapiti in a purpose built theatre to create a visitor attraction

- Council / wider Kapiti tourism industry - i-SITE and catalytic, focal role of welcoming visitors

(TRC Toursim, Destination Planning Ltd, Pynenburg and Collins Architects Ltd, 2013) 

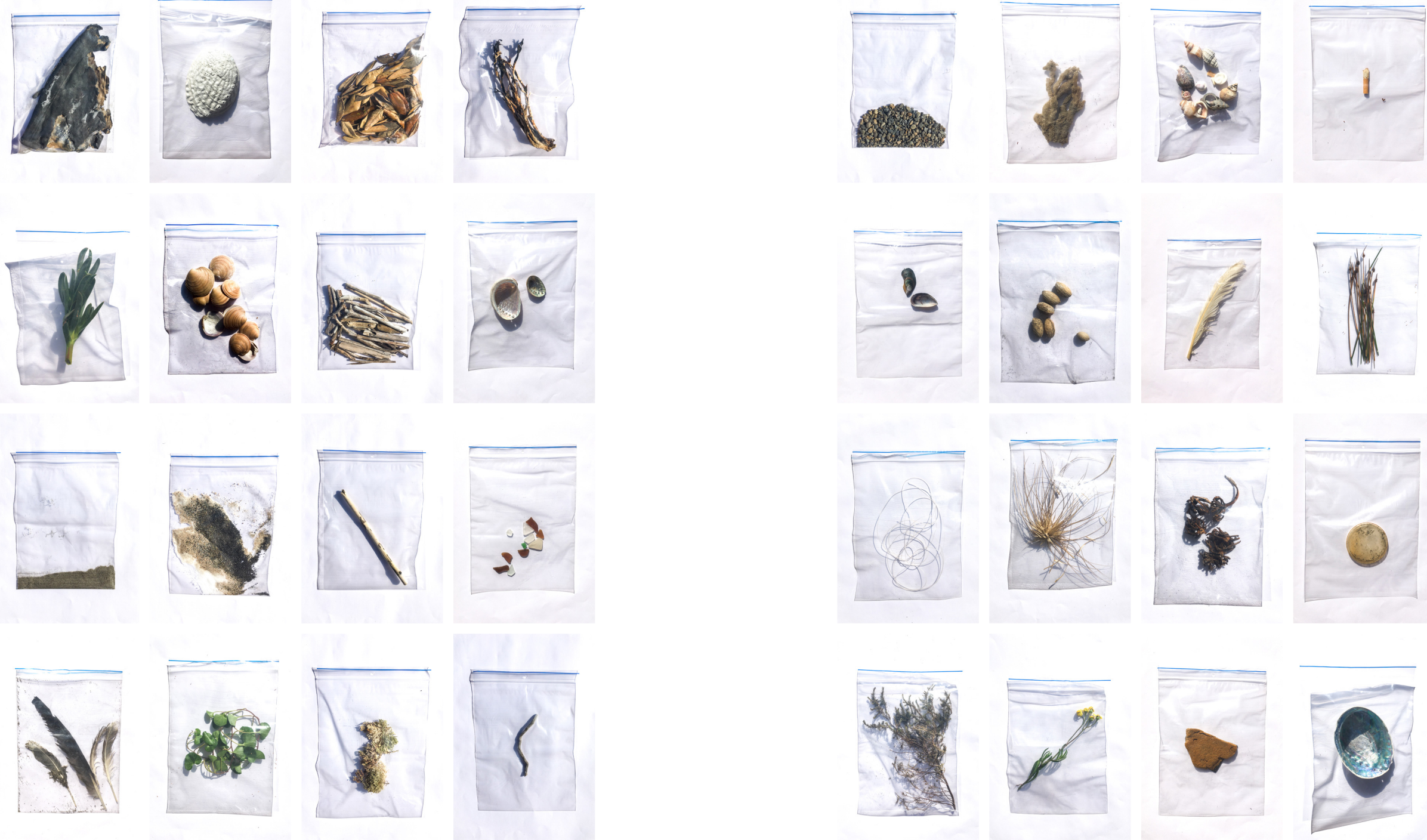


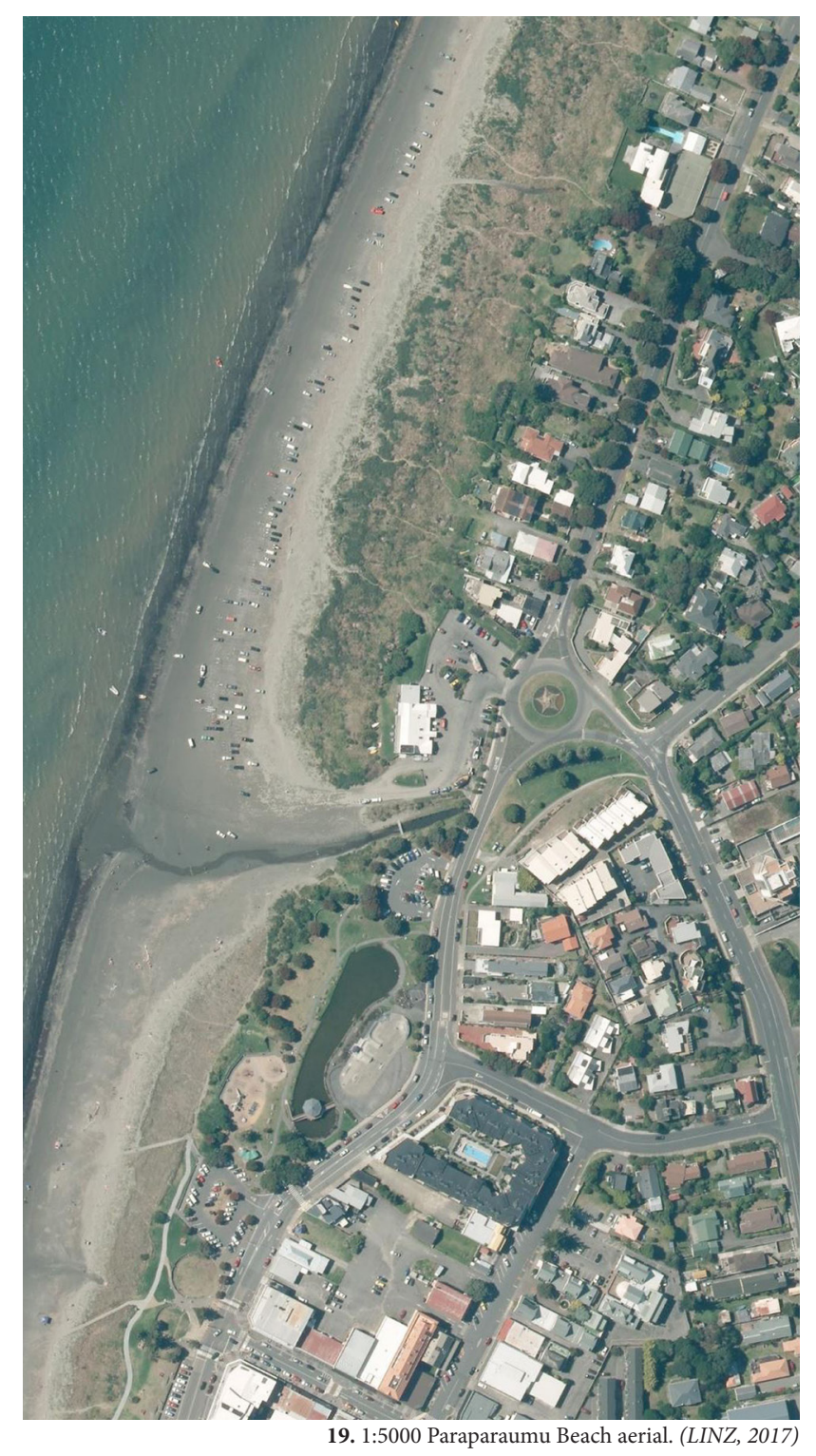

\section{Site: Paraparaumu Beach}

Paraparaumu Beach is a wide expanse of sand leading to Raumati in the south and Waikanae in the north (Kapiti Coast District council, 2017, p. 12). Only a fifteen-minute boat ride from Kapiti Island it is the closest boat launching spot on the mainland. Although not suitable for swimming, Paraparaumu Beach is still a hotspot for recreation. The beach is often covered in people and dogs out walking, picnics are common place on warmer nights and you would be hard pressed to visit without spotting at least one fisherman. Protected to the west by Kapiti Island, this is the favoured spot for fishing. The beach is often lined with rows of parked cars and boat trailers. The intense boating activity does, however, have an adverse effect on the environment. Fish carcasses and fishing rubbish litter the shore, and paired with washed up seaweed create an aroma of dampness and decomposition. The rubbish as well as the polluted runoff from washing the boats fortunately does have the opportunity to be minimised through the upgrade of boating facilities. 


\section{Site: Kapiti Boating Club}

The location of the existing Kapiti Boating Club was outlined in the 2013 Feasibility Study as the most suitable site for the gateway project. The site is easy to find as it is located at the end of Kapiti Road and just five minutes from the recently completed Kapiti expressway. The boat ramp is directly adjacent and there is plenty of public parking. Where the current club sits is ideal, just behind the apex of the dune, which offers unhindered views of the island and is relatively safe from rising sea levels.

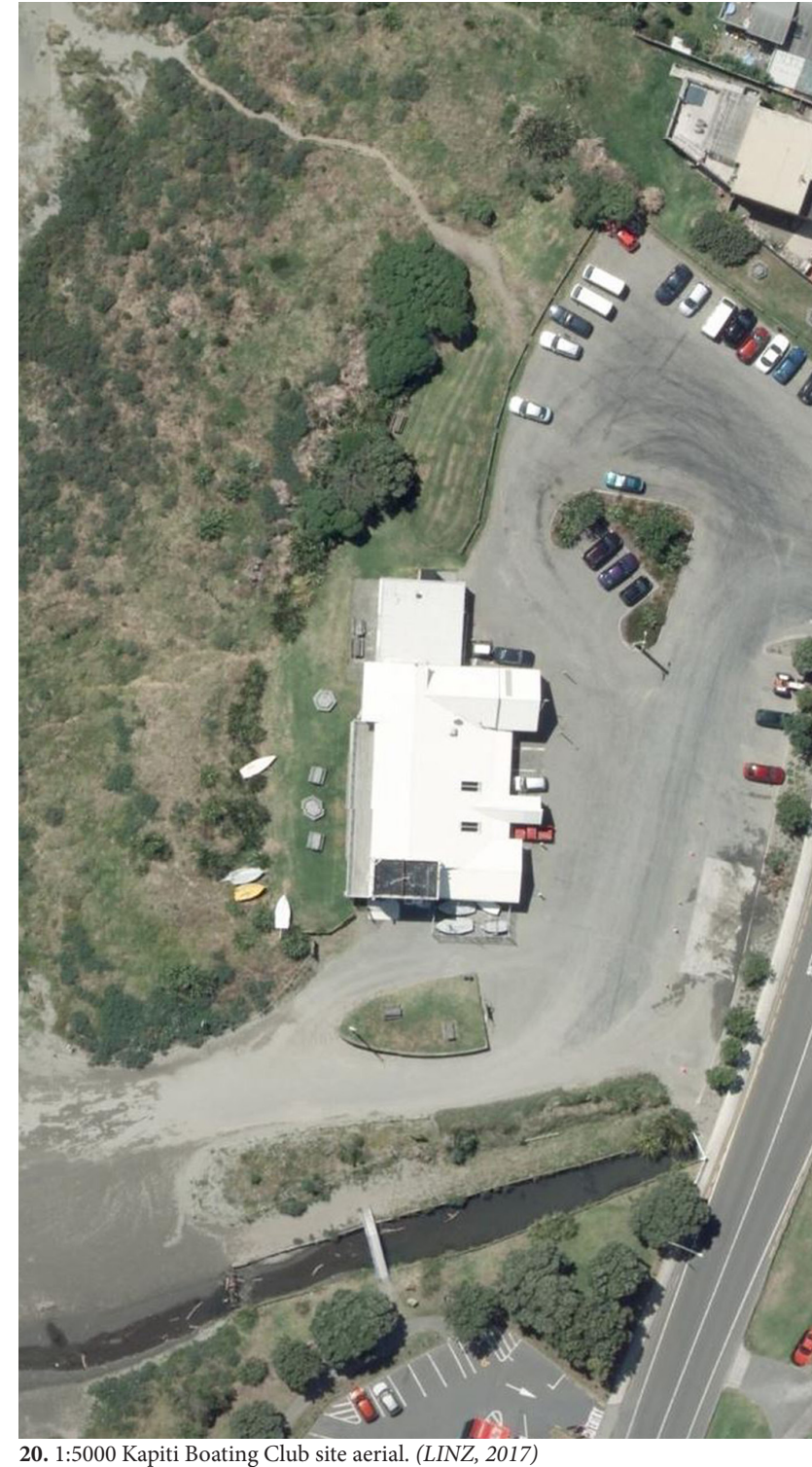




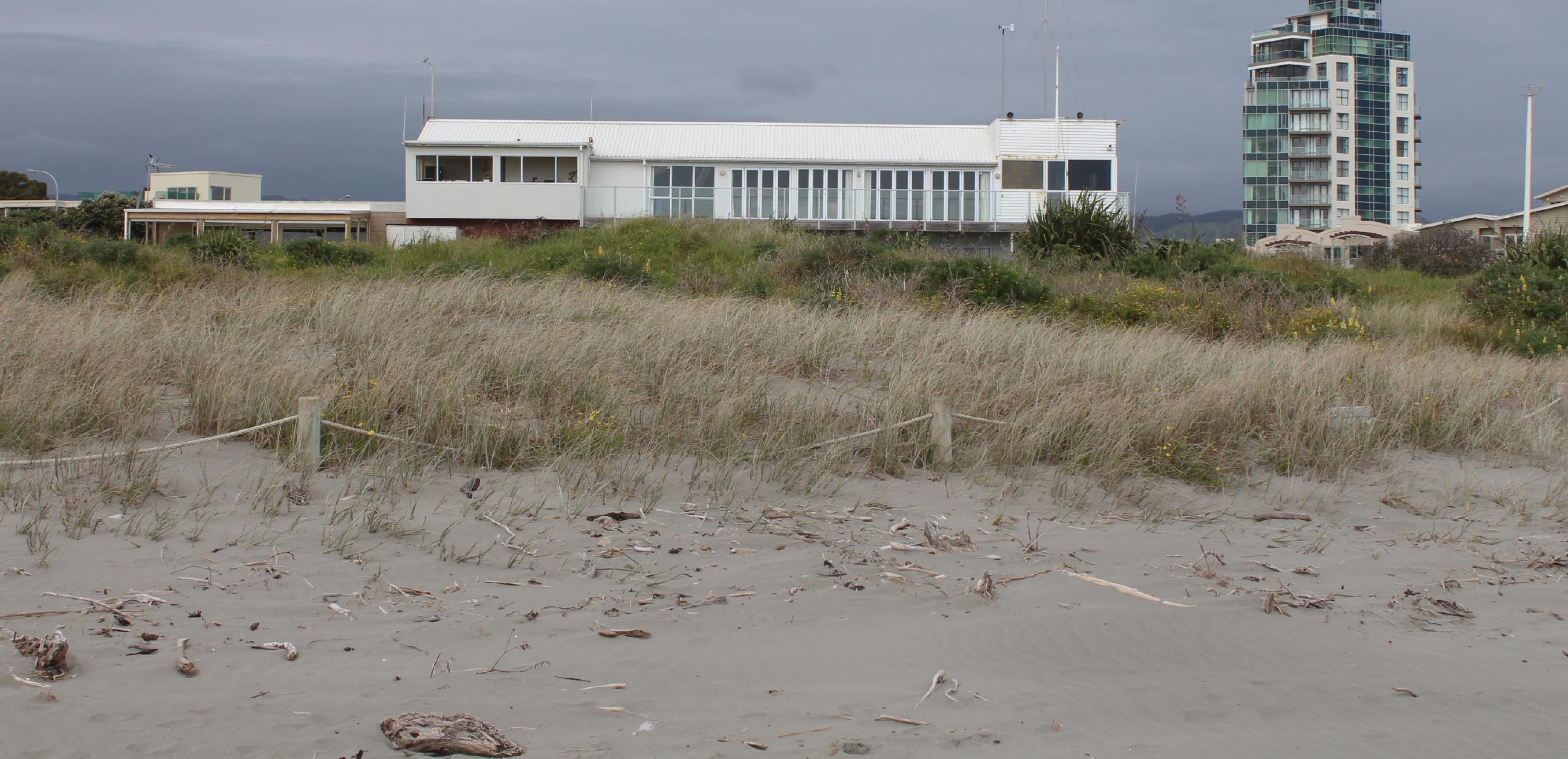




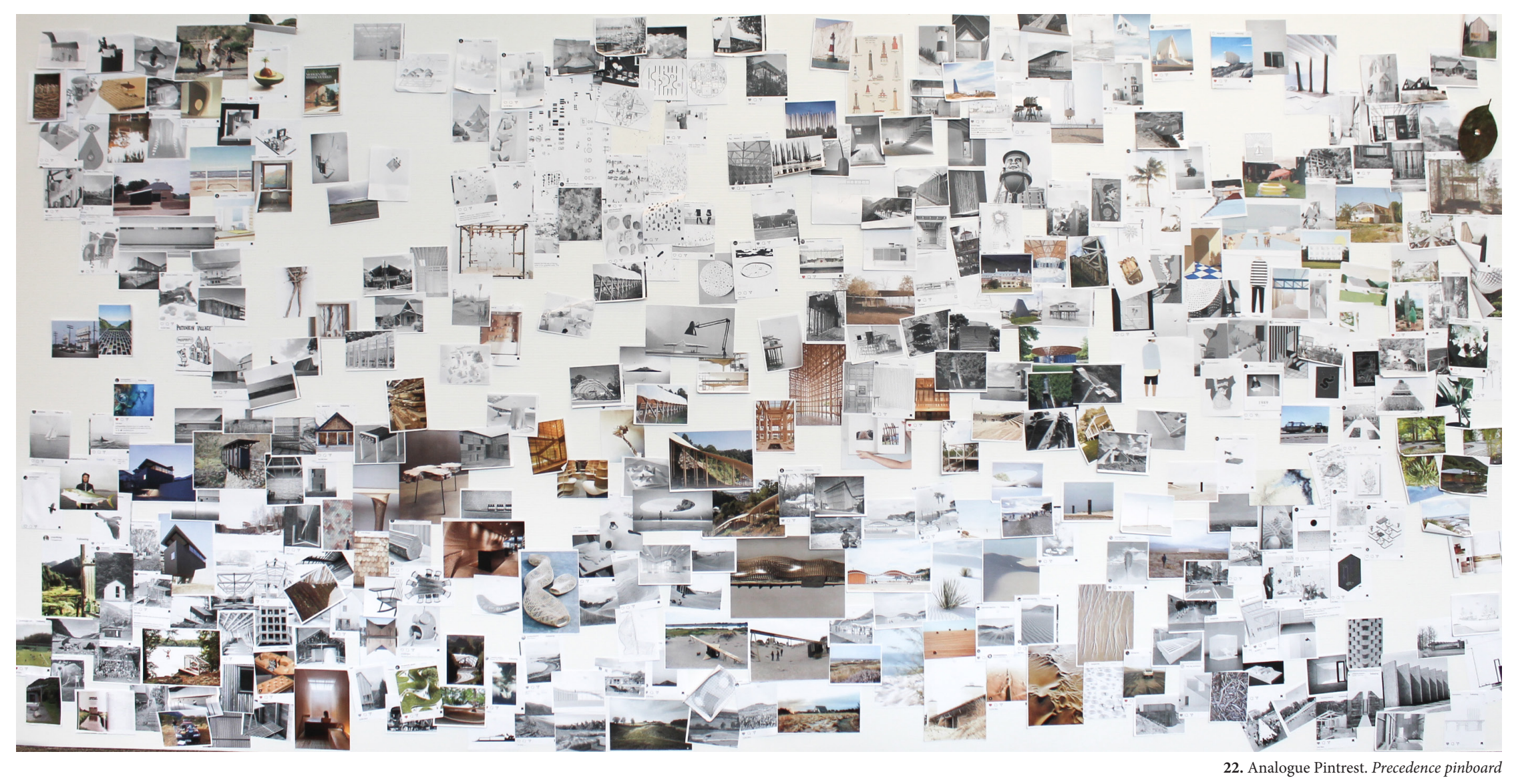




\section{Design Process}

In conjunction with the primary design process of models and devices, sketches and drawings were used to document the design. Orthographic drawings, either completed in $\mathrm{CAD}$ or as rough hand sketches form a spatial record of device outcomes.

Early on five quick-fire designs were also explored to rapidly uncover potential design responses. Dubbed the 'design ventures' these served to study and organise the complicated programmatic requirements. Each design venture involved the production of concept drawings as well as a programmatic bubble diagram.

Each design venture included a unique design focus outlined below:

- Eco- explored the outcome of fulfilling programmatic requirements with minimum environmental impact.

- Beacon - explored how the design could be a landmark and literal beacon.

- View - explored the outcome when designing from one perspective.

- Sandbox - explored the relationship between shifting sand and the built environment.

- Dune - explored a design which mimicked the form of the coastal dunes.

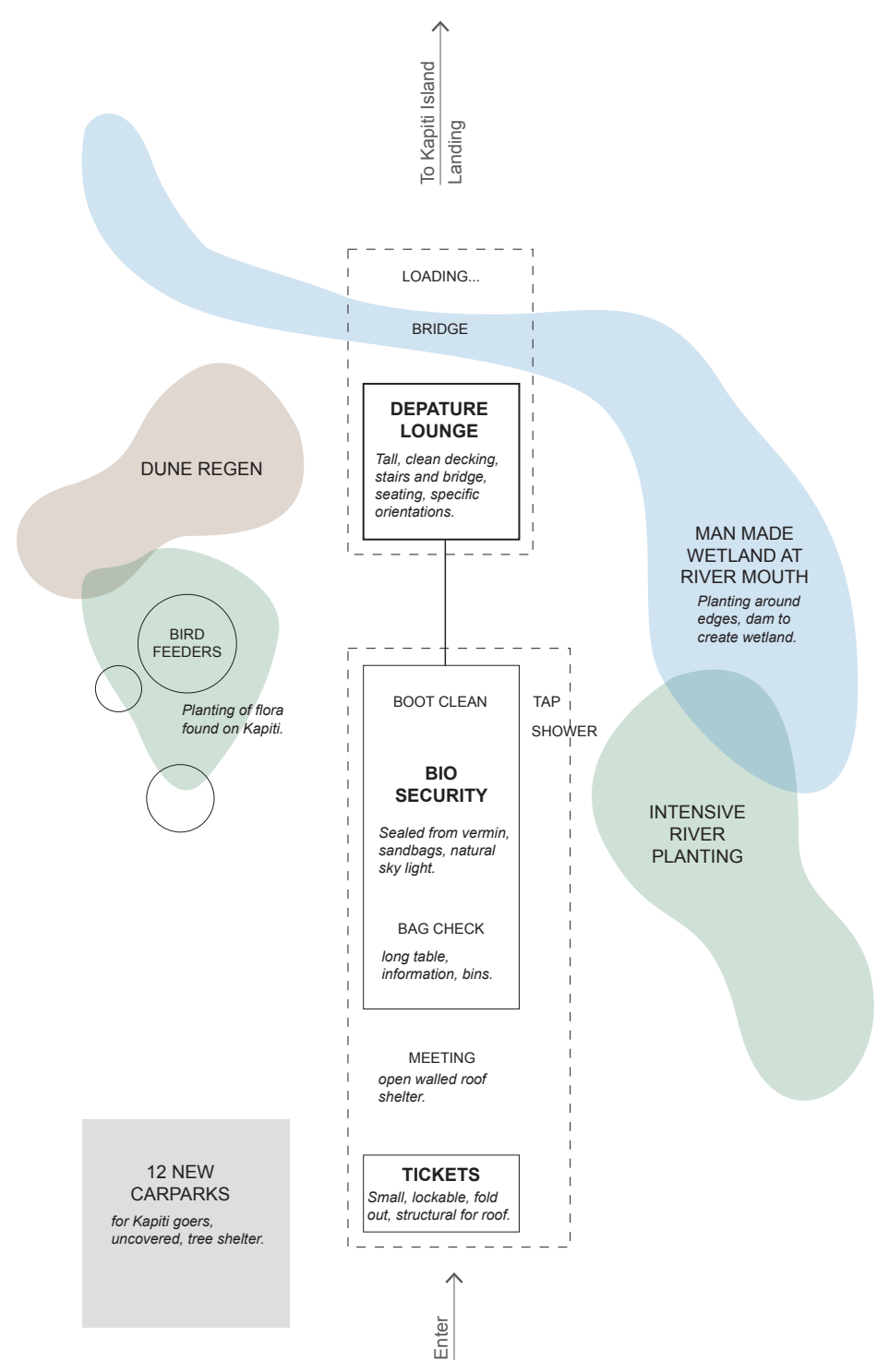

23. Hippy. Programme diagram 


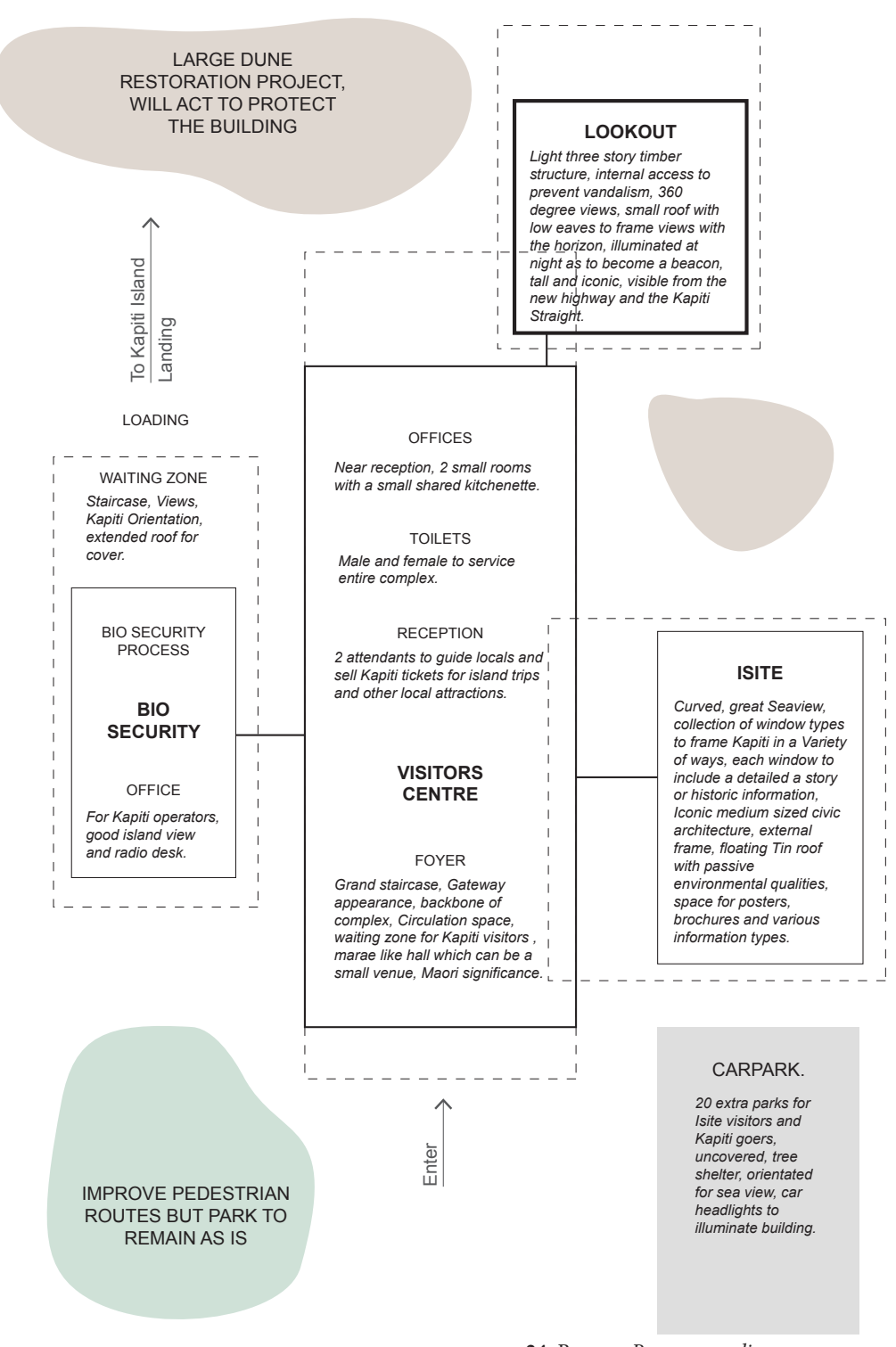

24. Beacon. Programme diagram

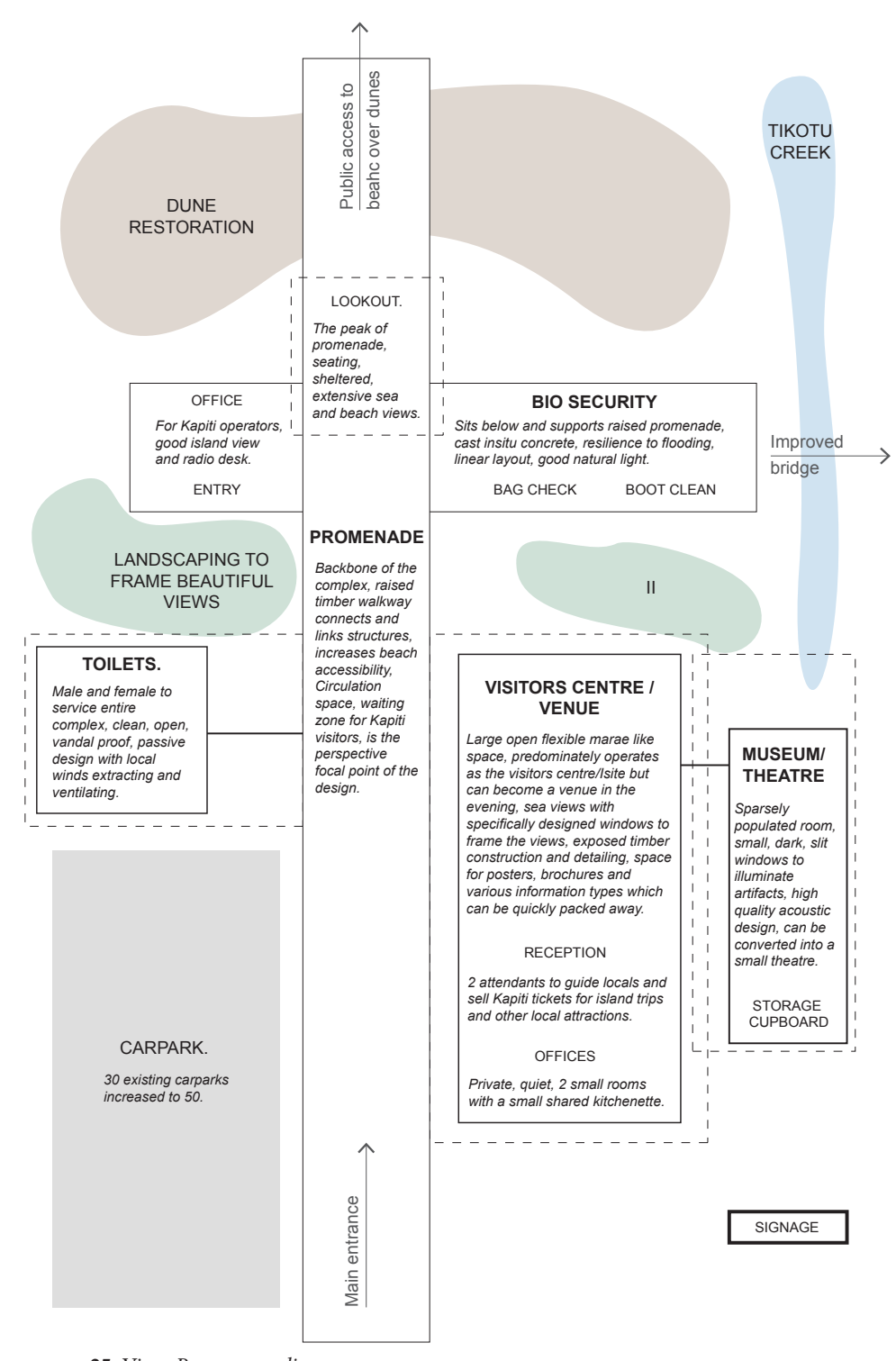

25. View. Programme diagram 


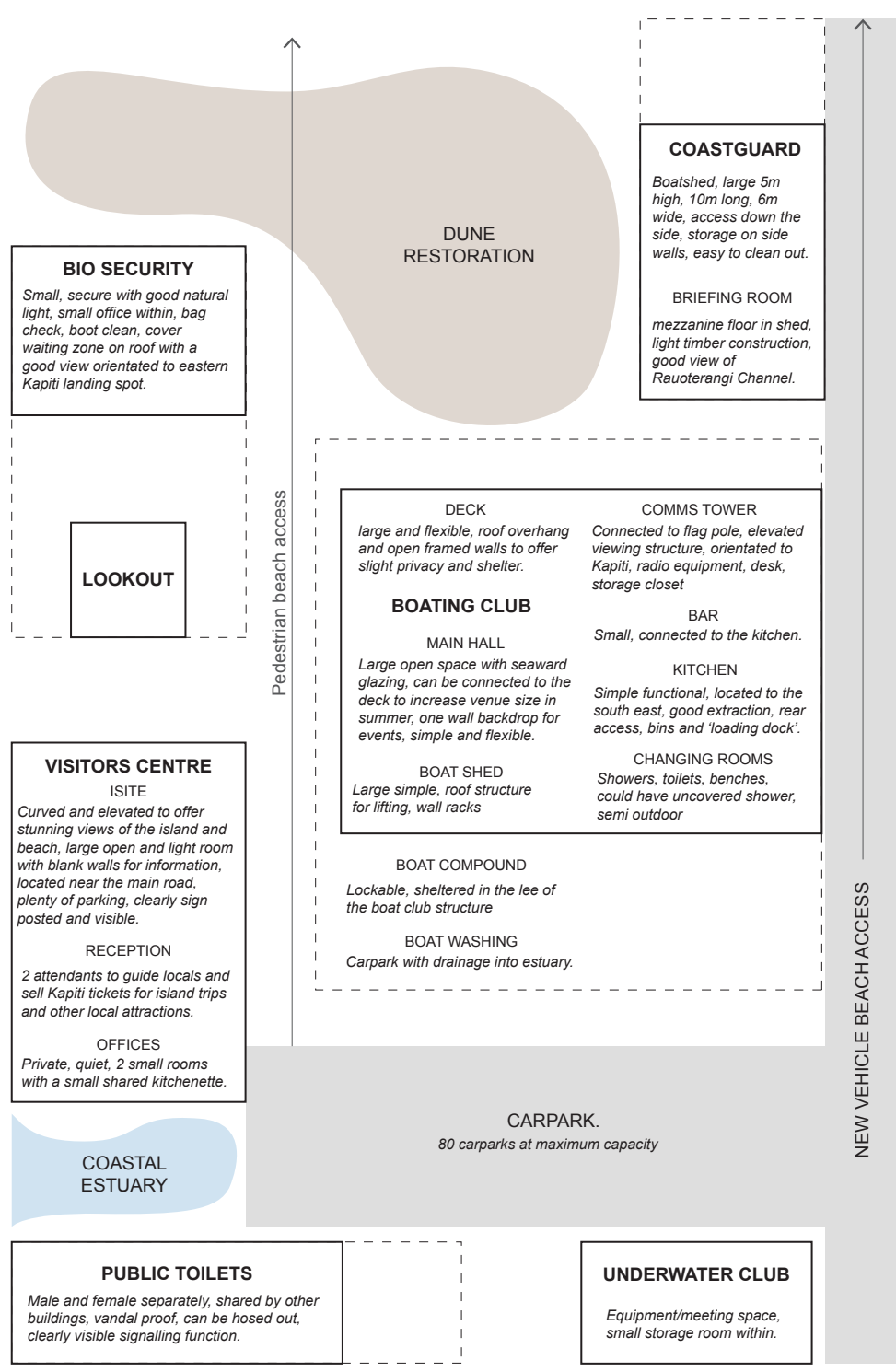

26. Sandbox. Programme diagram

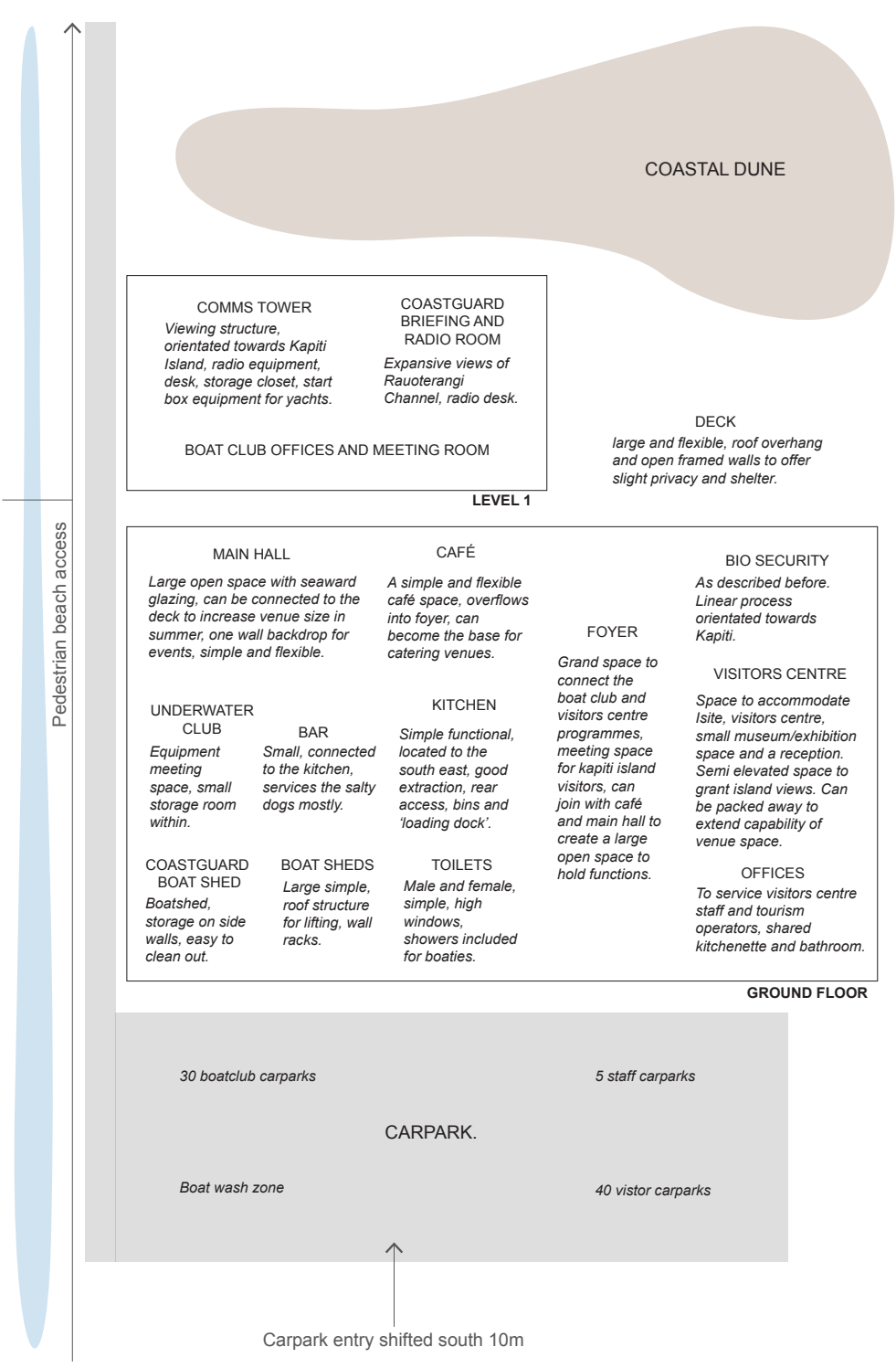

27. Dune. Programme diagram 

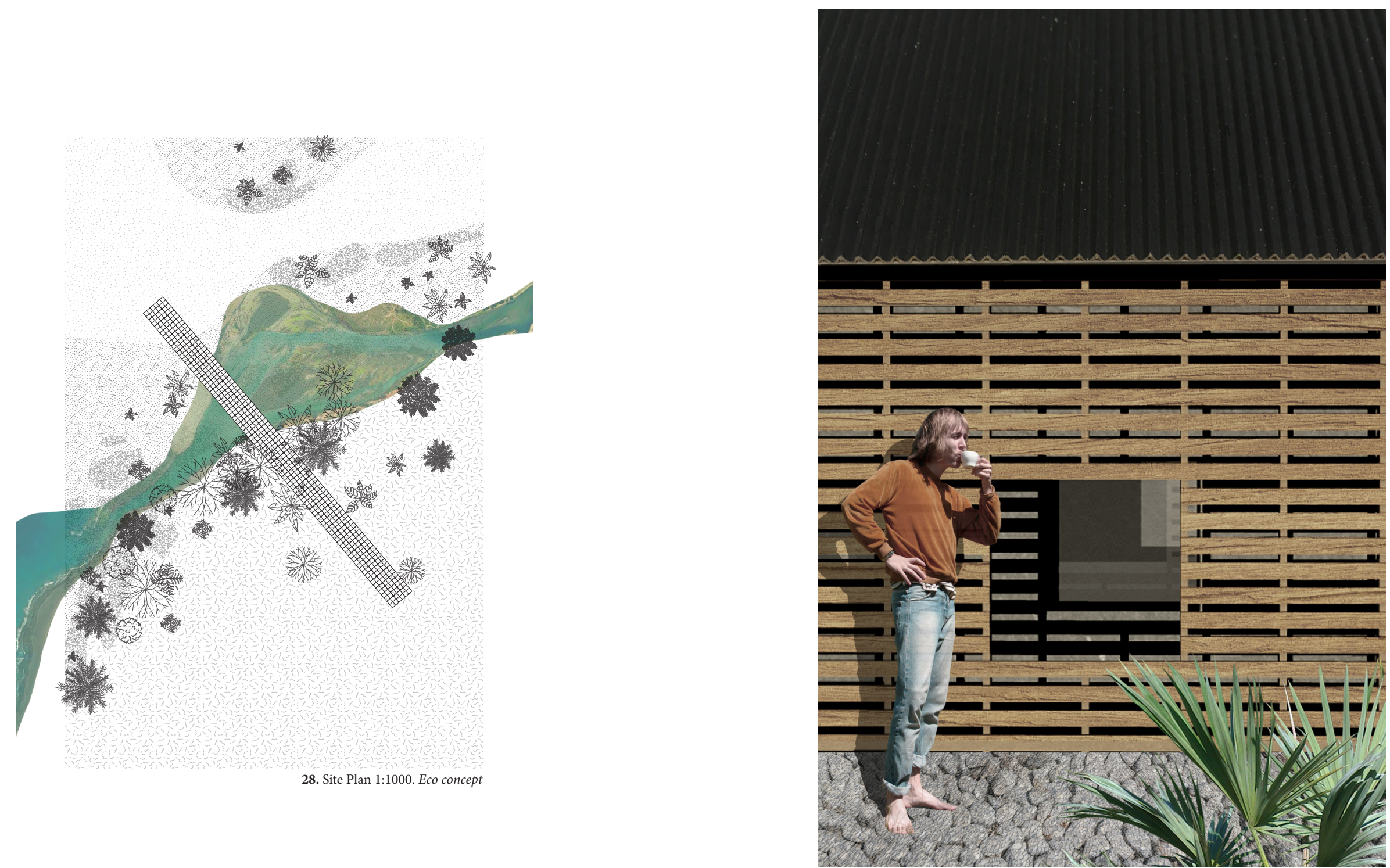


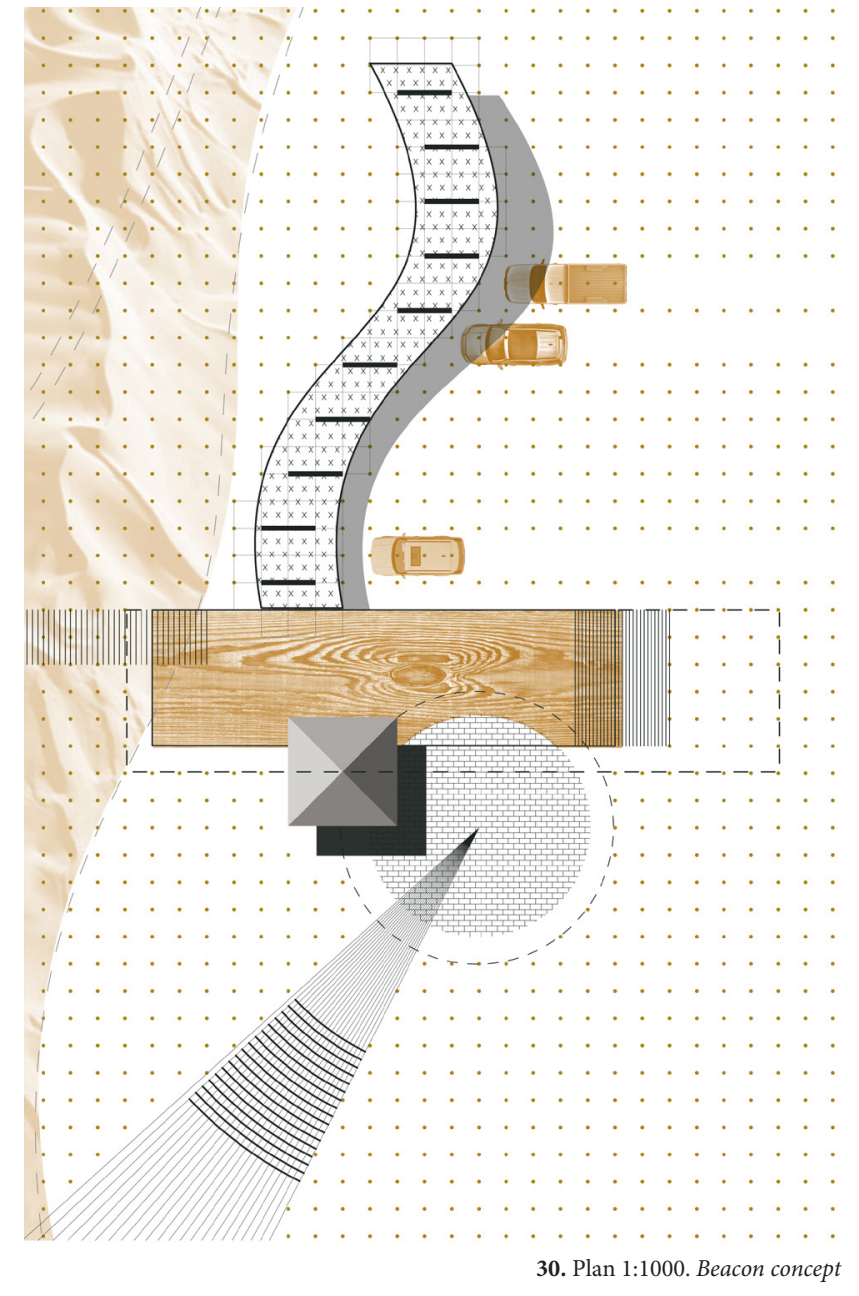

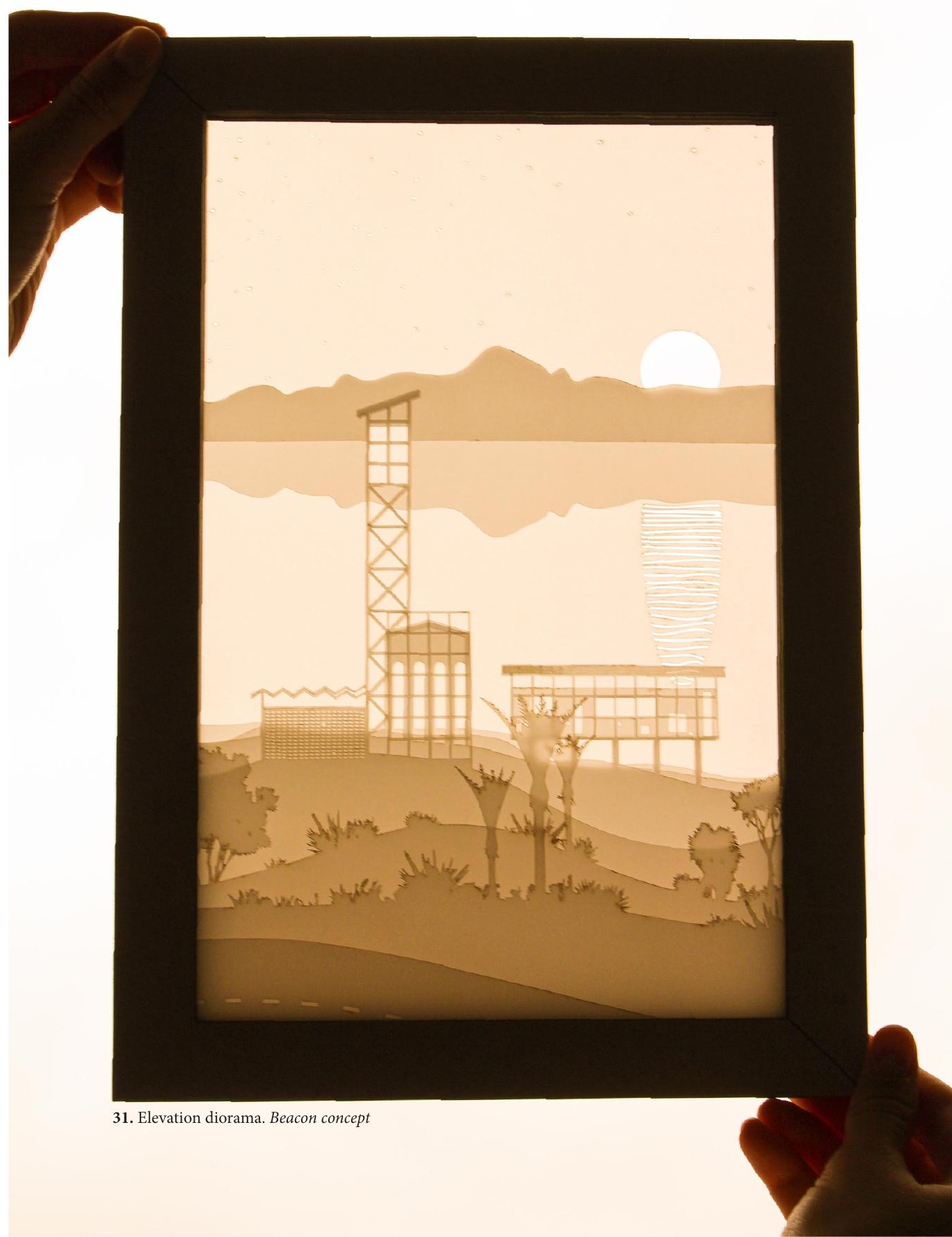



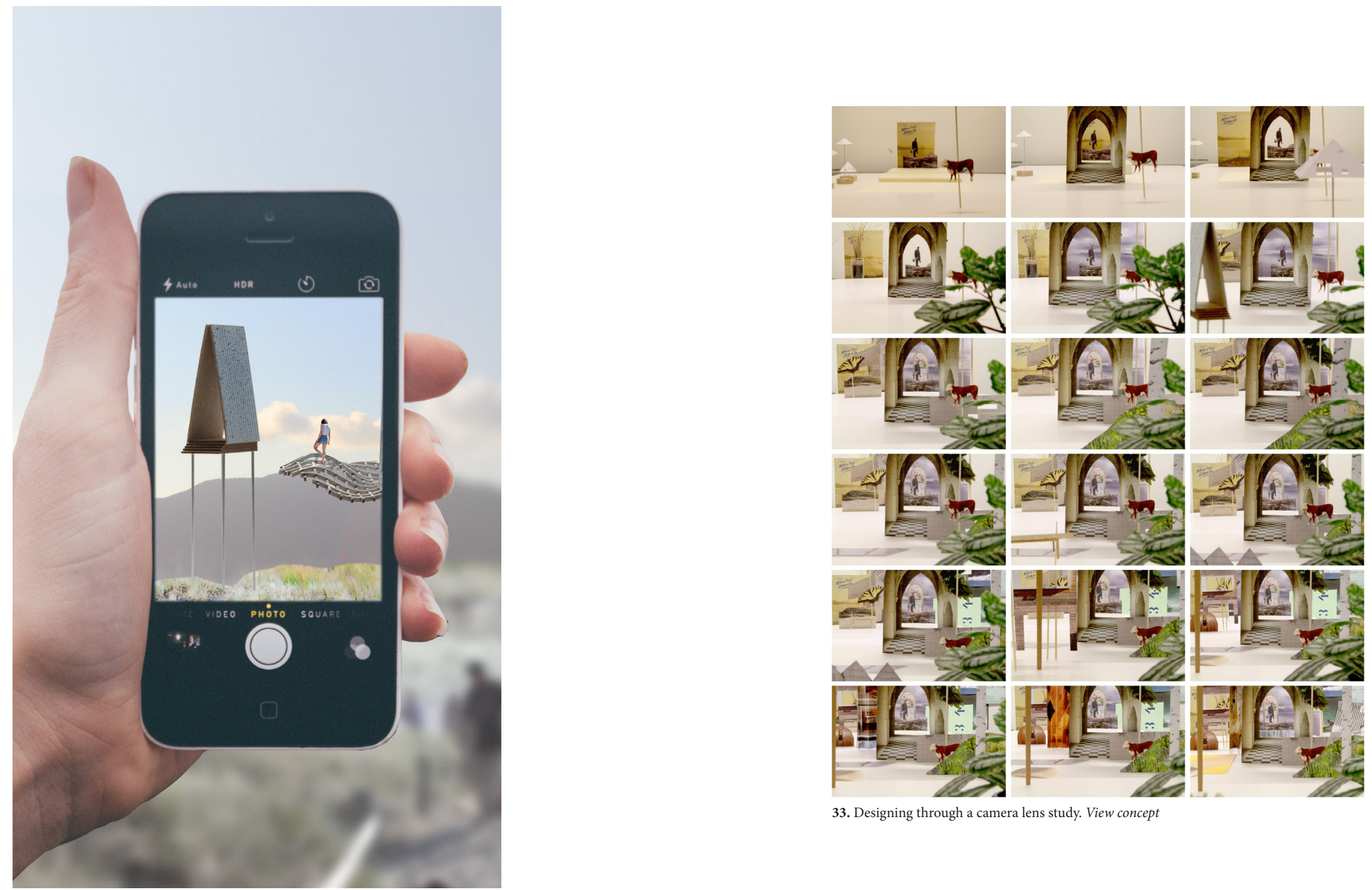

32. Image Based Tourism Diagram. View concept 

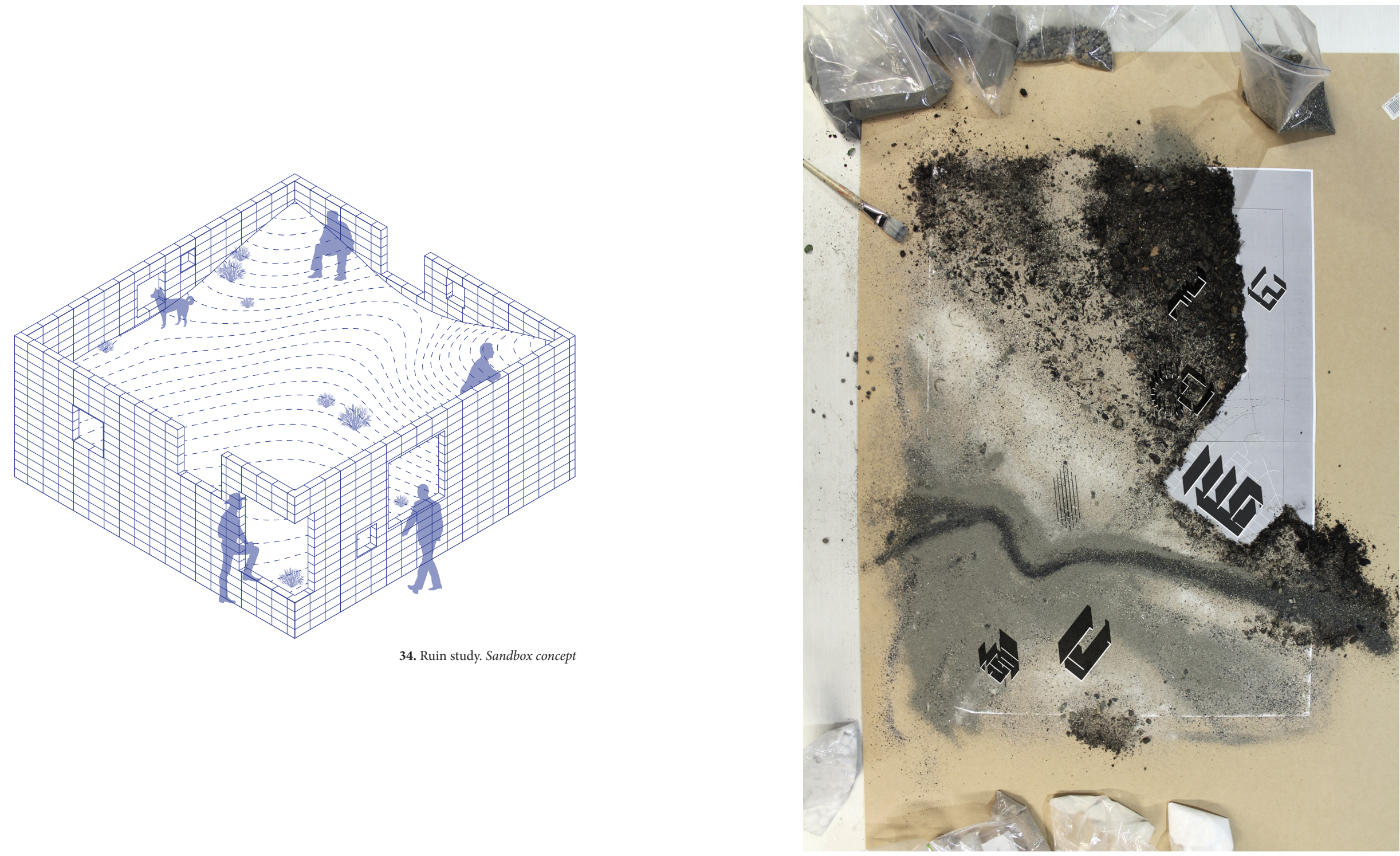

35. Ruin indicative plan. Sandbox concep 

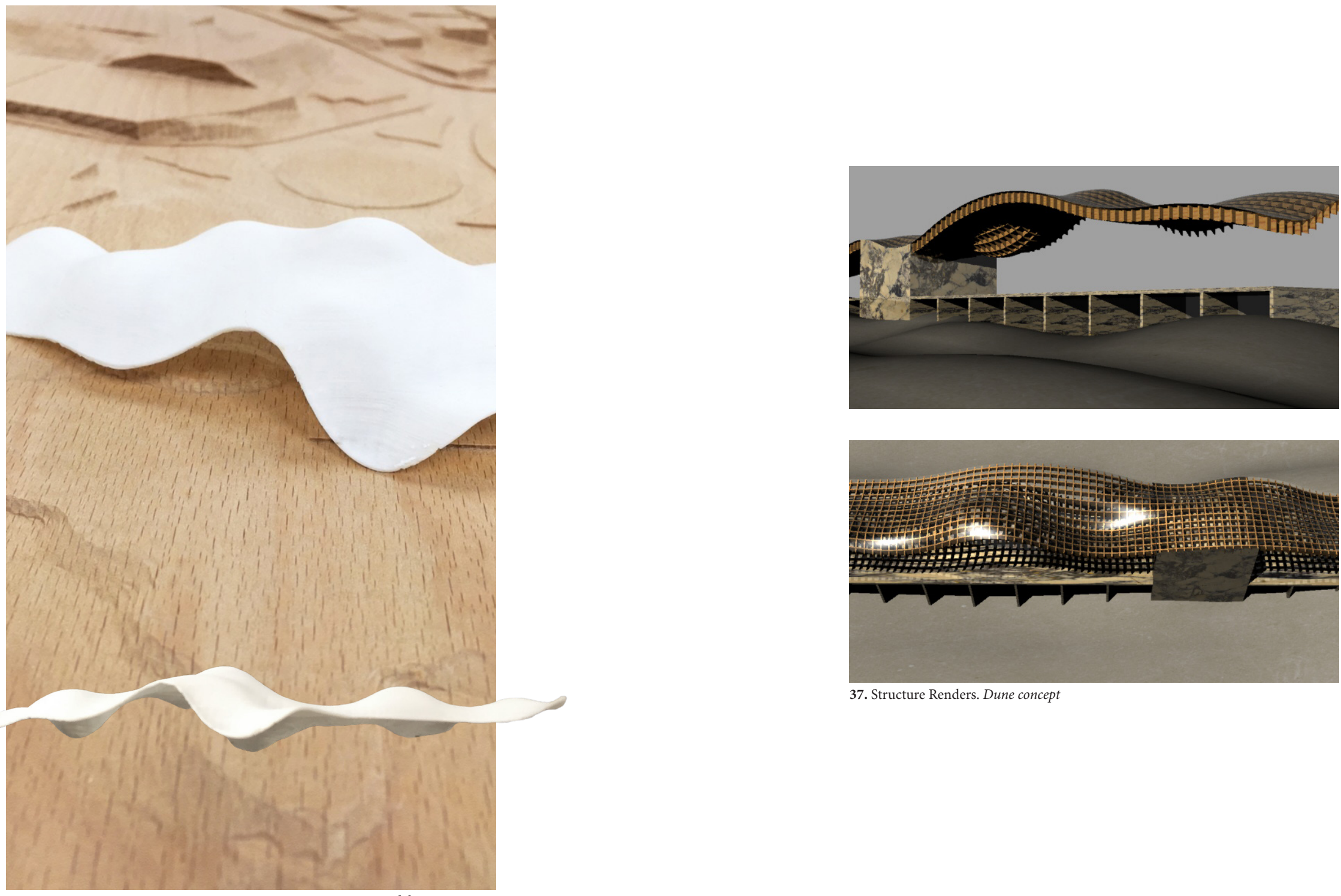

36. Massing model. Dune concept

37. Structure Renders. Dune concept 


\section{Design Response}

This proposal suggests a medium-scale public building to be built to replace the existing Kapiti Boating Club. The design includes local club rooms, boatsheds, visitors centre, café and biosecurity checkpoint. The design aims create a centre of regional identity, a landmark which services both tourists and locals. The following describes what the design includes and how it operates:

The reorganised carpark design uses permanent dunes used as windbreaks and partitions to create a clear distinction between visitor and club parking. French drains line the periphery to collect polluted water run-off and act as a first stage filter. The drains lead into a swale system lining the Tikotu Creek which improves water quality further before releasing it into the sea.

Wet activities which include boat sheds, public toilets and showers are allocated on the ground floor. Constructed from concrete these areas are durable, able to withstand flooding and can be easily cleaned out with a hose. Large concrete fins support the timber structure of the upper floors and act as shear walls. Tension cross-bracing and large glazing panels run perpendicular to maintain transparency towards the island view.

The main entrance invites visitors into a large fernery/ atrium space which acts as a waiting space for large groups and as circulation. This is a six metre tall space is enclosed with translucent polycarbonate walls and roof to allow plenty of light in. The temperature controlled fernery offers a genuine glimpse into the unique ecosystem waiting on the island. A café overlooking the fernery offers visitors somewhere to wait and grab a bite to eat.

The northern end of the building contains the visitor centre, ticket sales, theatre and offices for both DoC and the tour boat operators. Sitting on the highest part of the site and slightly raised this space offers expansive sea views. The western face of the building is lined with flexible outdoor spaces. Sheltered from strong winds, decks and lawns can be used as extended function space, for picnics, or a place to store yachts during regattas.

A long pier extends from the top floor over the coastal dune system and steps down onto the beach. This offers a safe and photogenic path to the beach away from the dangers of the boat ramp. The biosecurity check room sits at the start of the pier. This small space is used to brief and educate visitors to the island. Tables, posters and foot wash stations guide visitors through the process.

The top floor on the southern wing of the complex accommodates club activities. A large hall space is designed to host events alongside the stunning Kapiti backdrop. The hall is lined with smaller spaces including a bar, offices, meeting room, and a radio room. A staircase sits at the southern end to creating a private entrance and fire escape. 


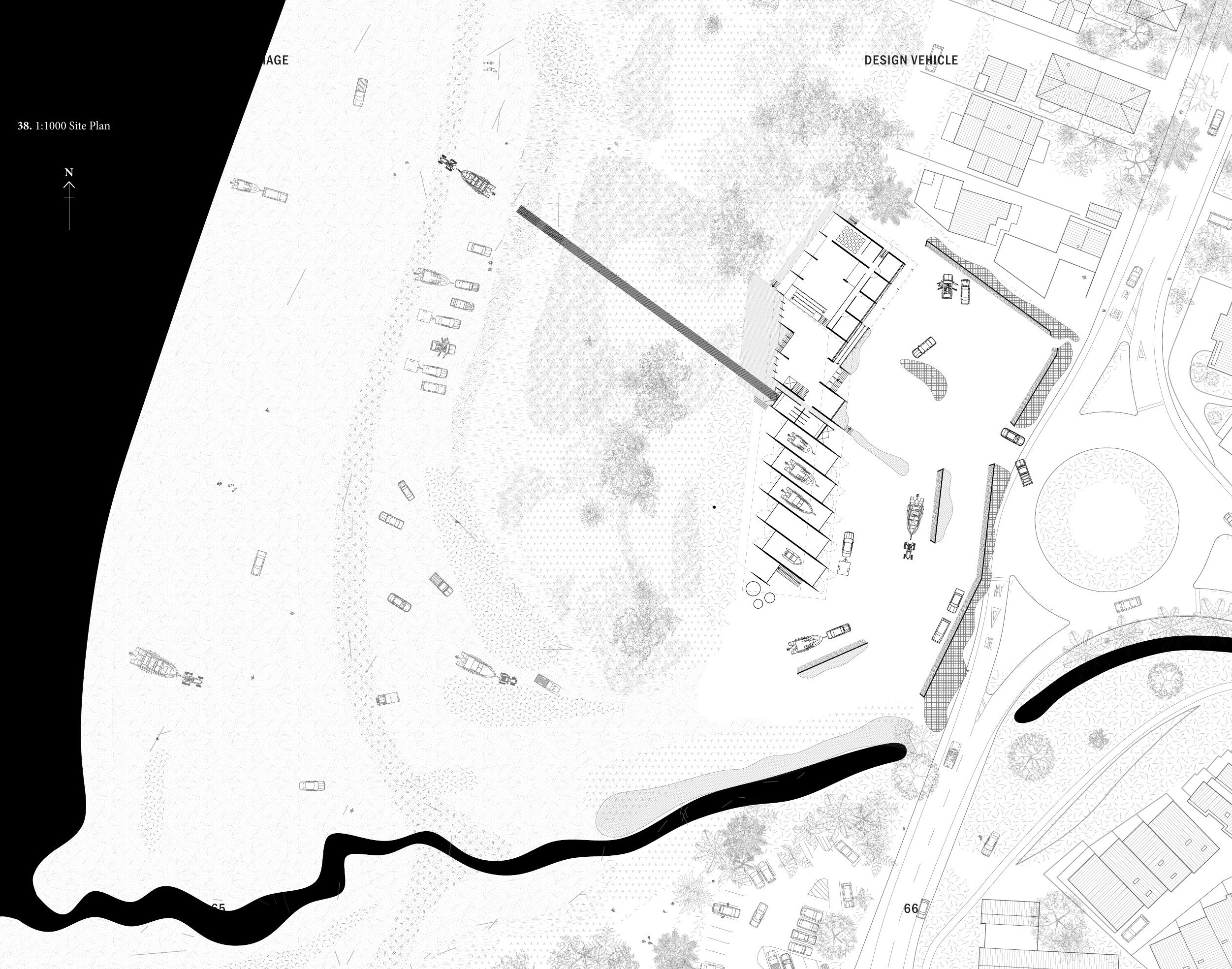



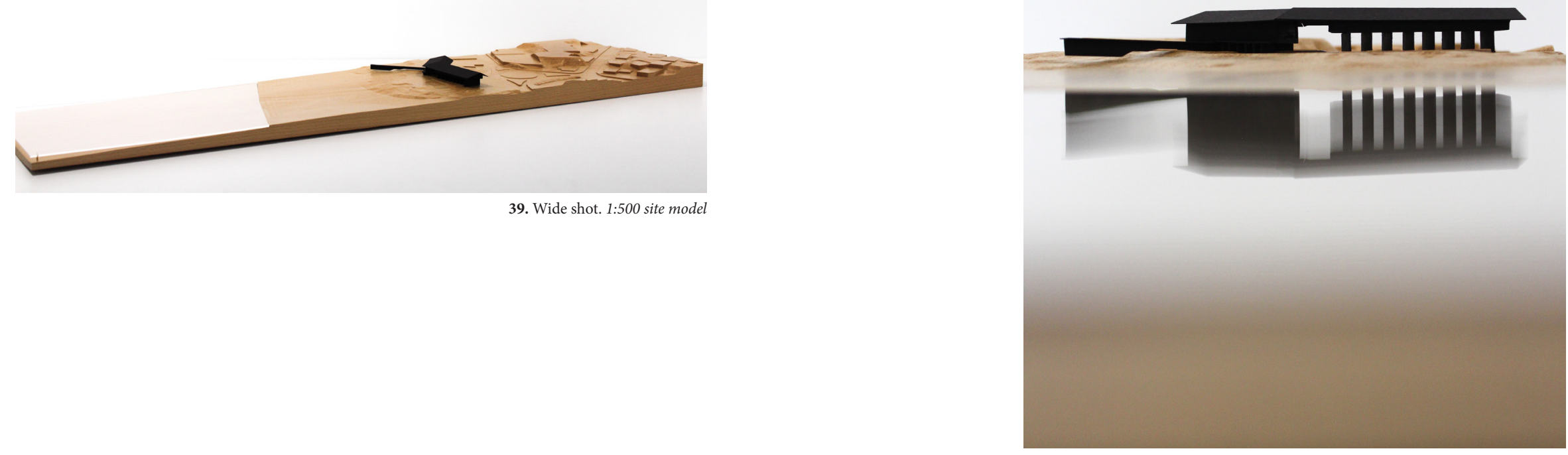

40. Massing model with reflection. 1:500 site model 


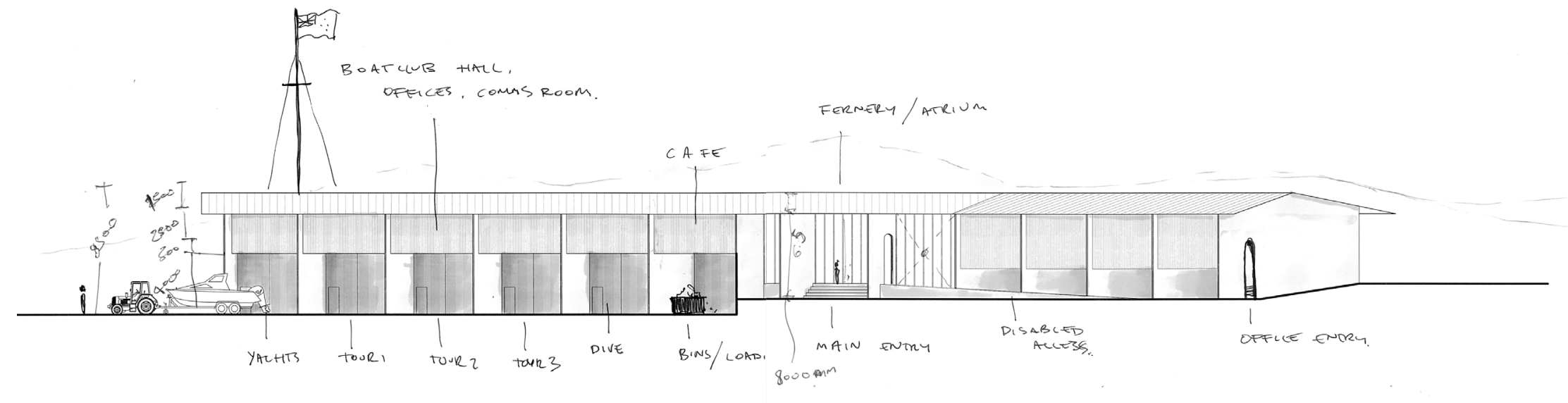

41. 1:500 East elevation

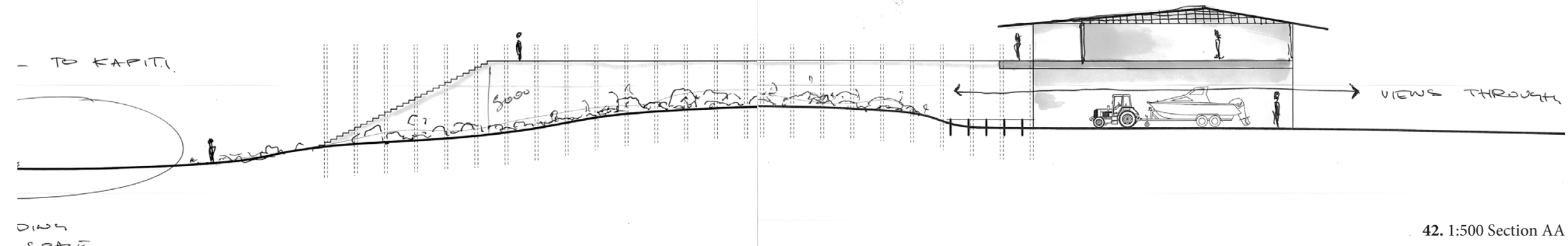

SPACE. 


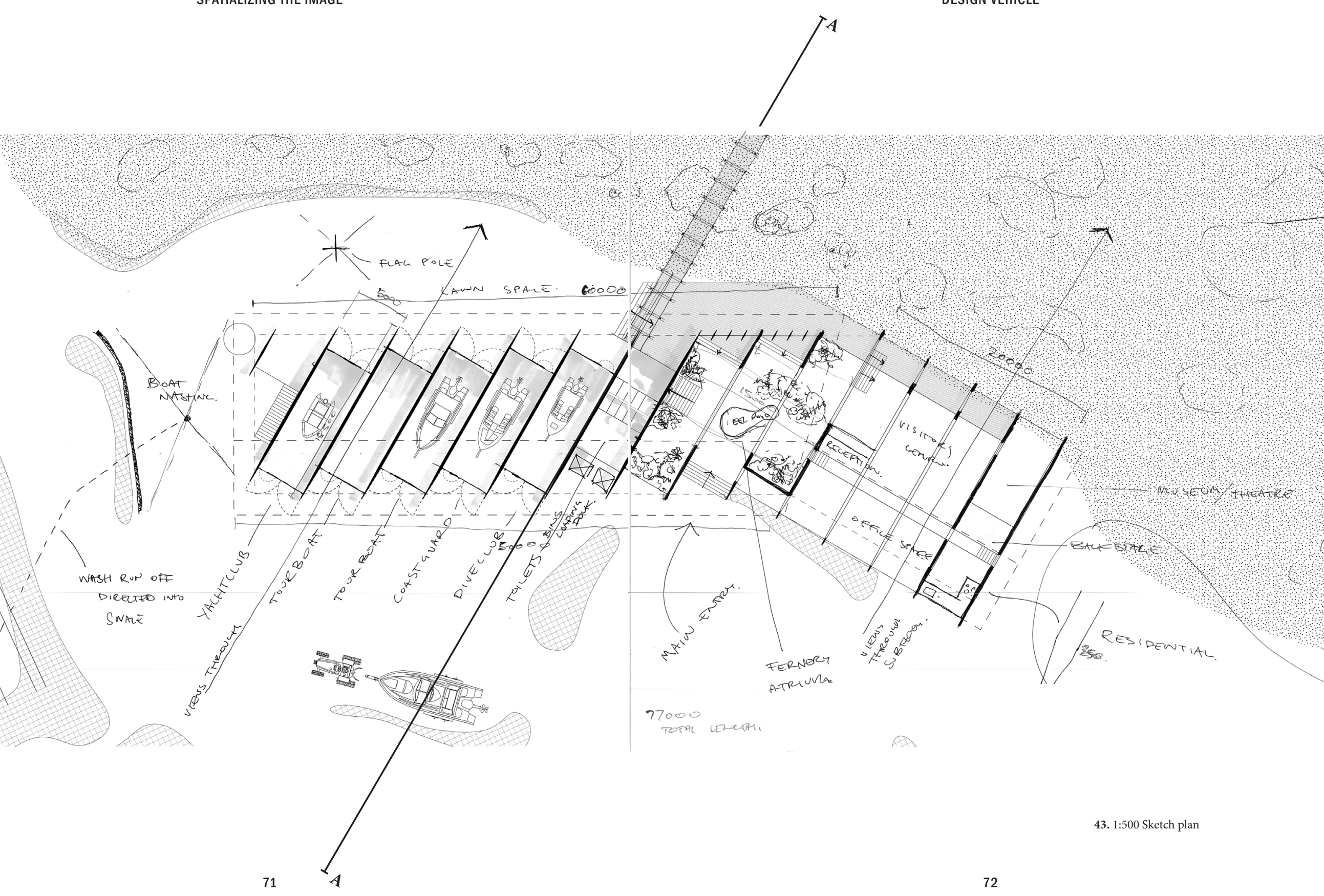




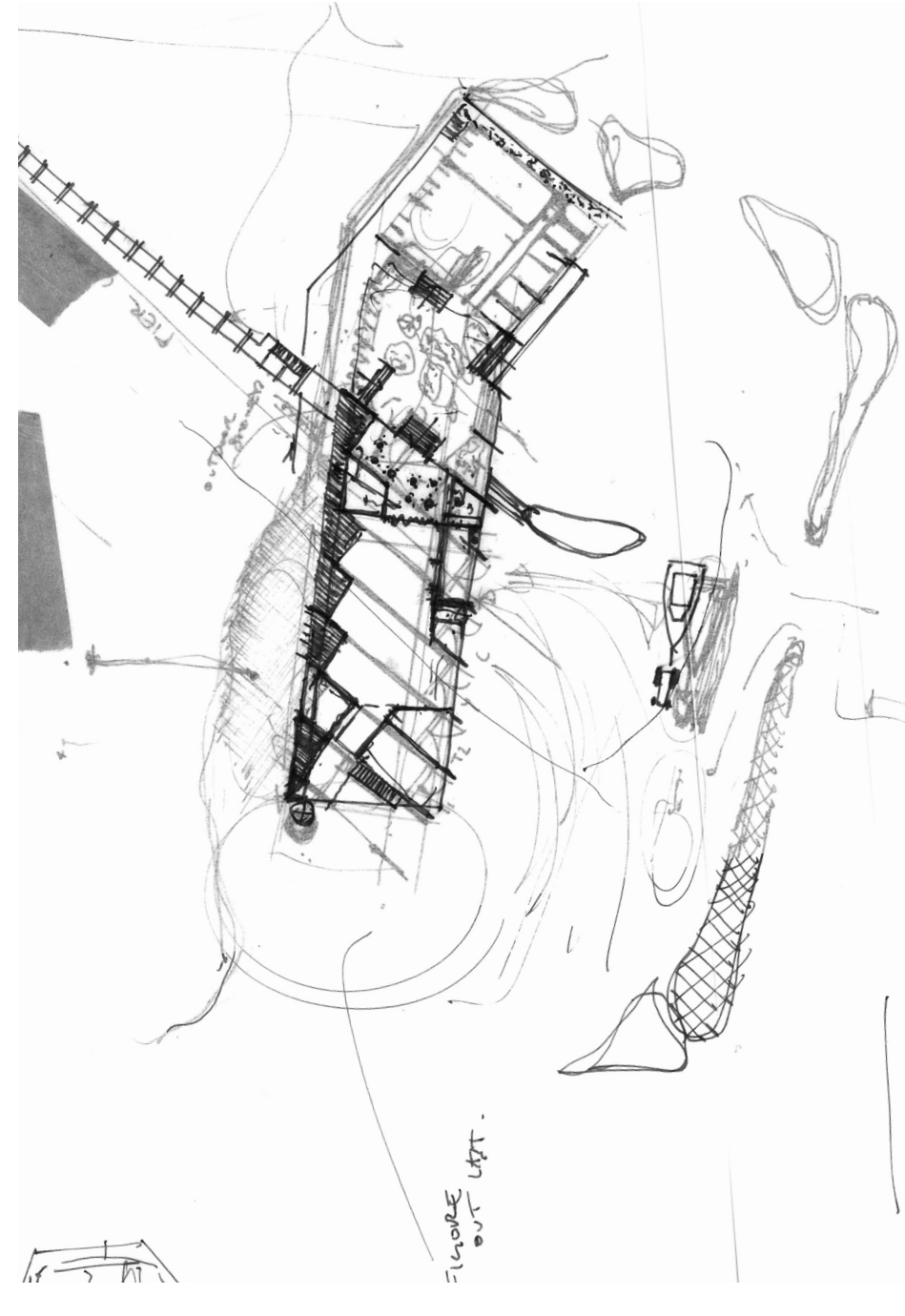

44. Process plan 28

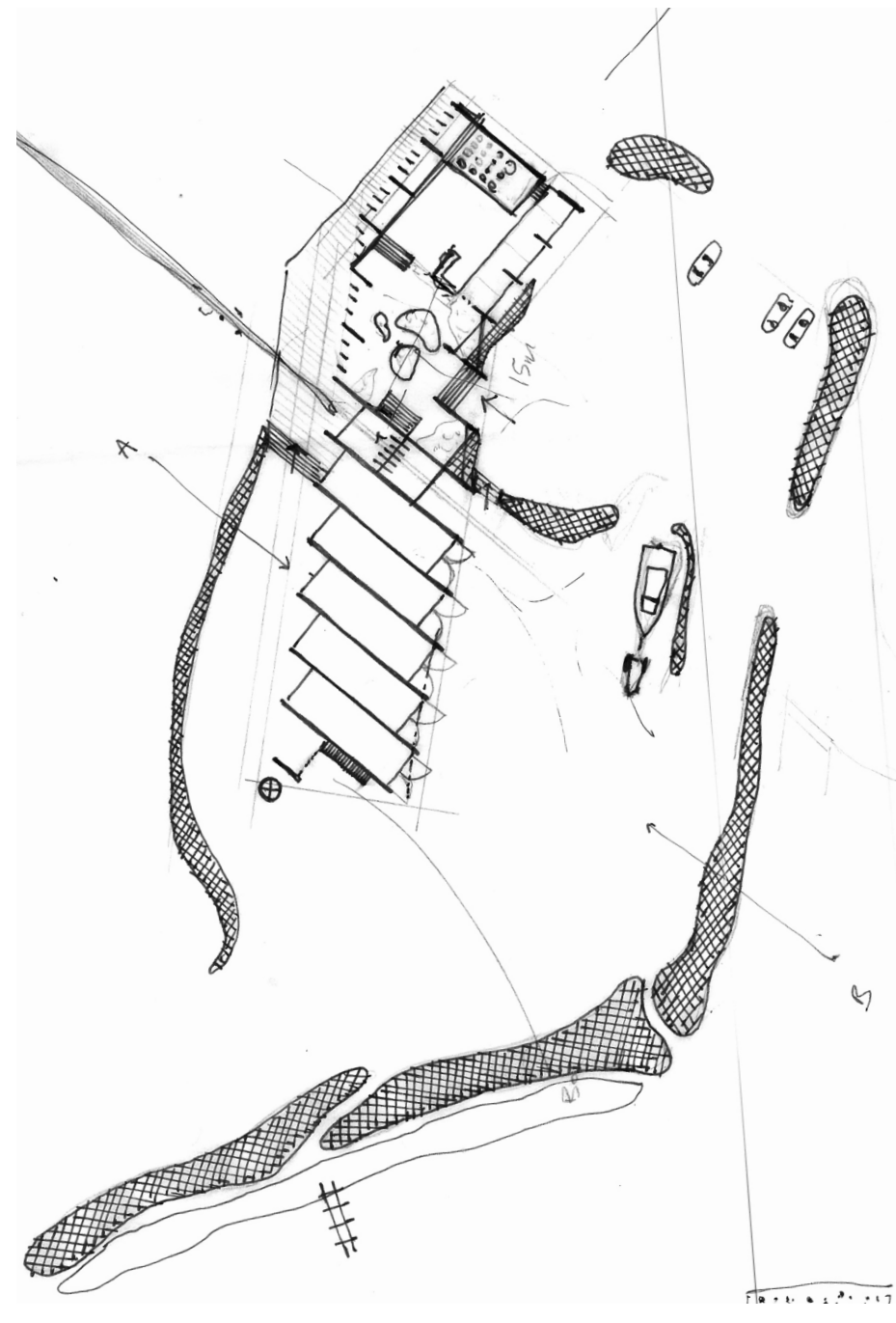

45. Process plan 29 

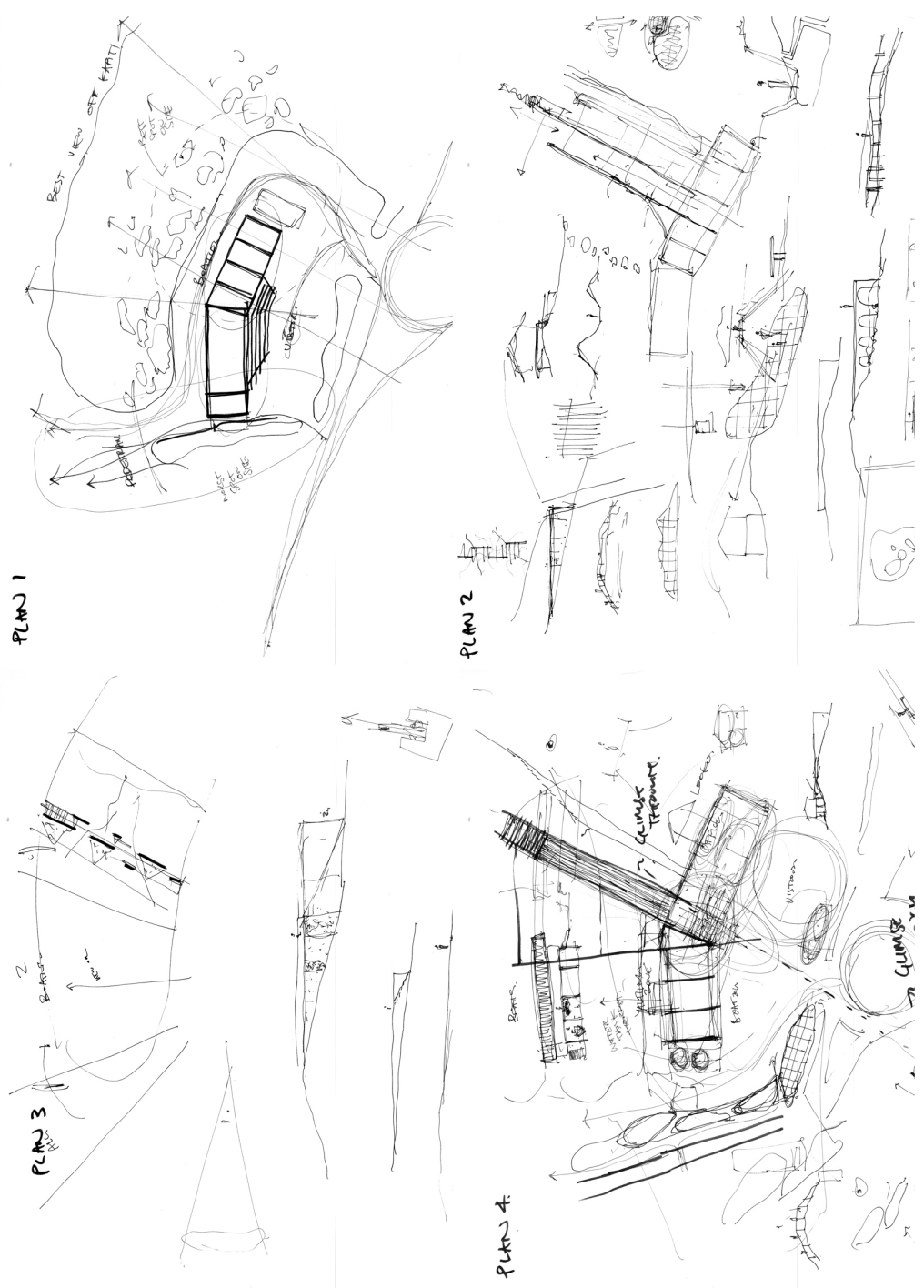

46. Plan process sketches 1-4
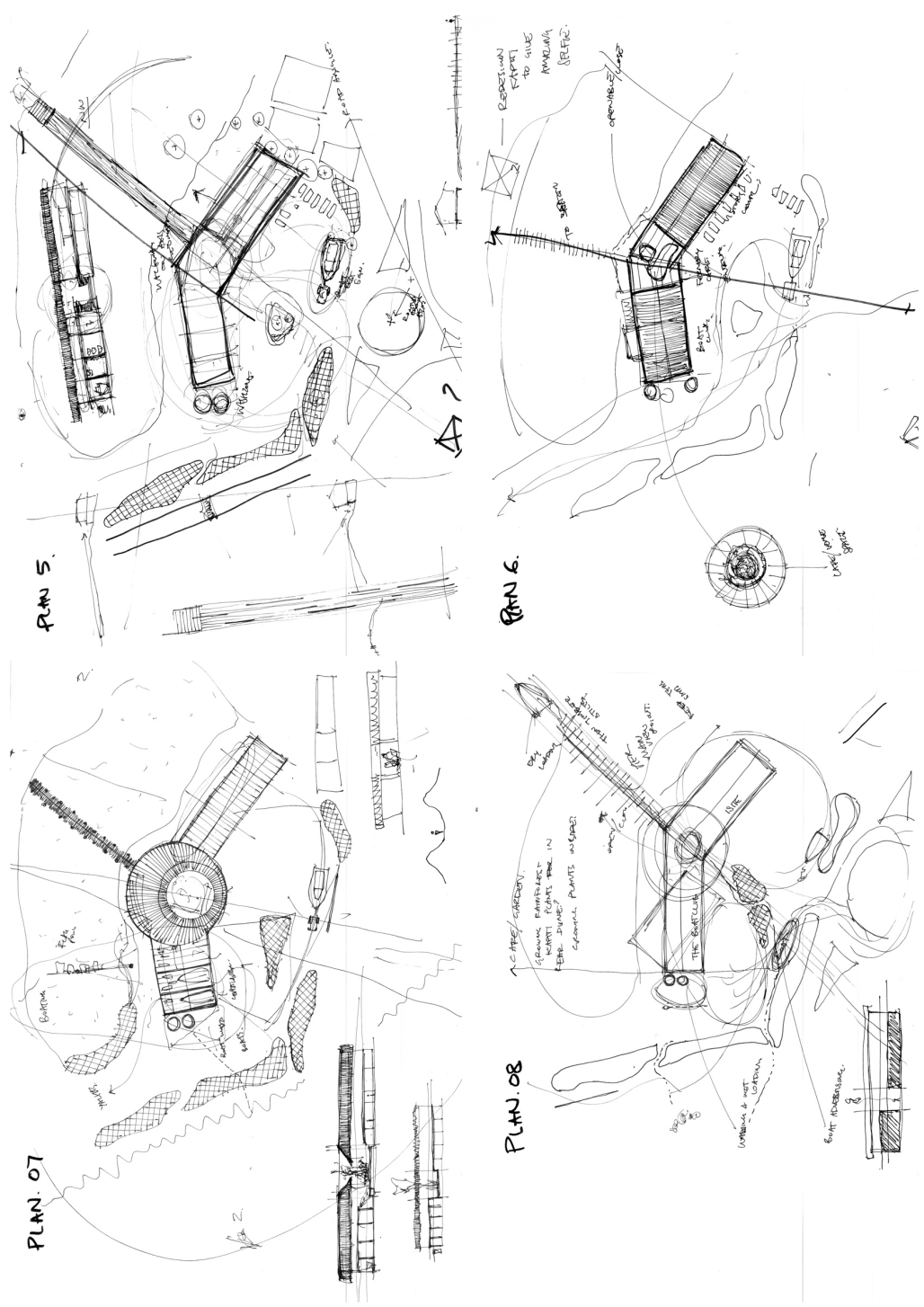

47. Plan process sketches 5-8 

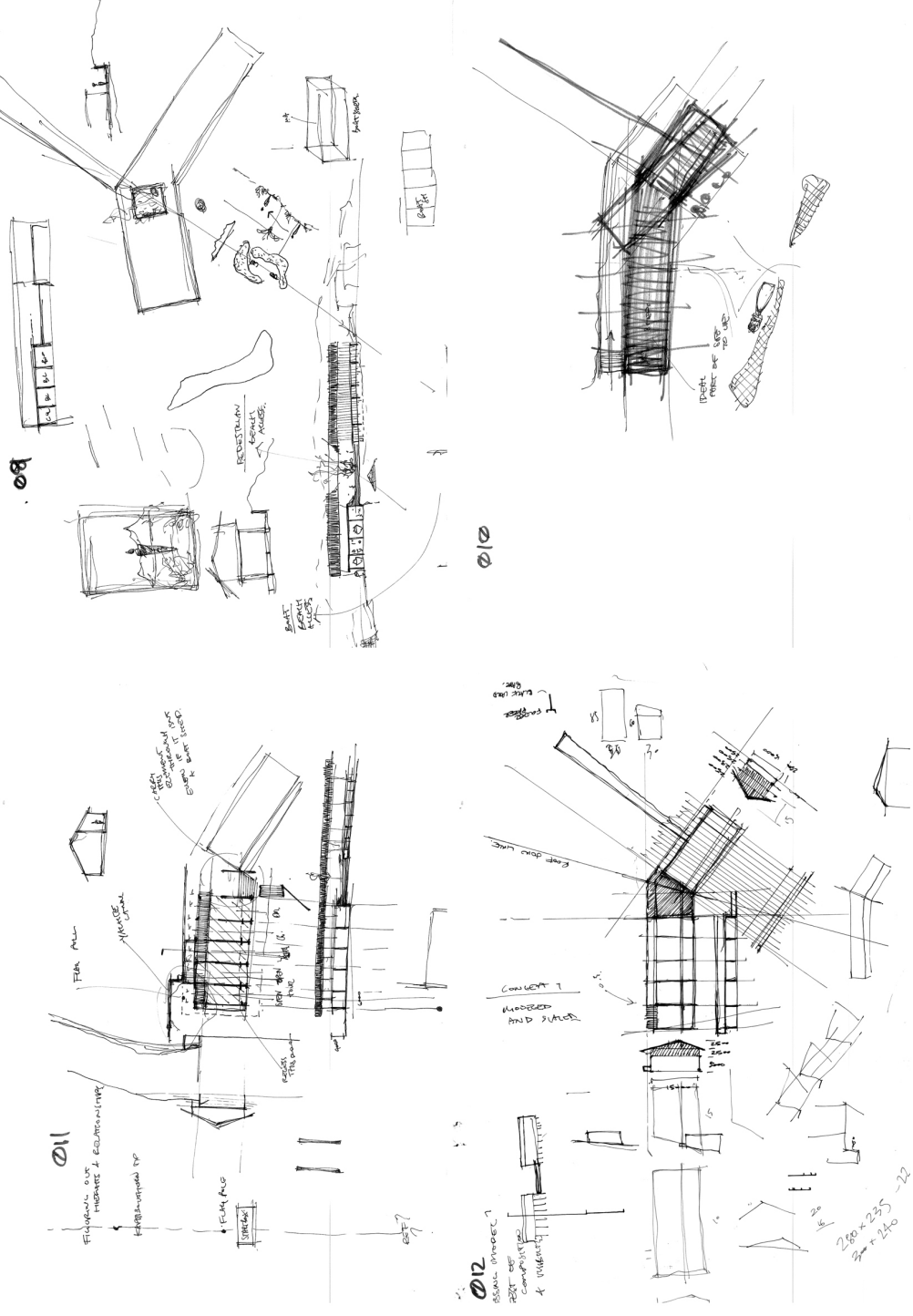

48. Plan process sketches 9-12
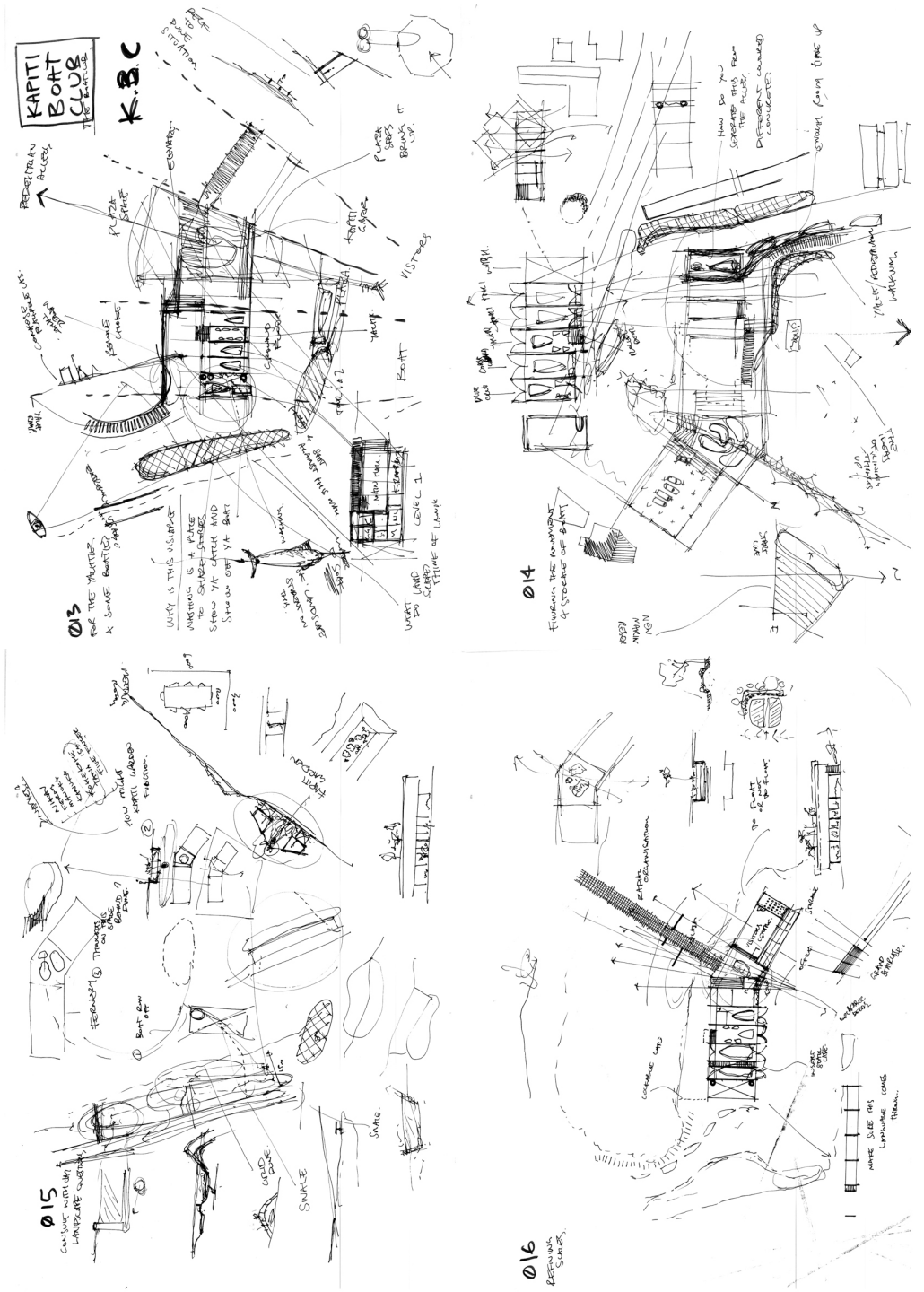

49. Plan process sketches 13-16 

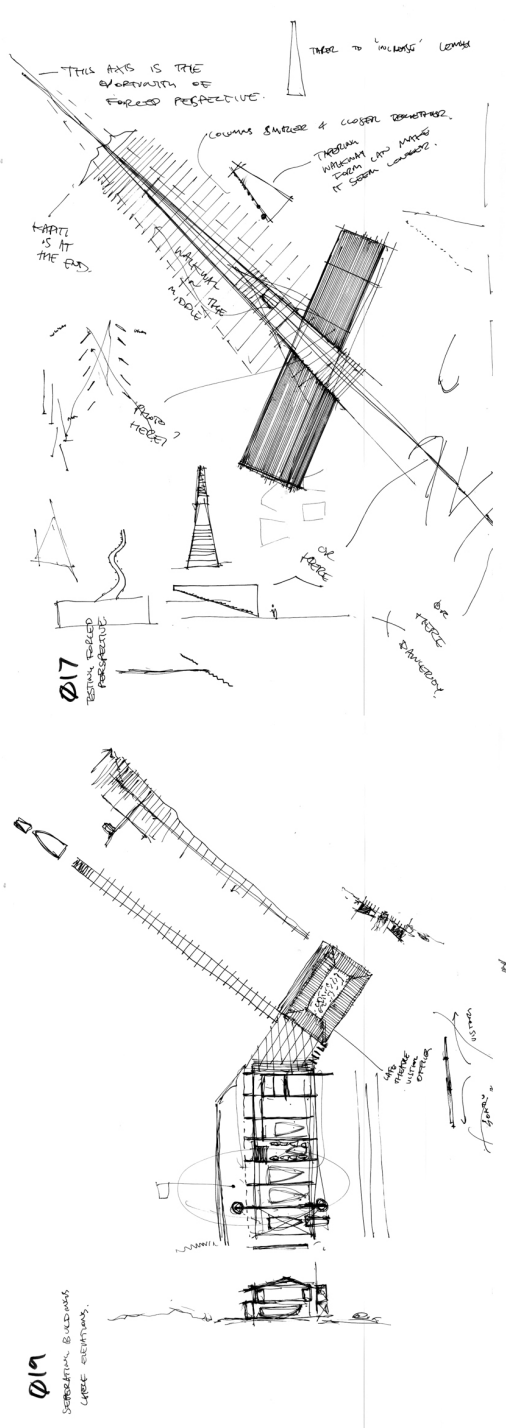

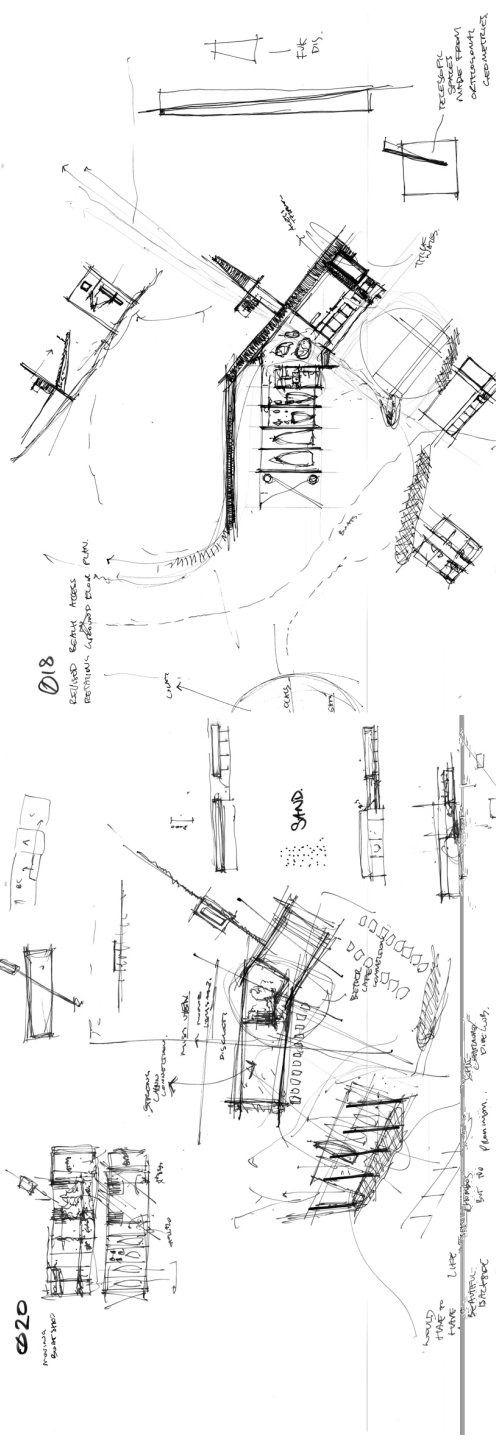

50. Plan process sketches 17-20
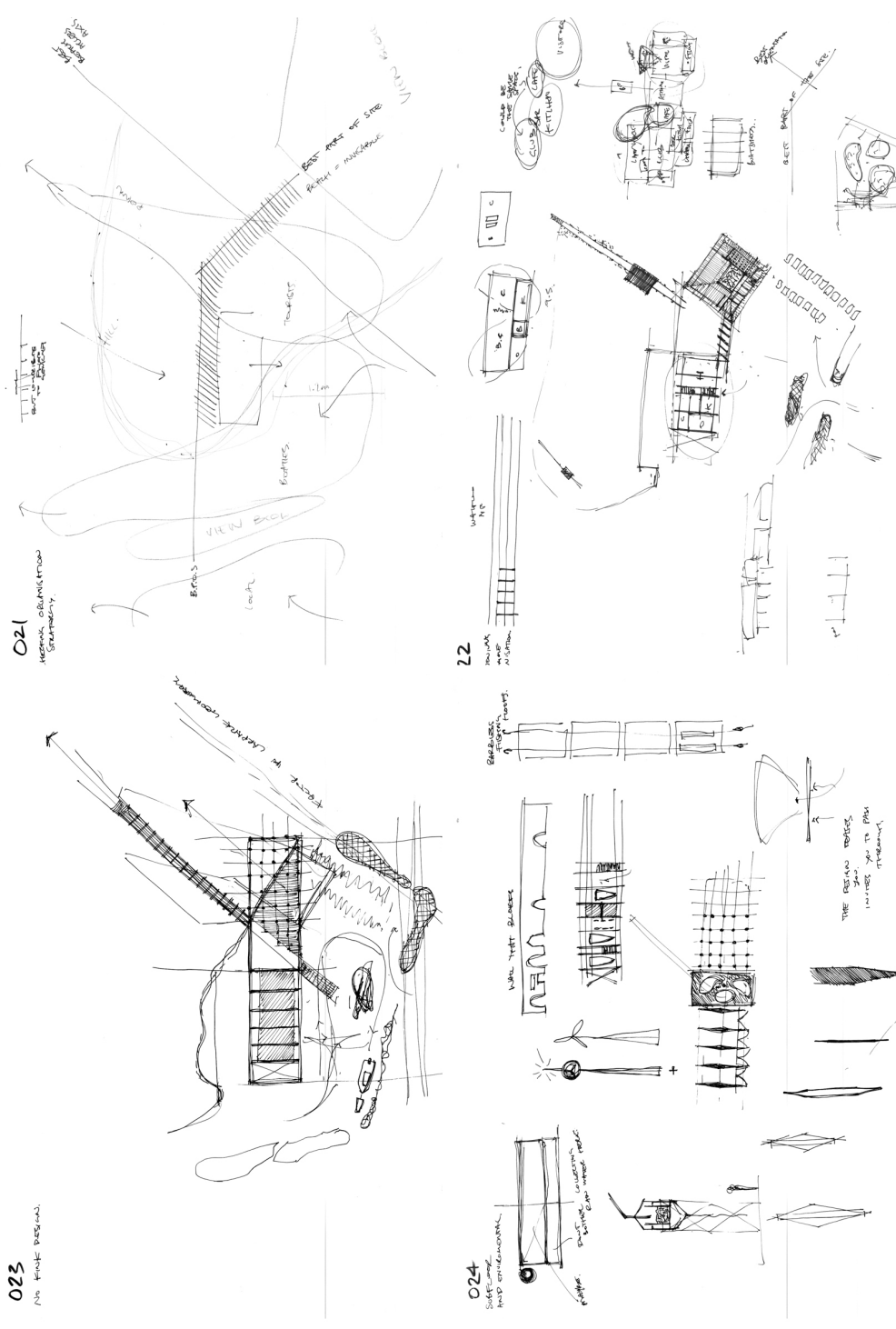

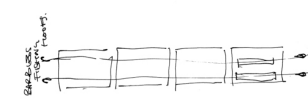

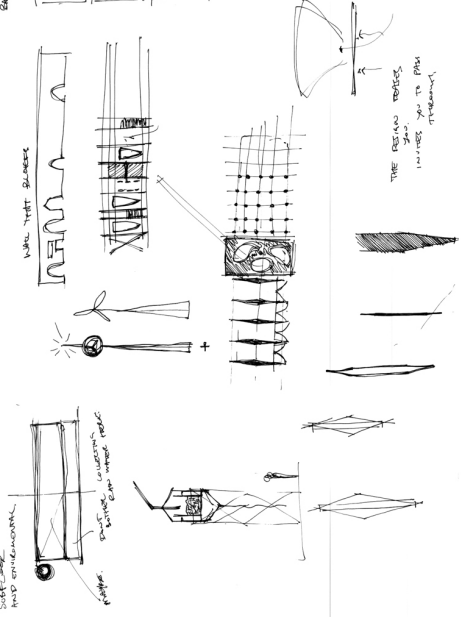

51. Plan process sketches $21-24$ 

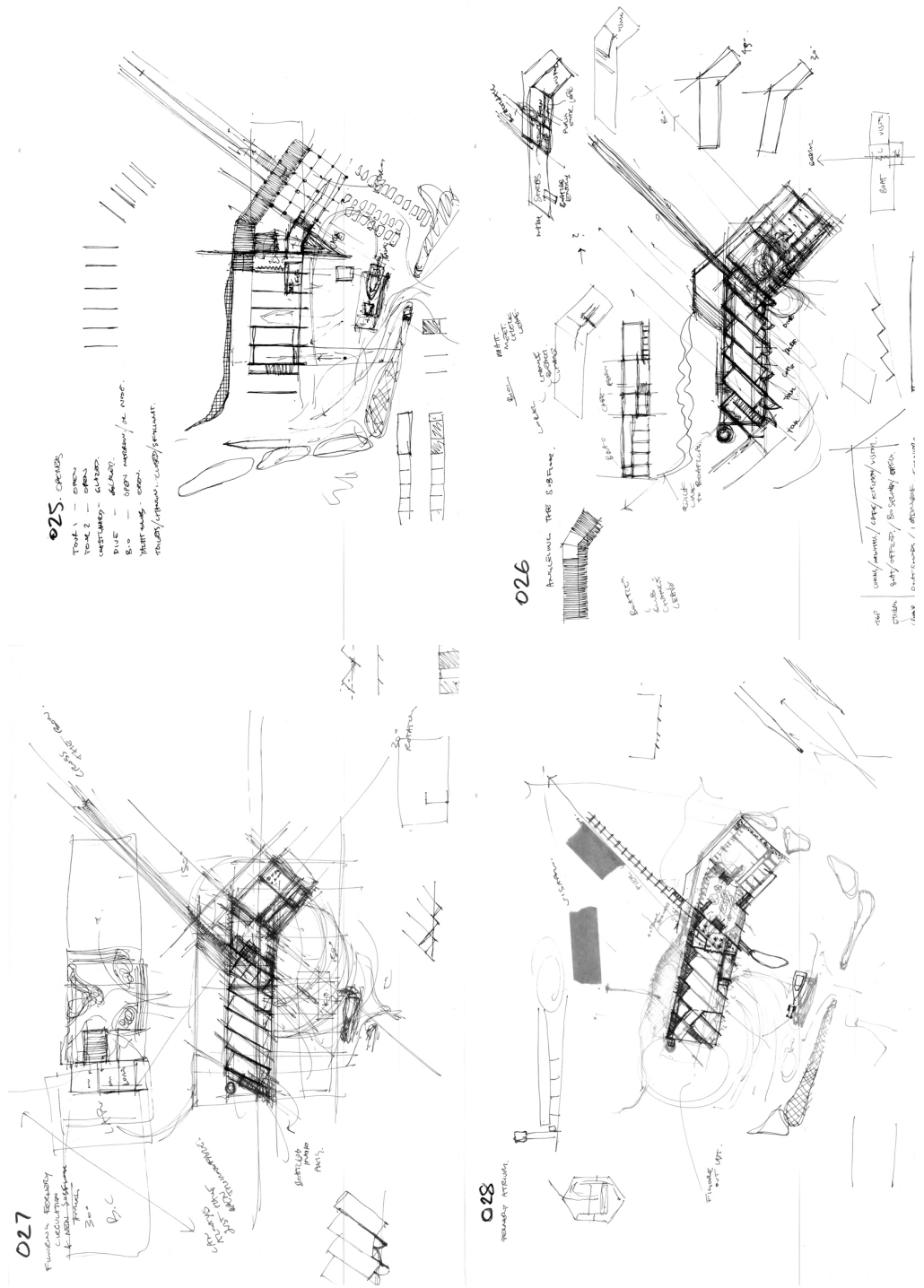

52. Plan process sketches $25-28$

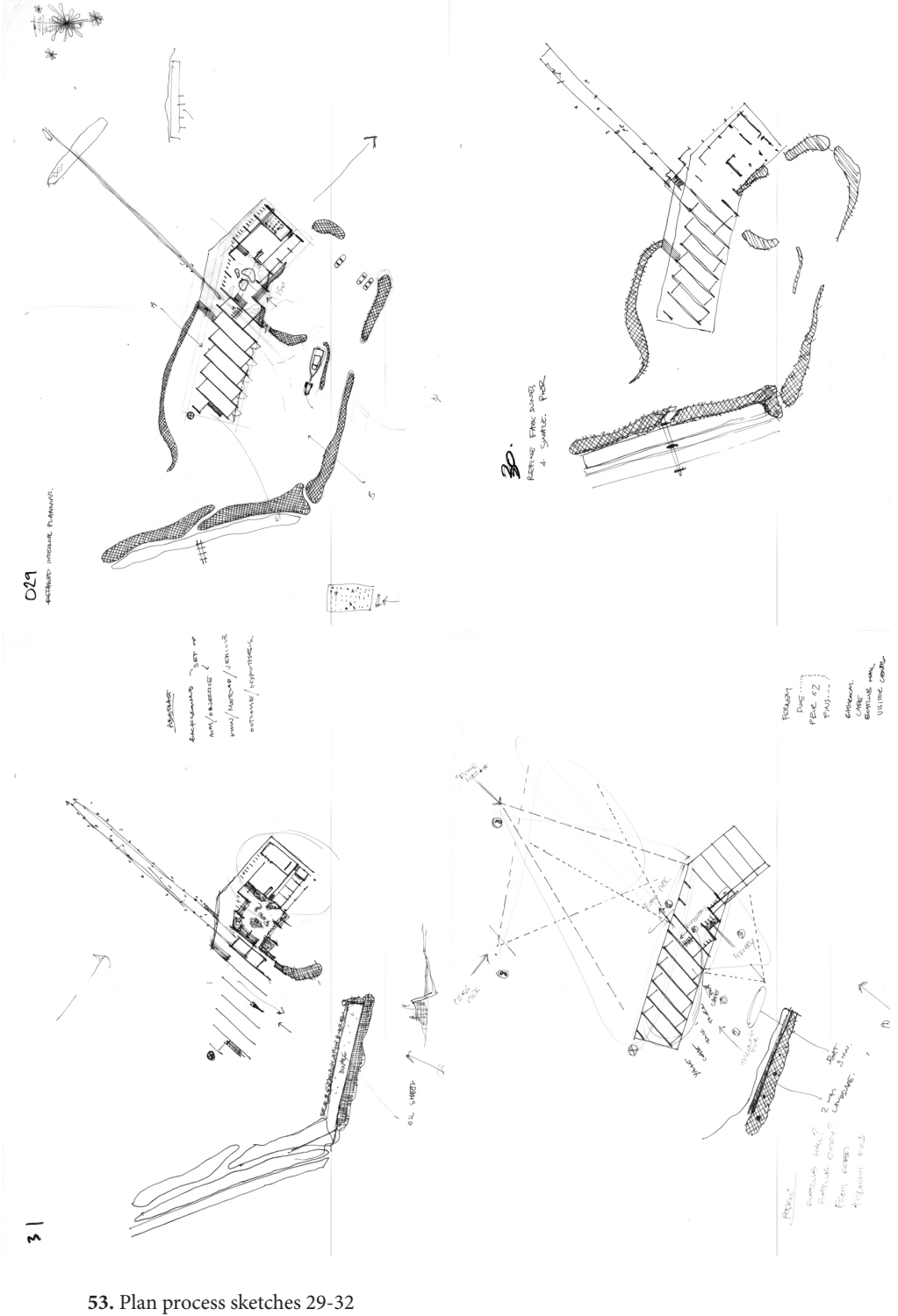


Chapter Three

CONTEXT 


\section{Smout \& Allen}

Mark Smout and Laura Allen are senior lecturers at the Bartlett School of Architecture, UCL. Their mostly speculative work explores relationships between architecture and landscape. Projects from them often exhibit a range of methods of design process which are tailored specifically to the nature of the design problem.

In their 'Panorama Landmarks' project they create a series of models which form physical manifestations of the design problem. The project proposes a series of landmarks designed for the east of England. Each model represents an unique landmark which "seeks to enhance this relationship between ground and sky, utilising elevated positions, constructed vistas, and reflective surfaces" (Smout \& Allen, Augmented Landscapes, 2007, p. 26). Inspired by the panorama theatres of the nineteenth century, the landmarks became a "viewing mechanism that taught people how to see a view as it was organised the visual experience for the eye" (Smout \& Allen, Augmented Landscapes, 2007, p. 6). The landmarks which sit thoughtfully in their context mimic and exaggerate existing site qualities.
This project was examined specifically in terms of the model representation and operation. The proposed landmarks and subsequent models are designed with a focus on the view, and the position of the viewer. "The viewer is precisely placed relative to the horizon on which the new elements are po-sitioned, juxtaposed to the fore-, mid and background" (Smout \& Allen, Augmented Landscapes, 2007, p. 8)". Each model is built with the scale of the body in mind as to be easily held up to the horizon which "enables them to be viewed at the scale of an object or within the scale of the horizon" (Smout \& Allen, Augmented Landscapes, 2007, p. 7). 


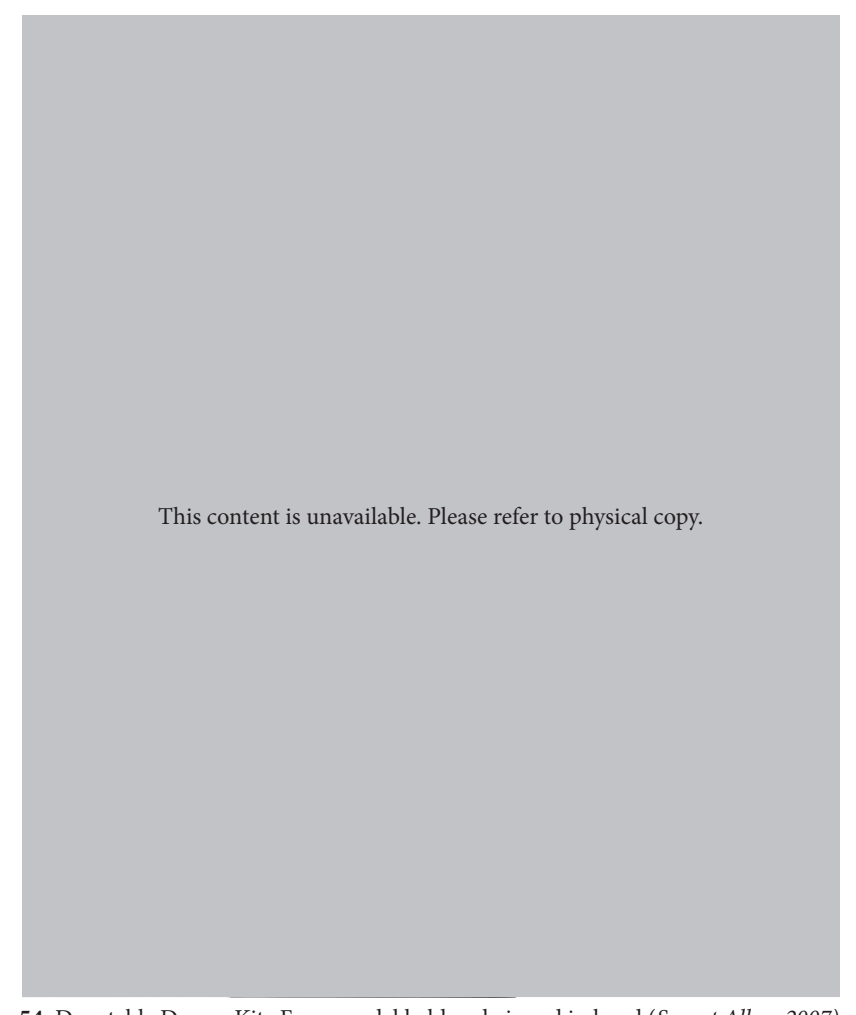

54. Dunstable Downs Kite Farm model held and viewed in hand (Smout Allen, 2007)

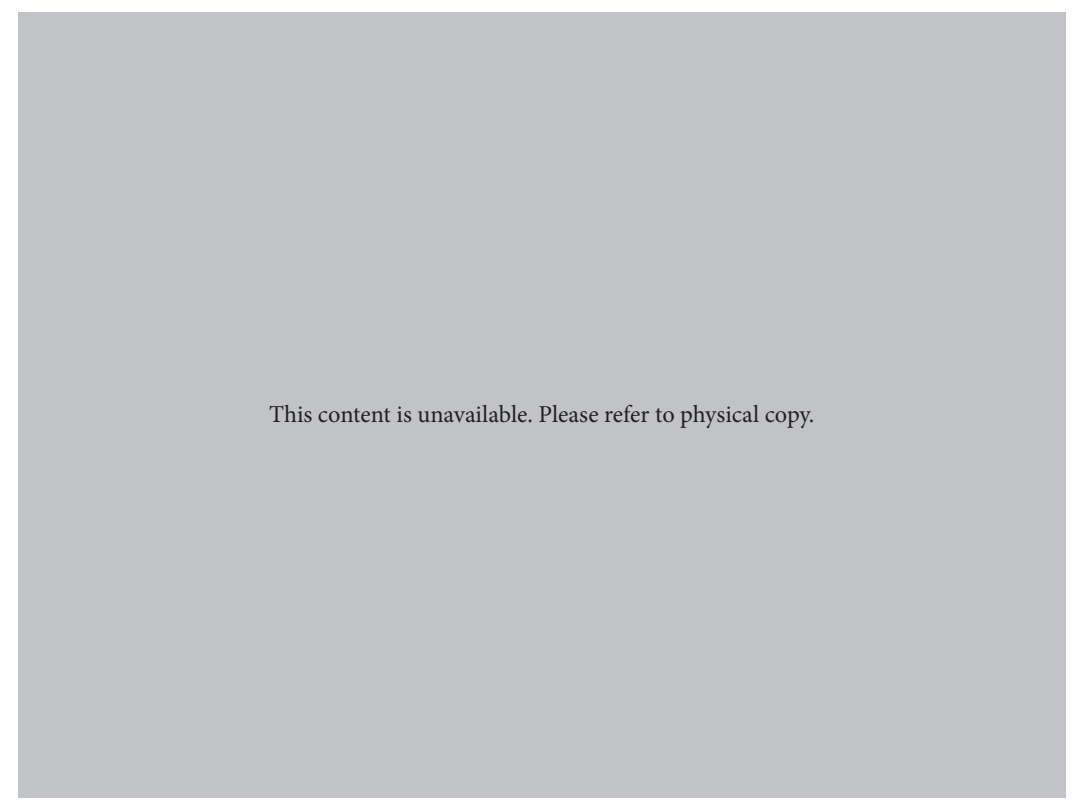

55. Landmark model positioned relative to horizon backdrop (Smout Allen, 2015) 


\section{Nat Chard}

Nat Chard is also a lecturer from Bartlett School of Architecture. Among many things he is known for designing and making architectural machines which observe, look, photograph and draw. Chard refines explorations of complex phenomena into simple objects. Describing these objects Peter Cook remarks that they "become much more interesting and telling than the conditions or objects that are being observed (2005, p. 2). The following section examines and evaluates Chard's 'Cold Bog Camera'.

The Cold Bog Camera is a small and highly specific pinhole camera designed to study the panoramic qualities of the Cold bog diorama in the Yale Peabody Museum of Natural History (Chard, Nat Chard: Drawing Indeterminate Architecture, 2015, p.83). In creating the panoramic backdrops, flat picture planes taken on site had to undergo a series of mathematic calculations In order to maintain perspectival accuracy (Chard, Drawing Instruments, 2005, p. 25). Fascinated by the process Chard designed and built a device which could "make all his calculations in one photograph." (Chard, Nat Chard: Drawing Indeterminate Architecture, 2015, p. 83).
The device looks surprisingly simple, a pinhole camera with specific dimensions and a curved picture plane (Chard, Nat Chard: Drawing Indeterminate Architecture, 2015, p. 83). The device is however embedded with great knowledge and has as many hidden complexities. The creation of the device takes so much knowledge that by the time its built Chard already understands the problem. Chard states "I learned almost everything I needed to know by designing and making the camera rather than using it" (Chard, Drawing Instruments, 2005, p. 26). Alongside his personal gathering of knowledge the small hand held device also forms a strong representation of an idea. 


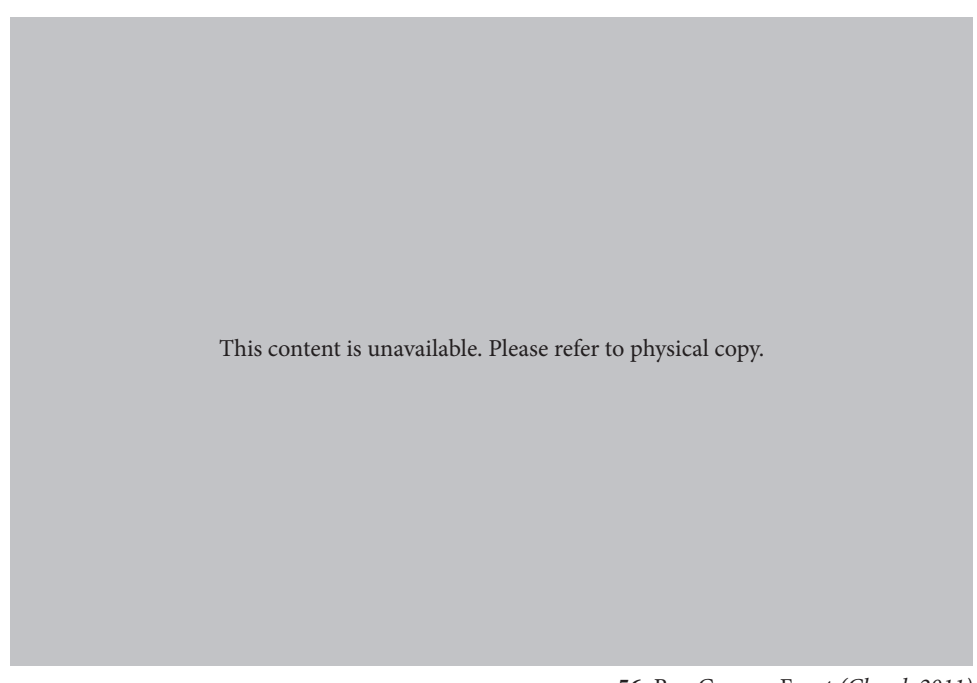

56. Bog Camera Front (Chard, 2011)

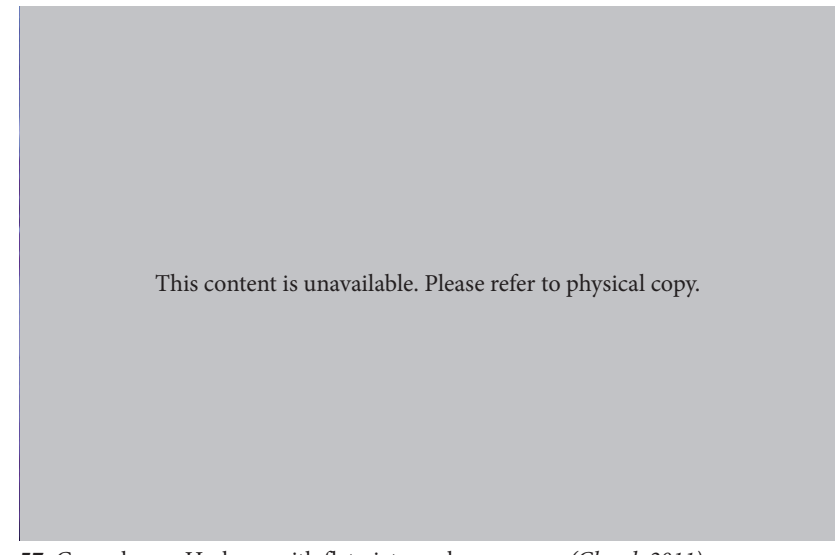

57. Copenhagen Harbour with flat picture plane camera (Chard, 2011)

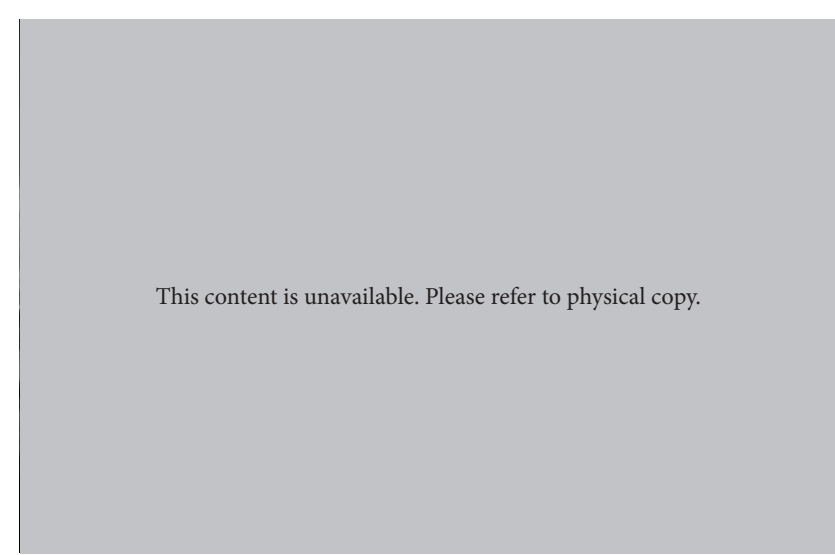

58. Copenhagen Harbour with Cold Bog Camera (Chard, 2011) 


\section{Georges Rousse}

Georges Rousse is a Paris based photographer and installation artist (Feireiss, 2010, p. 198). Rousse is most well-known for creating perspective illusion installations, usually set in abandoned or derelict buildings. These installations rely on single point perspective which acts in "transforming these sites into pictorial spaces that are visible only in his photographs" (Rousse). At first glance the images of his installations appear to be digitally altered photographs, made by superimposing boldly coloured geometry over the picture. However this is not the case, Rousse works with the medium of space, which he activates using paint. Rousse paints the floors, walls and ceiling correcting for such things as the interruption of beams or the slope of the floor. Although operating spatially his ultimate goal is creating a photographic image (Rousse).
The forced perspective installation encourages the viewer to position themselves at the point of the artist's perspective. At this point the viewer is confronted with a discussion about the relationship between the second and third dimensions. The installation although spatial creates a two-dimensional plane. Stepping between this point and elsewhere in the room allows each dimension to give insight to the other. While his works are optical illusions Rousses goal is not to deceive the viewer but to enlighten them on the complexities of depth and perception. 

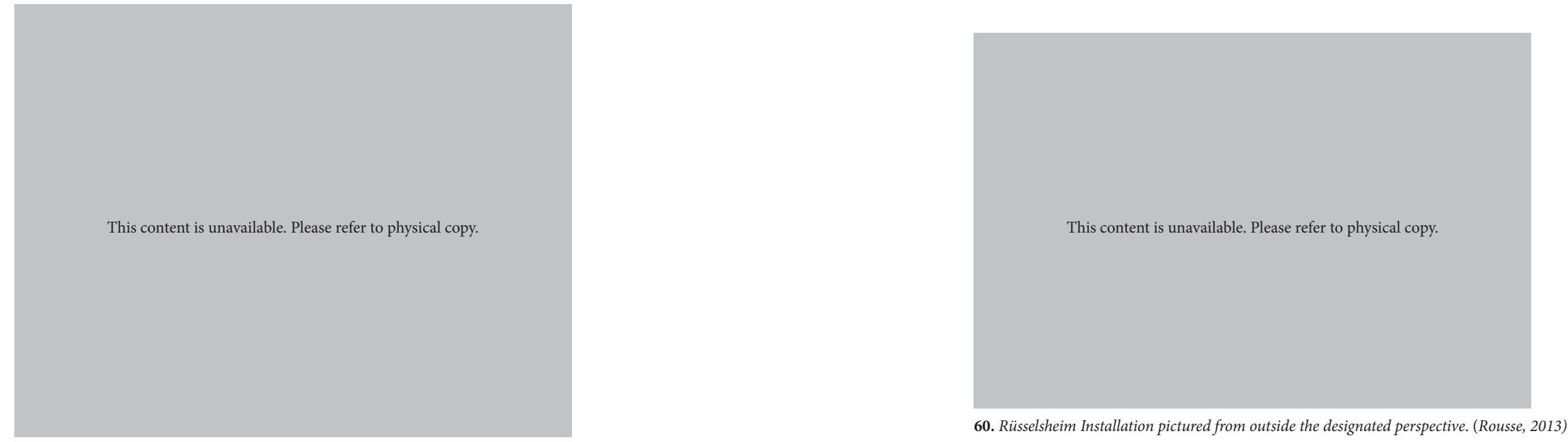

59. Rüsselsheim Installation pictured from designated perspective. (Rousse, 2013) 
Chapter Four

METHODOLOGY 


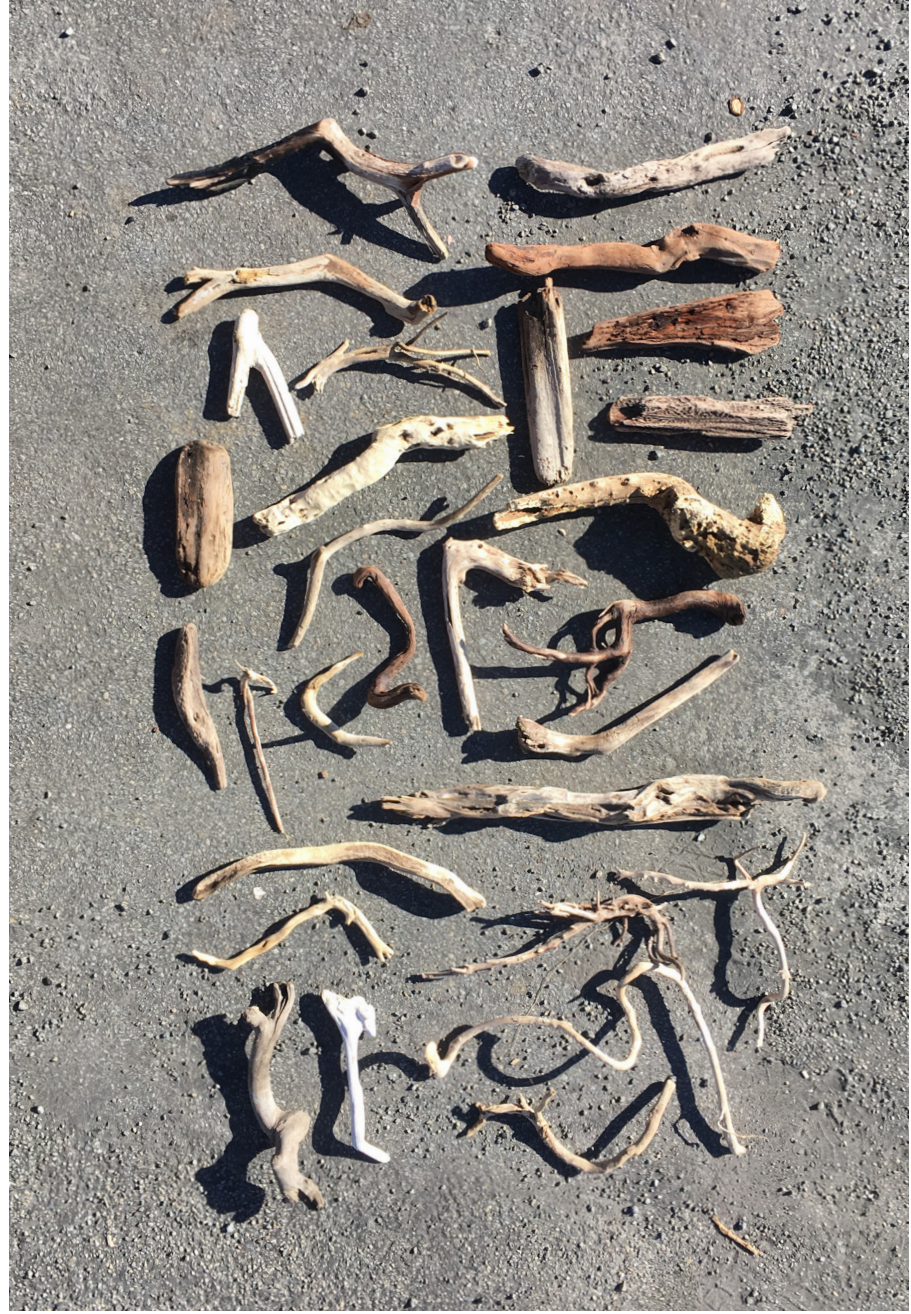

61. Driftwood composition made on-site. Beach art

\section{Design-led Research}

This research portfolio operates through design-led research, a methodology of learning through the design process. Peter Downton states "design is a way of inquiring, a way of producing knowing and knowledge, this means it is a method of researching" (2003, p. 2). This methodology is a 'learn by doing' strategy where knowledge is uncovered through a cycle of continual design and critical reflection. The design of the Kapiti Biosecurity Gateway was both the "subject and the method by which the research is conducted" (Colletti \& Sheil, 2009, p. 8). Jane Rendell suggests "in much design research the process operates through generative modes, producing works at the outset that may then be reflected upon later" (2013, p. 117). Critical reflection concluded each design experiment where strengths and weaknesses were outlined in relation to the developing research question. The research proposition was slowly drawn out of the emerging work. Ideas shifted, were pursued and abandoned, but methodically became more focused through each design test. Alongside design experimentation, ideas were also investigated through reading, writing and conversation. Precedents and theories were compared and contrasted in relation to the design. 


\section{Beach Art: Doing What You Love}

Jane Rendell states "Instead of posing research questions and then finding answers, in much design research the process operates through generative modes, producing works at the outset that may then be reflected upon later" (2013, p. 117). The beauty of this method is how the production of work can begin without the hesitation and fear of trying to predict the final outcome. The other strength of this is that if you begin by doing something you enjoy, there is a good chance the following research will continue to be about what you delight in.

My research began with the making of a Biosecurity Beach Drawing (Fig 62). It was drawn on Back Beach, New Plymouth with a rake and some builder's line. The concept was designed on a newspaper over breakfast, a hybrid of the biosecurity symbol and Len Lye's Tusalava, 1928. It took all day to complete including set up, practicing some techniques and a few quick dips in the sea to cool off. The day was concluded by posting a picture of the drawing online to my personal Instagram account.

Reflecting upon this enjoyable experience reveals the significant aspects of it; novel methods of representation, public interaction, lightly touching the landscape, hands-on process, social media, and photography. What I found most satisfying was the hands-on creation of something spatial and that the public could also appreciate the creation.

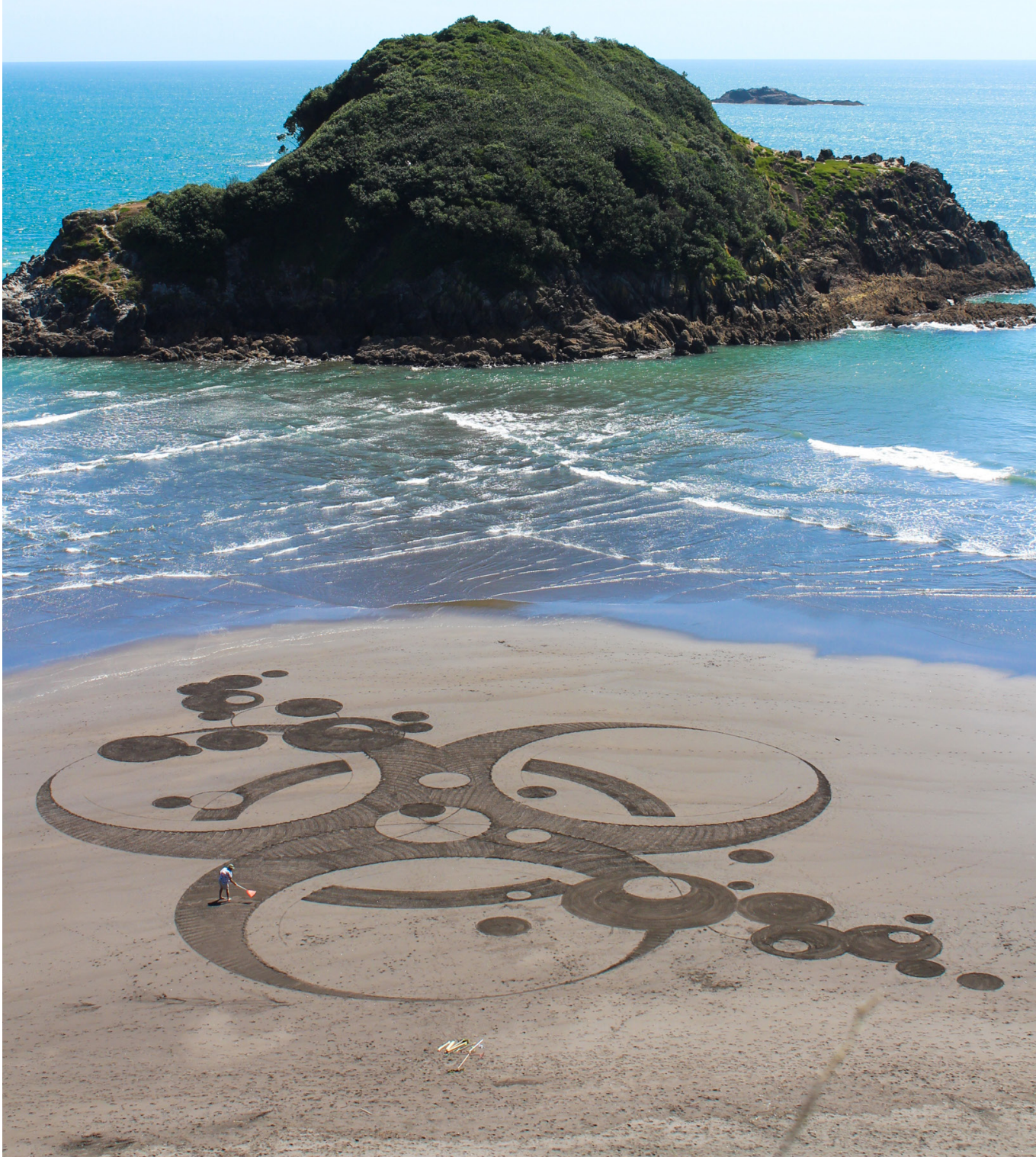




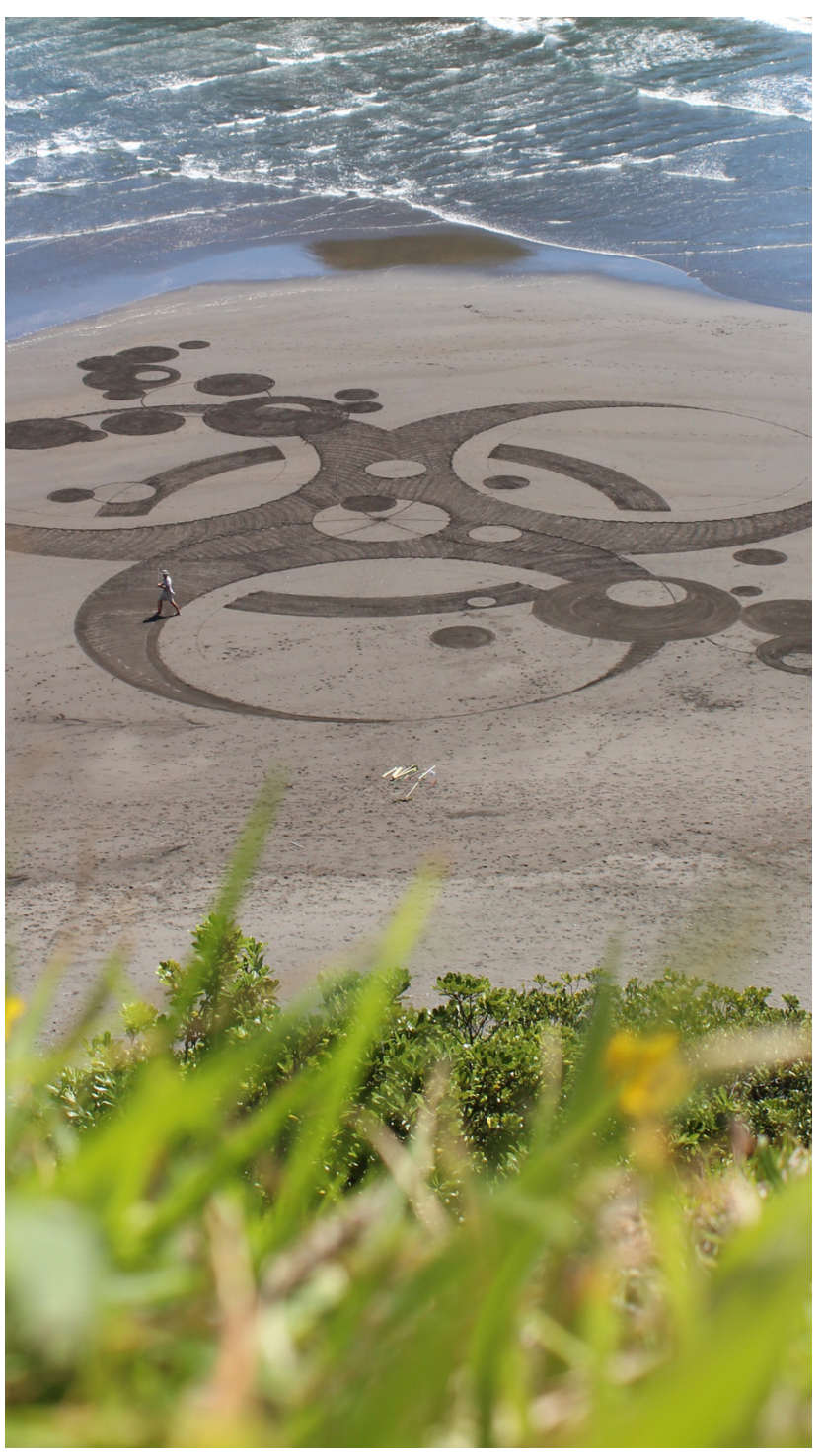

63. Sand drawing shot from nearby cliff. Beach art

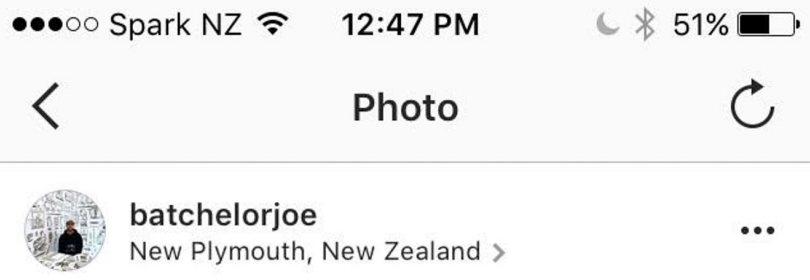

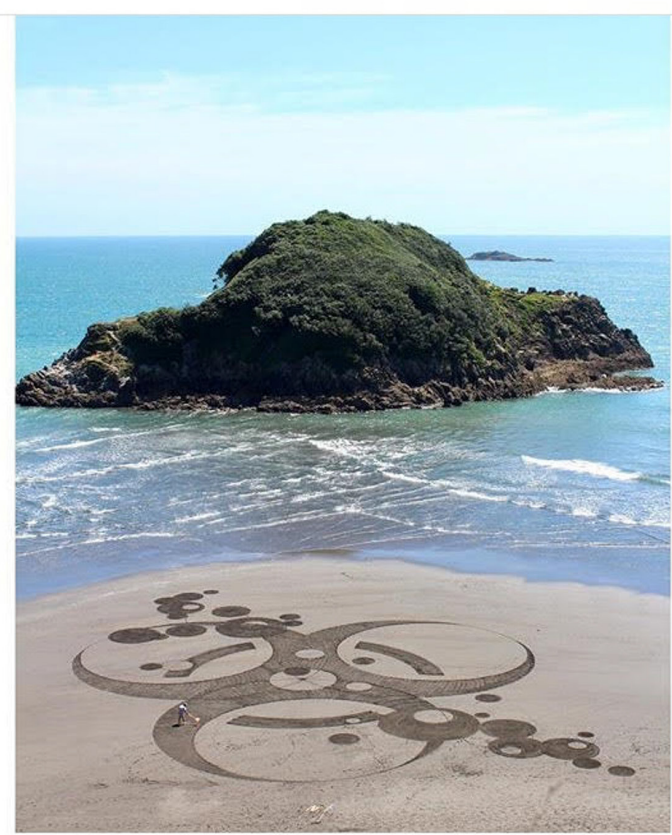

$\bigcirc \bigcirc \nabla$

ఐ

Liked by jr_b, andrebankierperry and 135 others batchelorjoe Starting my thesis early with a bit of
$\Omega$
Q
$\oplus$
O
( 


\section{Medium}

A range of mediums and methods have been implemented to produce this portfolio. Fraser states "Architectural design research is not just the beginning process but involves and extensive amount of means and techniques to design and make throughout. These include drawings, physical models, digital models, sketches, material testing, site, case study analysis etc."(2013, p. 2). A similar range of methods have been used here with physical models and photography forming the primary modes of investigation.

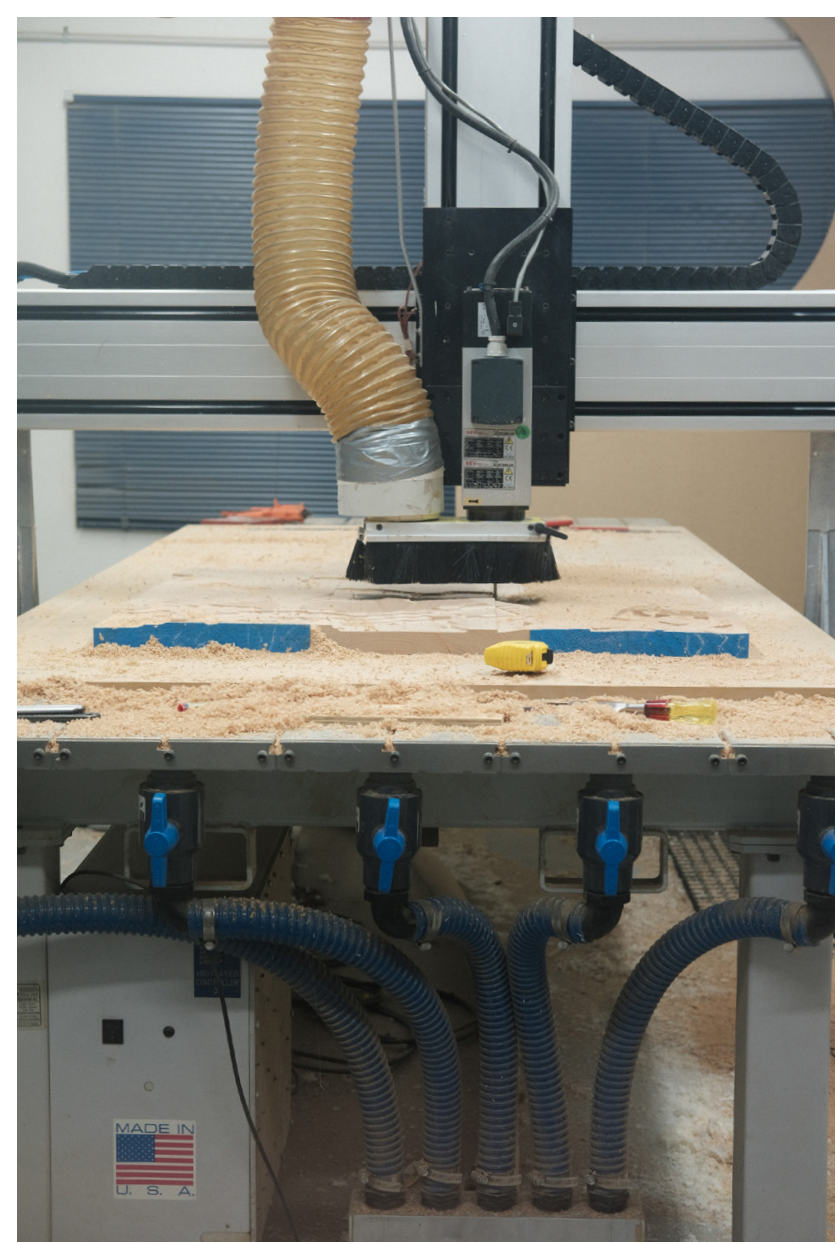

65. Timber site model in production. CNC milling 


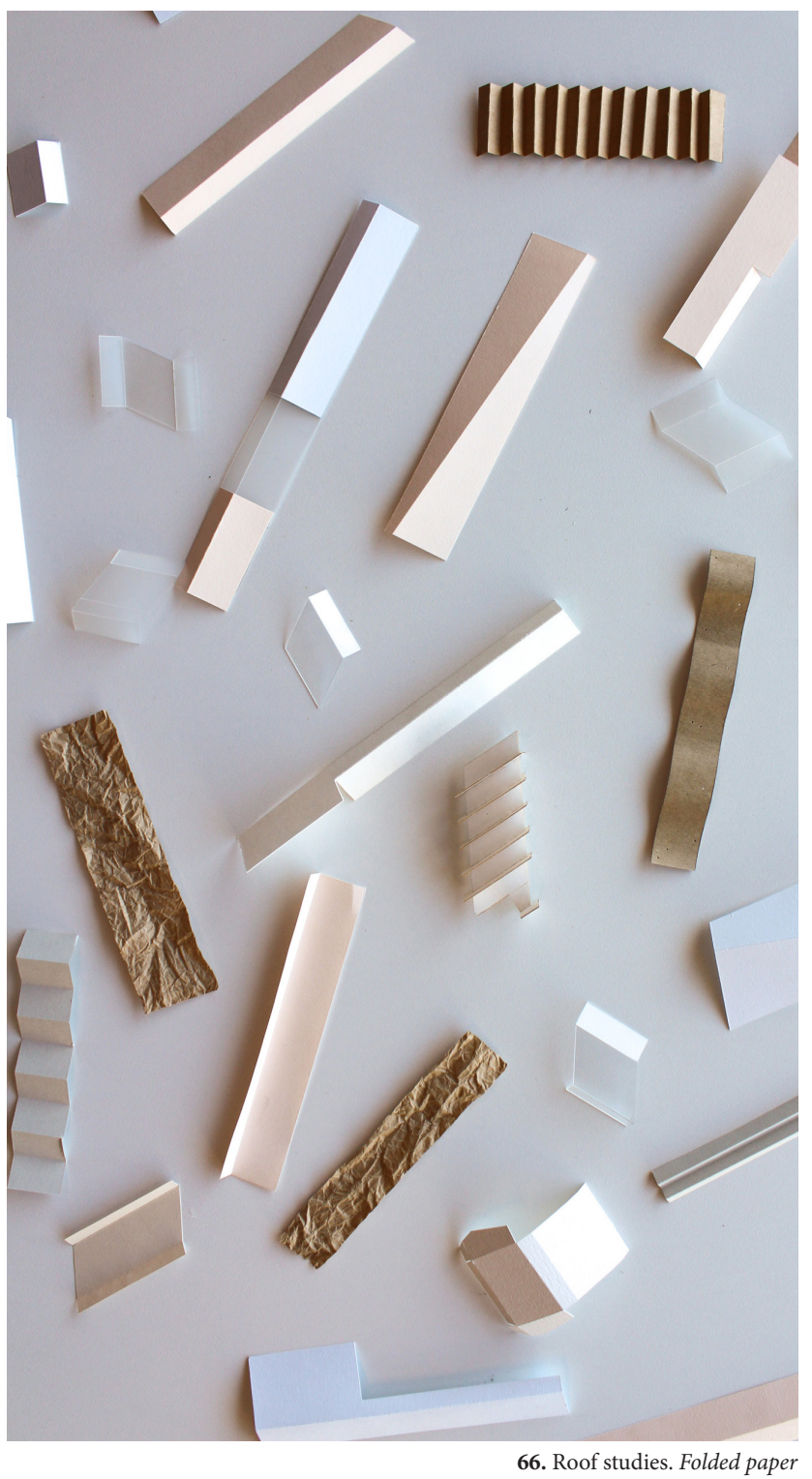

\section{Physical Models}

The term physical model is used in this portfolio to describe a plethora of objects, from folded scraps of paper to complex spatial devices. Albert Smith offers the definition, "A model is typically a small object usually built to scale, that represents another, often larger, object"(2004, p. 62). Stanford Hohauser suggests "architecture models are the most easily understood presentation technique" (1970, p.6). Due to their tactility, physical models can be easily understood not just visually, but spatially. Bernard Otte states "A scale model has greater power of persuasion than a two-dimensional image" (2013, p.12). This research portfolio advocates for the model arguing that even in an age of digital renders the effectiveness of the model has not been supplanted. 


\section{Models as Machines}

Extensive physical testing in the form of models and devices was born from a desire to physically connect to the design process. As Chard states, "the aim of developing tools is to make the medium active in the design process" (Chard, 2005, p. 24). In this research devices are defined as physical models which are used as a tool for design. These devices are models that focus on the creation of space rather than the representation of it. Smith argues, "historically, the architectural scale model was employed as a thinking machine that is an idea used for the understandable measuring and testing of the prevailing reference standard's concepts of invisible things" (2004, p. 70). The "invisible things' investigated by the devices in this portfolio are the nuances and spatial implications of each specific perspective view.

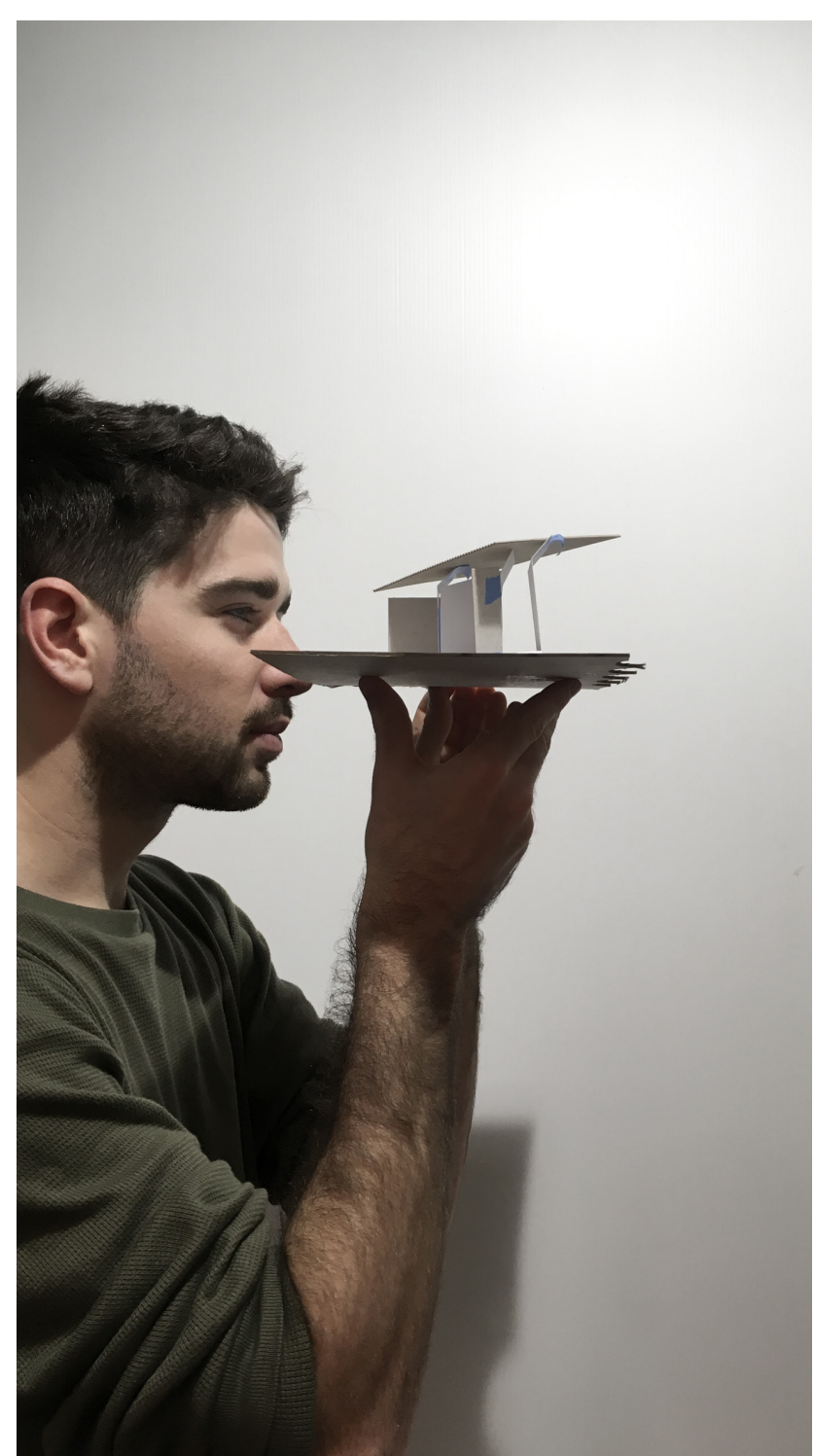

67. Testing an early device prototype. Fernery Diorama Optical Device 


\section{Photography}

Photography has been used to translate the spatial qualities of models into images. Richard Pare states "a photographic representation of architecture has a close affinity to a drawing and the actual experience of space". As Pare elaborates "Photography strives to present a visual parallel to the experience of passing through architectural space by means of optical laws and the exactitude of presentation" (1996, p. 220). Photos are not used only to document models but are an essential tool in the design process. The camera viewfinder allows space to be assessed as a $2 \mathrm{D}$ image. As the view became fundamental to the design process the camera became itself a component of the devices.

Akiko Busch in the book The Photography of Architecture describes a photographers relationship between the second and third dimensions,

"The photographer is more inclined to perceive in three dimensions than the architect, even though the photographer's medium is two dimensional. This is principally because the photographer must translate spatial perceptions to a flat sheet of paper. The photographer is more likely to think of layering in terms of composition, with a more static quality" (1987, p.57).

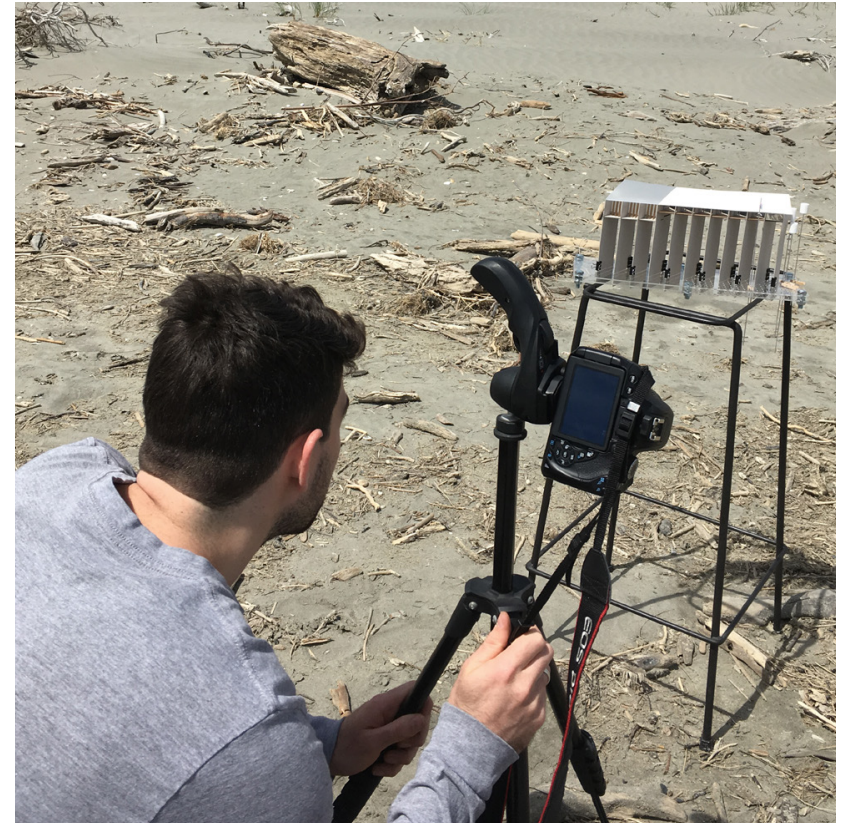

69. On-site device photography. Dune Superimposition Device 


\section{Instagram}

In many cases the value of models and devices was determined from their resulting image. With the aim of making the process less subjective social media strategies were implemented to gain feedback on images. An Instagram account named @flatlandd has been developed as a platform to share resulting images of the design tests. Viewers on Instagram can like and comment on posted photos. This data was used as an aid to determine the popularity of certain images.

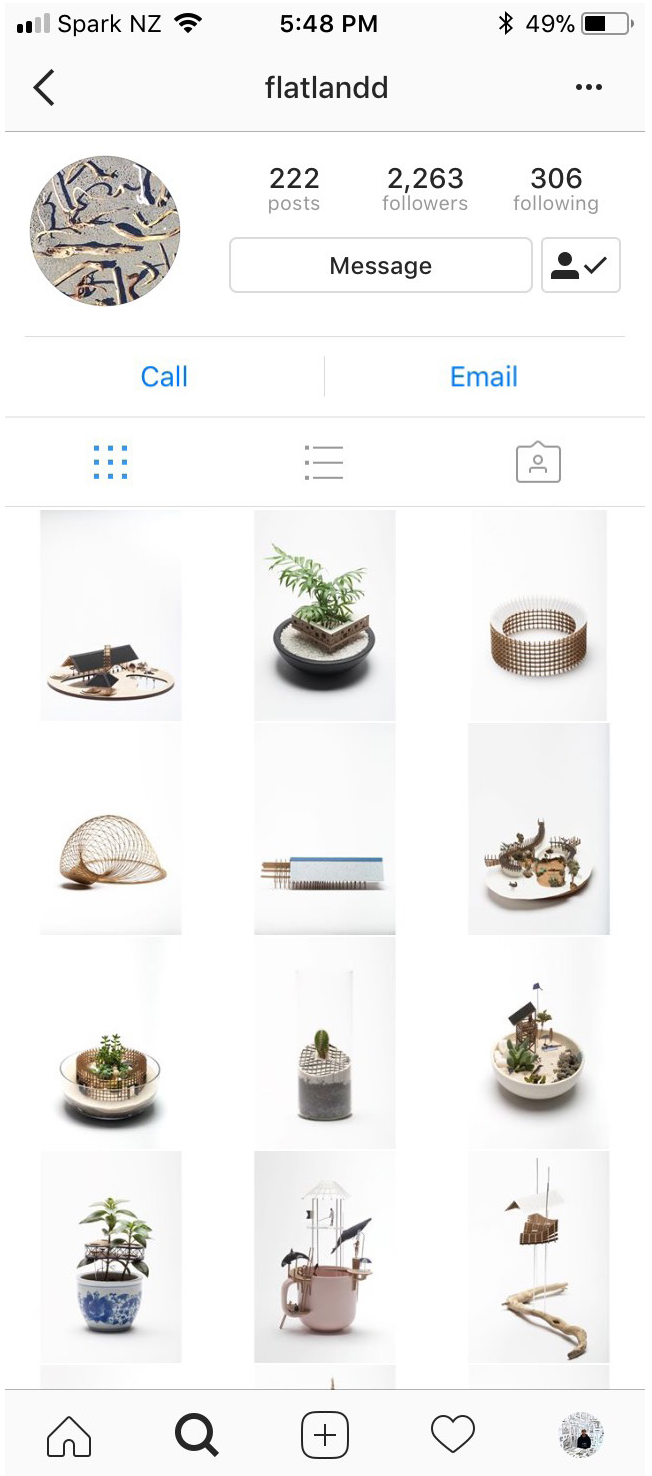

71. @flatlandd. Thesis Instagram account 
Chapter Five

PROCESS MODELS 


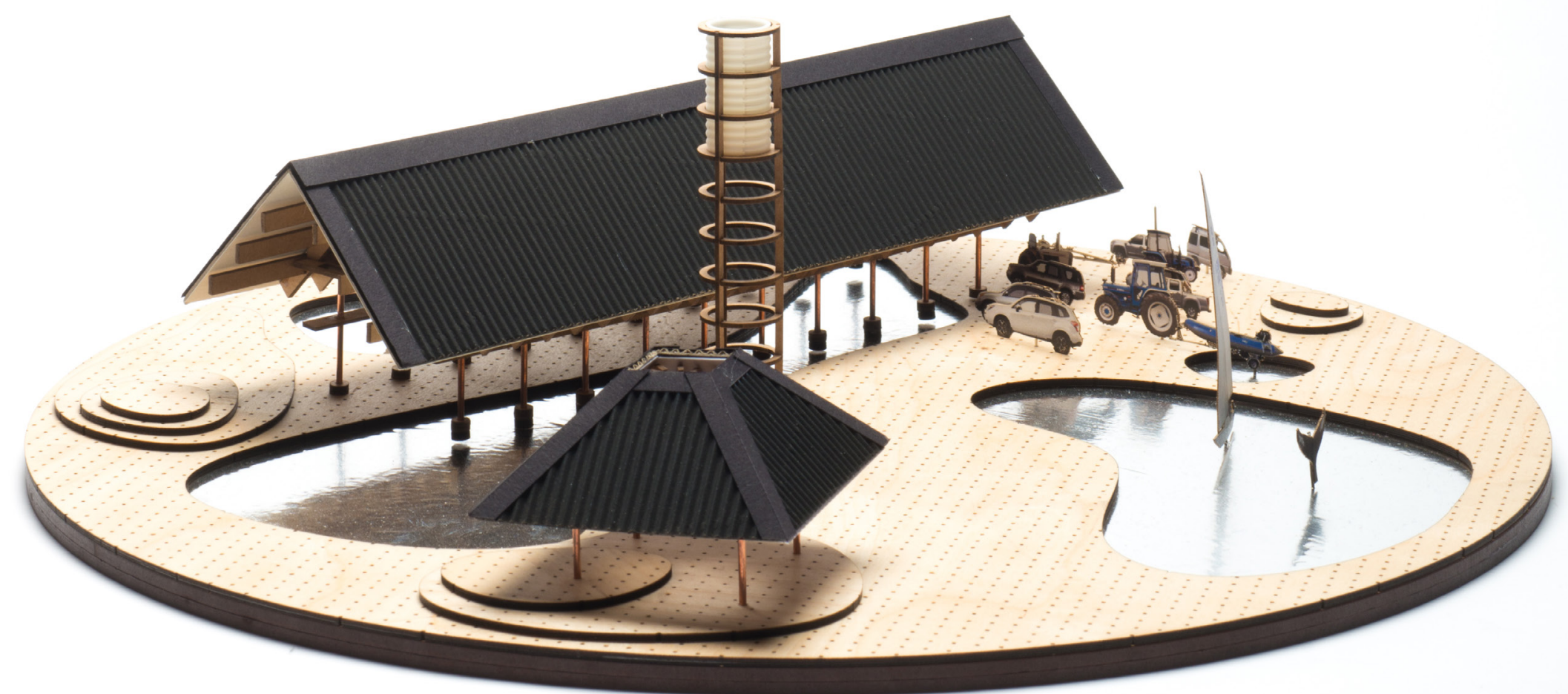

73. 1:100 Beach Whare. Study two 


\section{Introduction}

Progressing forward, an extensive set of models were developed from the beach drawing exercise. These models were a tool to materialise, critique and develop ideas. As Albert Smith describes, "The architectural scale model can be perceived as a mechanism for thinking (2004, p. 61). This series investigates programmatic design responses, site conditions and construction techniques. However, their most valuable contribution was the design processes they uncovered. The process began simply by creating models based on hunches developed after visting the site. The models were then evaluated and developed through five progressive photographic studies. This uncovered much about the relationship between the image and space. Discoveries made here culminated in the final design process strategy, established in chapter six.

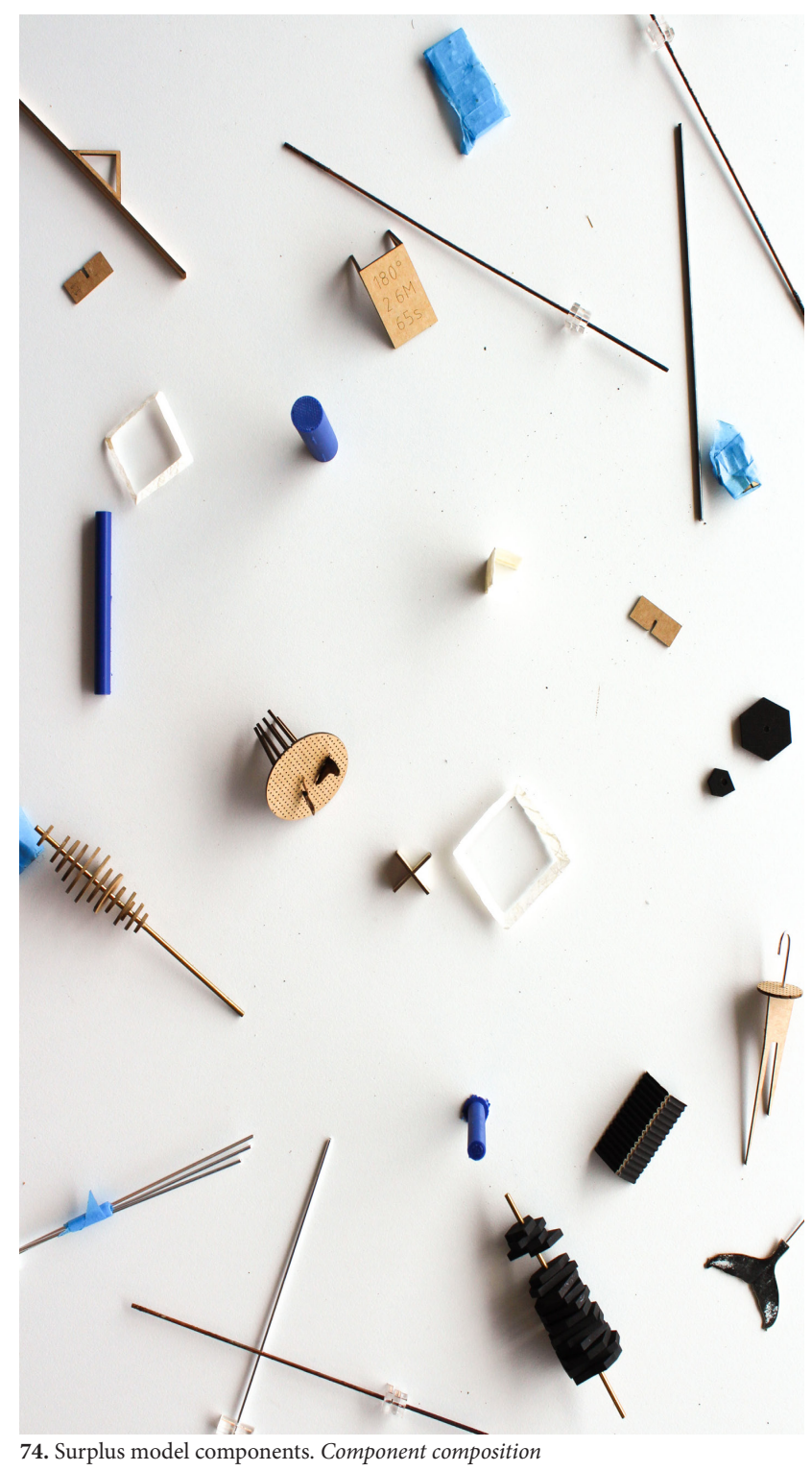




\section{Study One: Spatializing an idea}

The first stage of design involved realising conceptual space. As Porter argues, "conceptual space is that which we perceive and visualize. The design of space is, initially, a mental concept and any resultant response is primarily experienced through visual perception" (2014, p. 46). Spatial concepts were translated into two dimensions, sketched, and then were drafted in autoCAD. This process allowed the practicalities of scale and proportion to be introduced. Drawings were then translated into three-dimensional models using folded paper, laser cutting and CNC milling. Three-dimensional software was avoided in an attempt to engage with spatial imagination.

Once the components were produced and constructed their spatial conditions were examined. Smith describes that "Models are used to visualise elaborate shapes and new design forms, allowing difficult spatial problems to be more thoroughly and effectively studied three-dimensionally" (Smith, 2004, p. xvii). The outcome of many models differed from their initial sketch as they were distorted by the translation process. Sheil's discussion aligns with this discovery as he/she desribes how"Realising ideas into built form is a transition during which some qualities are gained and others are lost" (Sheil, 2005, p. 7). With many of the models the results were not as envisioned, the attempts made however did serve as a framework for further development.

Perceiving ideas as physical models revealed many aspects which had not been considered in the two-dimensional design process. Criss Mills explains how "Many of the design decisions cannot be visualised until the model is established.
A number of ideas will be established by the model itself, and the new readings may prove more interesting than the original construction (2011, p. 44). The ability to touch and play with the models was enlighting. Stacking, twisting, slotting, bending, breaking and combining models unveiled important design discoveries. Through the creation of the model, ideas are able to be refined and discoveries can be made (Mills, 2011, p. 44). Through this process many of the models underwent many stages of development following their first construction. Some were easily altered, while it was easier to rebuild others completely. 


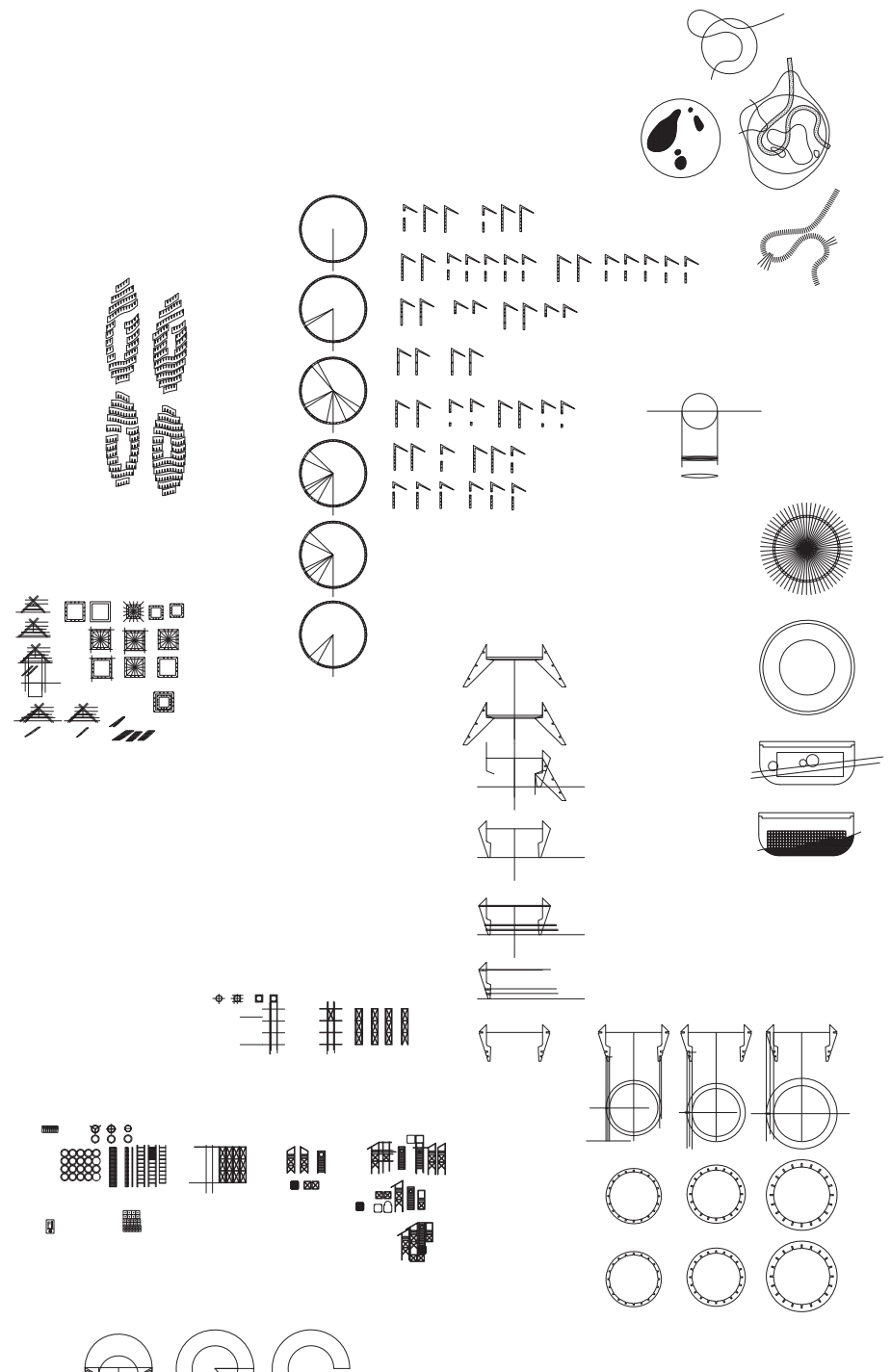

75. Dune structure model CAD design file. Component drawings

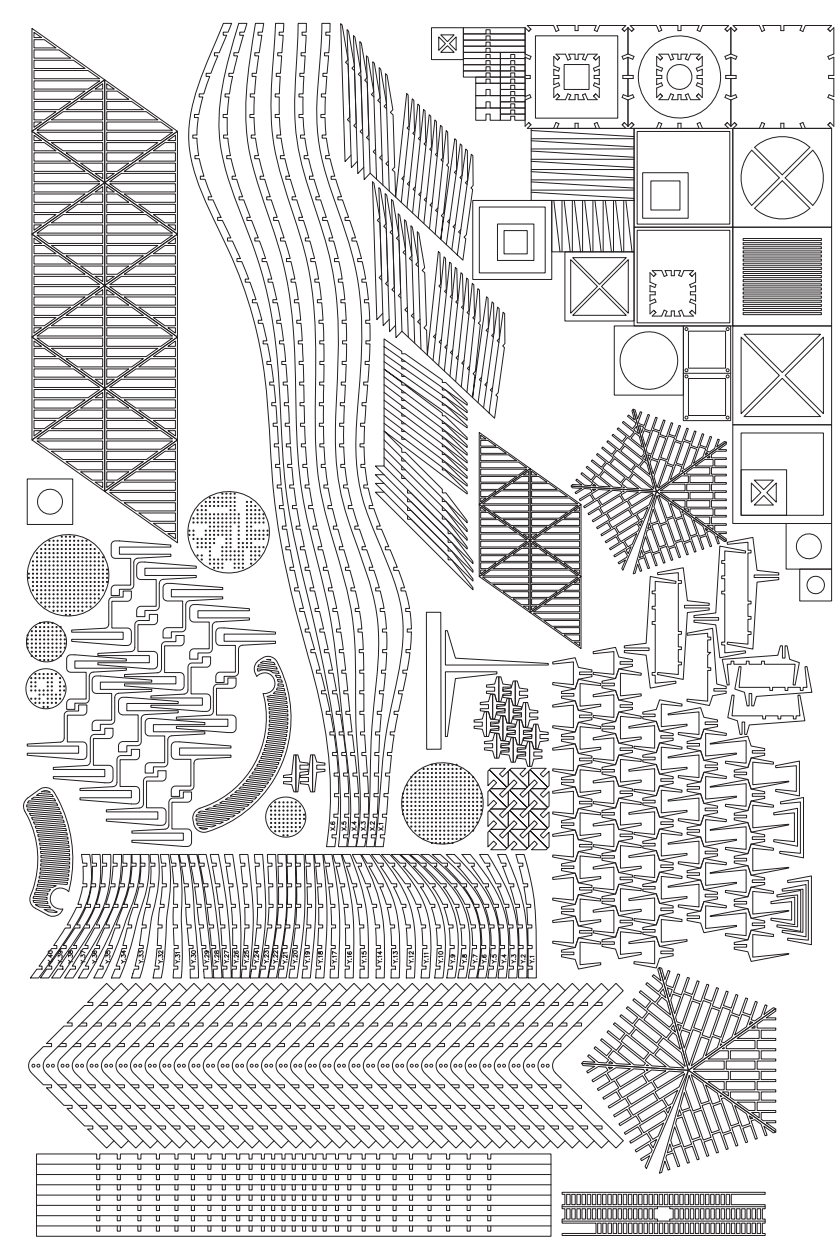

76. Miscellaneous model laser cutting vector file. Component drawings 

PROCESS MODELS
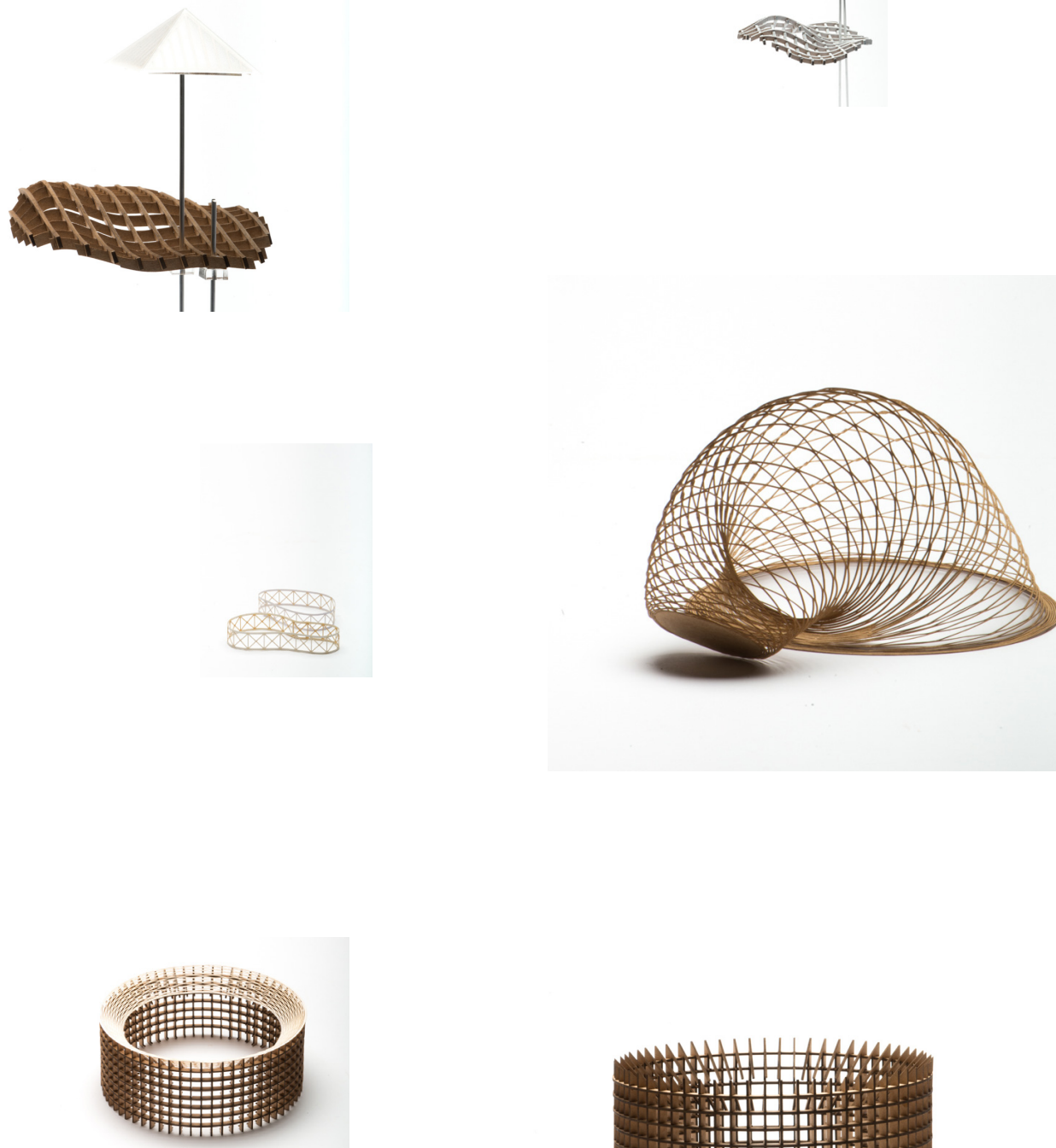
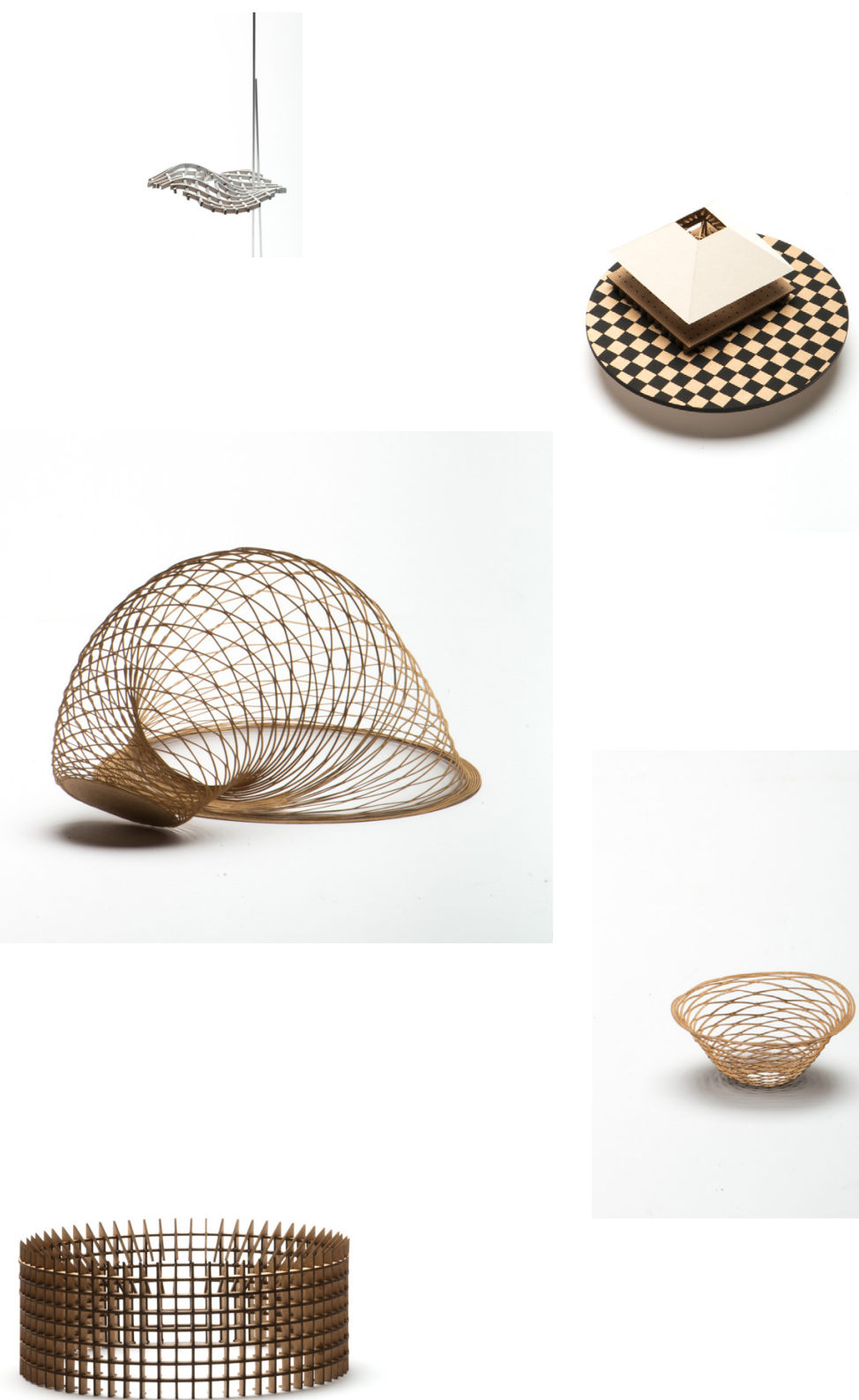
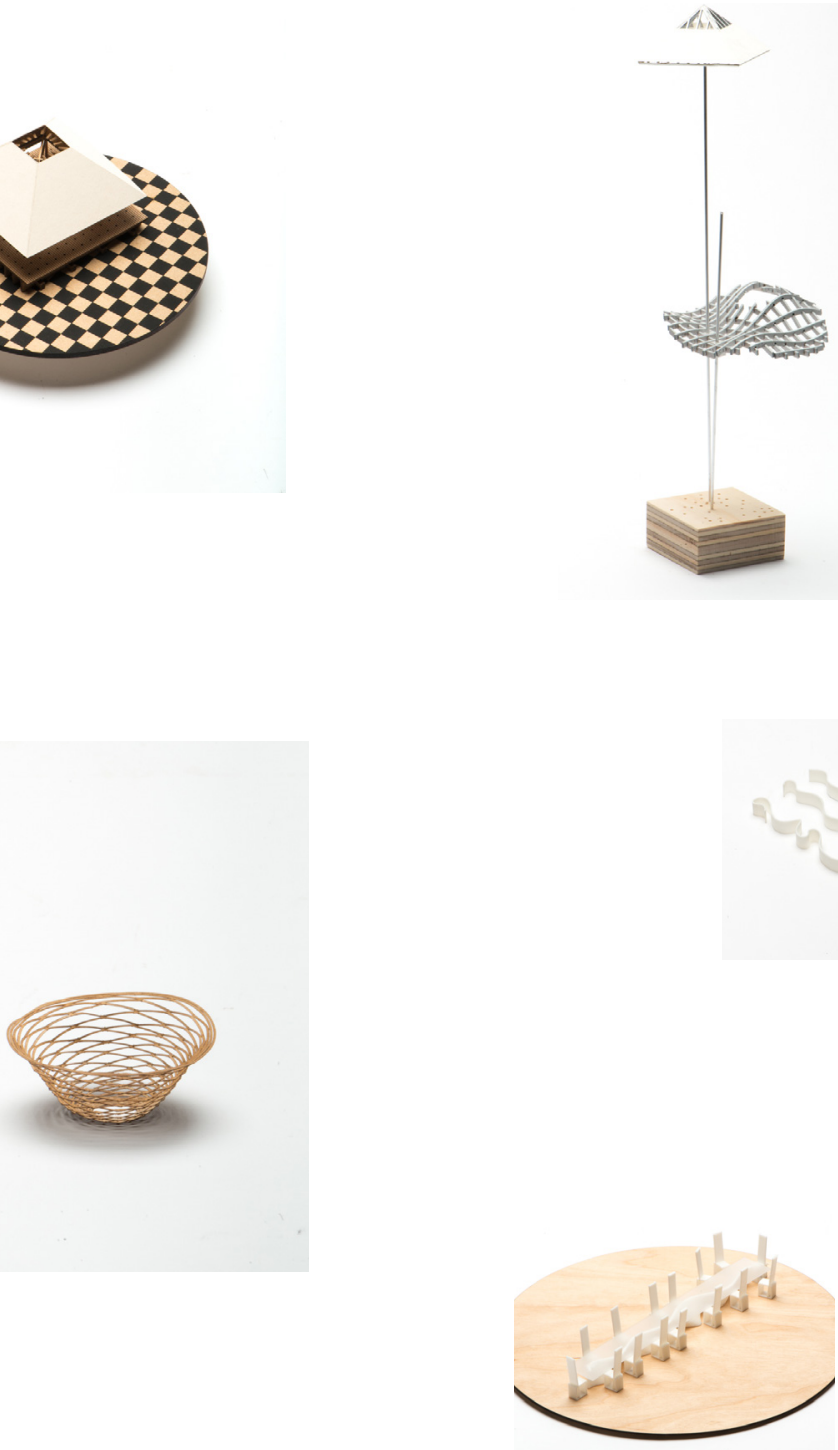

79. Collection part I. Process models 

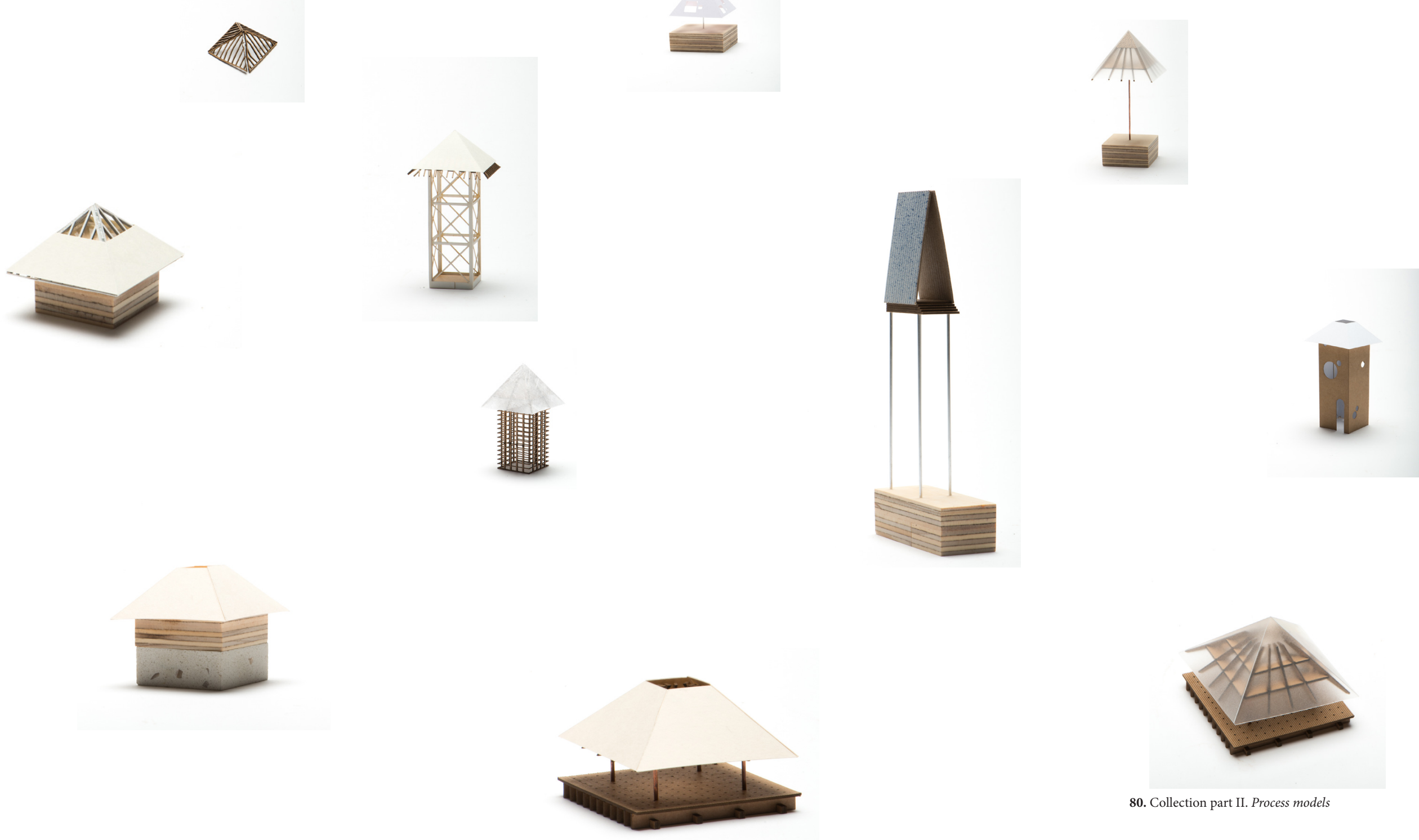

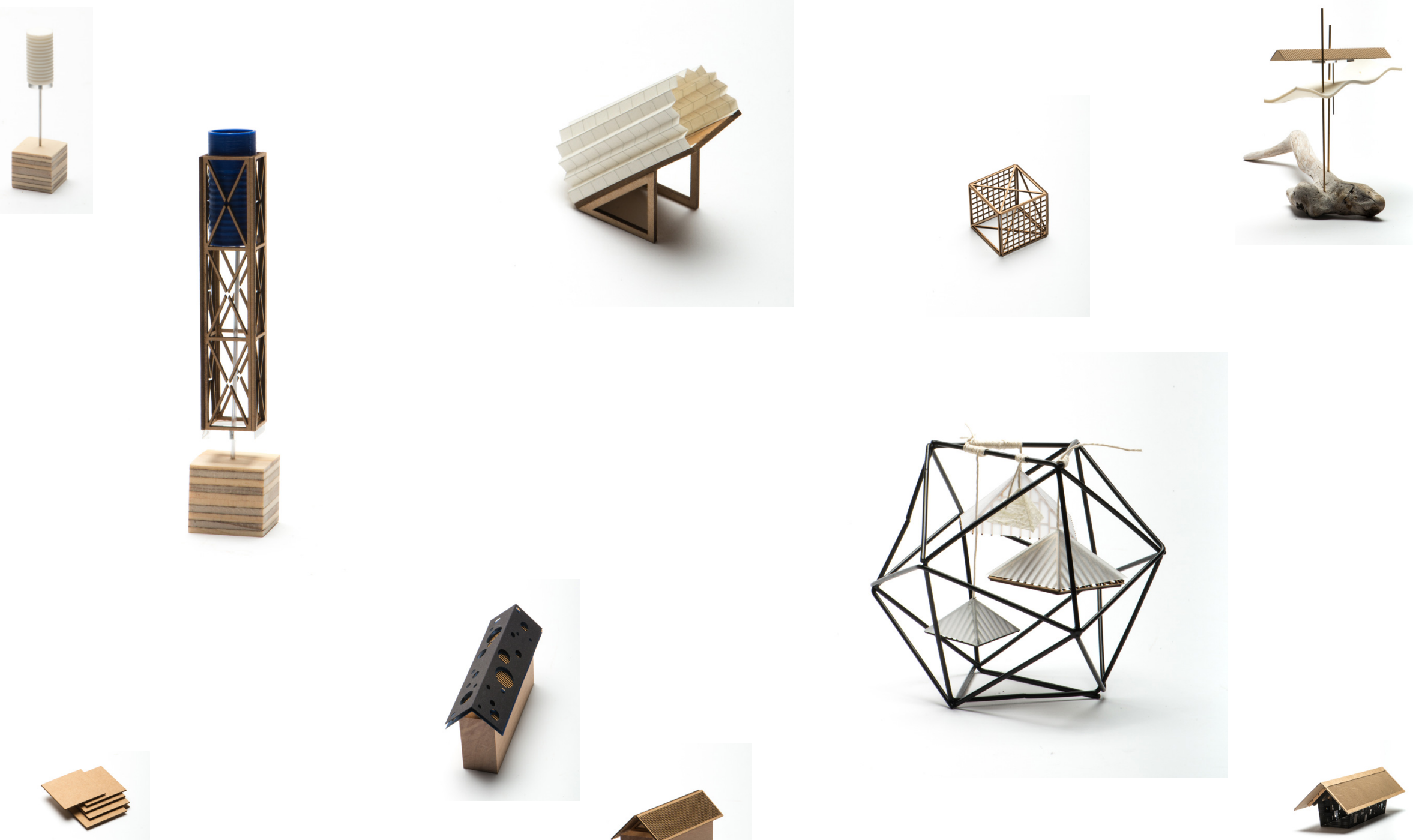

81. Collection part III. Process models 

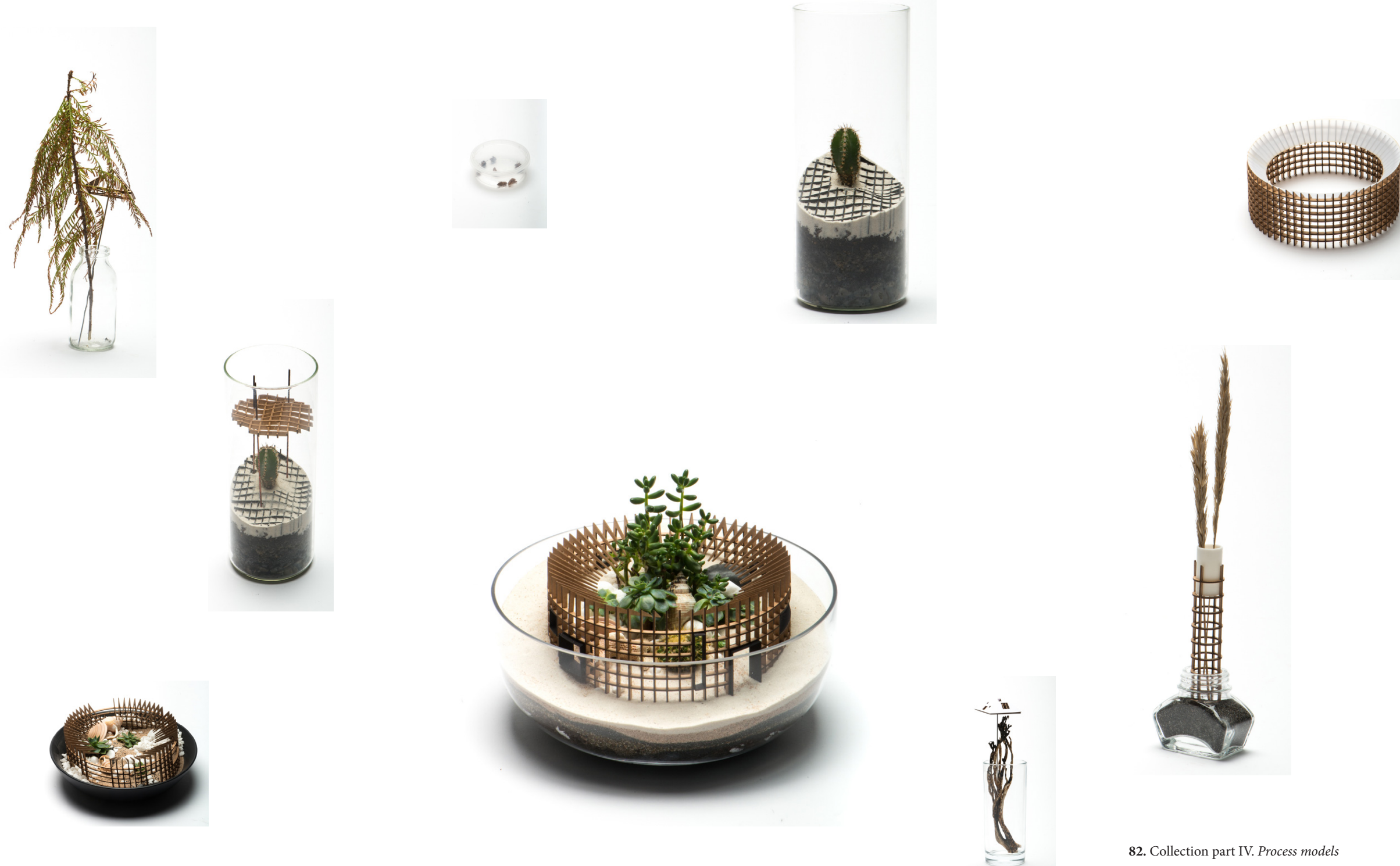

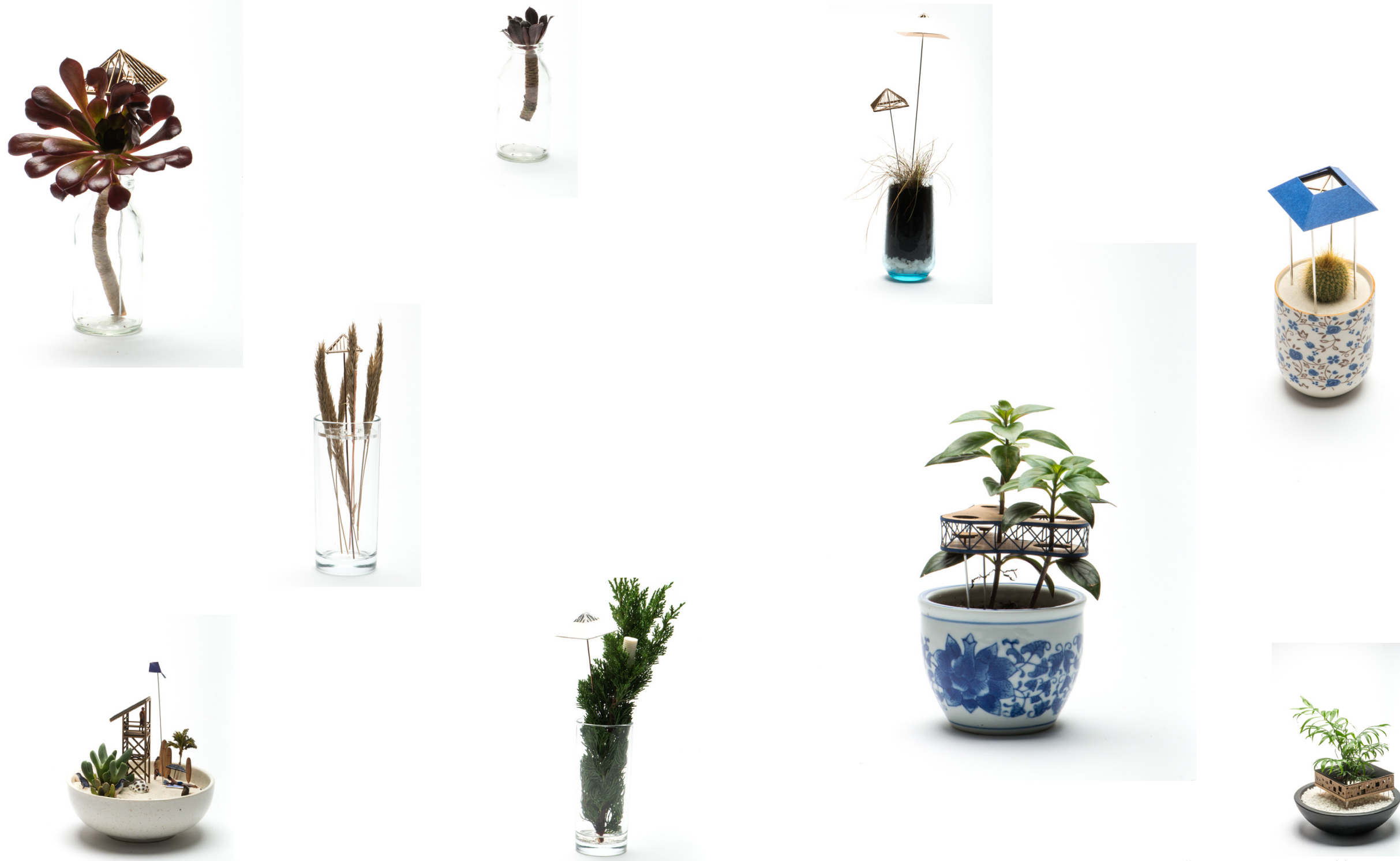

83. Collection part V. Process models 

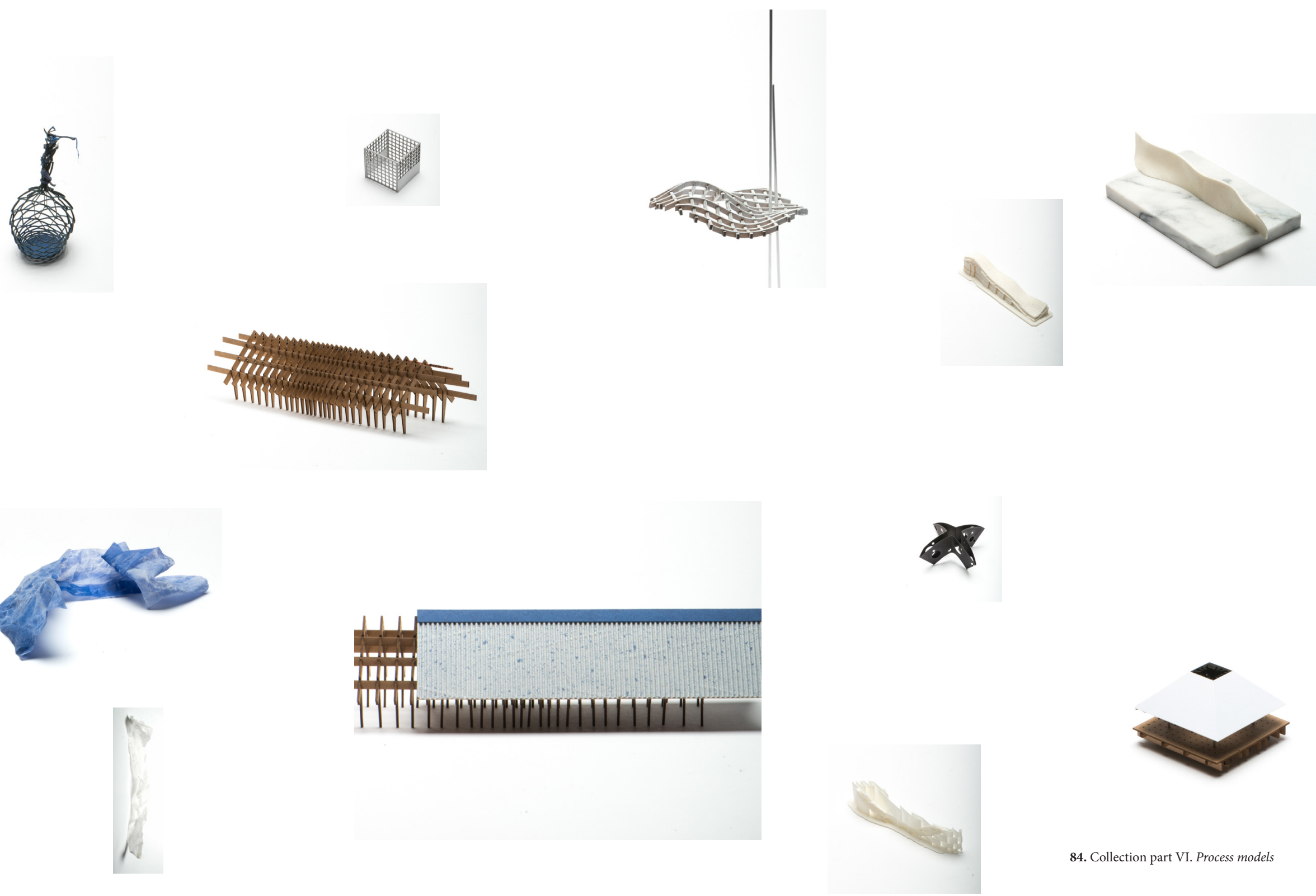

84. Collection part VI. Process models 

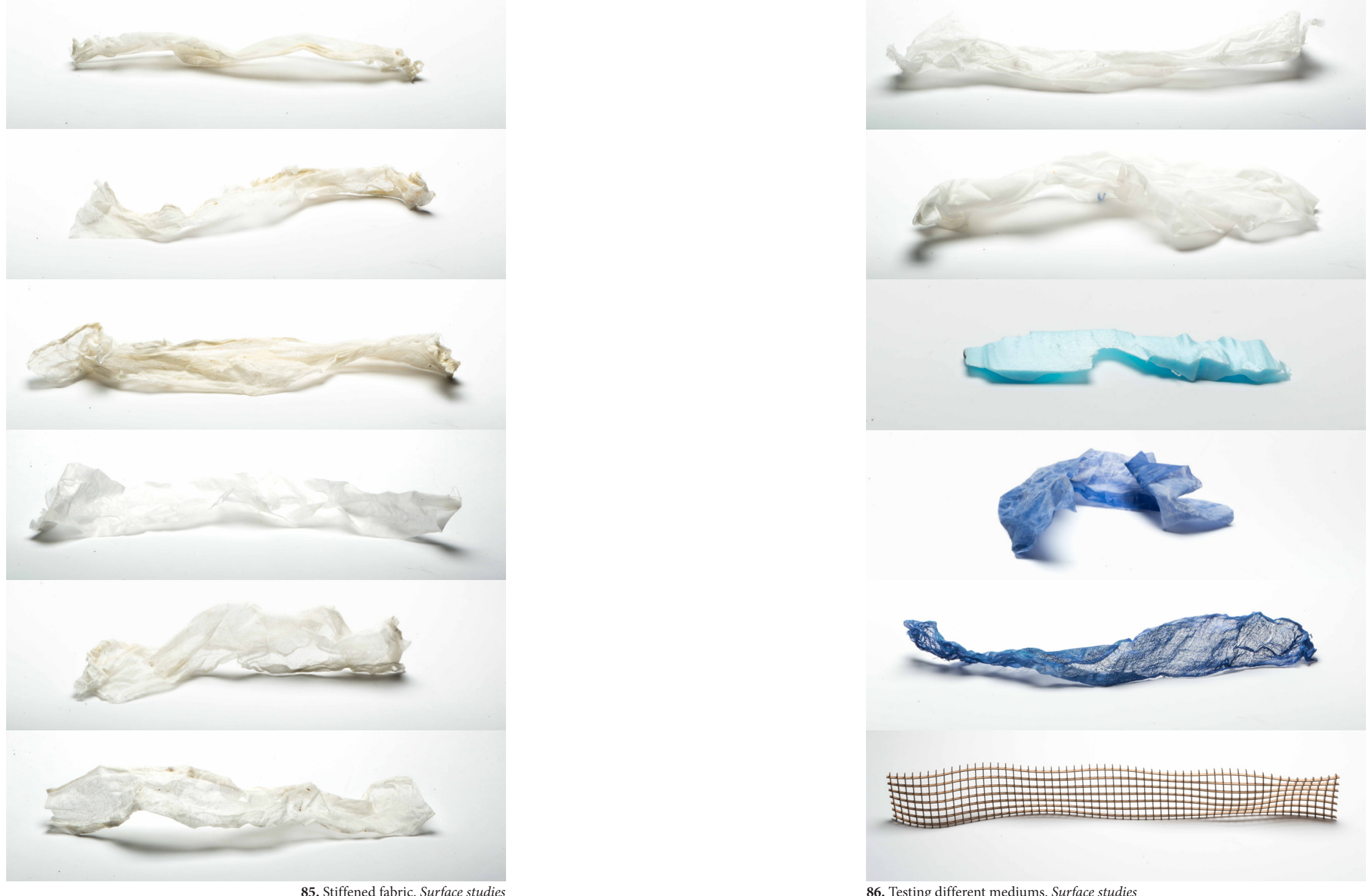

85. Stiffened fabric. Surface studies

86. Testing different mediums. Surface studies 


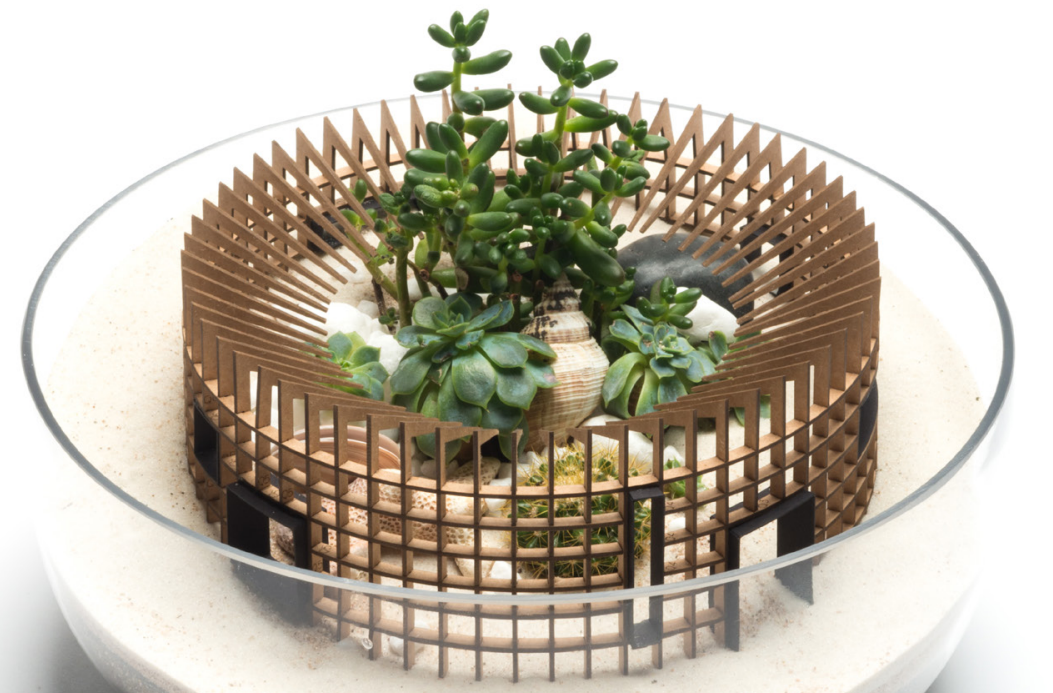

87. 1:100 Dune Structure. Favoured perspective

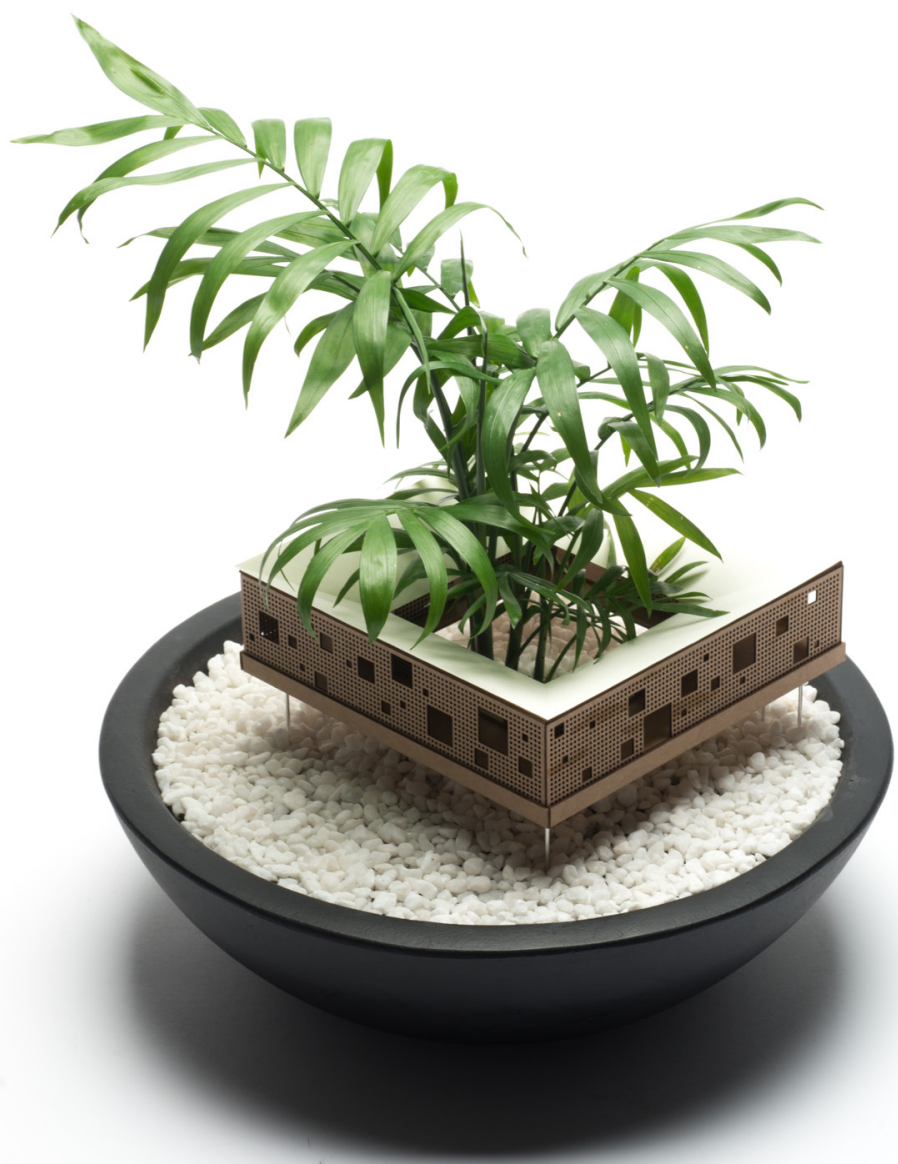

88. 1:100 Plant House. Favoured perspective 


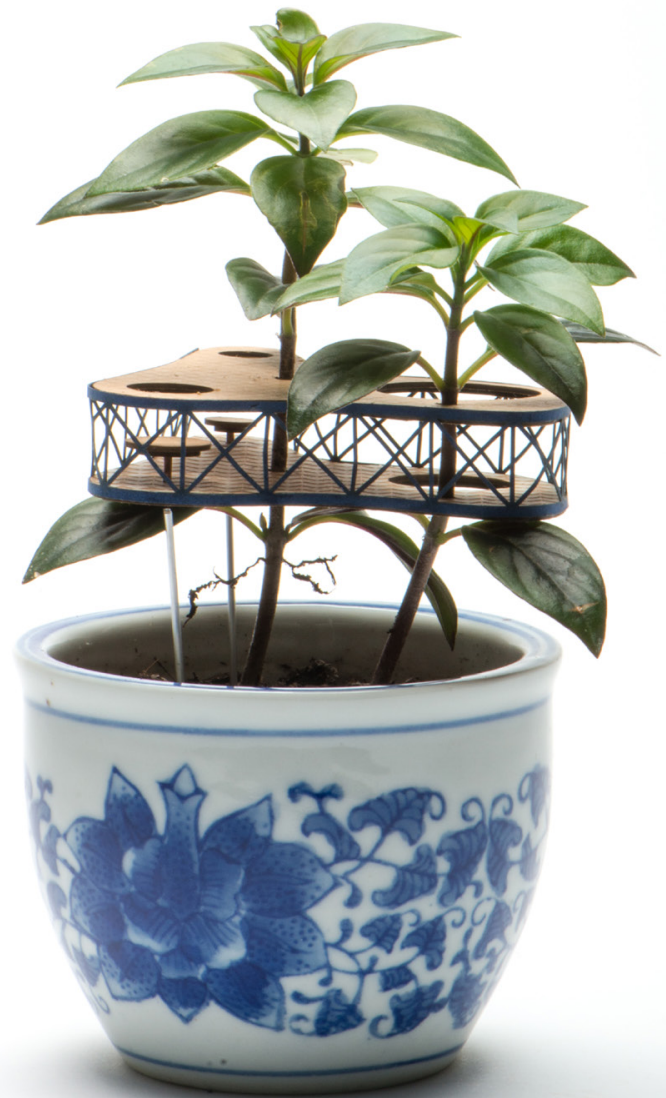

89. 1:100 Seedling House Cafe. Favoured perspective

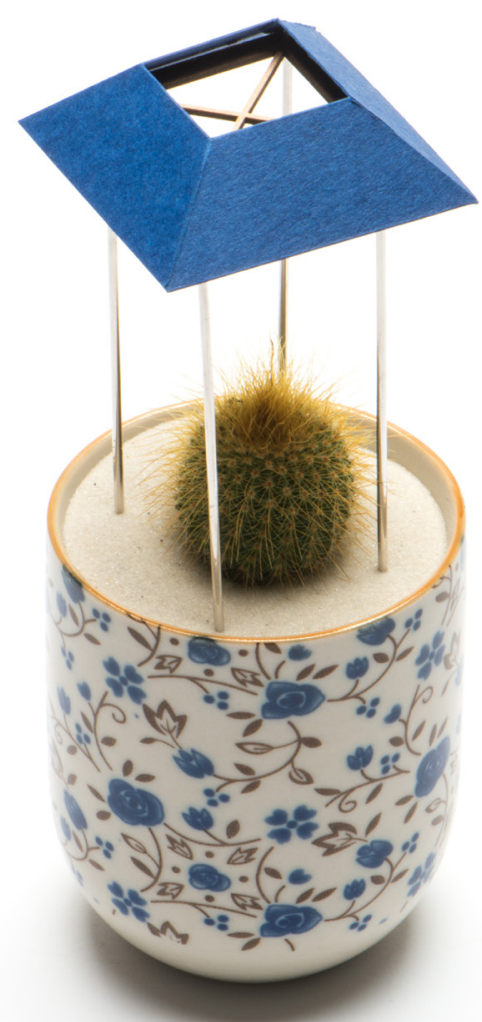

90. 1:50 Dune Shelter. Favoured perspective 


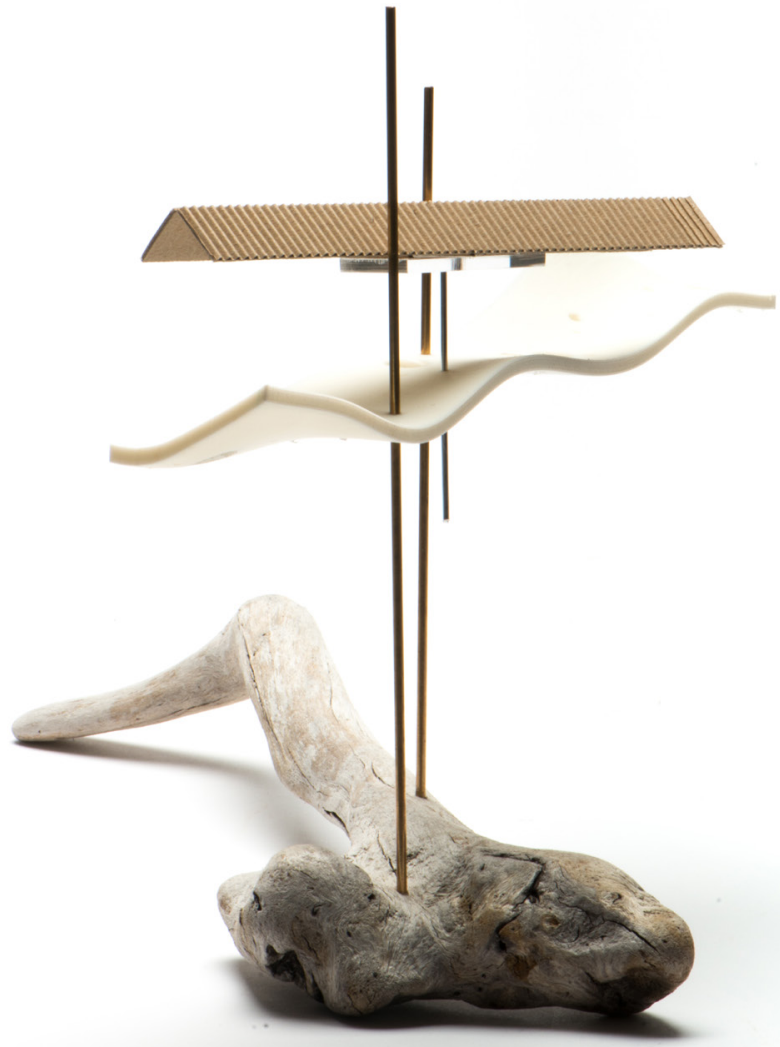

91. 1:100 Dune Pier I. Favoured perspective

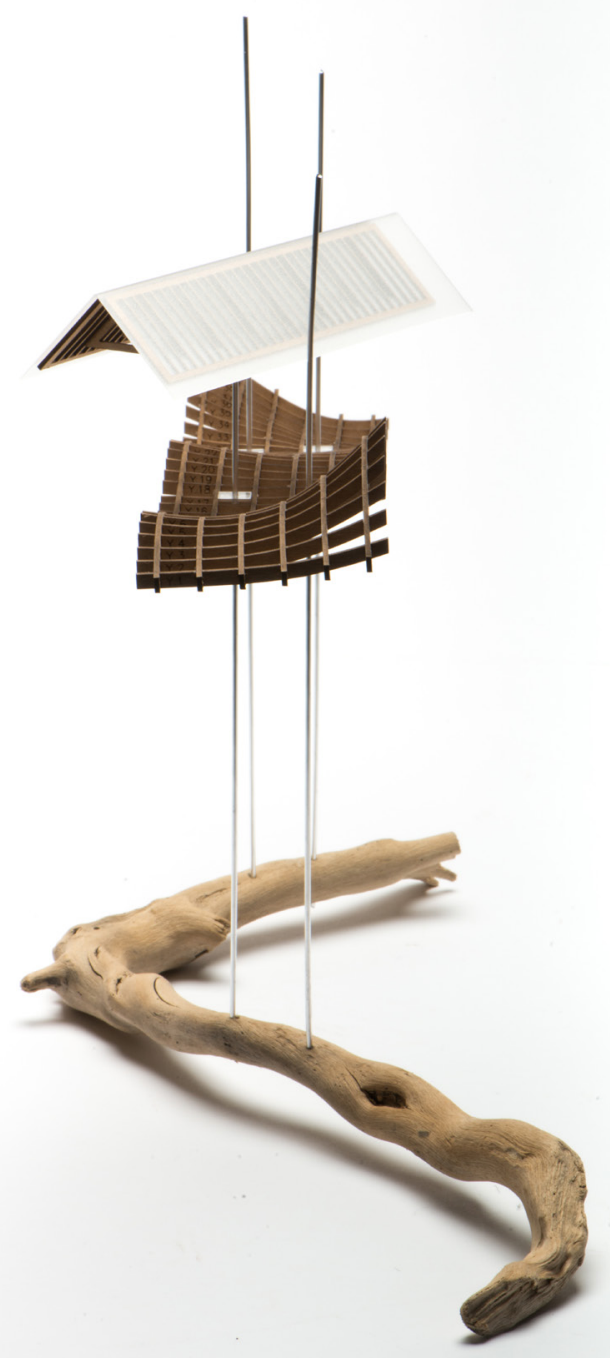

92. 1:100 Dune Pier II. Favoured perspective 

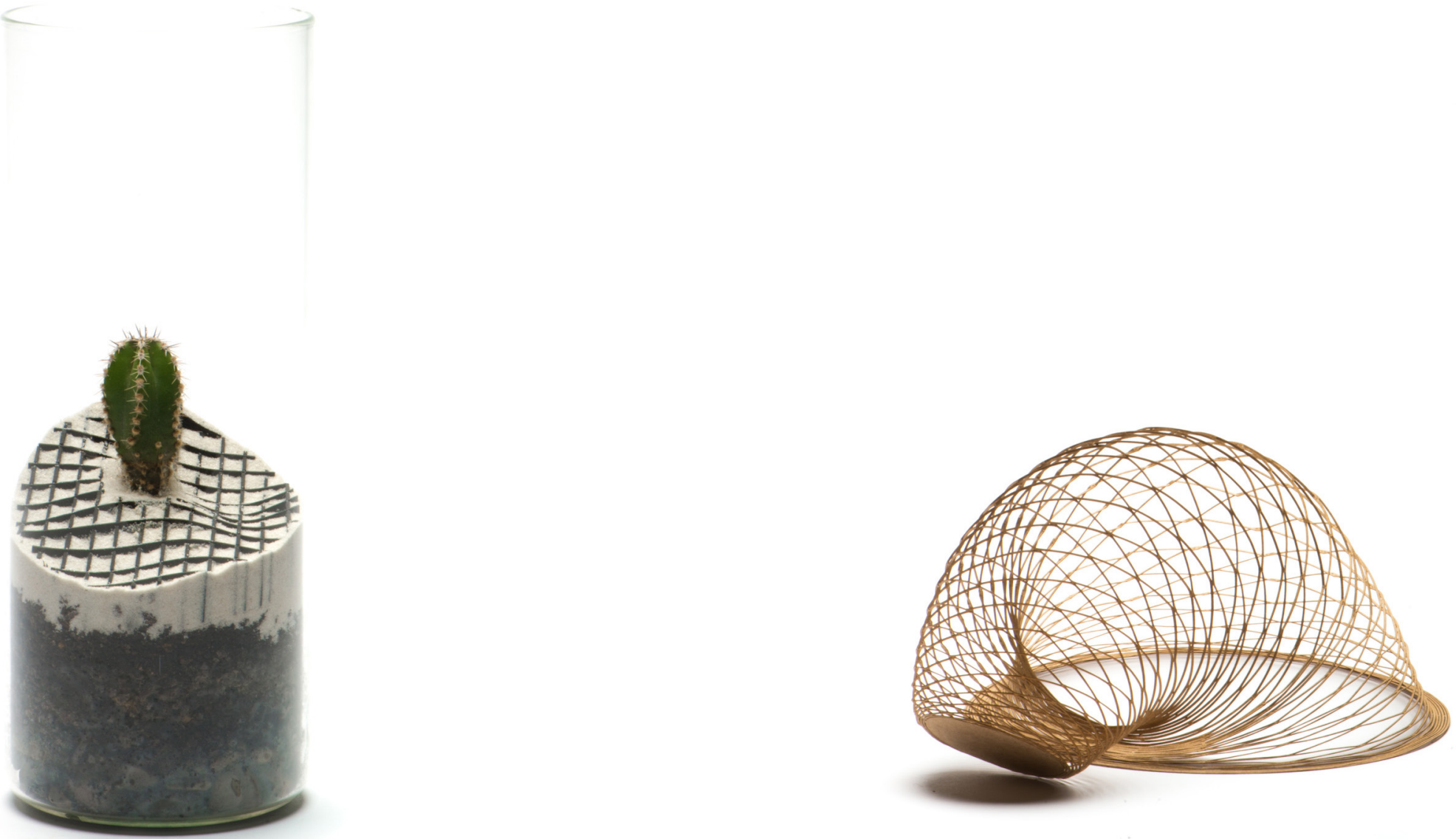


\section{Study Two: Particular perspective}

Study Two explores the idea of each model having a photographic 'good side. Each 'good side' was defined in this research in terms of how much of nature of the model was revealed, and also subjectively by what looked proportionally aesthetic. To uncover the angle of their 'good side' each model was rotated and the camera height was adjusted before photographing the result.

Four models were selected and developed further in regards to their favoured perspective. This was a turning point as the spatial qualities of the models were neglected in favour of the image it portrayed. This encouraged the use of flat elements positioned to face each nominated perspective.

A palette of two-dimensional figures were cut out to form a scenic lexicon. Criss Mills describes lexicons as involving a vocabulary of parts which "can be created as a number of platonic forms with variations producing unpredictable combinations" (2011, p.51). The lexicon contained figures of people, animals, vegetation and objects local to the site. Thematic scenes were able to be established through this process. Arranged by hand some scenes explored idyllic beach days while others depict the unique boat launching process on Paraparaumu Beach.

The process began by rotating each model in relation to the viewers position to determine the 'good side. From this defined perspective figures from the scenic lexicon were placed, shifted, removed and placed again until just right. The figure components of the lexicon were designed to slot in for quick and easy alterations to the composition which made it easy to focus on the perspective results. This proved to be extremely effective allowing design decisions to be made easily and intuitively by hand. The qualities of perspective are complex and many, nevertheless this method allowed these qualities to be easily navigated and manipulated.

Orthographic plan drawings were produced following the composition of each model. Inspired by a Smout \& Allen strategy who, "move between drawings and $3 \mathrm{~d}$ and both show the qualities of the other" (Superscape 2013, p. 124). This clearly reveals and documents the spatial implications of the perspective focused arrangements. 

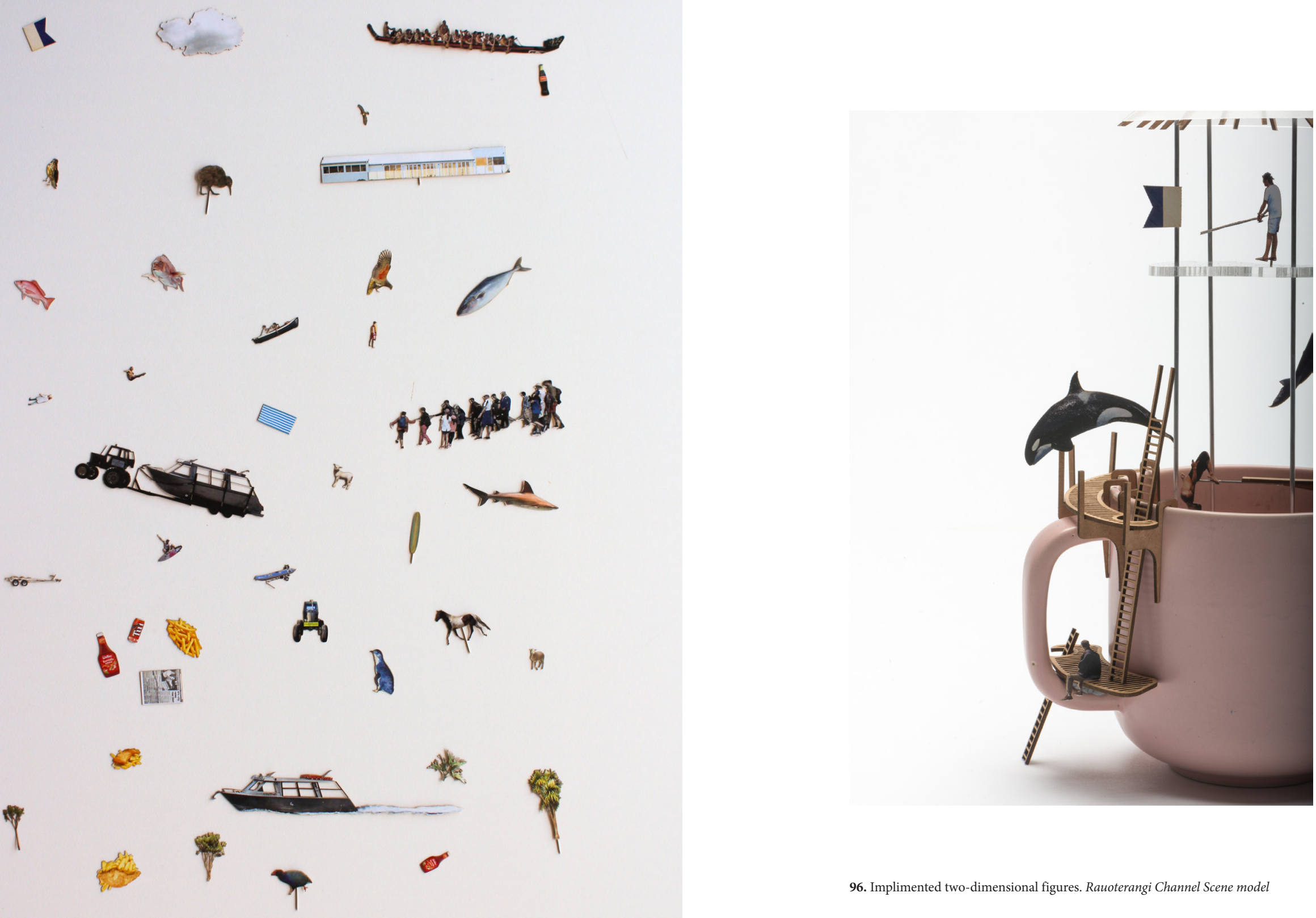

96. Implimented two-dimensional figures. Rauoterangi Channel Scene model 


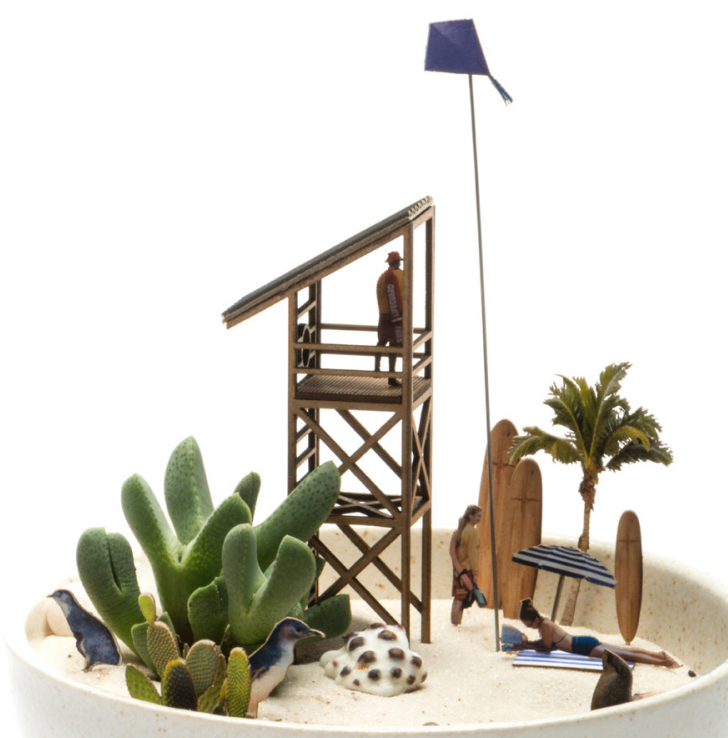

97. 1:50 Lookout - Idyllic beach scene. Developed perspective

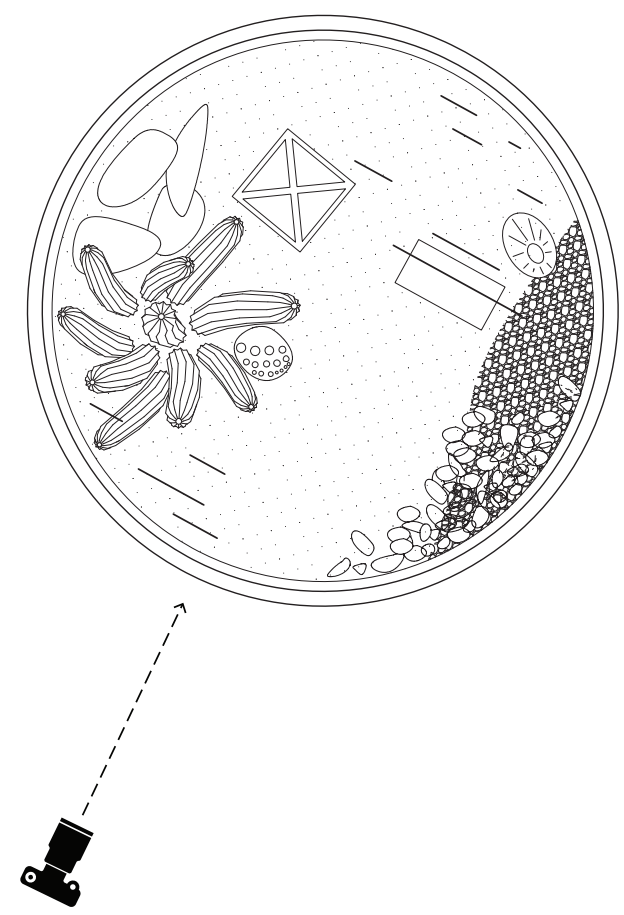

98. 1:50 Lookout - Idyllic beach scene. 1:2 plan arrangement 


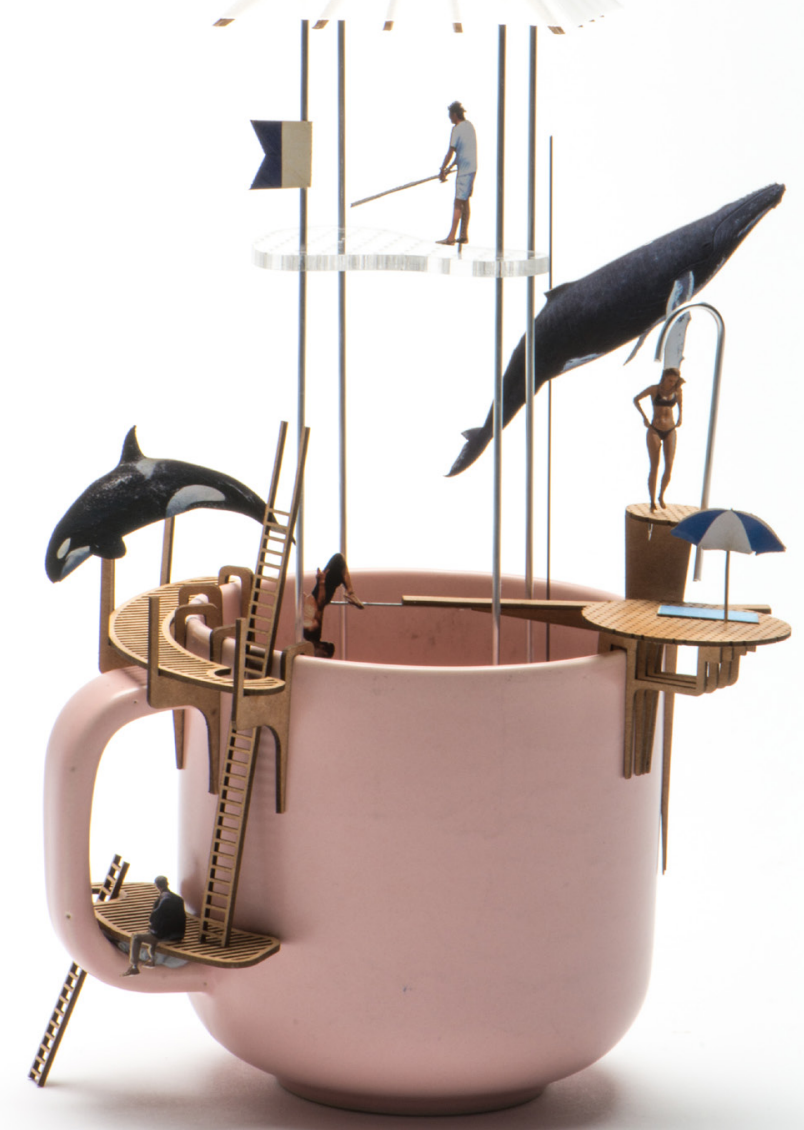

99. 1:50 Pier - Rauoterangi Channel scene. Developed perspective

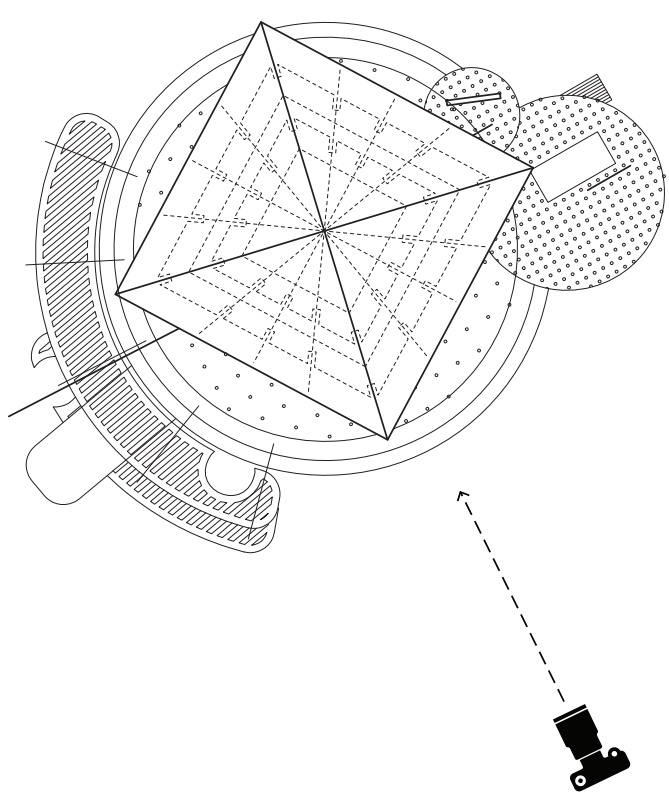

100. 1:50 Pier - Rauoterangi Channel scene. 1:2 plan arrangement 


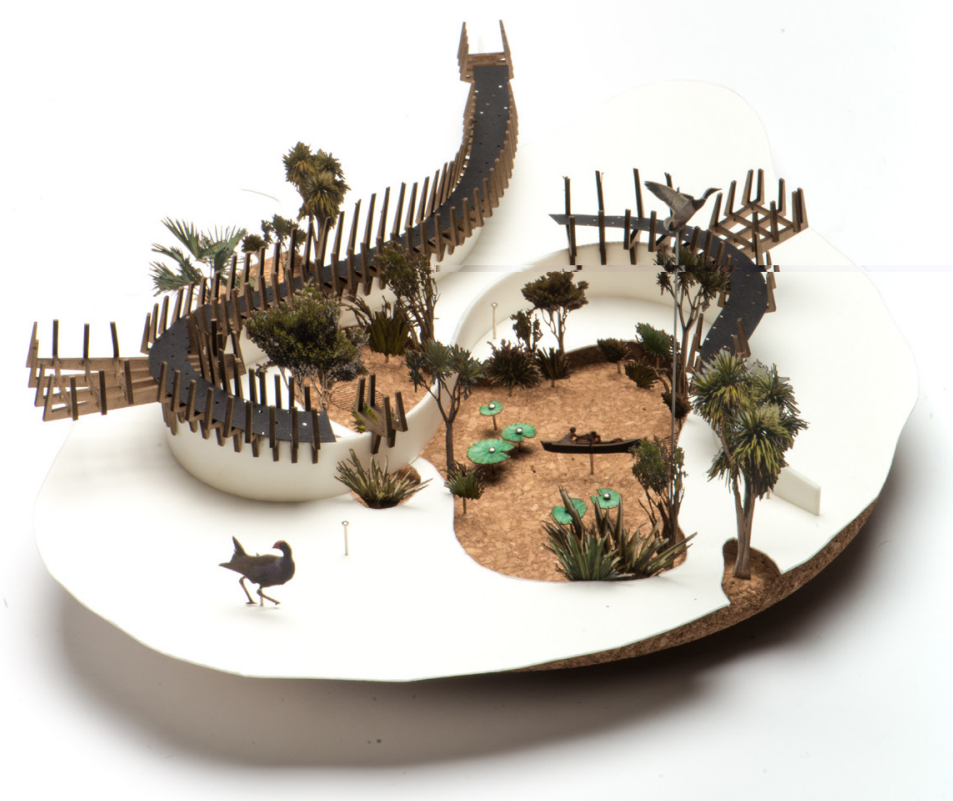

101. 1:100 Walkway - Coastal wetland scene. Developed perspective

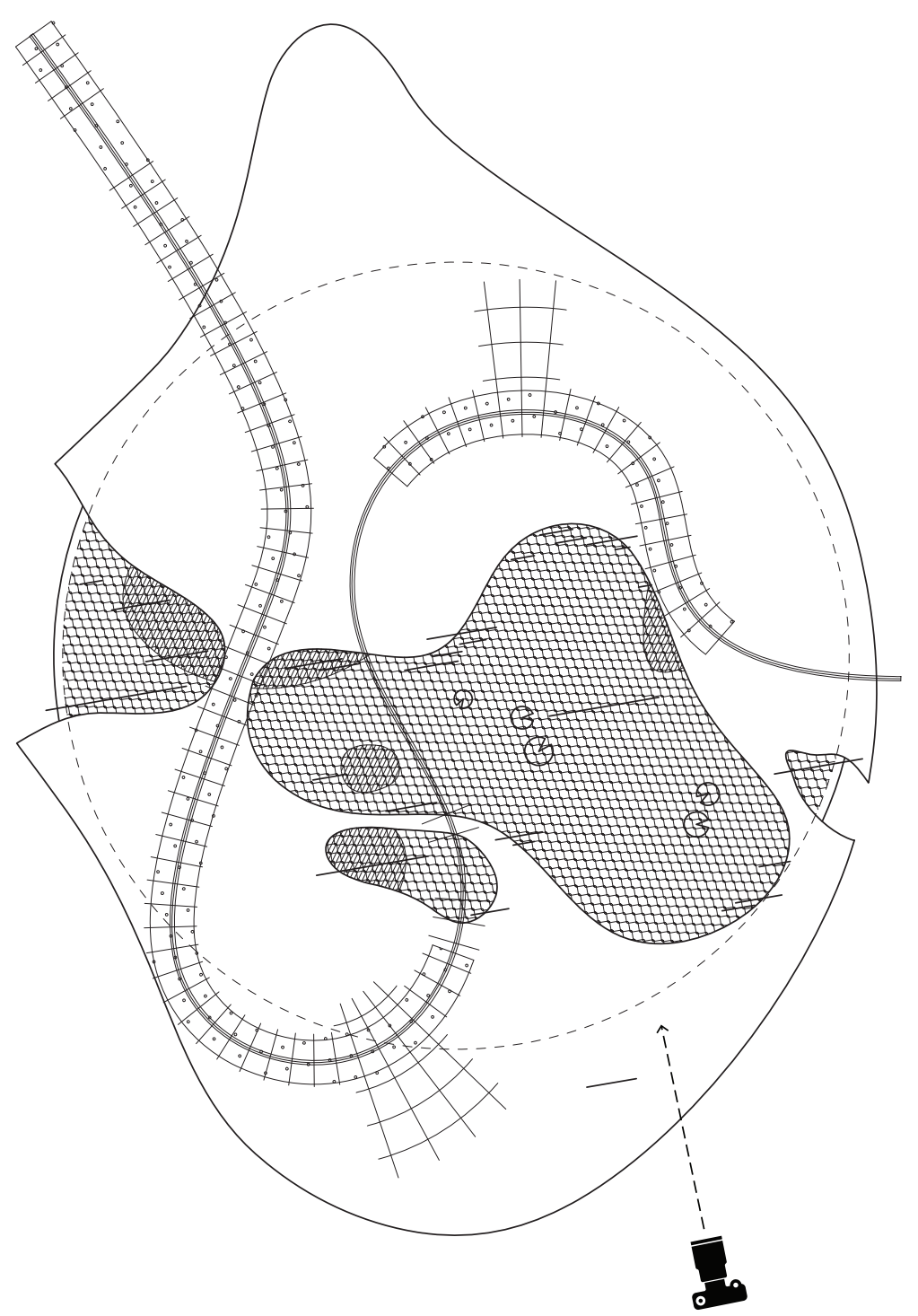

102. 1:100 Walkway - Coastal wetland scene. 1:2 plan arrangement 


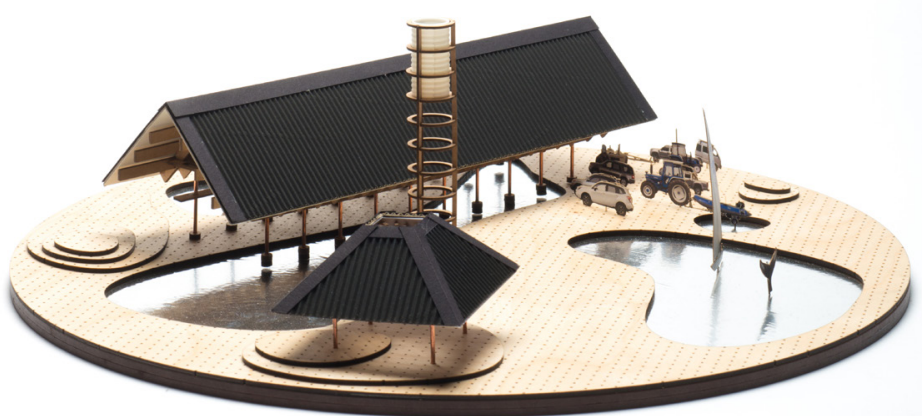

103. 1:100 Beach Whare - Boating scene. Developed perspective

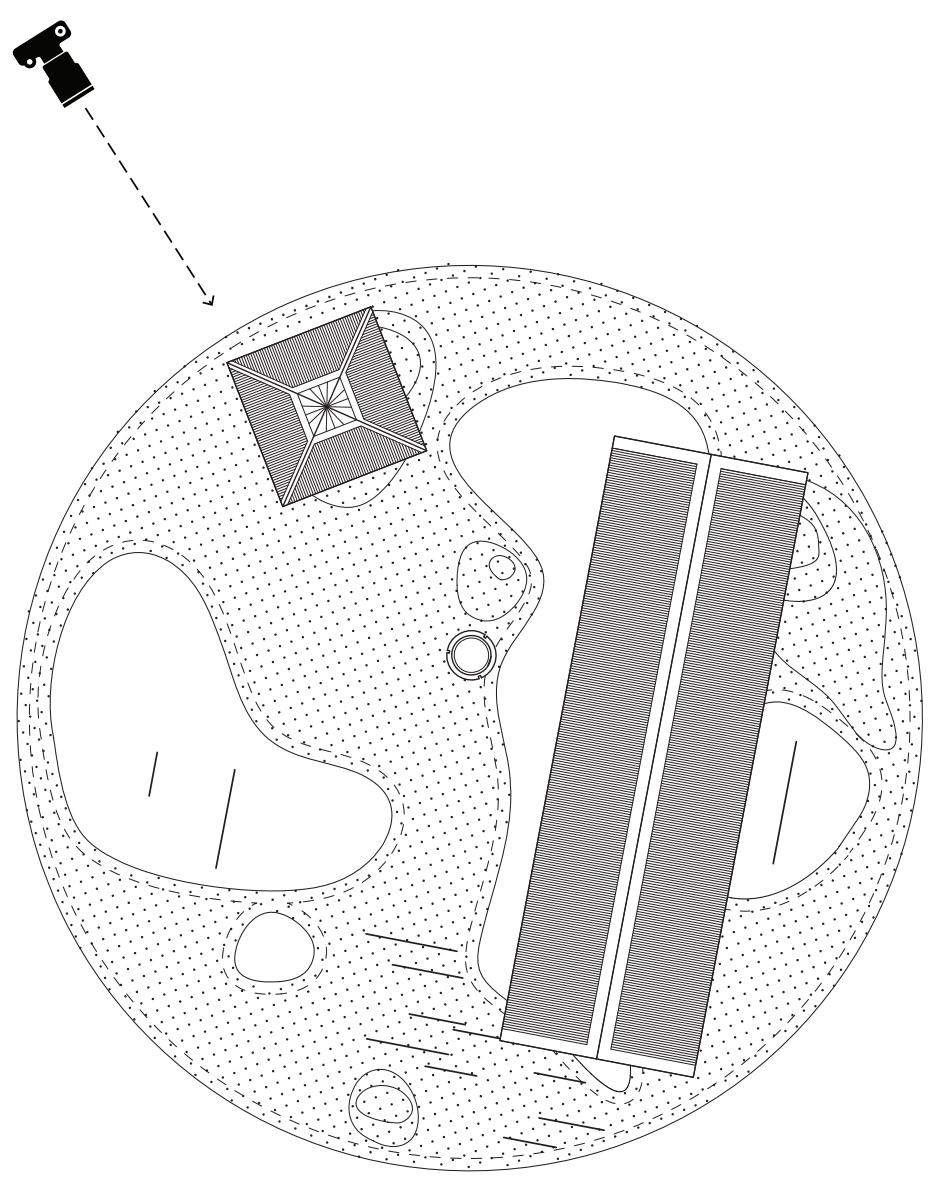

104. 1:100 Beach Whare - Boating scene. 1:5 plan arrangement 


\section{Study Three: Composing within a field of vison}

The intention of this series was to capture a 'family photo' of all the models in one shot to reveal their scope and extent. The photoshoot began with the simple aim of capturing the entire model series in one shot. During the time-staking construction of the shot it soon became clear that the process, which involved composing within field of vison, was more revealing than the shot itself.

The process began by setting up a digital camera placed on a tripod which remained stationary throughout the shoot. The next step involved repetitively jumping inbetween the field of view and the camera, shifting models, and checking the resulting image through the viewfinder. This was a laborious task at first, involving consultations with the camera after each small move however with each shift of a model the checks through the lens became fewer and fewer. As time went on I began to comprehend the correlation between a shift in space and a shift in the image. This allowed me to affectively 'feel the image'.

As with the two-dimensional figures used in the previous study, the models themselves were easily picked up and rearranged A strength of having the elements already designed.

During the process it became clear that the composition should be highly considered in order to effectively communicate the complex nature of the model series. Positioning similar iterations and explorations close together revealed trends present in the collection. Models were arranged based on physical traits including size, colour, structure, material and vegetation type. Small models scatter the foreground while larger models sit further back as to not obtrude the view. Plant species range from lush to arid which communicates the range of site conditions. Prototypes and failed models sit nearby their finalised counterparts to demonstrate their development.

The effectiveness of the composition became clear as this image was referred to countless times after it was taken. Ending up as my desktop background for easy access, the image acted as a contents page of sorts and was used as the first point of reference when referring to any process model. 


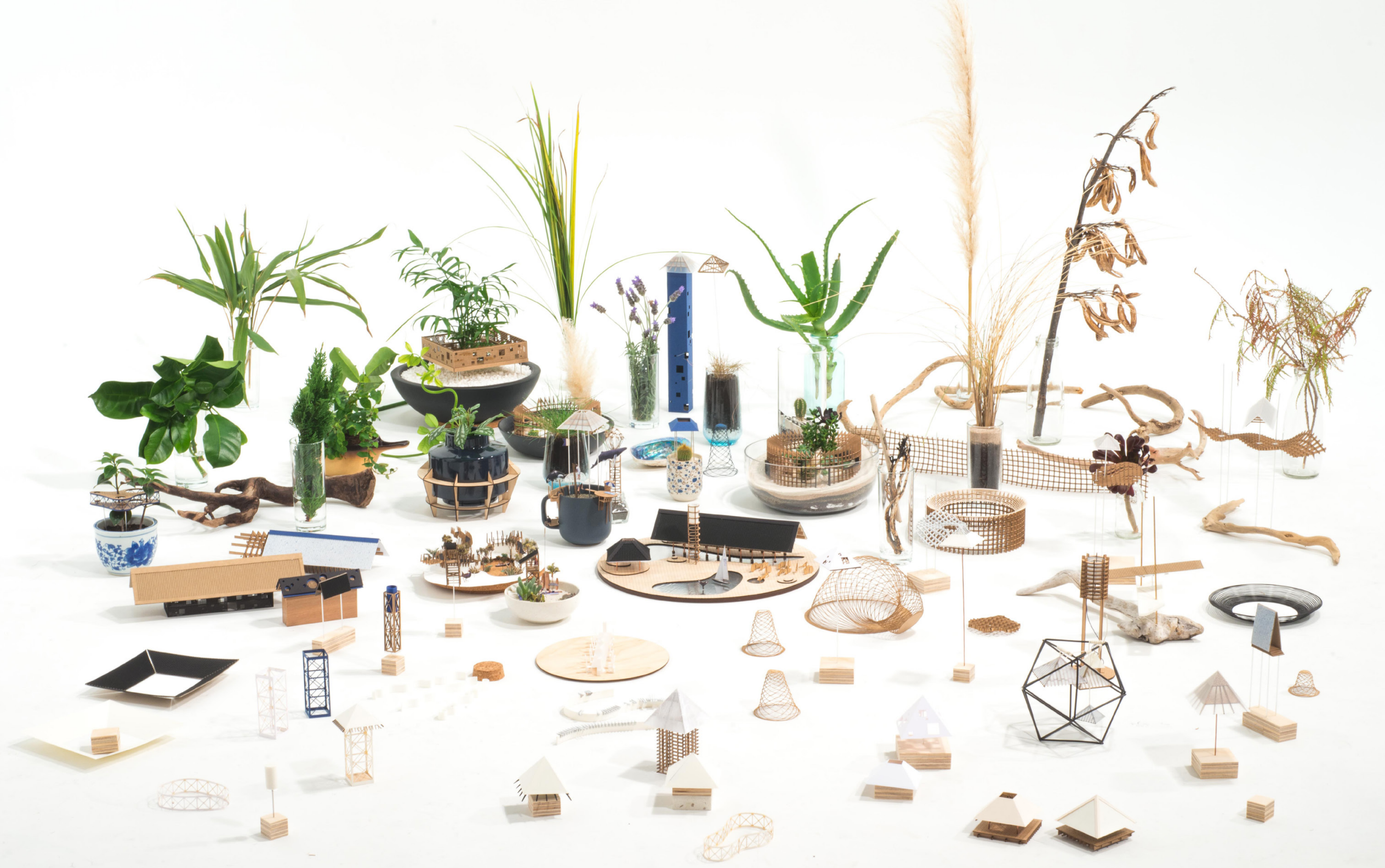

105. Final composition. Process model family photo 

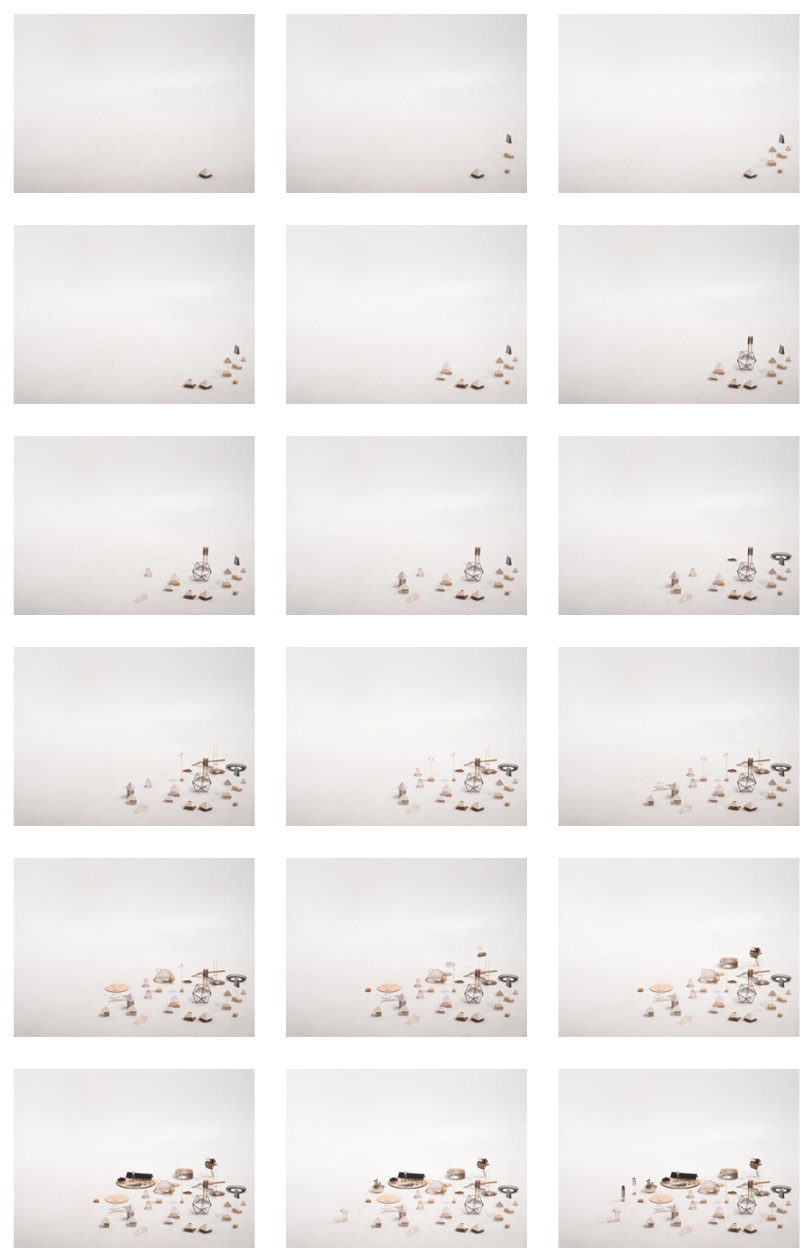

19:- $1:-\log ^{2}$

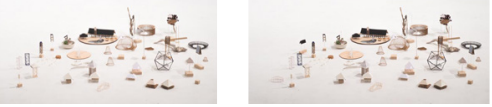

106. Arrangement process series 1-18. Image composition
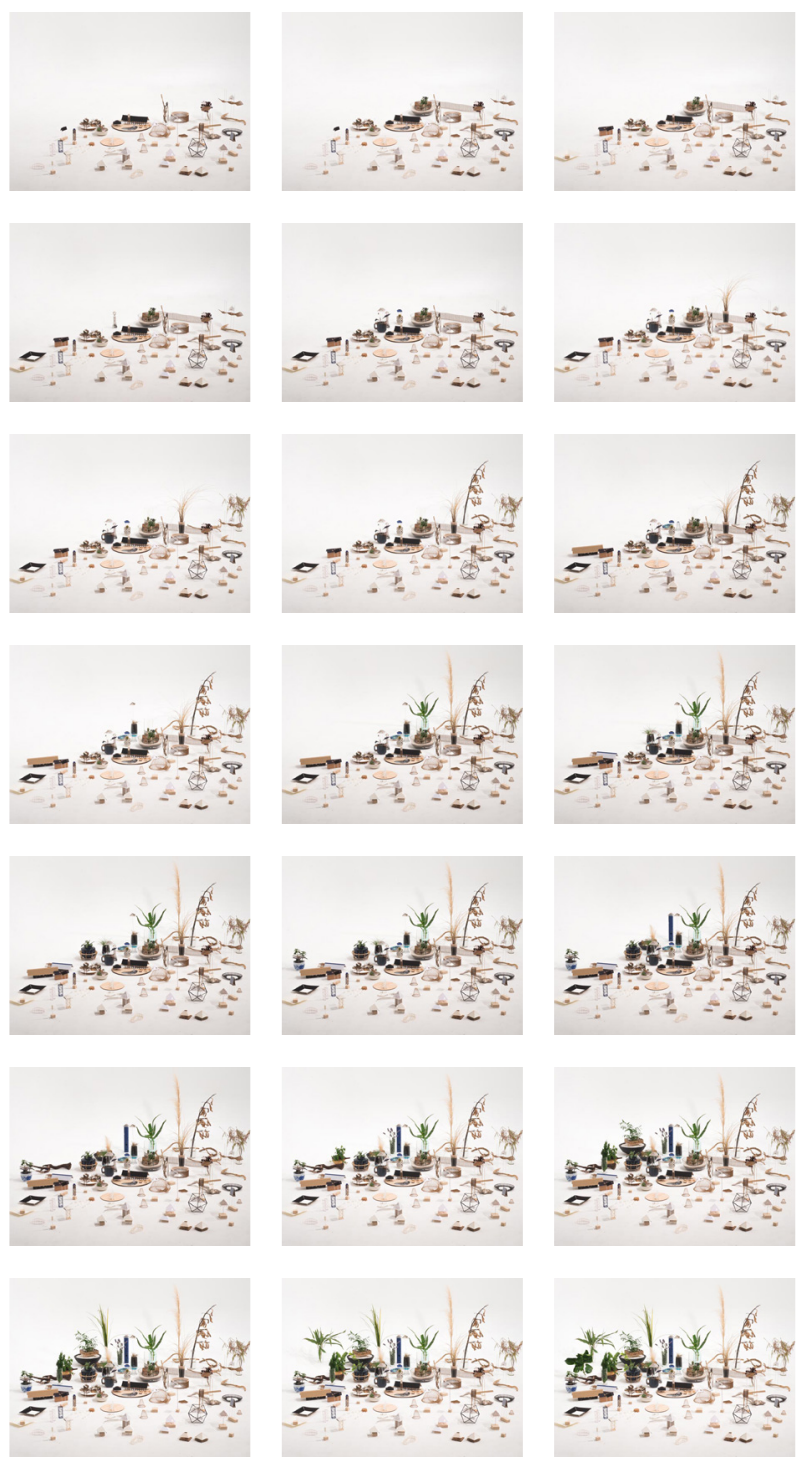

107. Arrangement process series 19-36. Image composition 


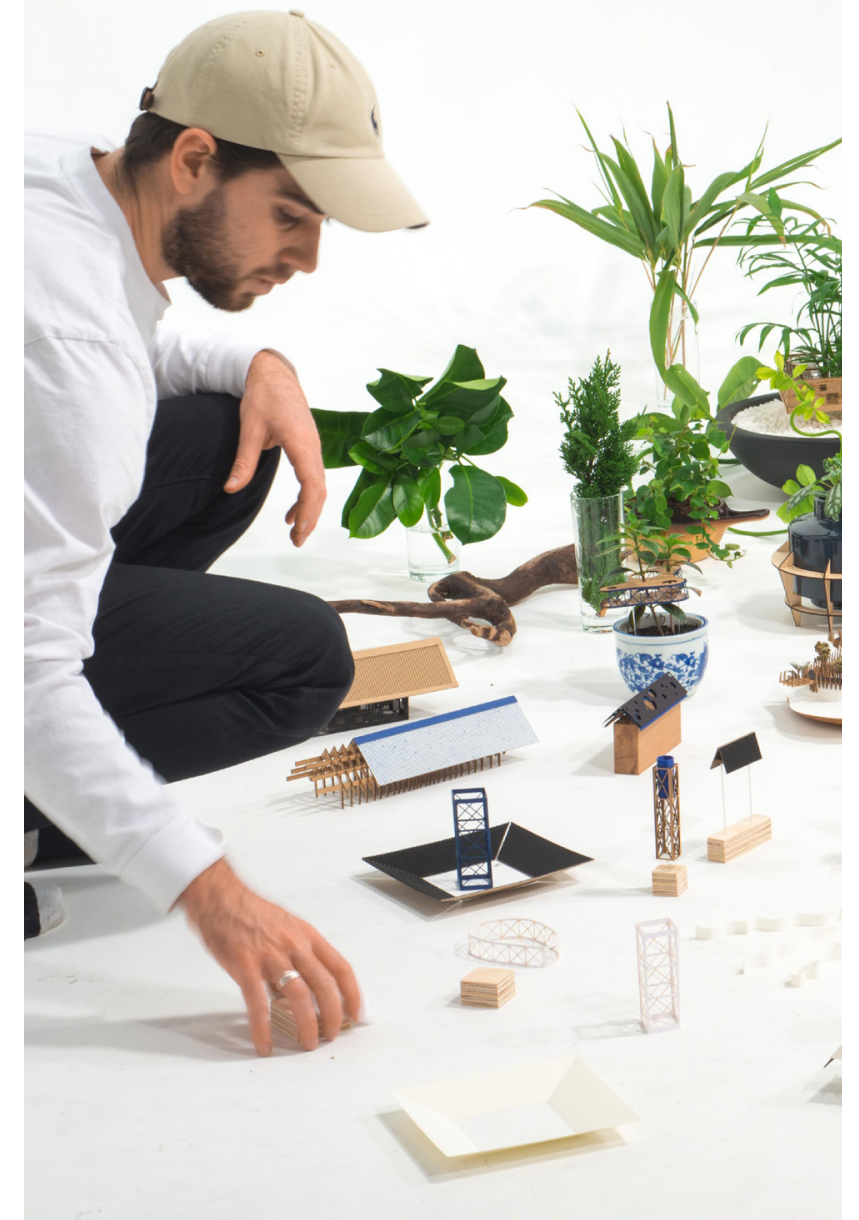

108. Composing by hand. Process model family photo

173

109. Rotating the Plant House model. Process model family photo $\square$

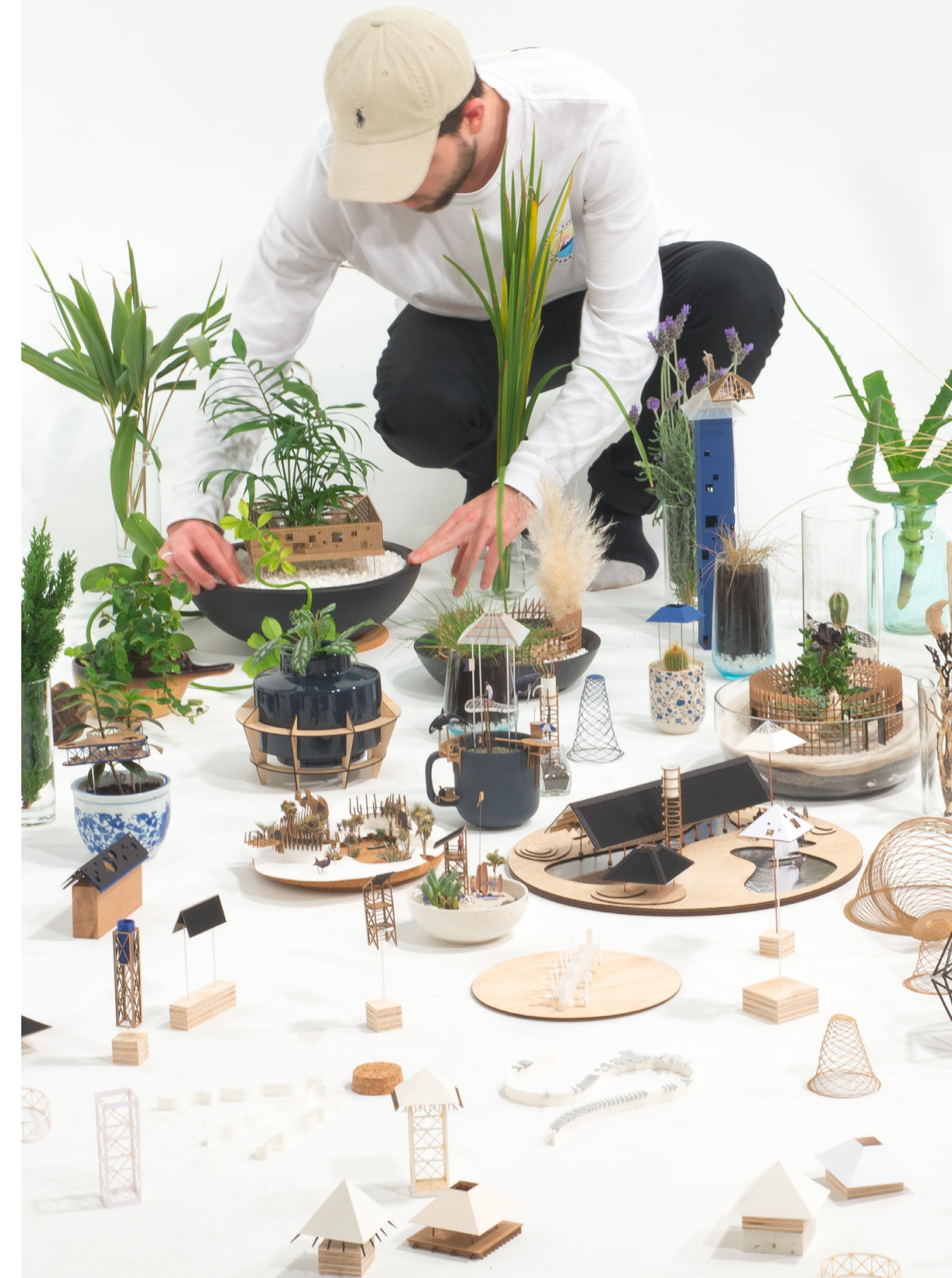




\section{Study Four: Framing the shot}

The fourth photographic series presents various opportunistic moments composed through the positioning of the camera lens. This series involves the an opposite process to what was explored previously. These images were created by shifting the camera around stationary subjects rather than shifting the subject matter around a stationary camera.

Through exclusion, the extents of the image were used as a tool to focus on particular elements. "The photographic frame could be considered a dialogue of selection and exclusion" suggests Ralph Gibson, where "unwanted information is subtracted by the parameters" and "that which remains in the frame is essential and reduced to the fewest elements possible" (2006, p.25). Purposefully cropping a scene has the potential to change the way the subject matter is perceived. This is possible because as Gibson describes, "a photograph is not a representation of the subject. It is more a re-presentation of the subject that has been enhanced by the medium of photography" (2006, p.23).
This photo series examines and highlights moments of detail and also creates new relationships between models. These photos began to utilise depth of field and the phenomena of diminishing forms to express spatial qualities. A fascination was born here concerning depth in perspective which was explored further in the succeeding study. 

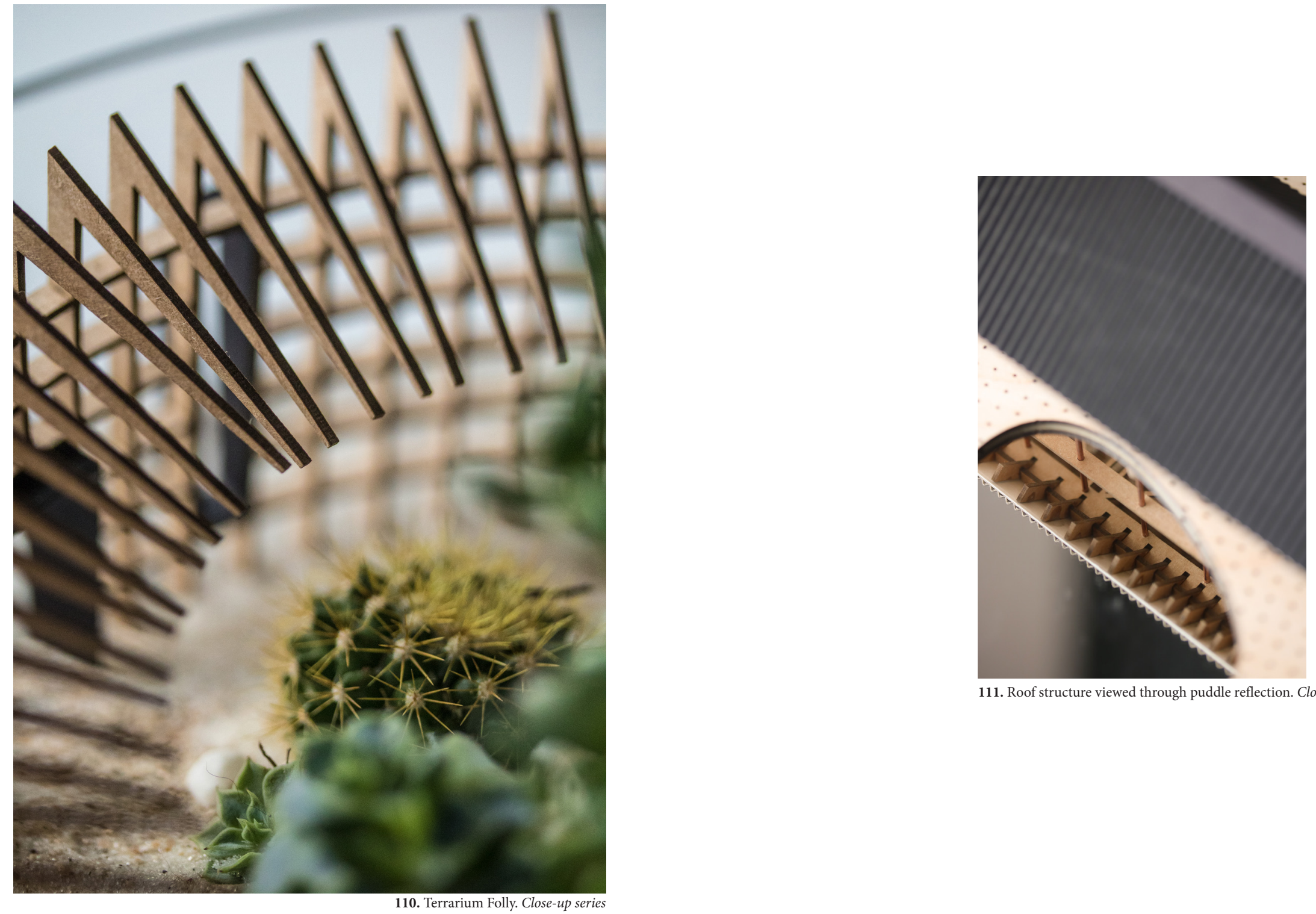

111. Roof structure viewed through puddle reflection. Close-up series 


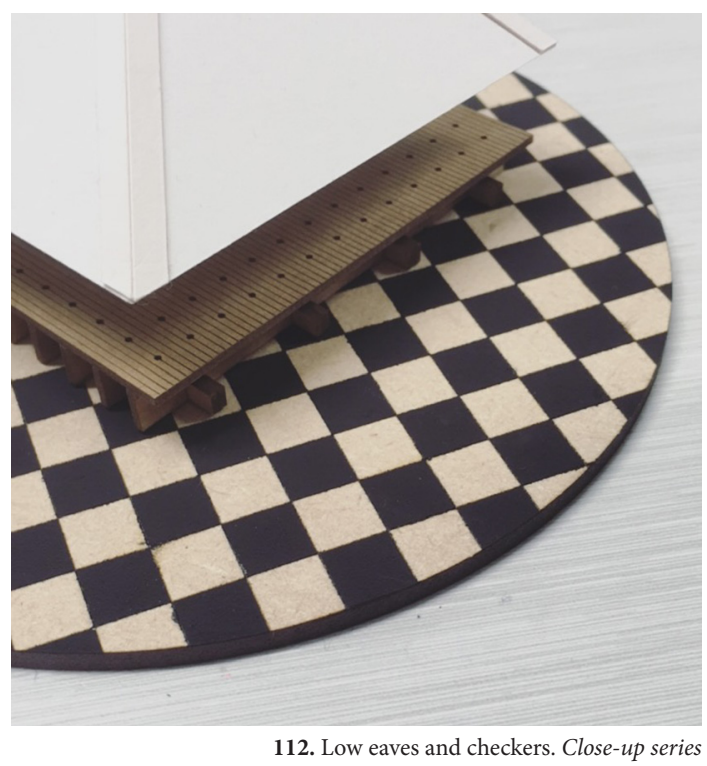

113. Process models waiting to be photographed. Close-up series

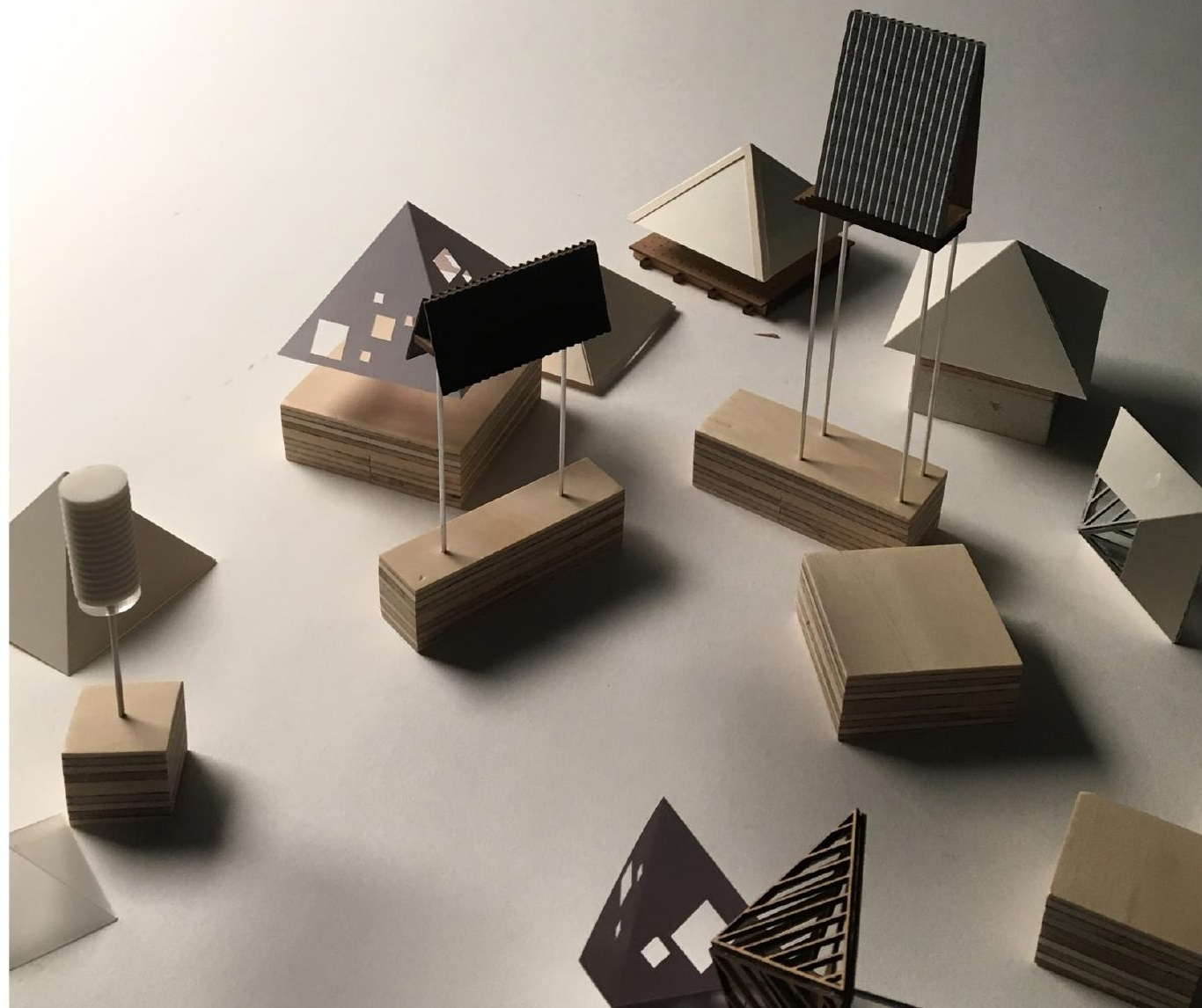




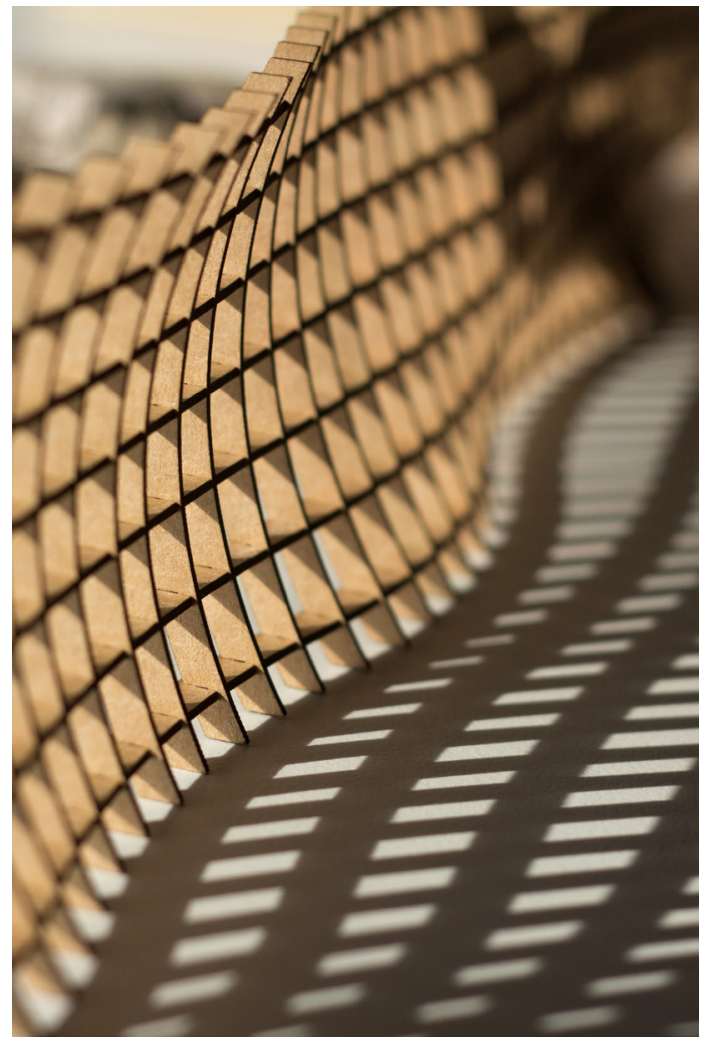

115. Afternoon shadows of a curvilinear surface. Close-up series 

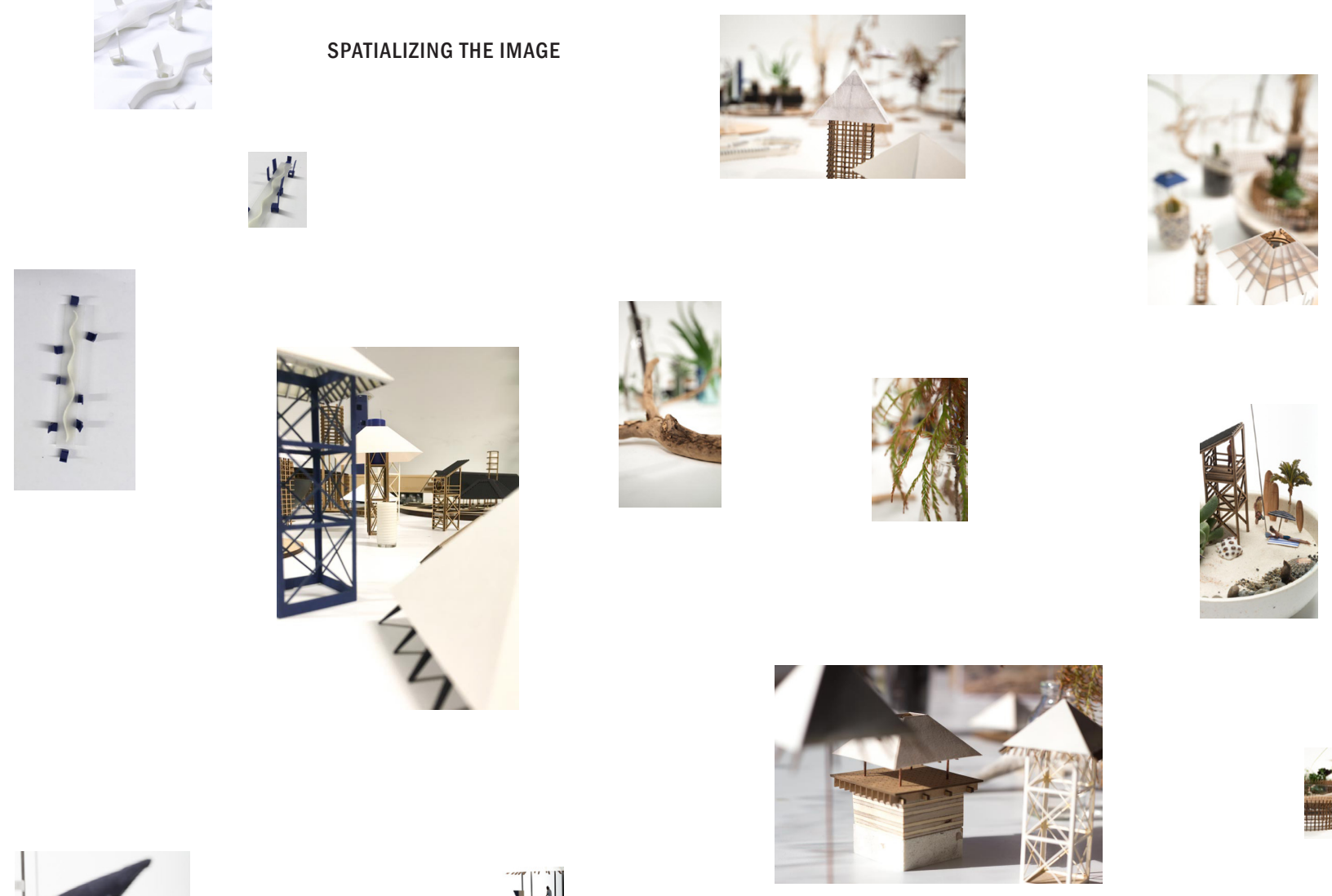

PROCESS MODELS
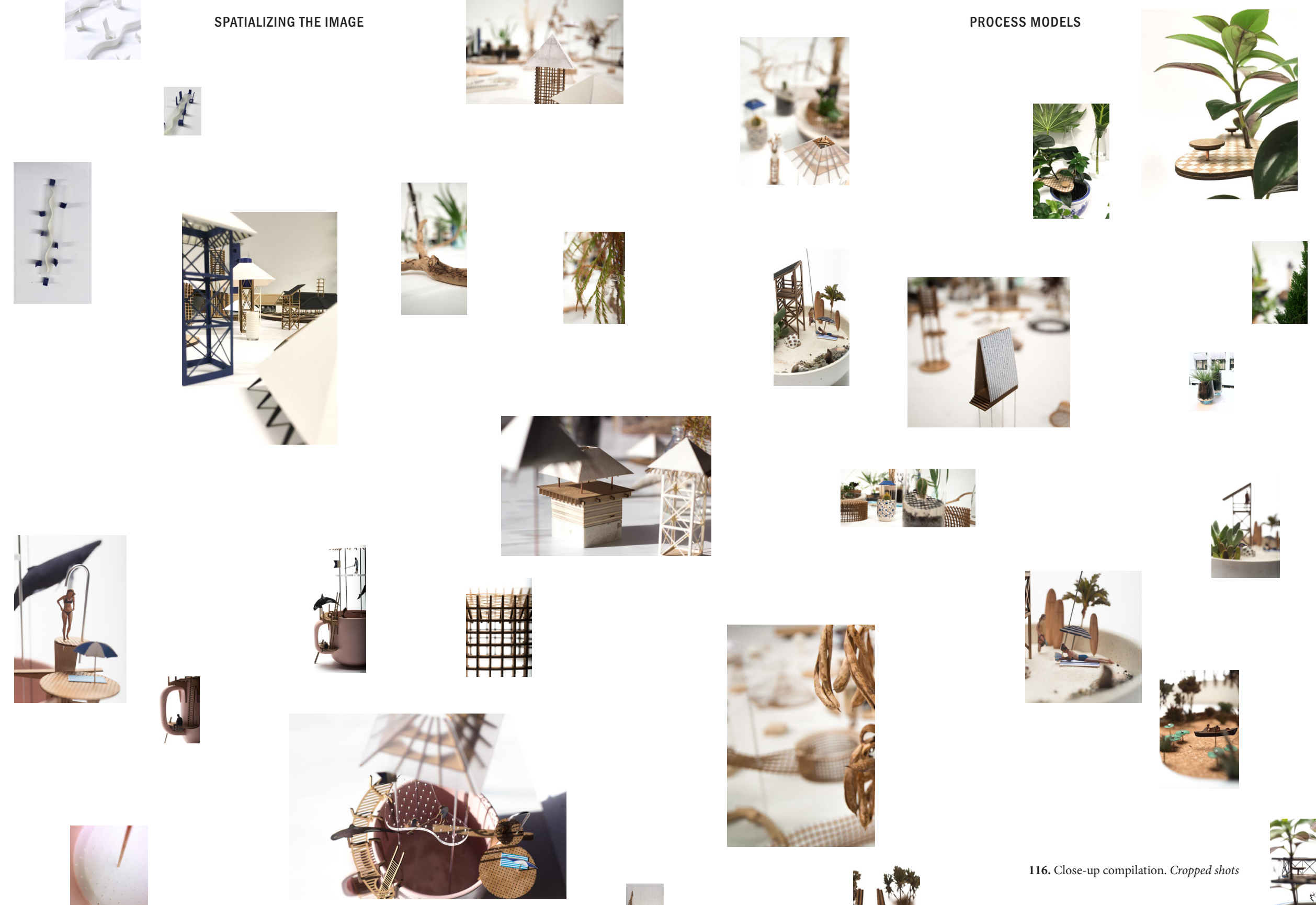
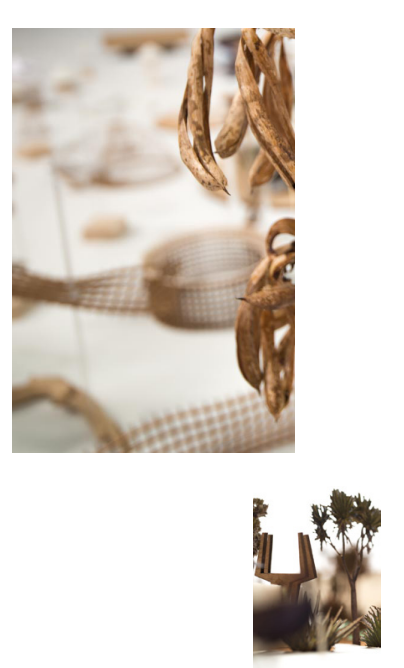
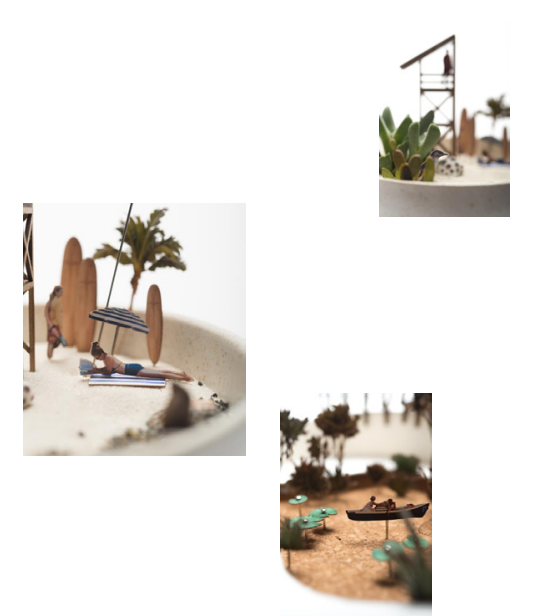

$\frac{161}{11}$ 


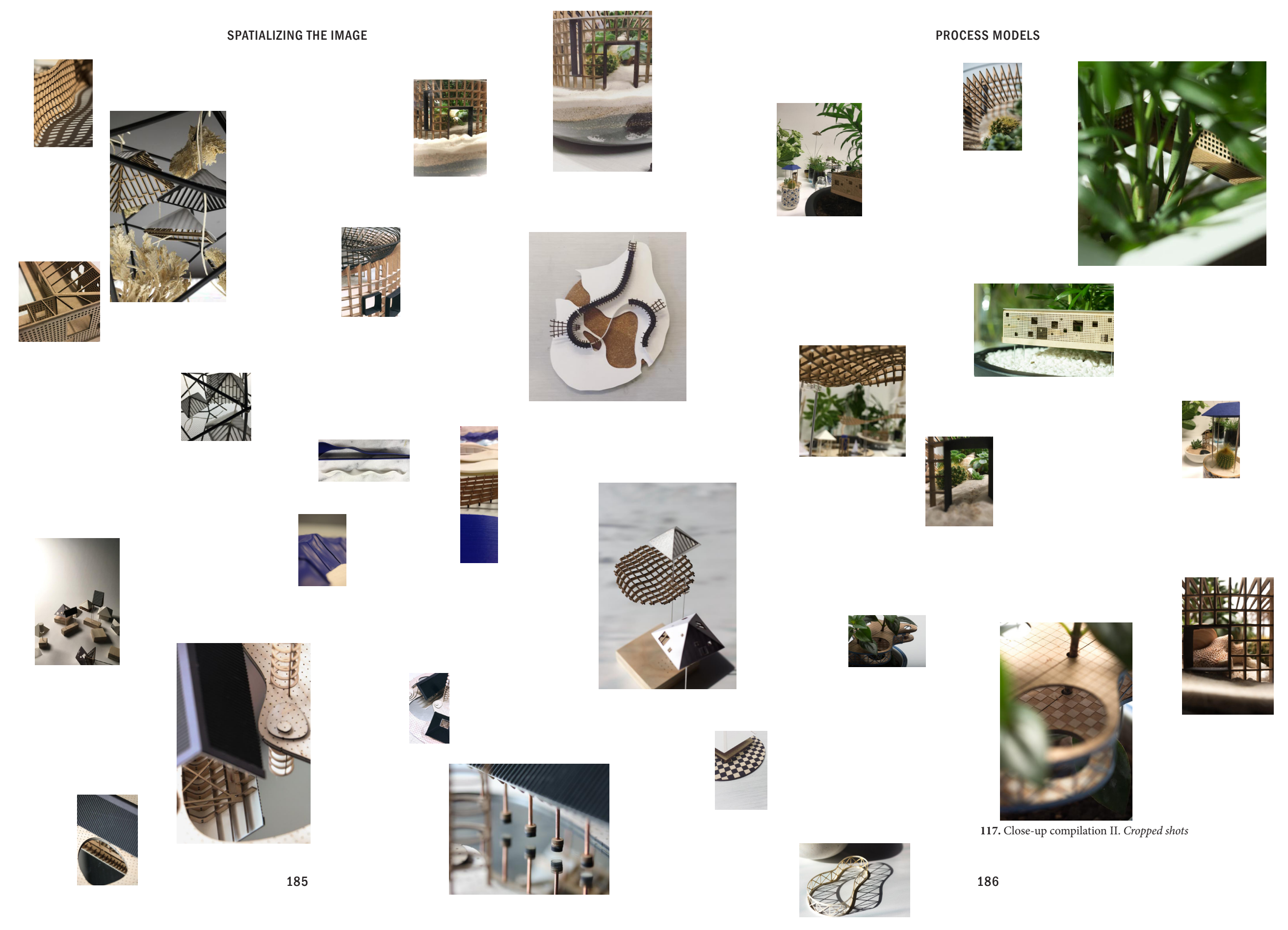




\section{Study Five: Setting the scene}

Inspired by dioramas the final photographic study introduced site specific backdrops to give the models context. The set-up involved arranging and photographing the models in front of two-dimensional images taken onsite. The French term 'Mise-en-scene' translates to, "put the thing on stage", which best desribes this process (Feireiss, 2010 , p. 2). Lukas Feireiss unravels the term as a "calculated scenic arrangement in which image and space merge to form a narrative and sense-generating whole" (2010, p. 2).

The first habitat diorama was designed by Gustaf Kolthoff in the Biological Museum in Uppsala built in 1889. Nat Chard describes how Kolthoff "noticed the birds and animals he shot were not as interesting when stuffed as they were when alive" and realised this was because "that many of their characteristics related to their environment" (Drawing Indeterminate Architecture, 2015, p. 49). In the same manner to Kolthoff's diorama the process models were placed in front of their context. In many cases this revealed the lack of consideration for the relationship with site. I found myself wanting to, but unable to re-compose models to align and react to the backdrop. However I was still able to shift the model and camera positions. Dictated by the backdrop the scene was shot from a restricted perspective, models were arranged in a field of vison by hand while camera position cropped and framed the shot.

The resulting images present a surreal perspective of space and abstracted context. Although the models were all built to standard scales (1:50 or 1:100), the figures, backdrops and materiality were disproportionate. This resulted in the images feeling more emotive rather than looking like possible architectural interventions. To exaggerate this further native insects from site were also introduced.

It was noted that models with simple forms were deemed the most successful and harmonious as they did not distract from their beautiful natural backdrops. This discovery was key in the design development process and as a result simple and adjustable forms became popular in the final model series. 


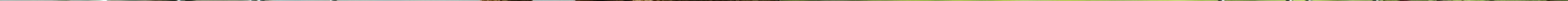



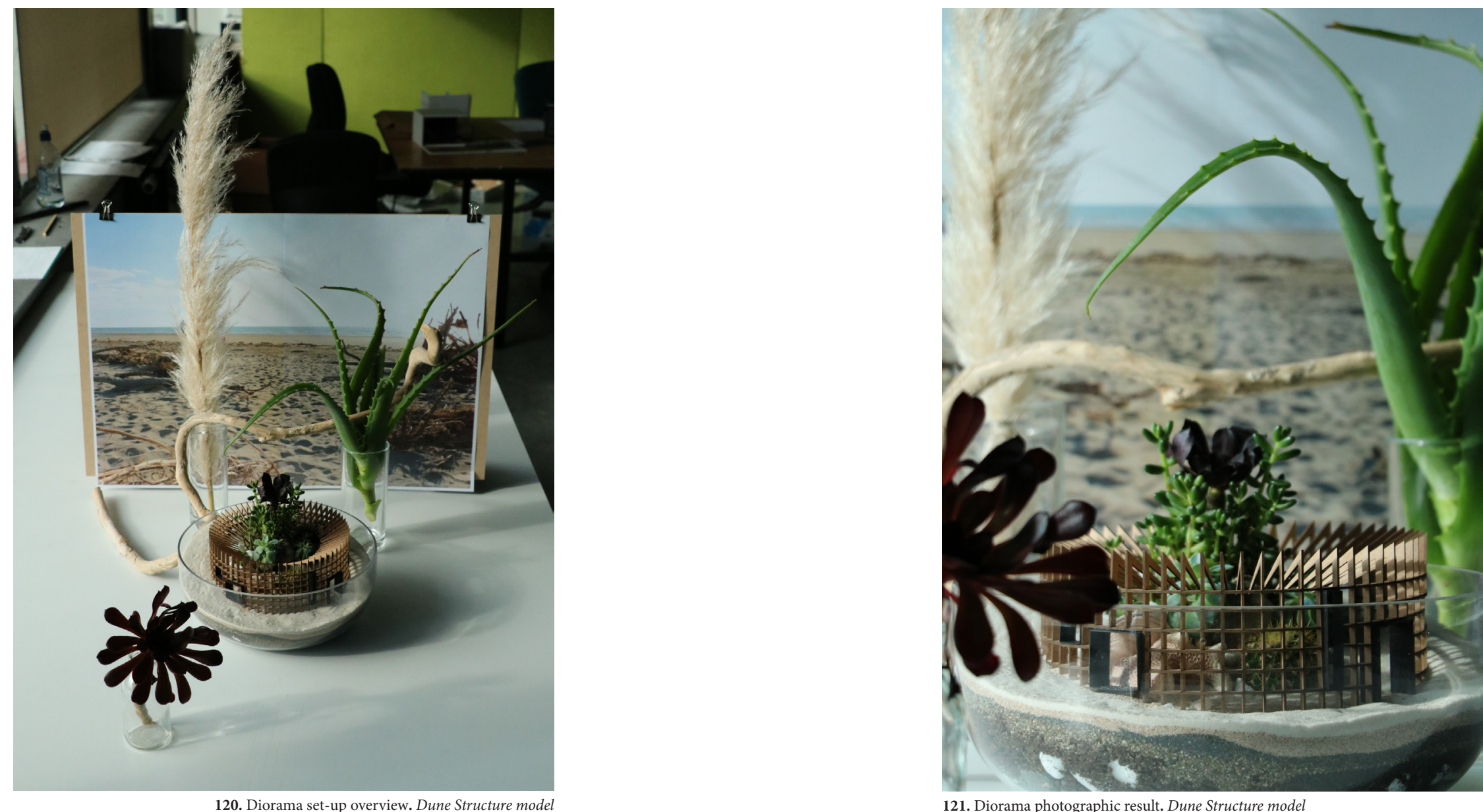

121. Diorama photographic result. Dune Structure model 


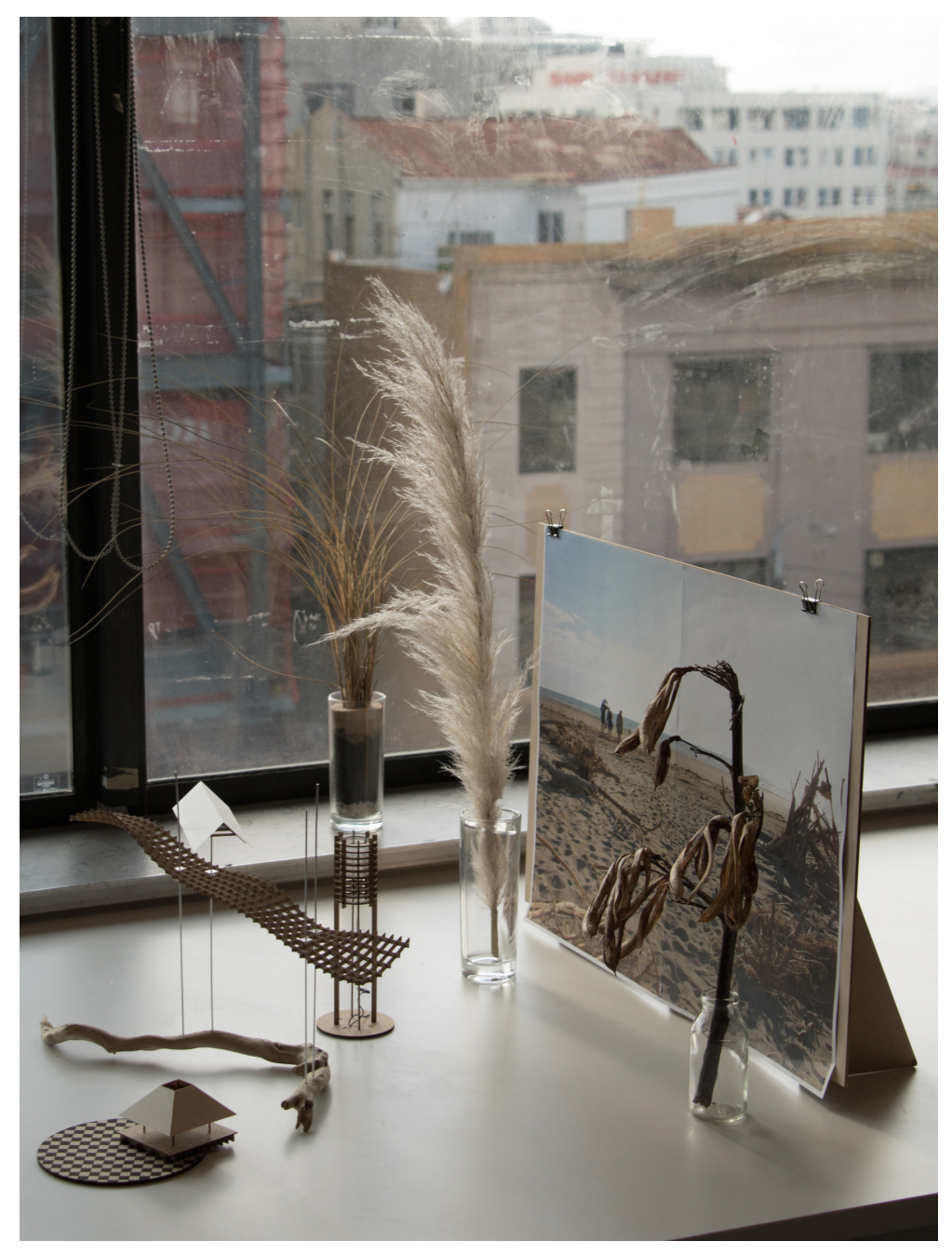

122. Model composition, backdrop and natural daylight. Diorama set-up

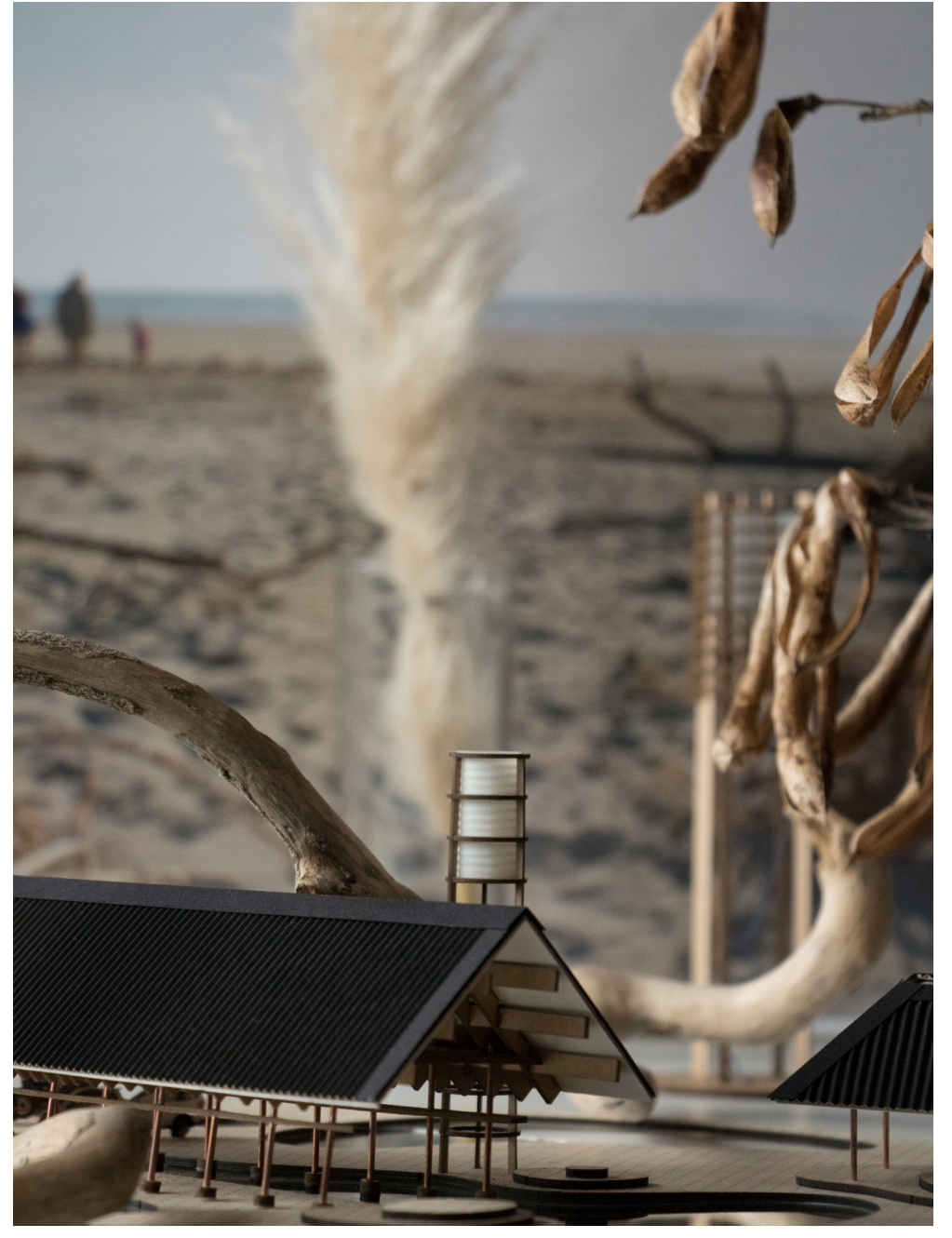

123. Beach Whare shot against photo of Paraparaumu Beach. Diorama set-up 

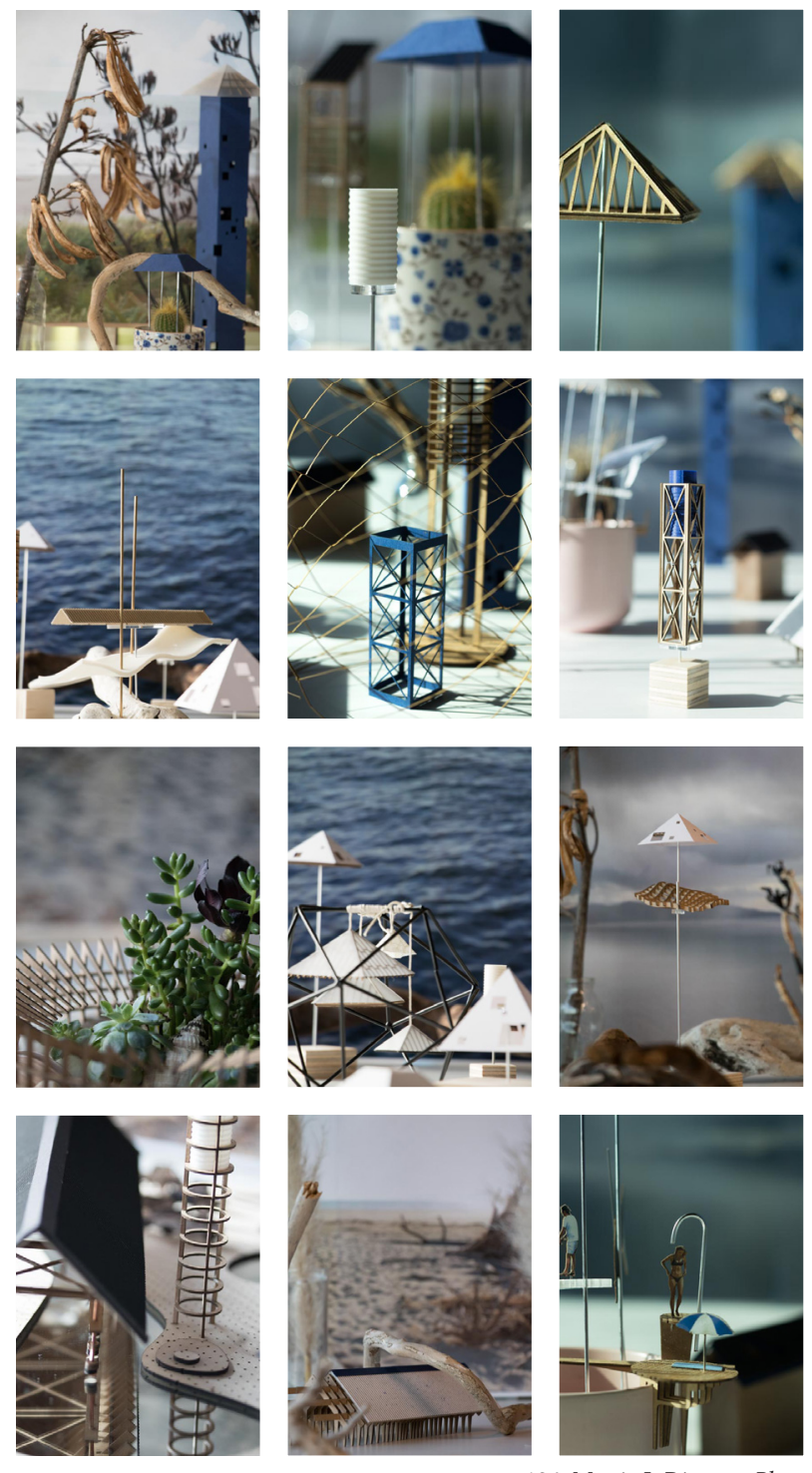

124. Matrix I. Diorama Photos
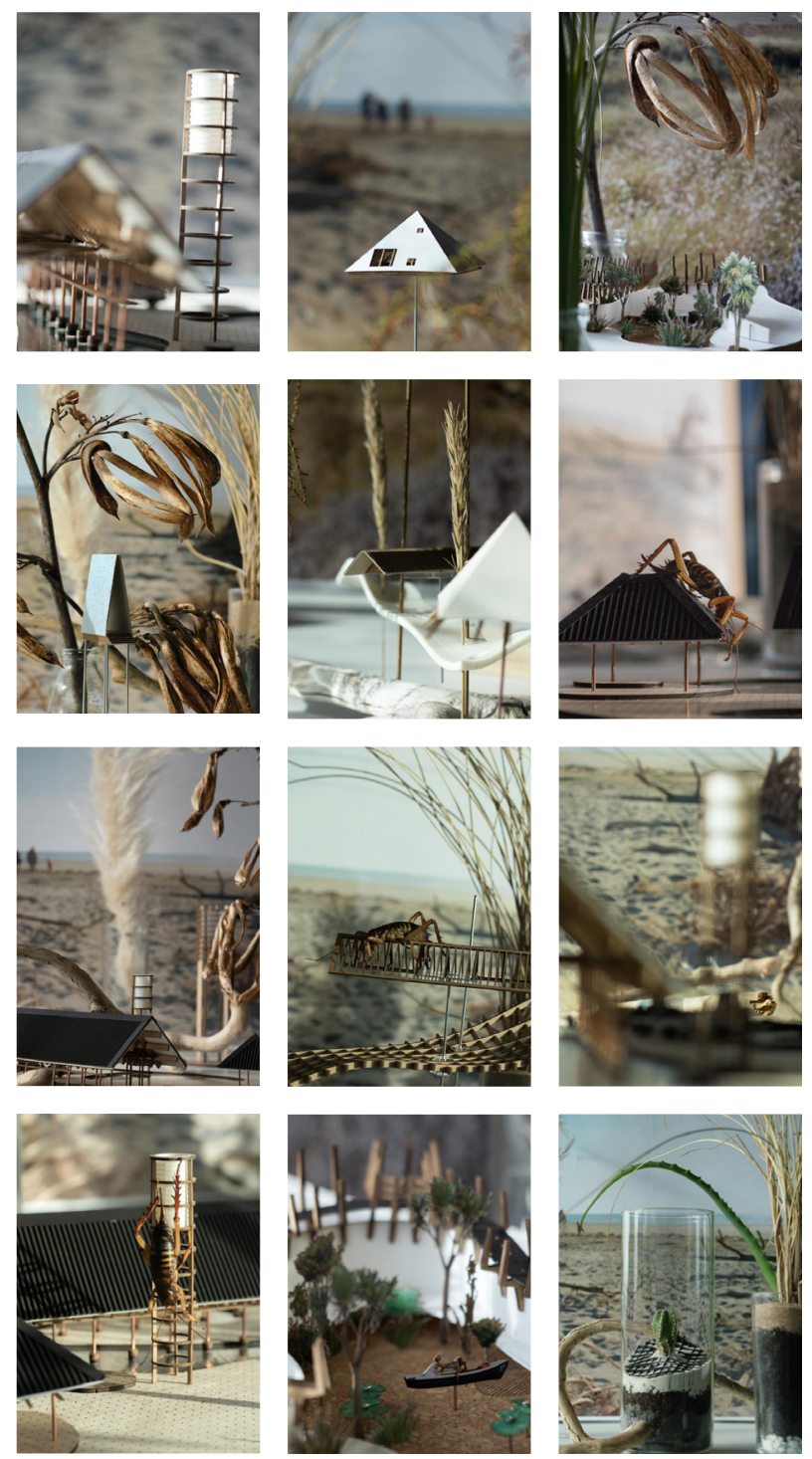

25. Matrix II. Diorama Photo

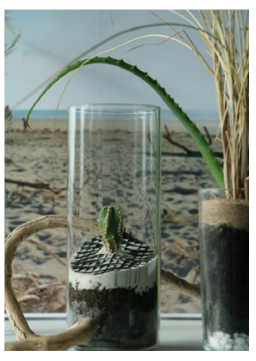



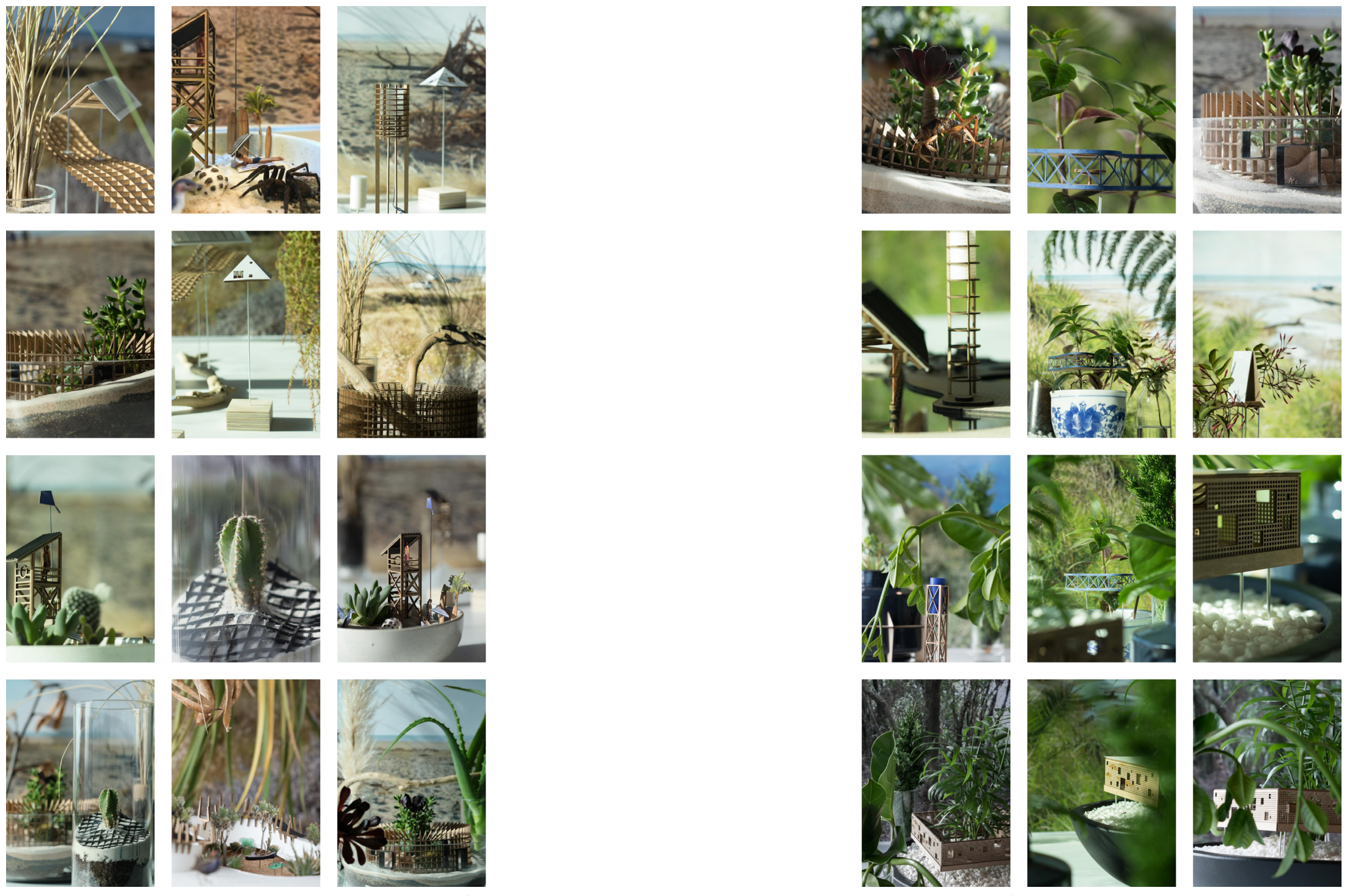

126. Matrix III. Diorama Photos
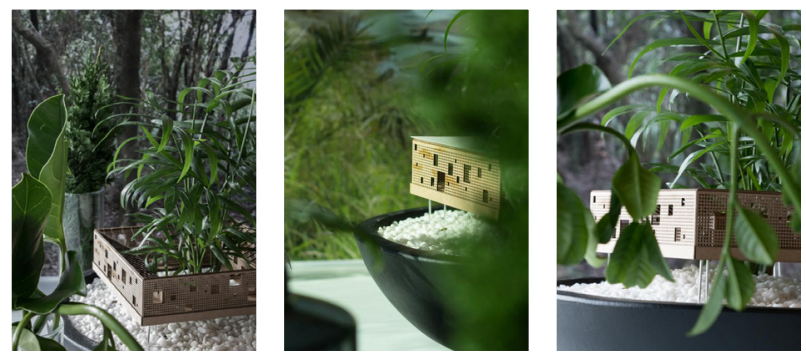


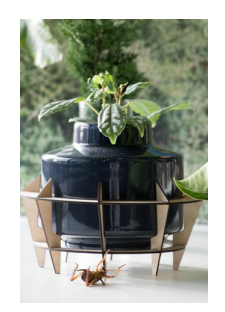

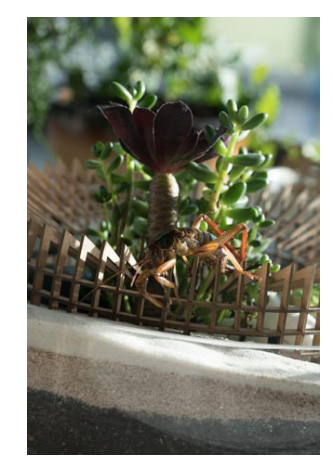
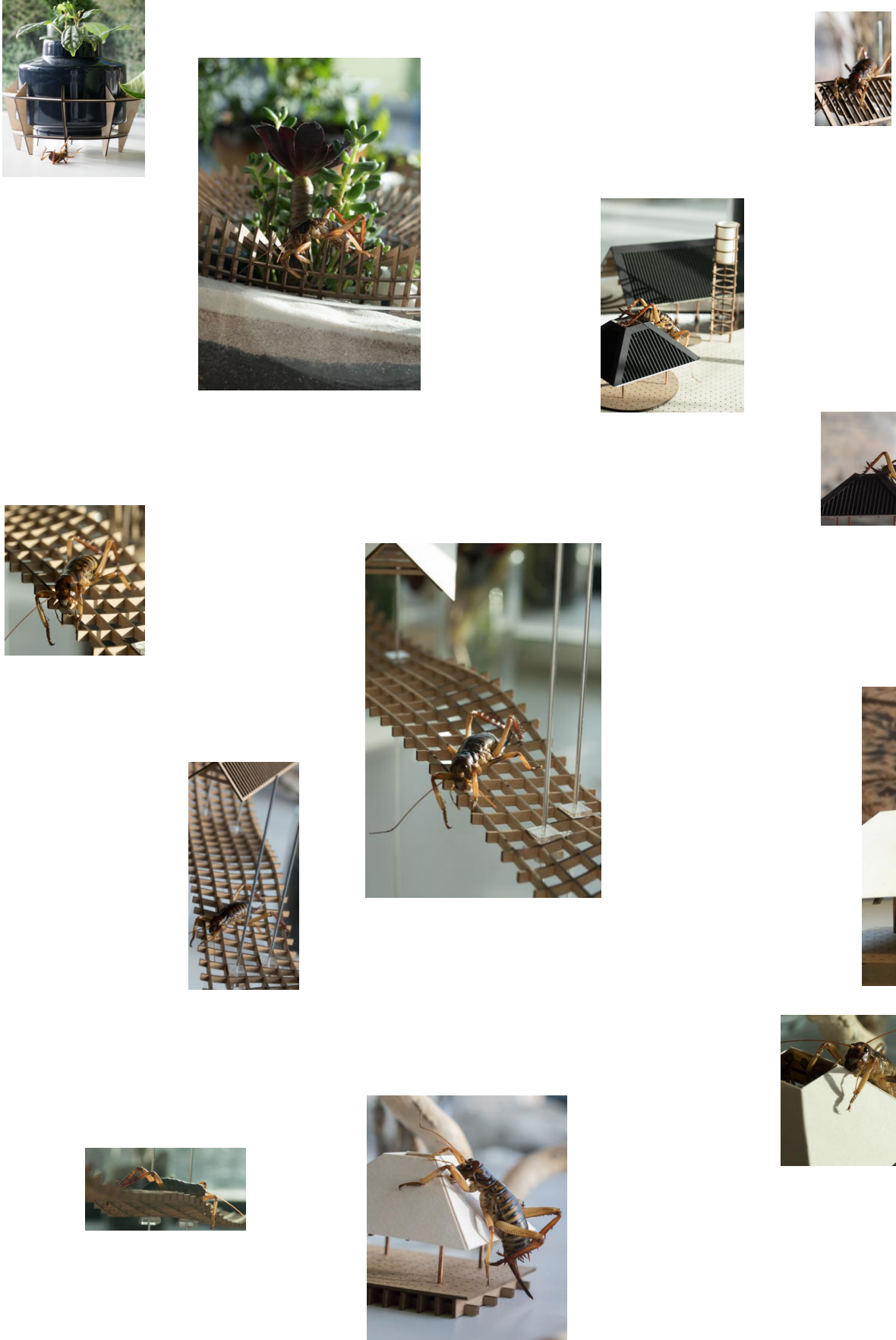
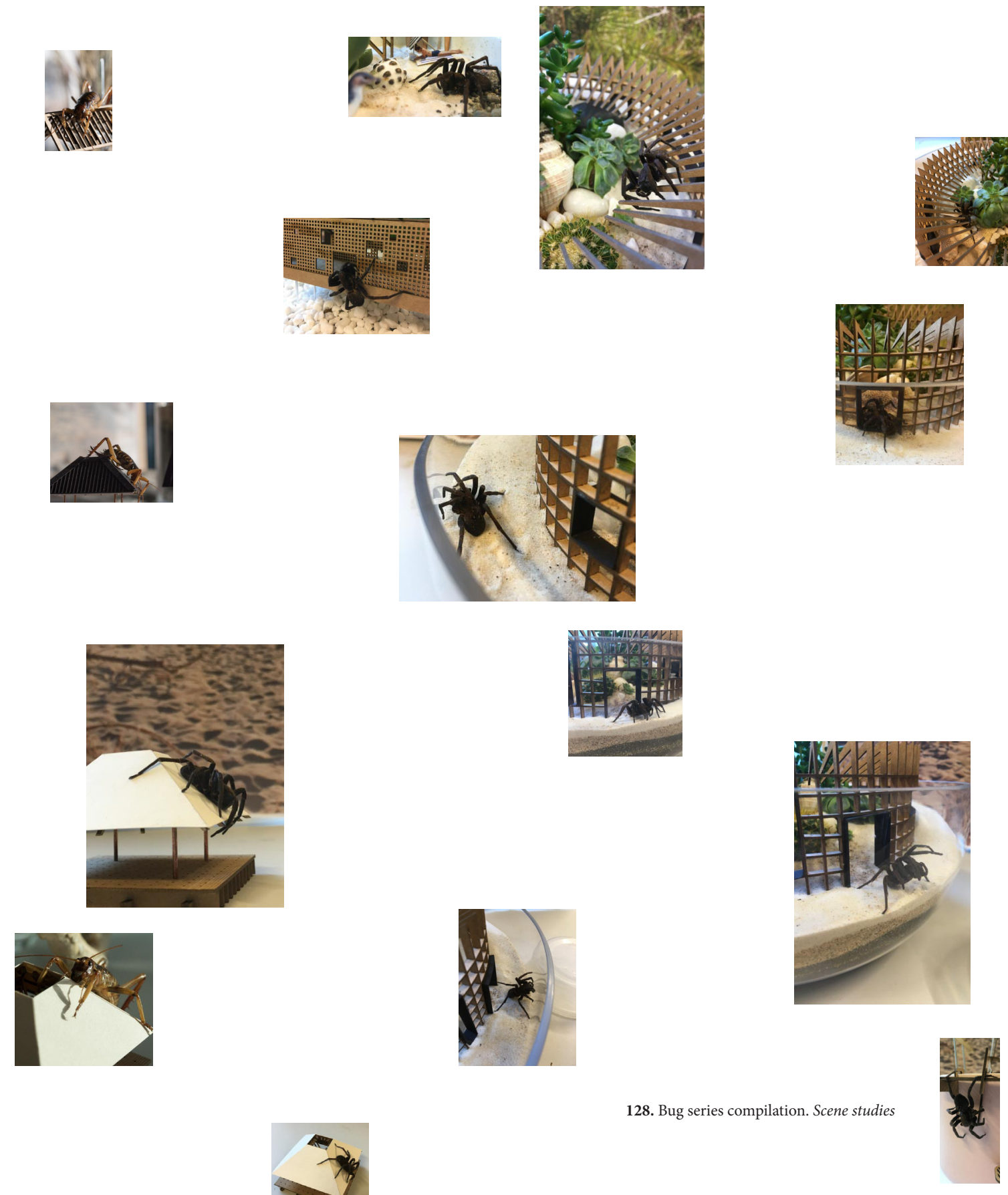

128. Bug series compilation. Scene studies
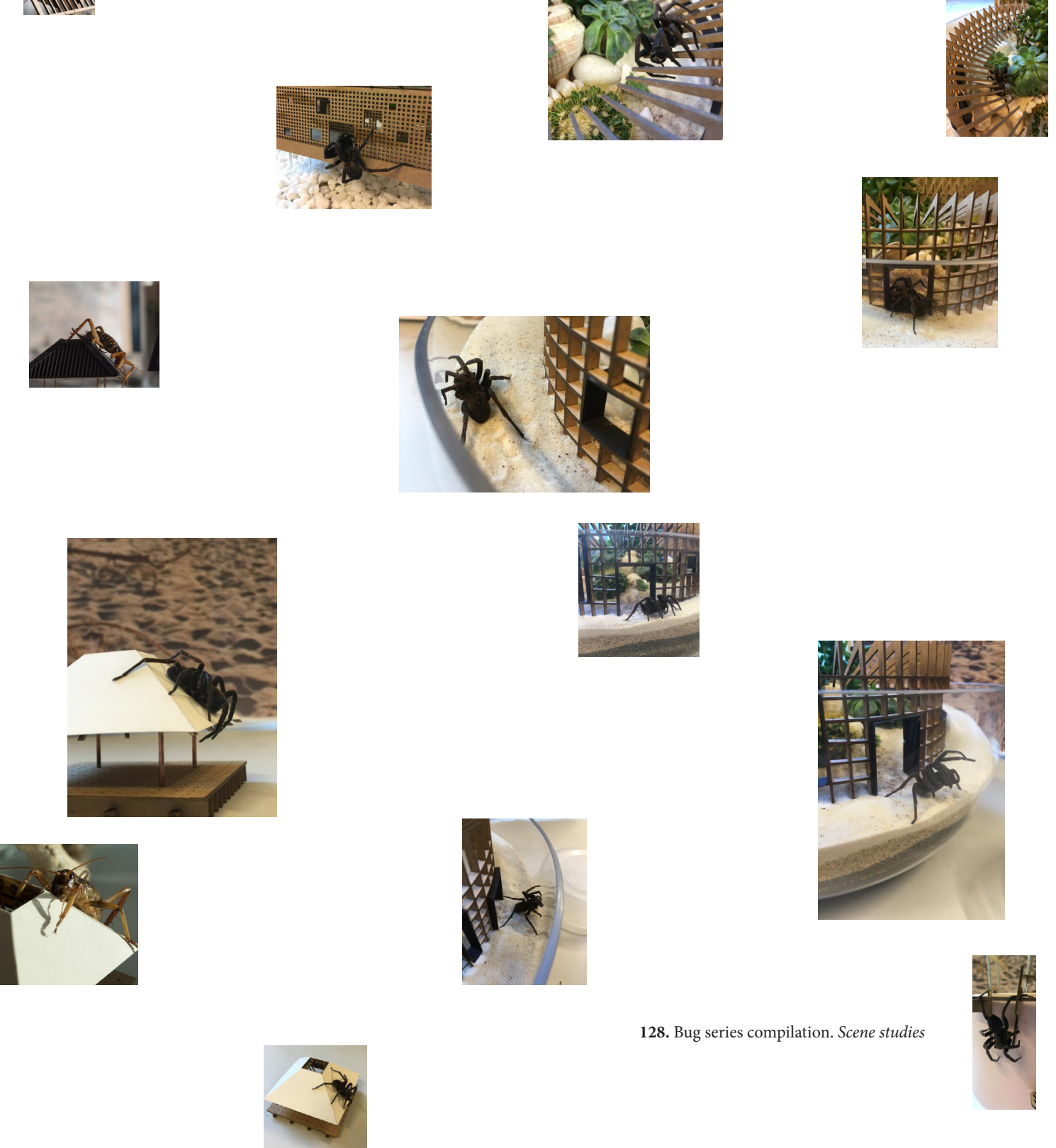


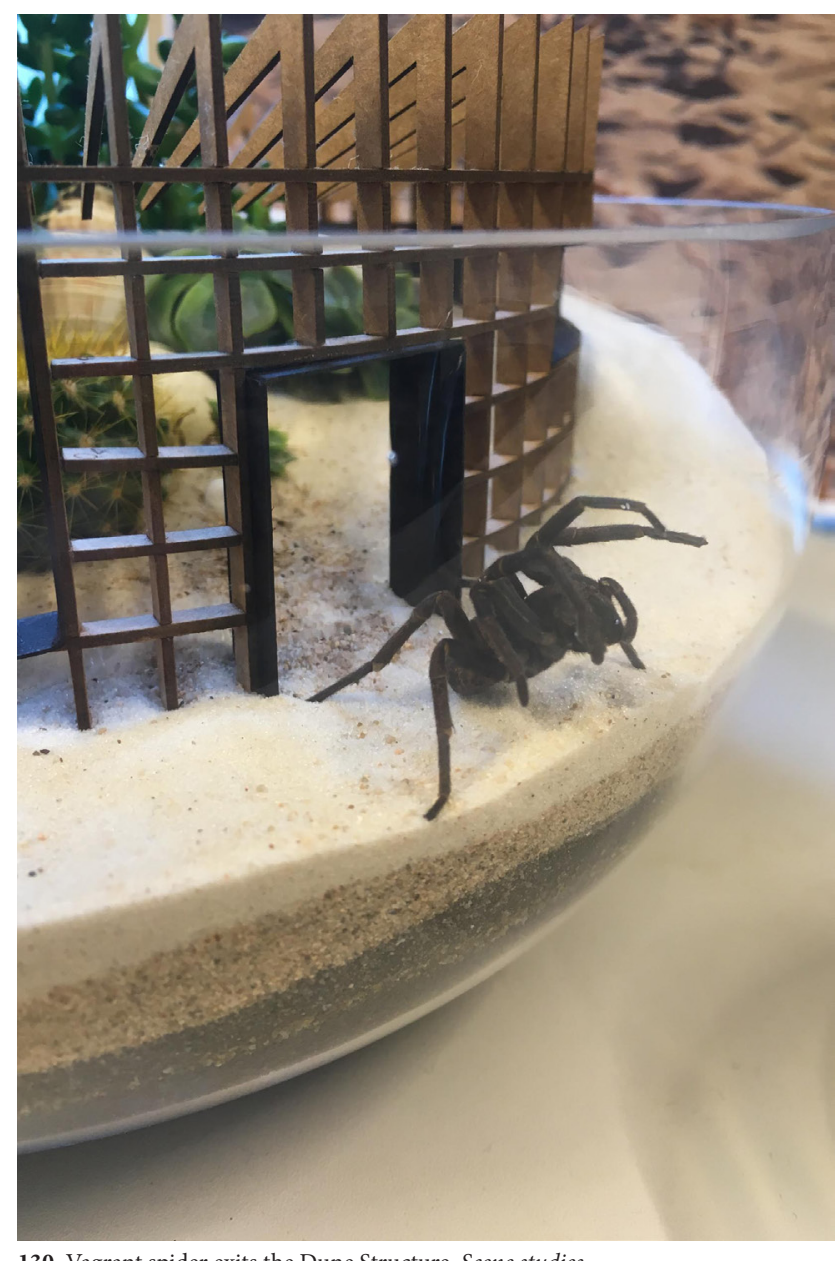

130. Vagrant spider exits the Dune Structure. Scene studies

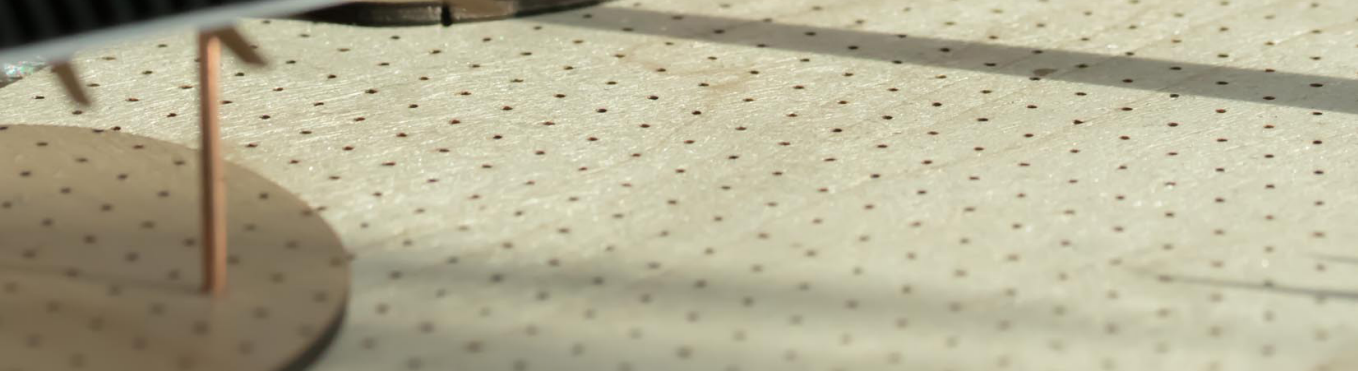


Chapter Six

DEVELOPED PROCESS 


\section{Architectural Model As a Device}

This research portfolio culminates with the development of a design process which involves the use of architectural models as devices. Smout \& Allen states, "a device is more or less a complex system" (Superscape,2013, p.125). Albert Smith Elaborates on the architectural device describing it as "an interaction of parts, with other parts, within a whole (or system) intentionally producing purposive activity"(2004, p. 64).

The devices that were developed in this research are spatial systems designed to compose particular architectural views. This process builds upon the discoveries made in the initial process-model series. Physical models designed with an emphasis on flexibility and adaptation they are able to be quickly and effectively rearranged by hand to alter the composition of a view. The result is a design process that focuses on the production of architectural imagery, but is inescapably linked to spatial design.

Each device is a unique machine designed to compose a specific view of the proposed Kapiti Island Biosecurity Centre. Representing prominent views of the building onsite the devices are designed to be viewed and composed from one designated perspective. The devices encourage their user to focus on the two-dimensional 'image' of the architecture. The composition of the image is altered by making spatial shifts to the devices variable components. Variables in the devices range from position of the site to moveable architectural elements. Once a composition is deemed complete, a photo is taken as a record. The resulting spatial information present in each device was then translated into orthographic drawings.
Each device is designed to become an extension of the body and is scaled appropriately. Smout \& Allen's 'panorama landmarks' operates in a similar manner. "Although of a similar scale, are not scale in a traditional sense; each is designed to be held in the palm of the hand or explored by being held up to the sky" (Augmented Landscapes, 2007, p.7). This exploration and and understanding of scale is directly related in this process.

The final devices are tools, and although indicative, should not be considered direct representations of the final proposed building. This aligns with Smout \& Allen's discussion on their work, "though our models may look very finished and look like very designed objects, they're still very much tools for us. They're handheld ways at looking at a problem or a question" (Superscape, 2013, p. 135)

This chapter provides a description of each device separately, explaining how they work and their spatial implications. The devices presented are the final versions of each idea, which involved numerous initial sketch models and prototypes in their development. The process of designing the devices is depicted at the start of the chapter. 


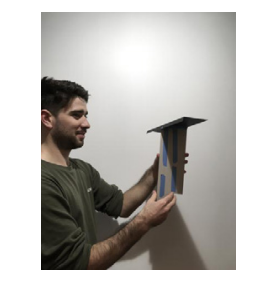

SPATIALIZING THE IMAGE
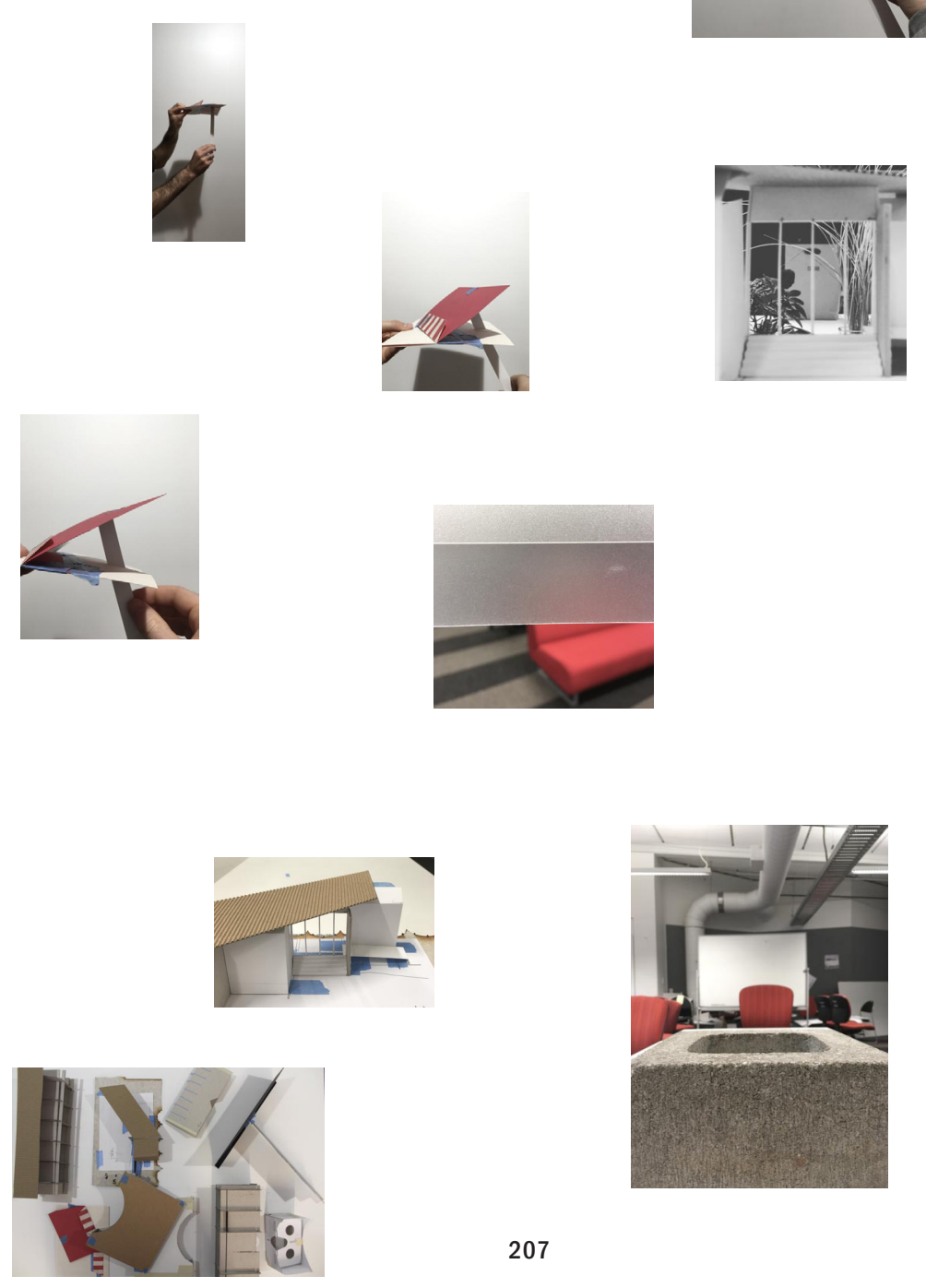
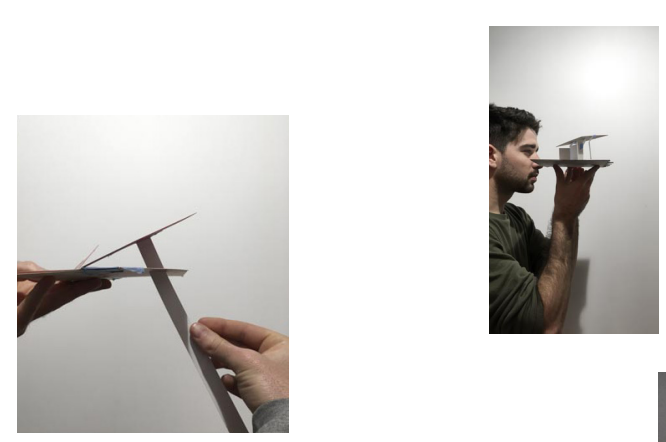

DEVELOPED PROCESS
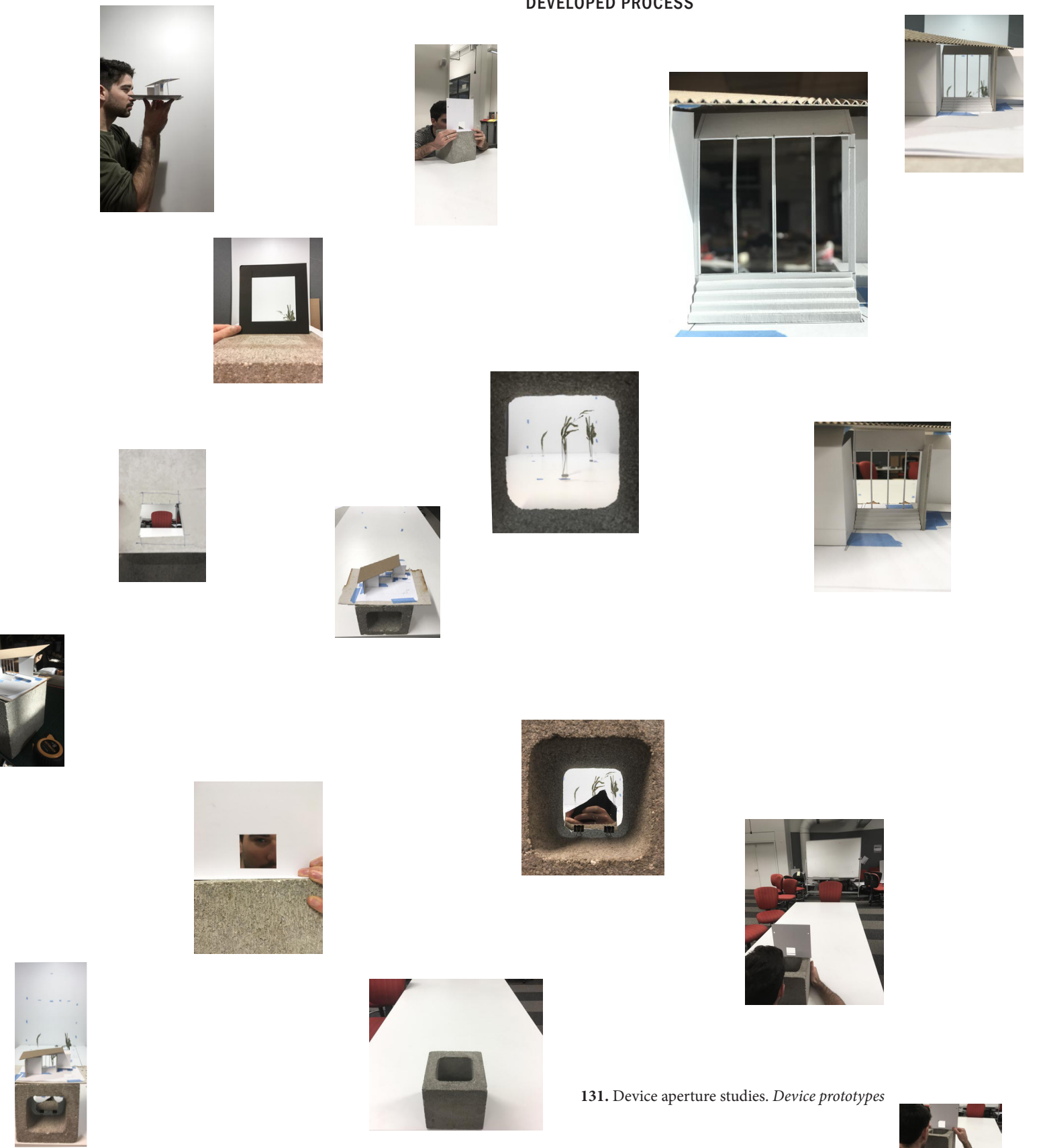

131. Device aperture studies. Device prototypes
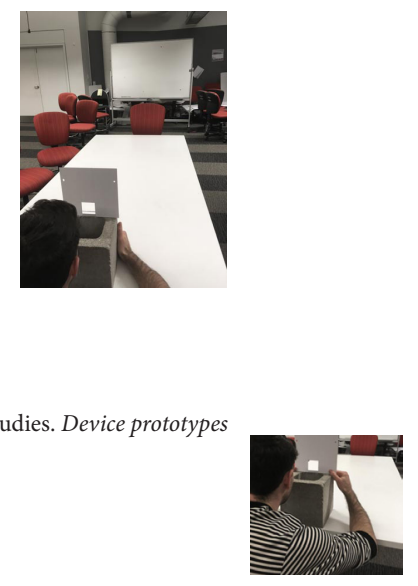


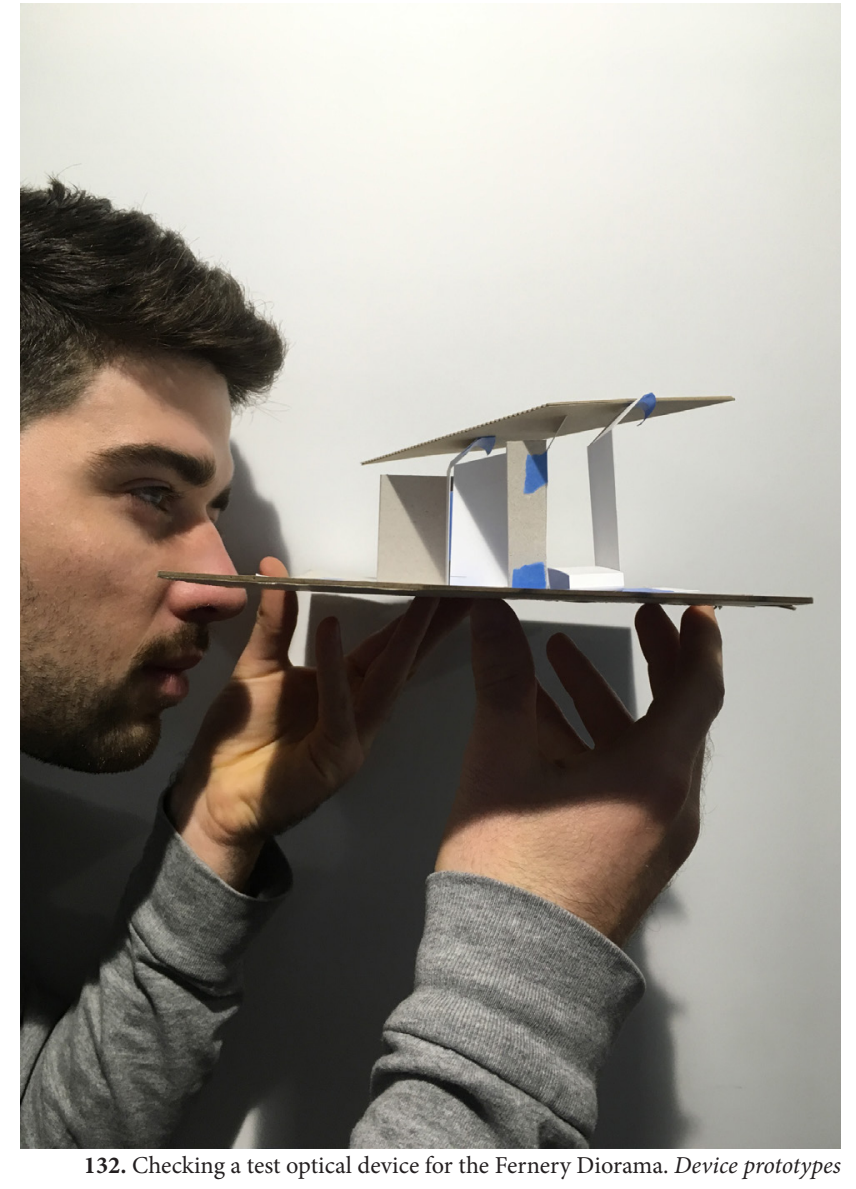

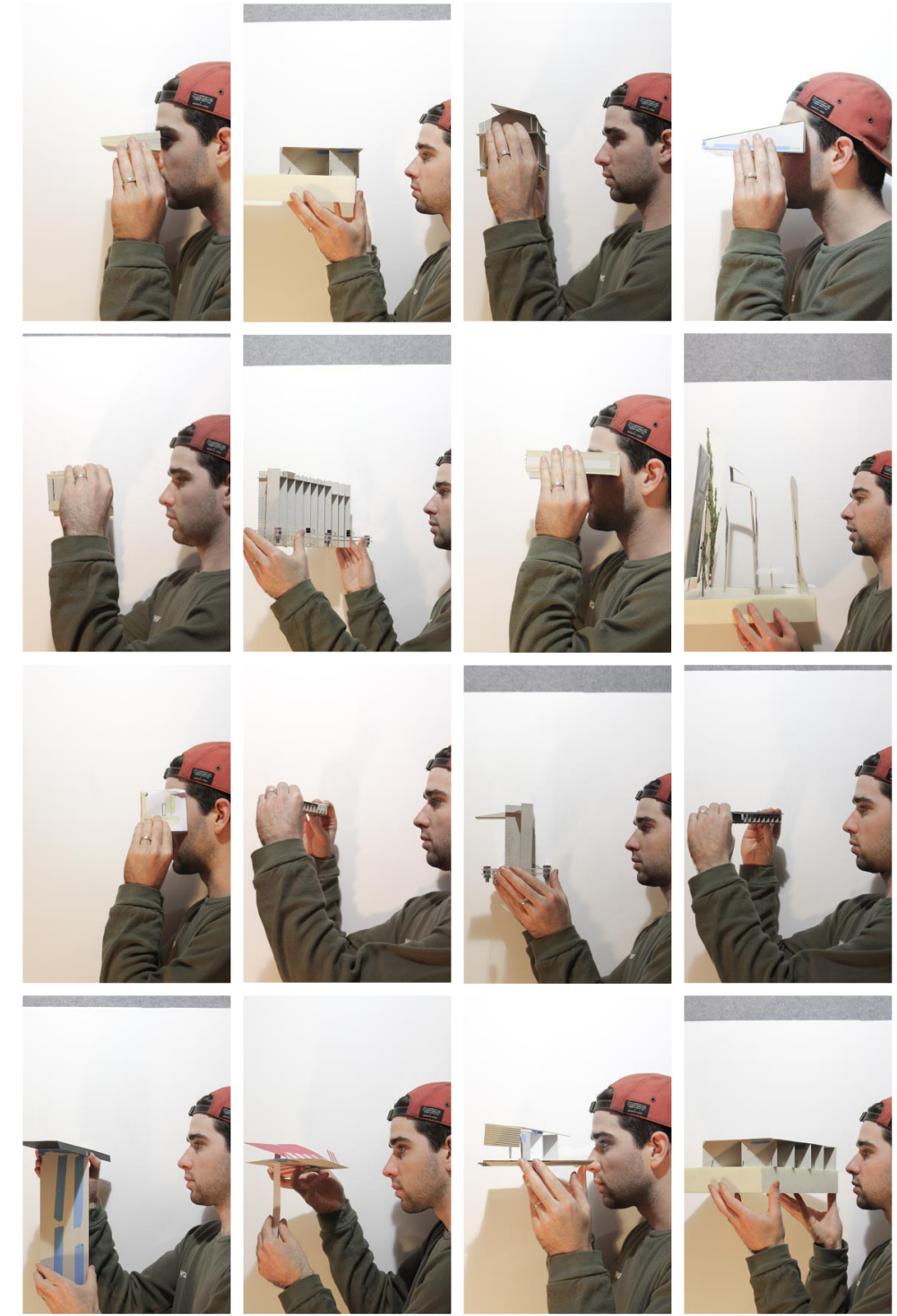

133. Device check matrix. Device prototypes 


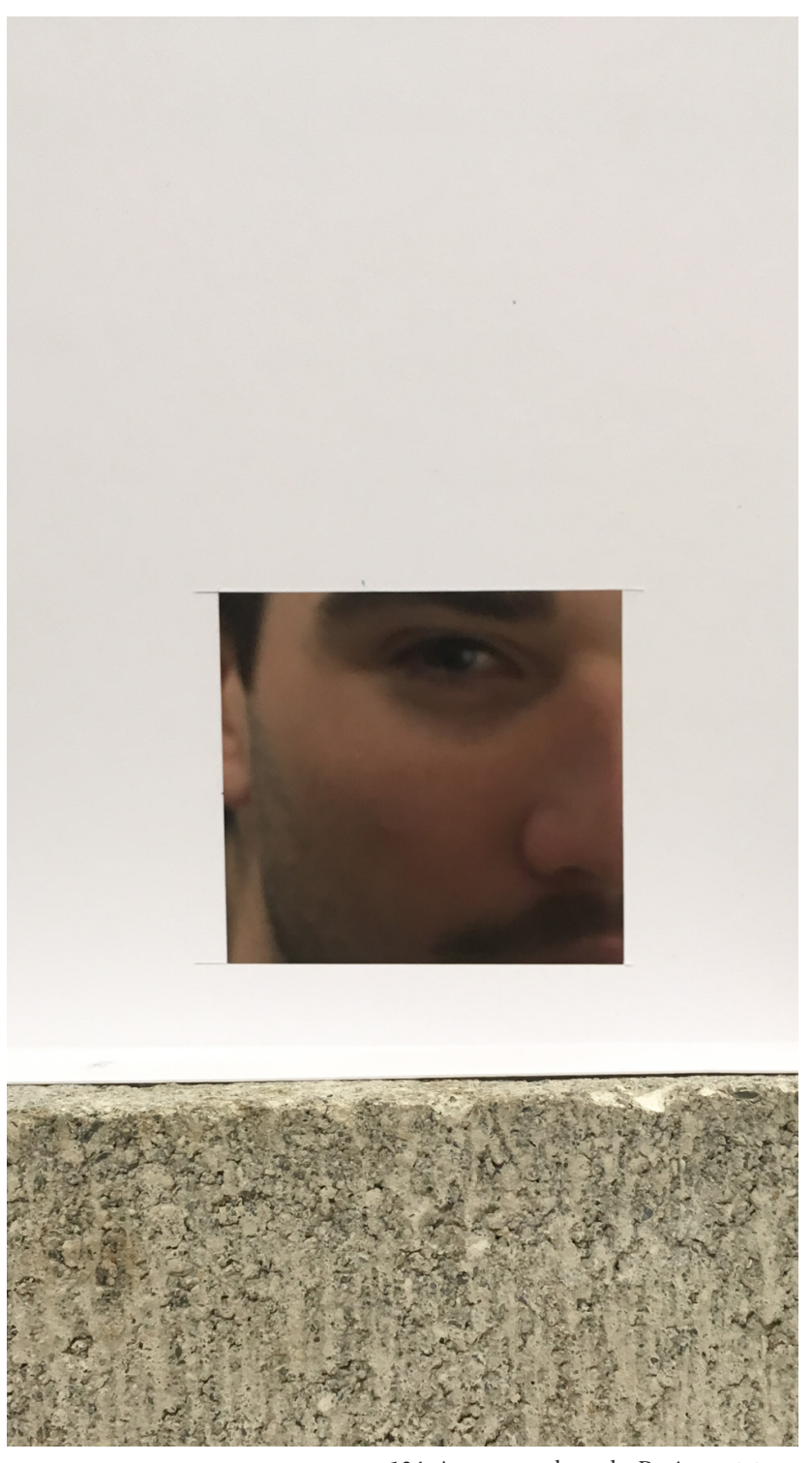

134. Aperture scale study. Device prototypes

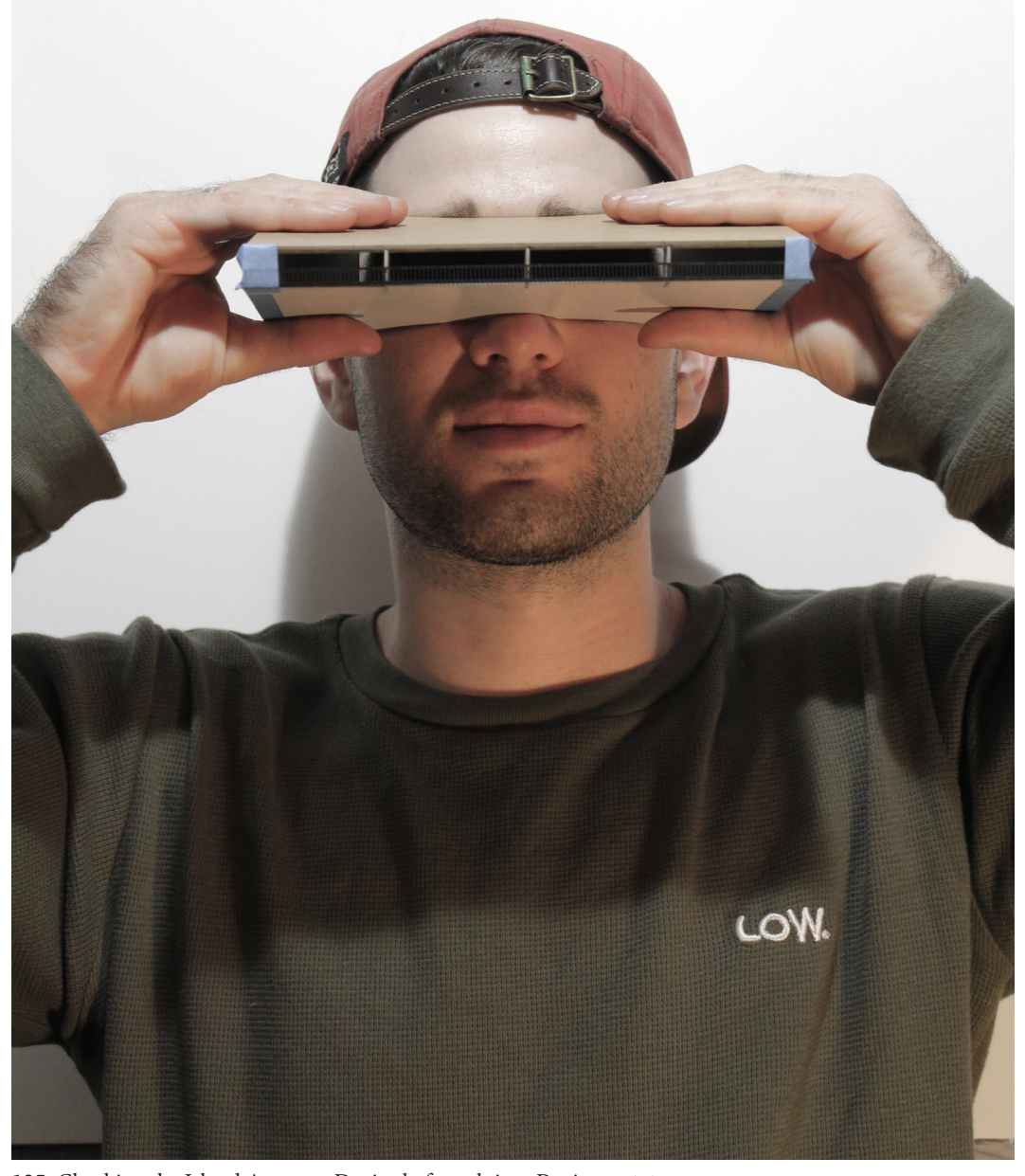

135. Checking the Island Aperture Device before gluing. Device prototypes 

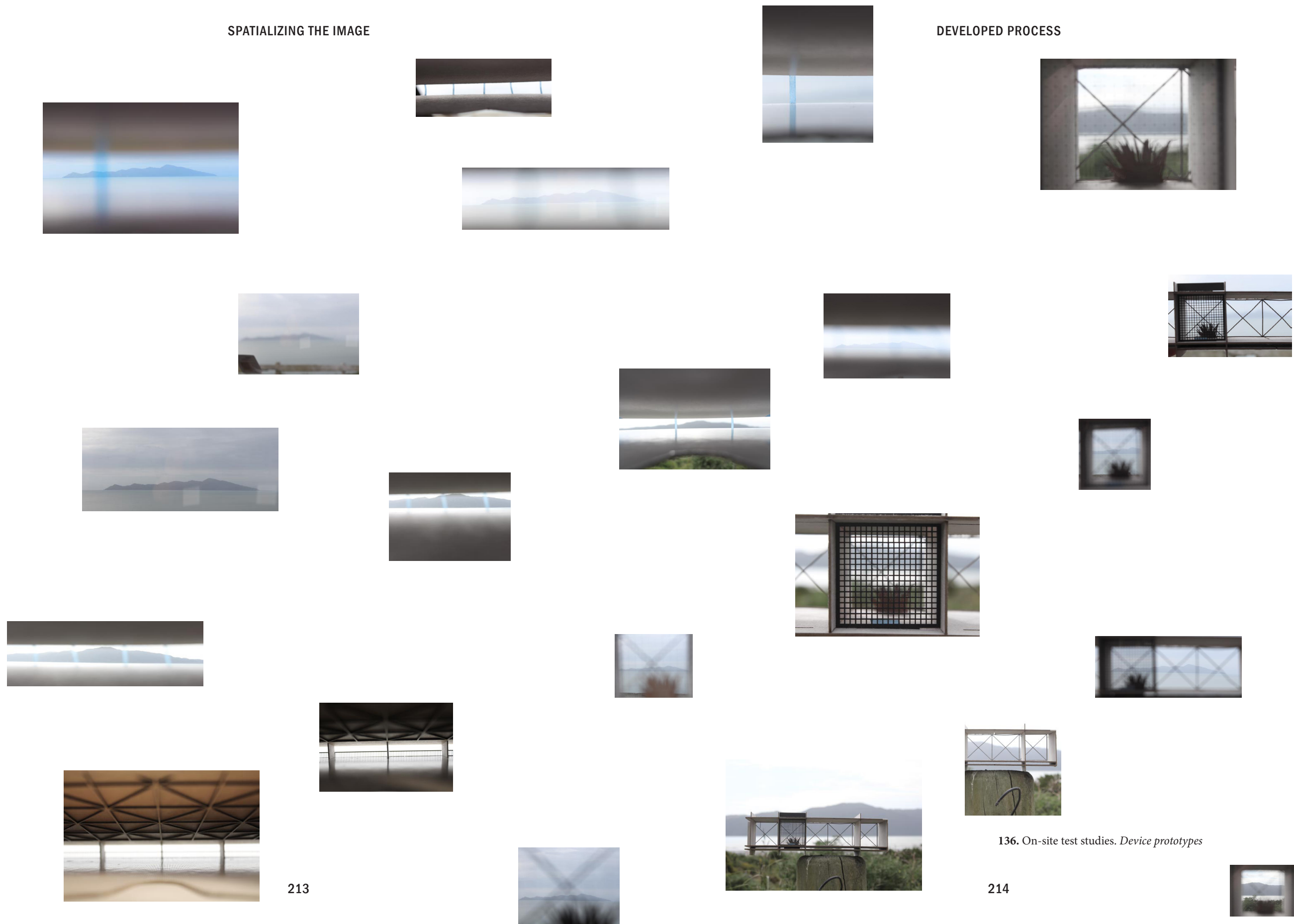

136. On-site test studies. Device prototypes 

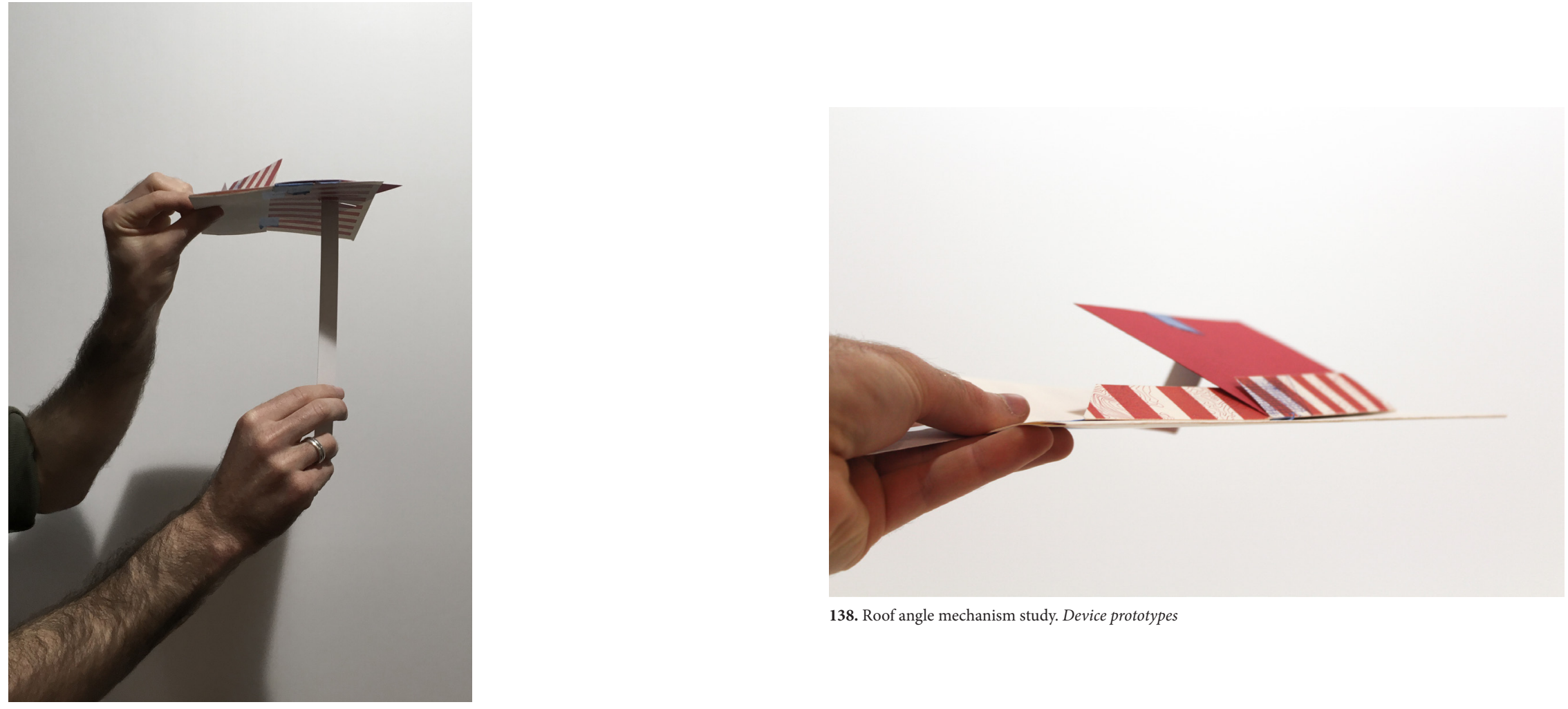

137. Testing roof angle slider. Device prototypes 

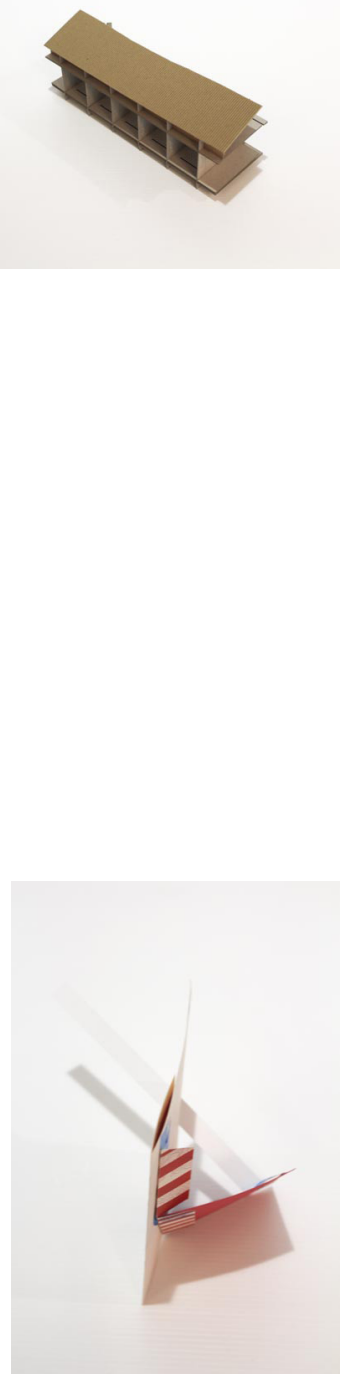
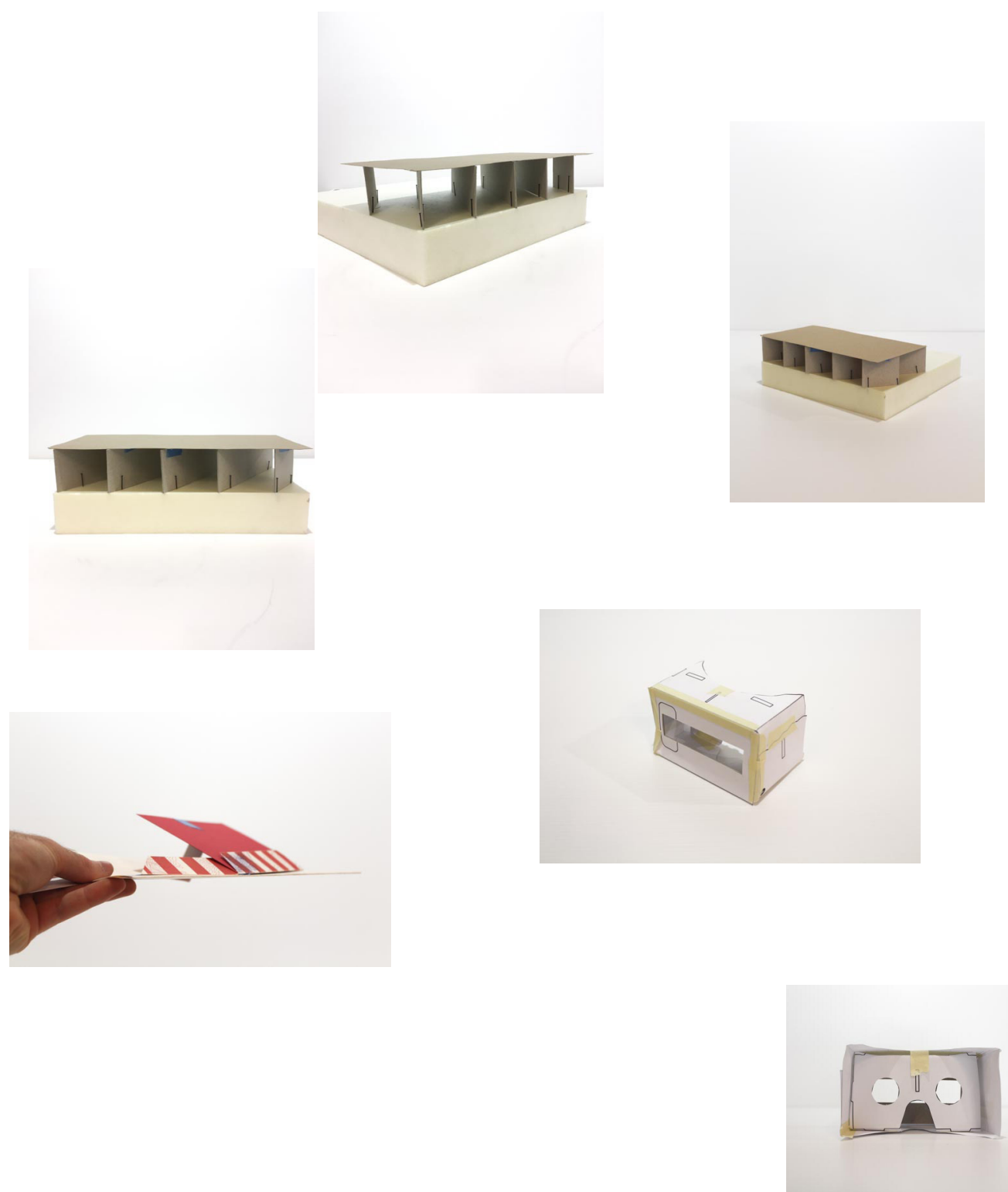
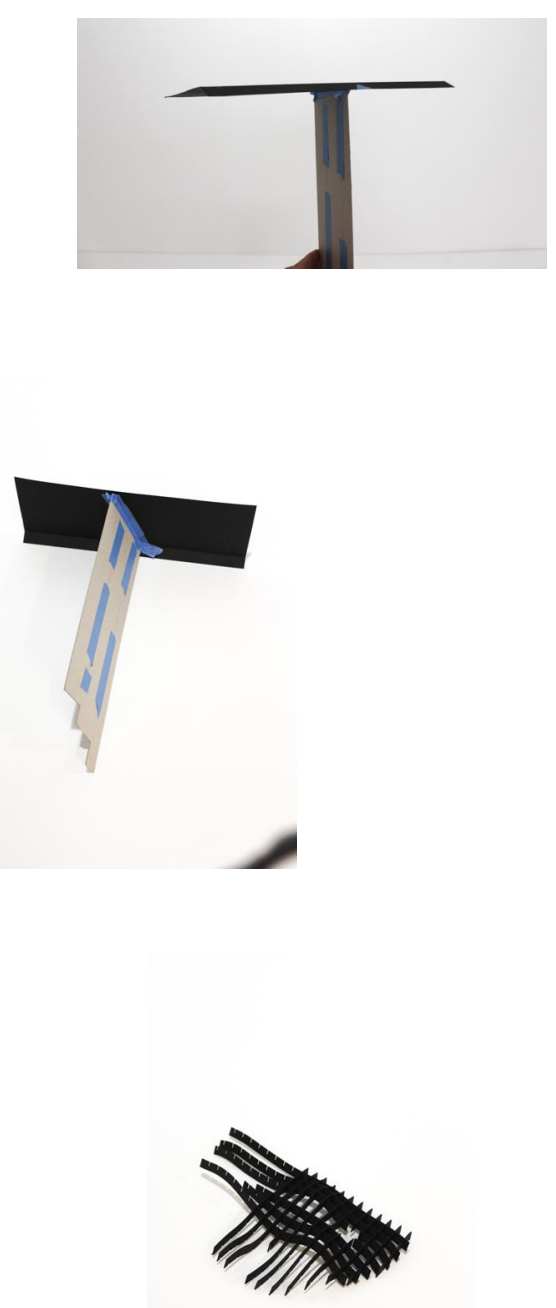

139. Test Devices. Device prototypes 

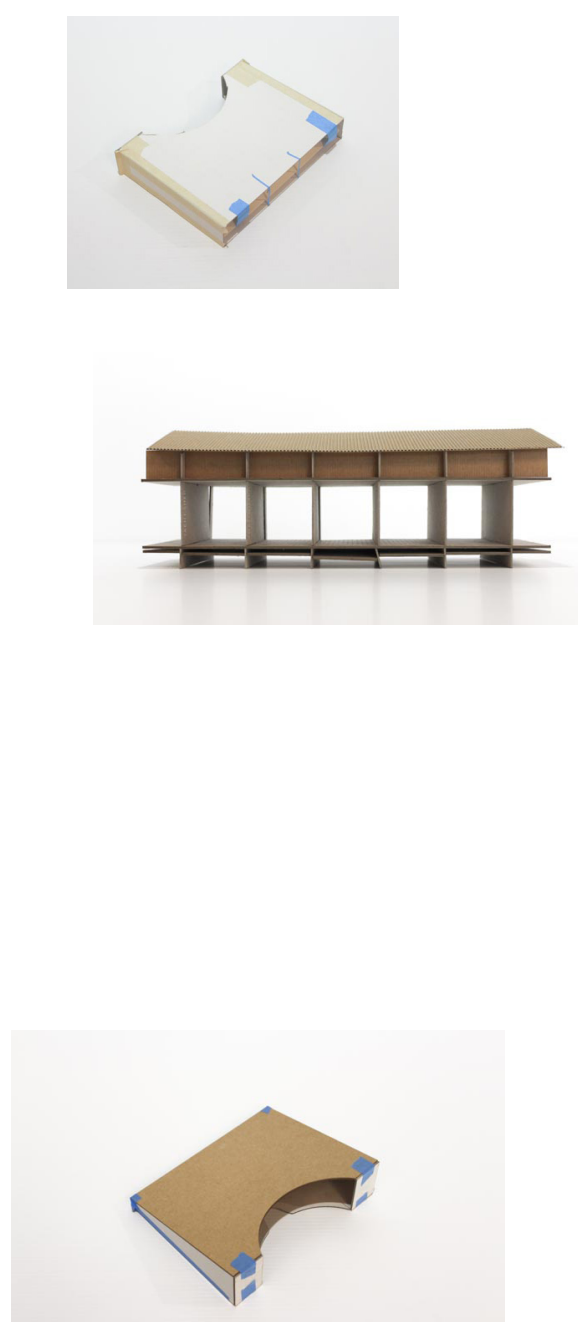

DEVELOPED PROCESS

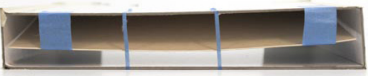

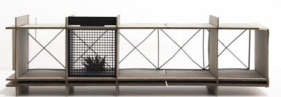
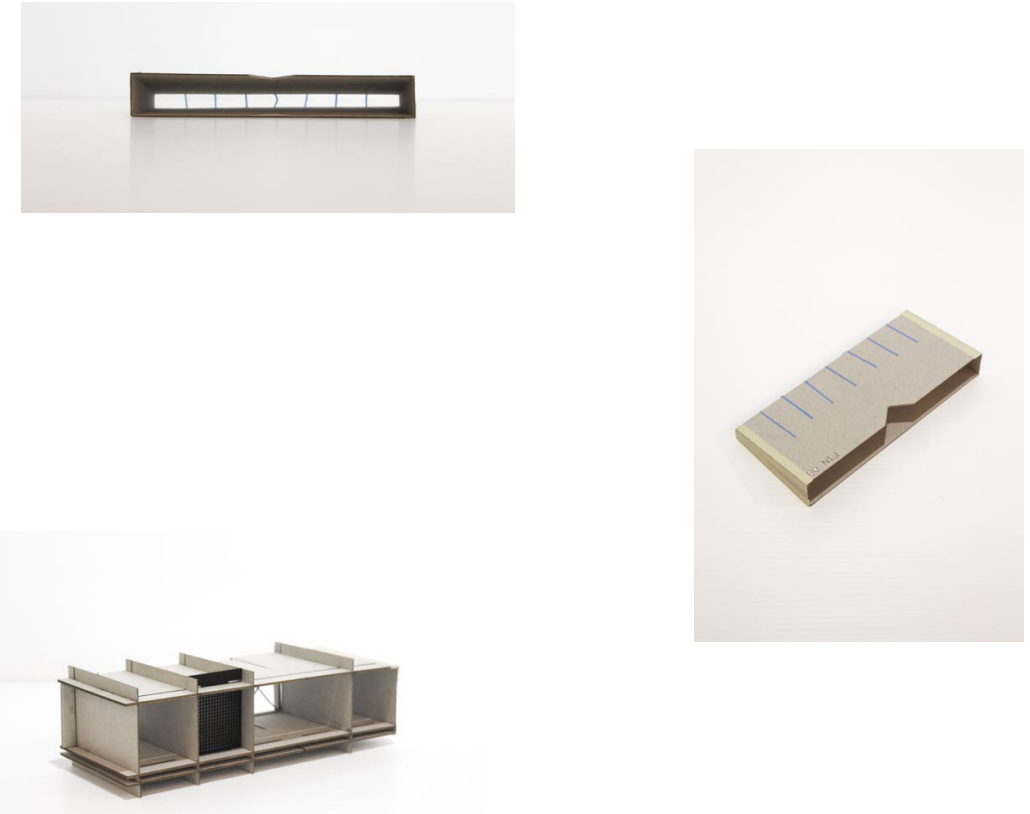


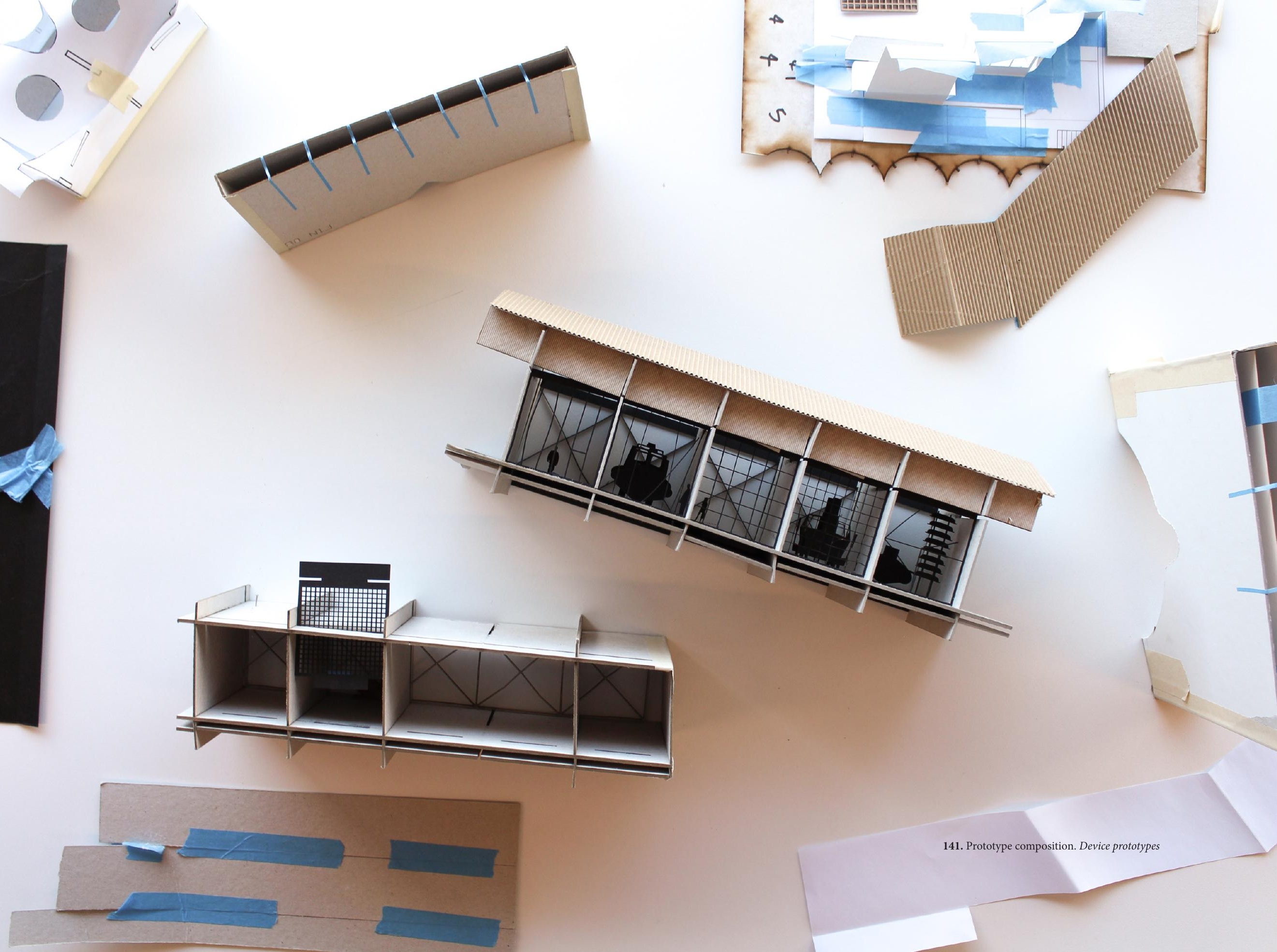


MATERIAL SWATCH DEVICE

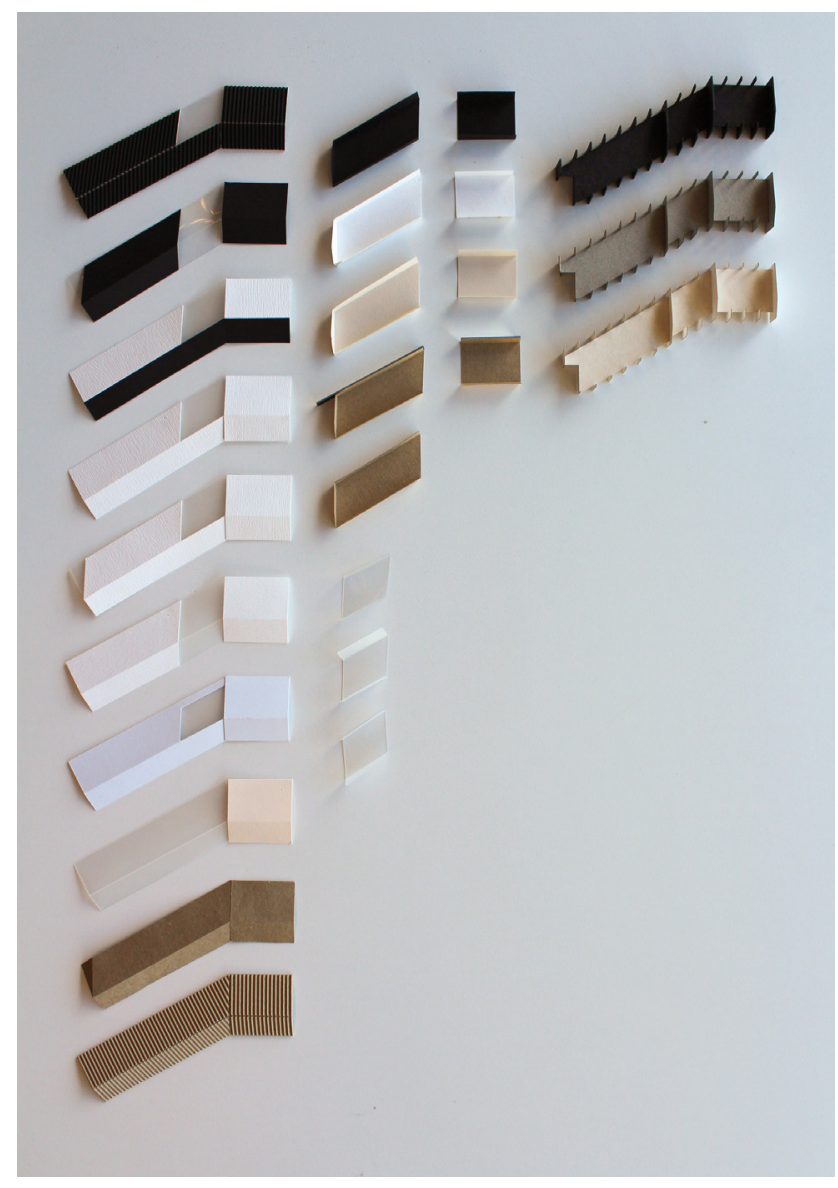

142. Component stocktake. Material Swatch Device 


\section{Material Swatch Device}

This device was used to determine the material and colour composition of the four main building elements; subfloor fins, walls, roof and the fernery glazing. 96 combinations were explored on site in relation to the context.

The selected combination was:

-White concrete subfloor fins

-Timber clad external walls \& highly reflective glazing -Powder-coated white steel roof

-Translucent polycarbonate fernery

This model was also used to consider the relationship between the roofline and Kapiti Island horizon, as viewed from site. 


\begin{tabular}{|c|c|c|c|c|c|c|c|}
\hline 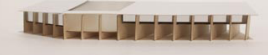 & 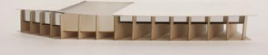 & 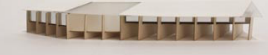 & 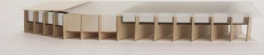 & 品 & 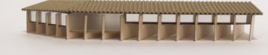 & 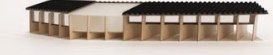 & 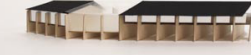 \\
\hline 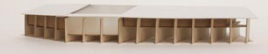 & 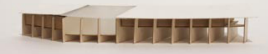 & 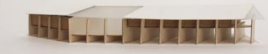 & 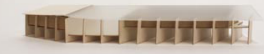 & 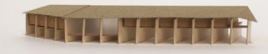 & 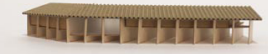 & 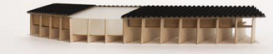 & Withent \\
\hline 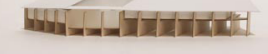 & 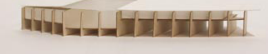 & 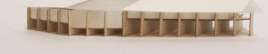 & 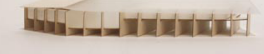 & 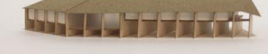 & 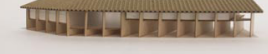 & minturit? & Firitivit \\
\hline 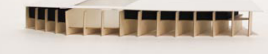 & 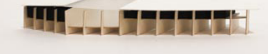 & 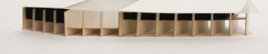 & 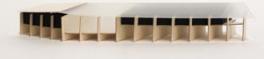 & 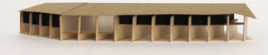 & 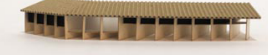 & A & thate: \\
\hline 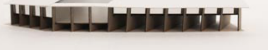 & 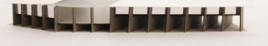 & 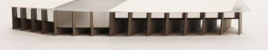 & 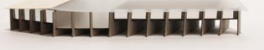 & 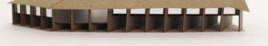 & 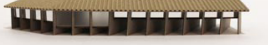 & 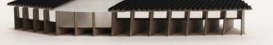 & 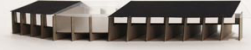 \\
\hline 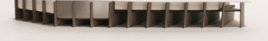 & 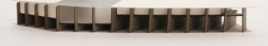 & 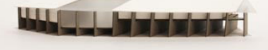 & 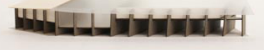 & 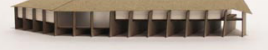 & 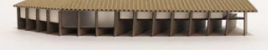 & Bentrivet & buts \\
\hline 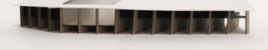 & 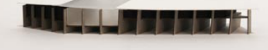 & 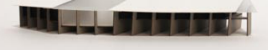 & 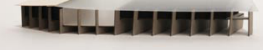 & 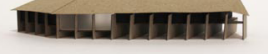 & 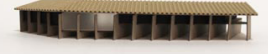 & Willinter & 배. \\
\hline Bas- & A & 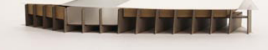 & 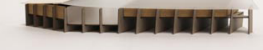 & 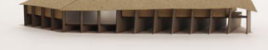 & 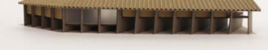 & Wrintert & \\
\hline 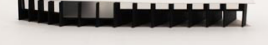 & un & un & unn & (16) & 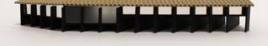 & 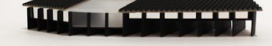 & -...- \\
\hline 1 & 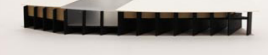 & 1 & 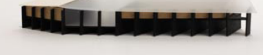 & 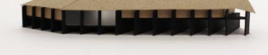 & mantom & (16) & aㅏㄷㅏ \\
\hline 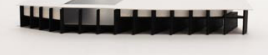 & 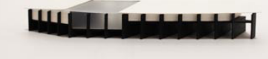 & 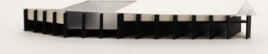 & 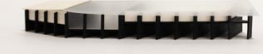 & 世ан & 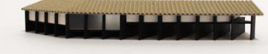 & 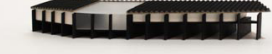 & $=-$ \\
\hline & menting & ty & Dat & man & man & كأس & \\
\hline
\end{tabular}




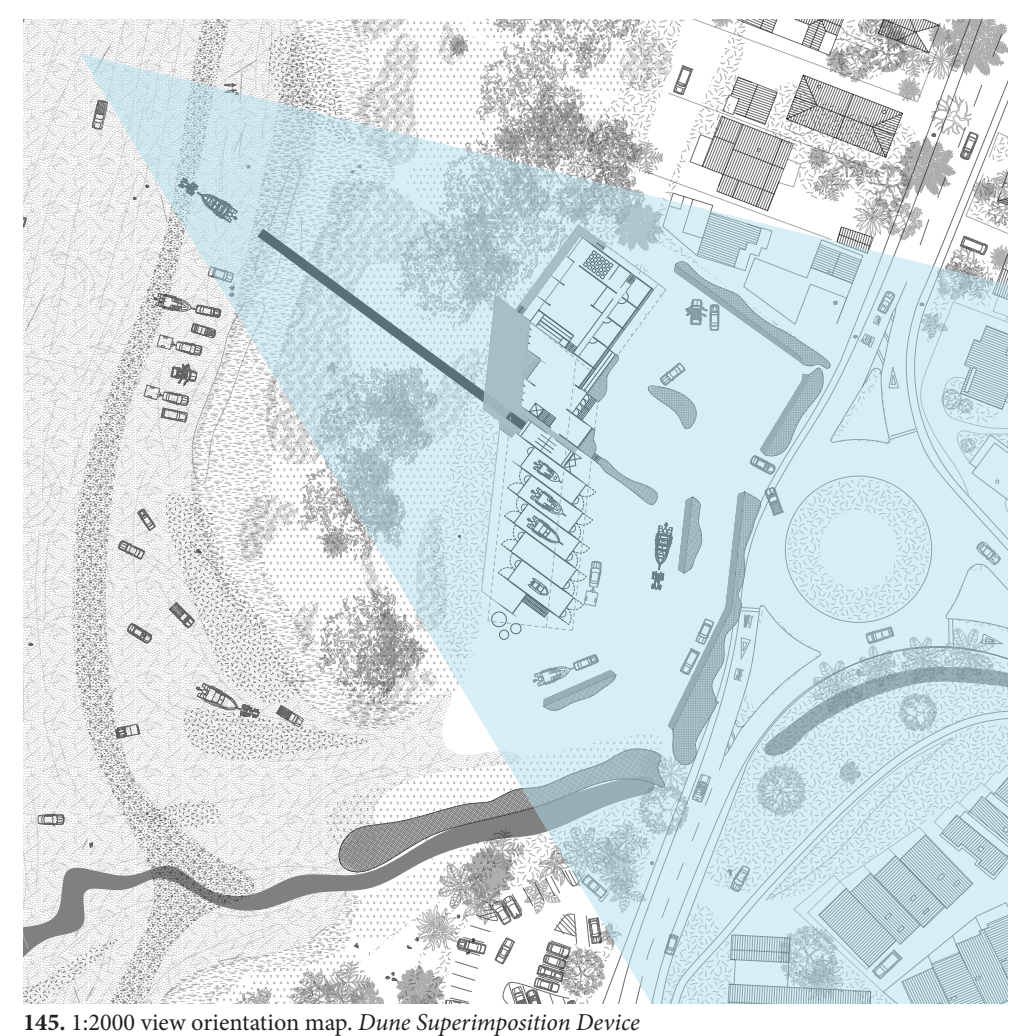




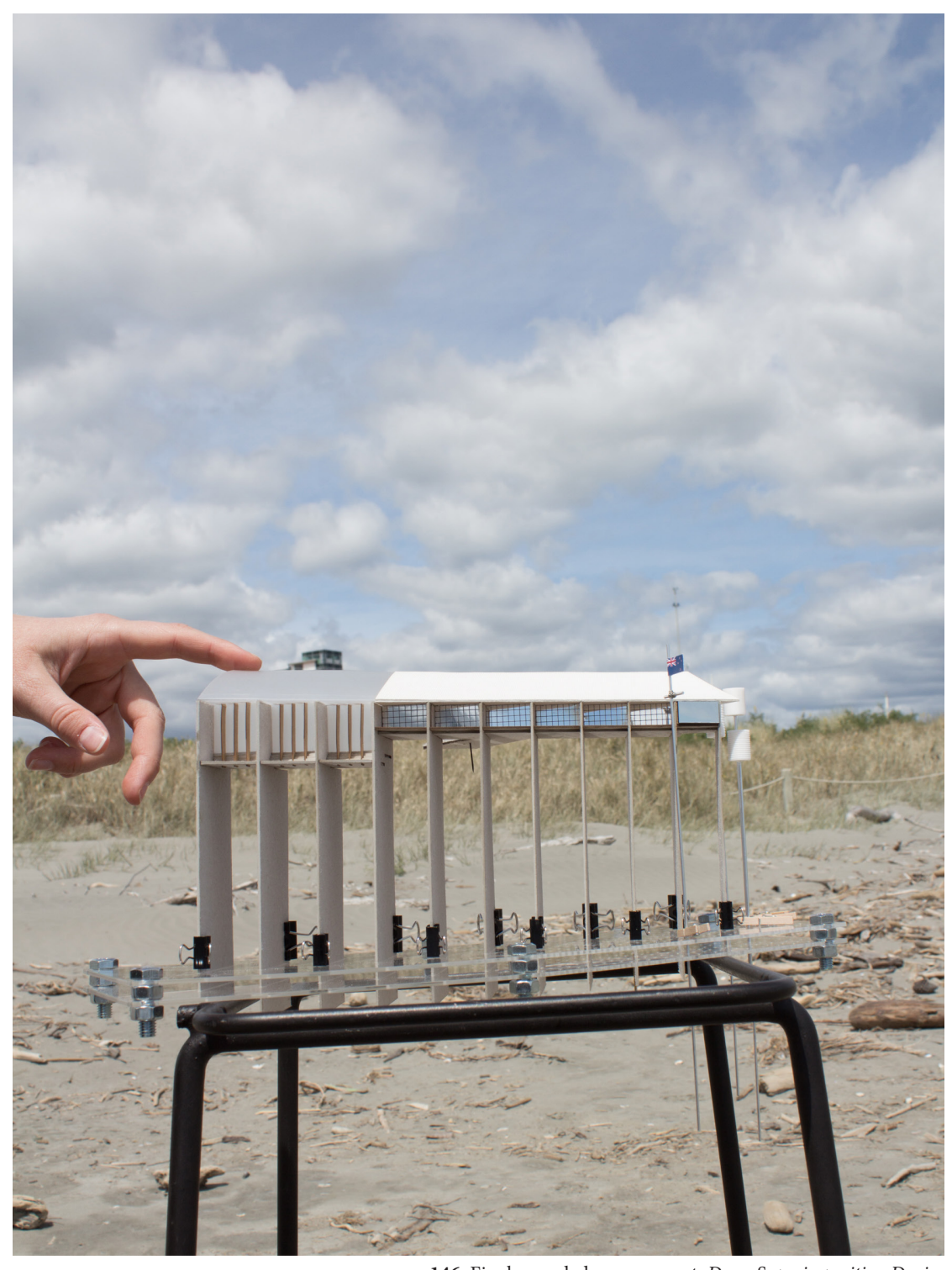

146. Final recorded arrangement. Dune Superimposition Device

\section{Dune Superimposition Device}

This device is designed to sit on Paraparaumu beach and be viewed through a camera lens looking east towards the site. Careful positioning of the camera allows the 1:200 device to be superimposed onto site and appear to be 1:1. Superimposition is described by Tom Porter as "the association of the size of juxtaposed forms with distance is an important depth cue related to the perpetual stance in which more distant objects appear smaller in relation to the viewers position in space" (2014, p.50). Once the device and camera were aligned, the adjustable components were shifted up and down as desired. This was used to determine the heights of architectural elements as well as the entire height of the building in relation to the dune system.

The primary spatial result of the device was the decision to shift the building back twelve metres from the apex of the dune. This allowed the dune to block the view of the less aesthetic boatsheds on the ground floor. Other results of the device were setting the roof pitch to $15^{\circ}$, placing the comms room on the far right-hand bay, and setting the heights of the flagpole and water tanks. 

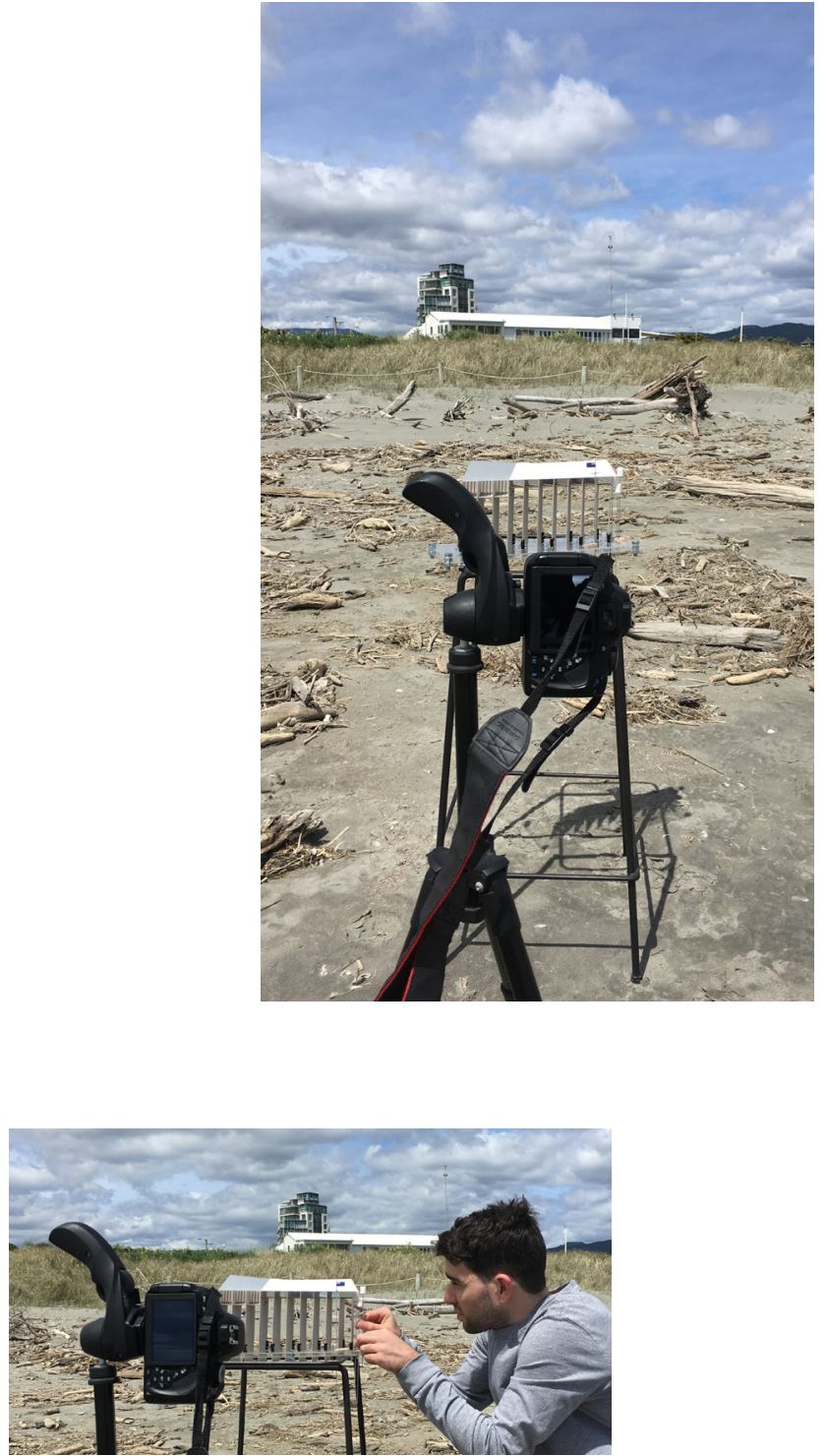
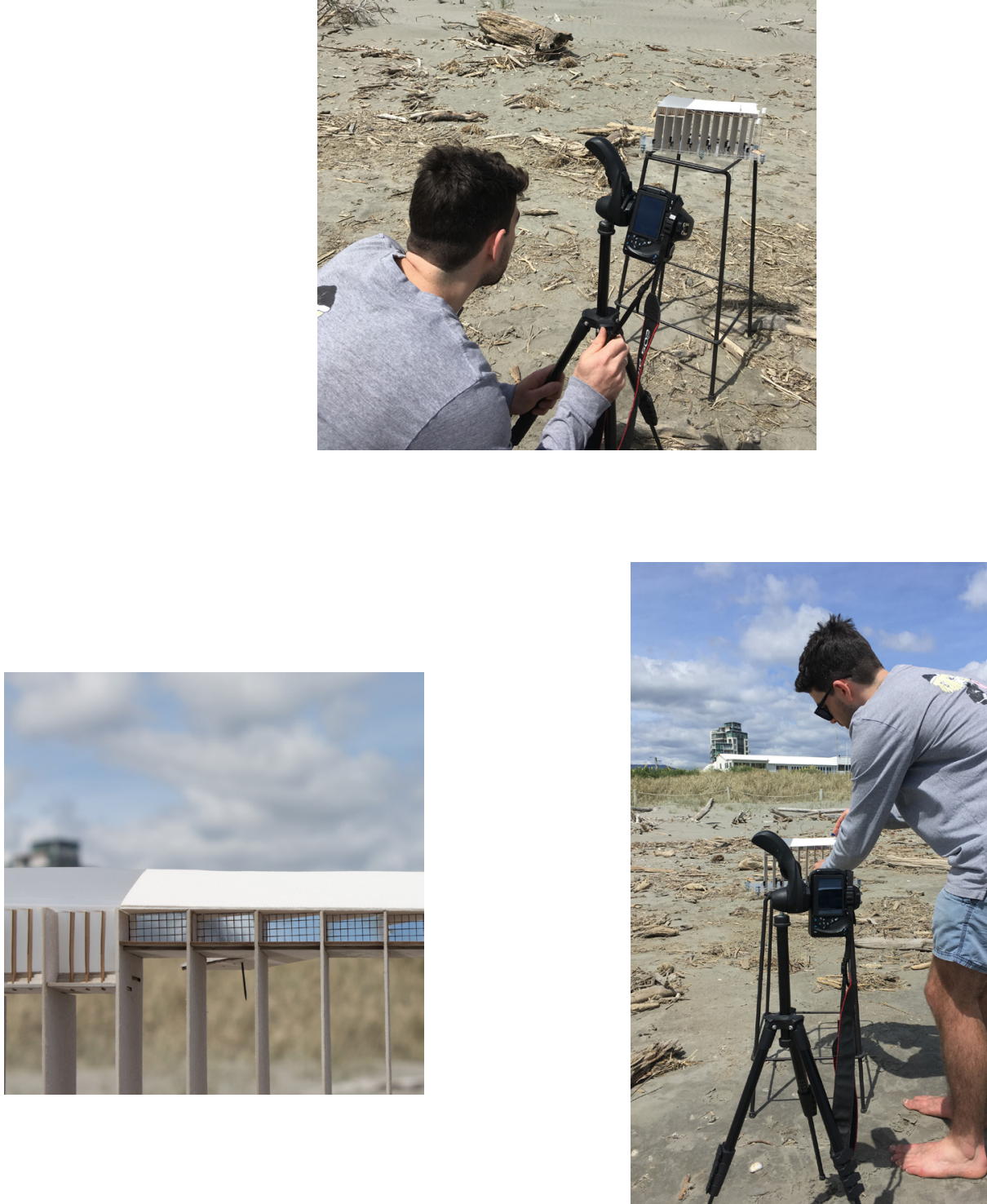

147. On-site operation series. Dune Superimposition Device 


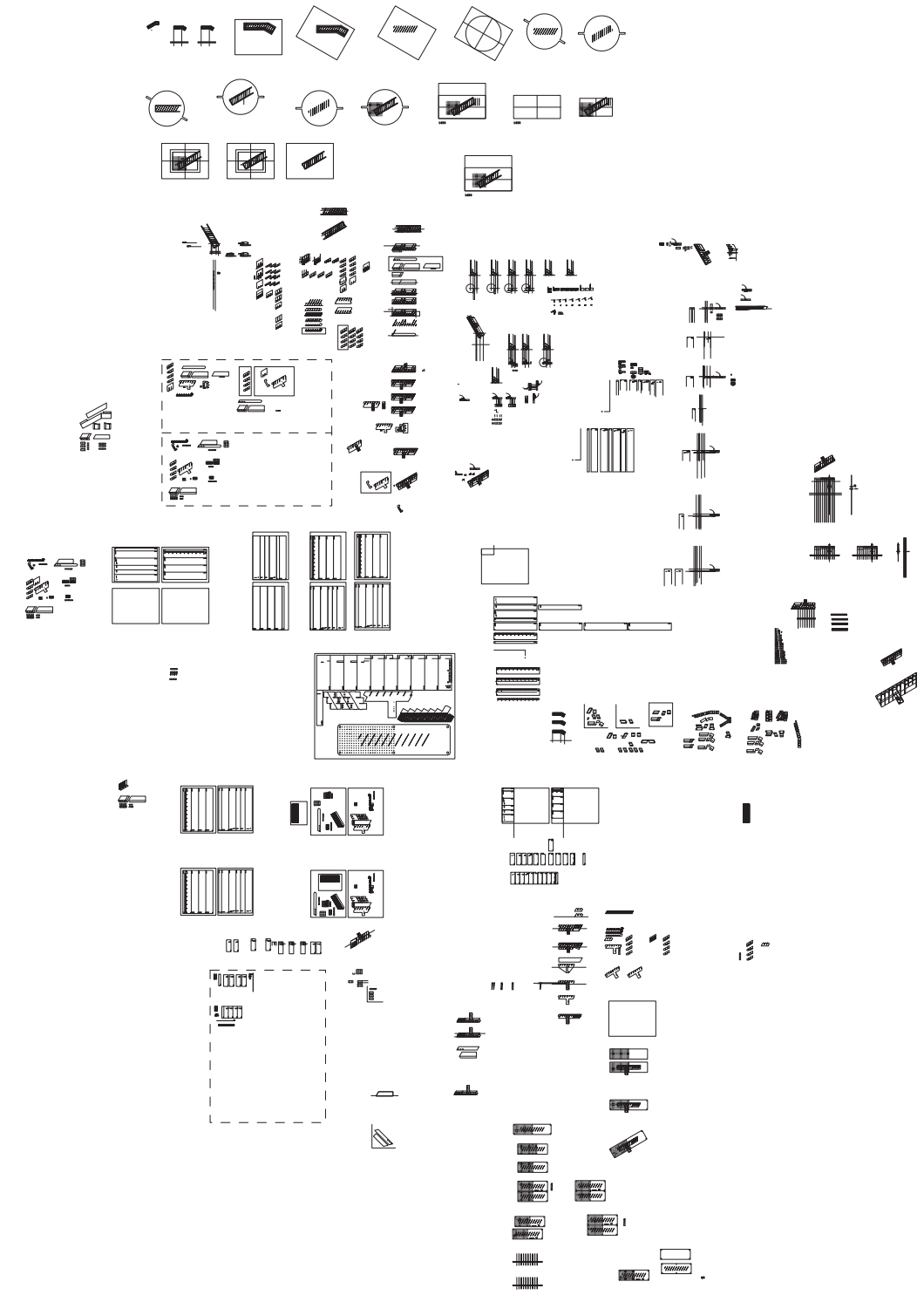

148. CAD design file. Dune Superimposition Device

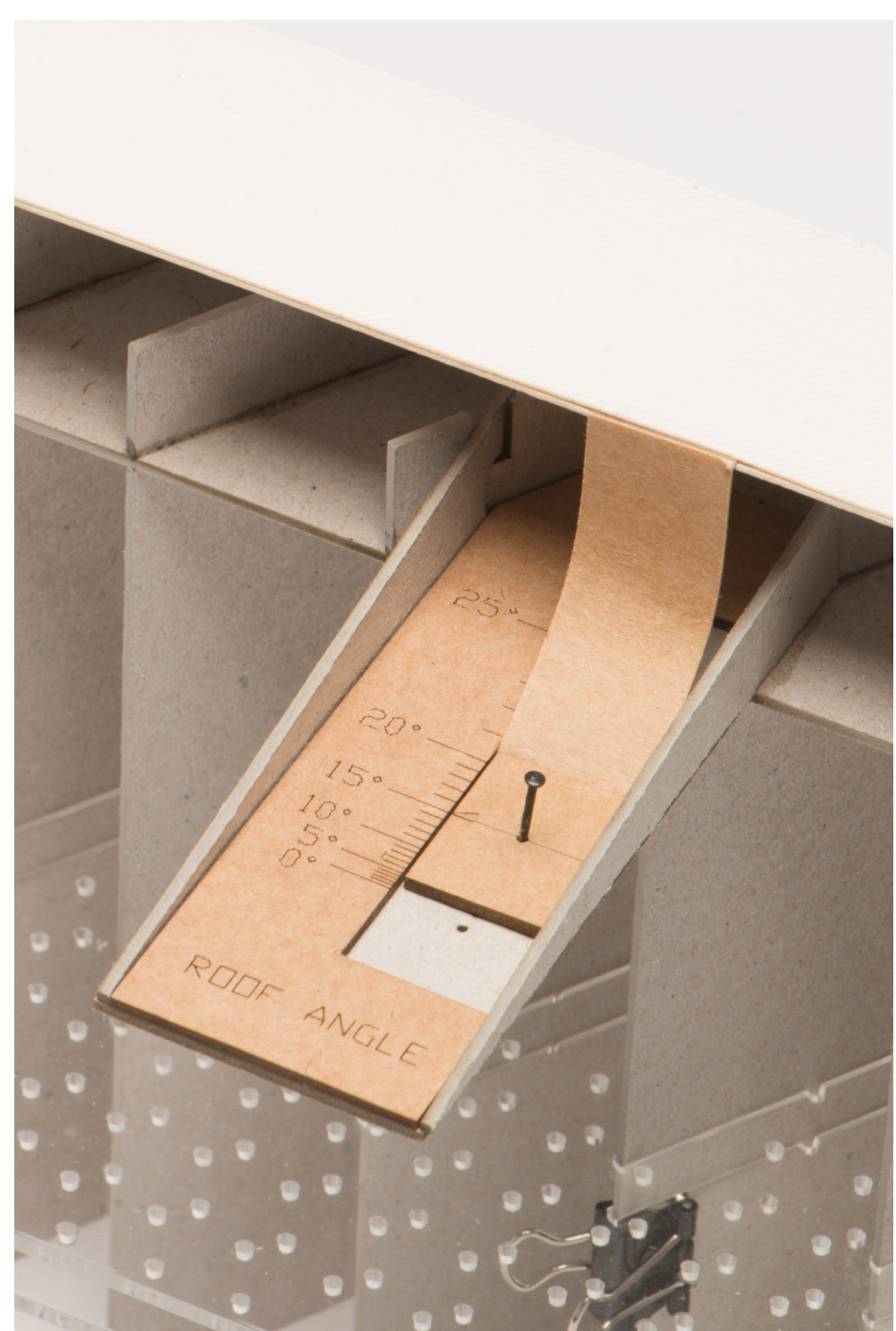

149. Roof angle control mechanism. Dune Superimposition Device 


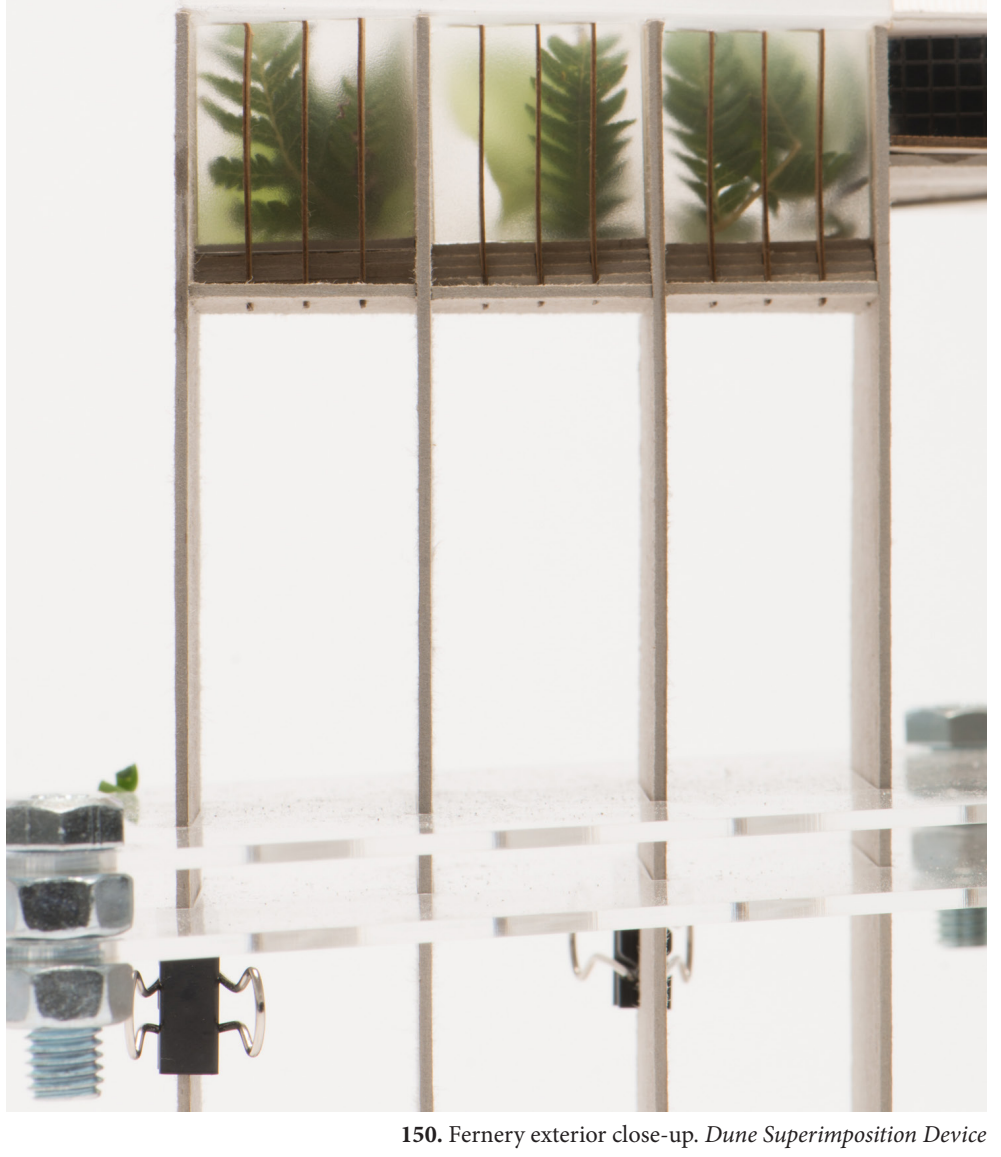

237

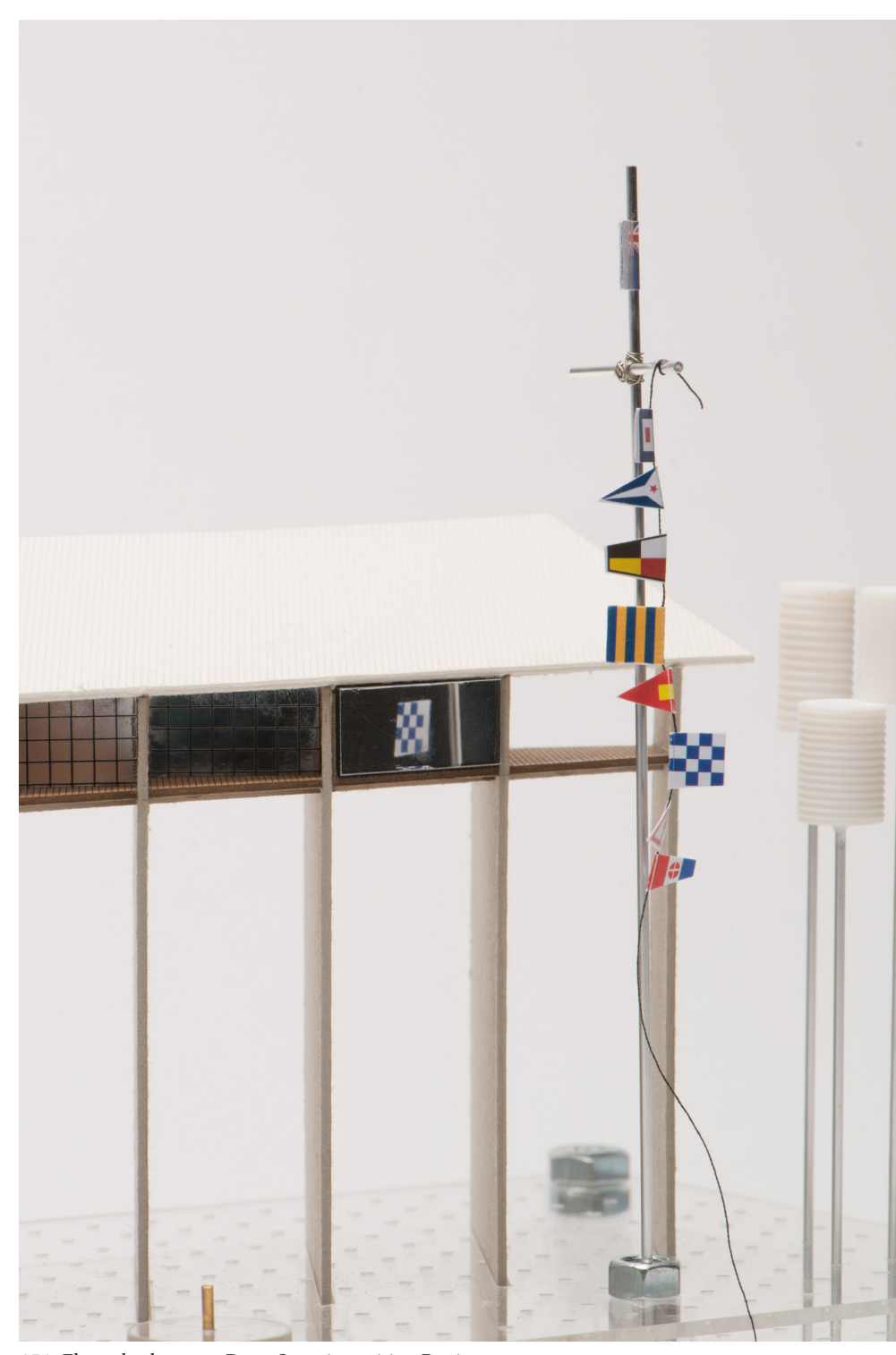

151. Flagpole close-up. Dune Superimposition Device 


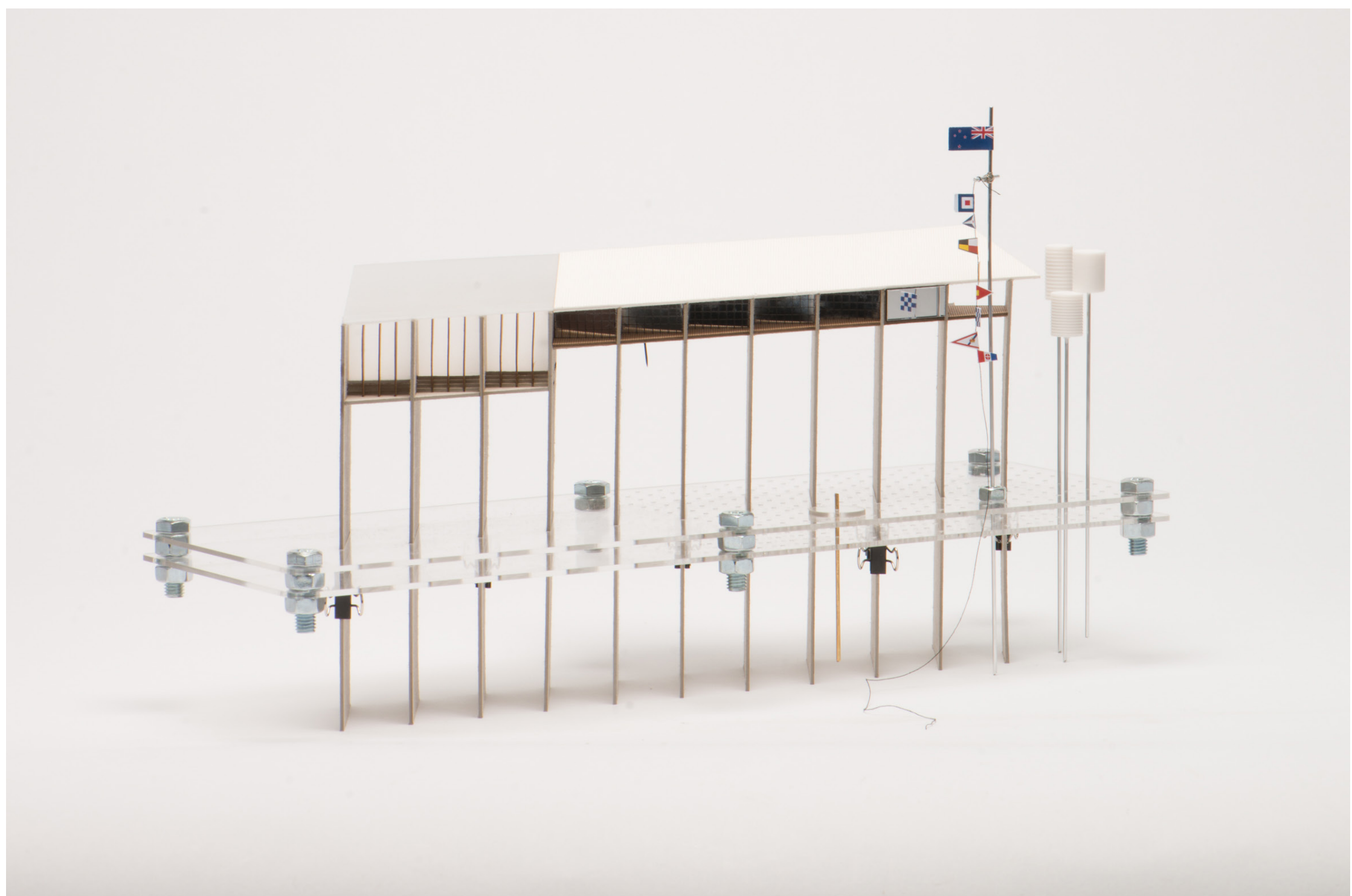




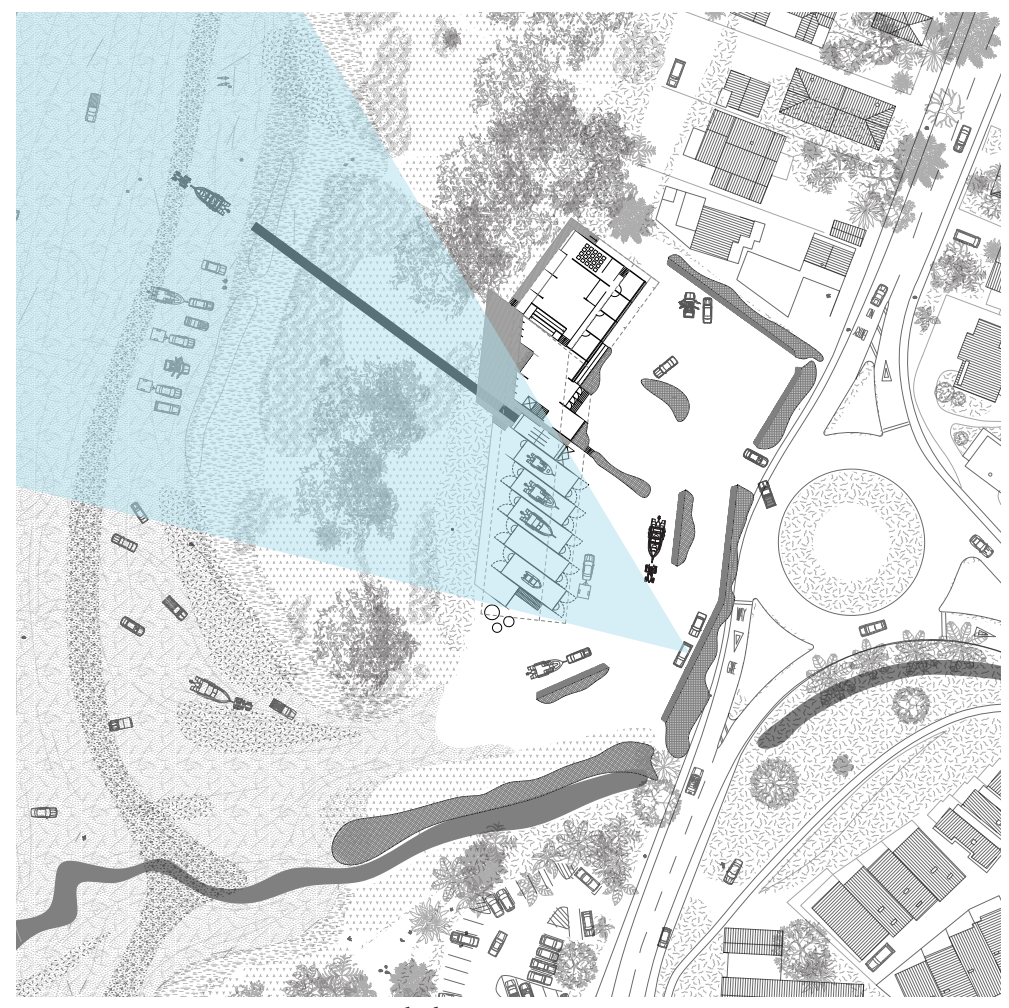

153. 1:2000 view orientation map. Boatshed Viewing Device 


\section{Boatshed Viewing Device}

Kapiti Island is a landmark, beacon, attraction and a guardian of the Kapiti region. Kapiti Coast local Chris Mclean suggests that "Islands have a fascination born of their isolation their inaccessibility, and the mystic of Kapiti is accentuated by its dramatic physical features" (1999, p.8). The Boatshed Viewing Device explores how the configuration of the boatsheds can react to the commanding view of Kapiti Island. Early explorative models revealed that long concrete fins could form the space and structure of the boatsheds. The benefit of using fins as opposed to stilts for transparency was not only for structural and functional purposes. The concrete fins are a mechanism which both offer and deny transparency based on their orientation.

The primary focus of the Boatshed Viewing Device was to explore the optimum orientation of the boatshed fins. The selection process involved evaluating which orientation and location offered the best view of Kapiti Island. An orientation of approximately $320^{\circ}$ (northwest) was selected from site analysis.

Held up to the face of its user the device is designed to be used as perception altering headwear on-site. Operation involved wandering around site and considering the Island view as seen through the transparent boatsheds. The desired position and orientation were recorded by GPS and compass. Once in position two-dimensional figures representing the various shed programmes were placed and shifted around to determine what the most aesthetic use of each shed would be. This was recorded through photography (fig 155).
The resulting fin layout forms the structural grid and overall organisation of the entire design. Tapering at each end the fins are seemingly thin and delicate while remaining thick enough in the centre to provide the required structural attributes. Views through fins offer a controlled image of the island that is aligned, proportioned and cropped just like a photo.

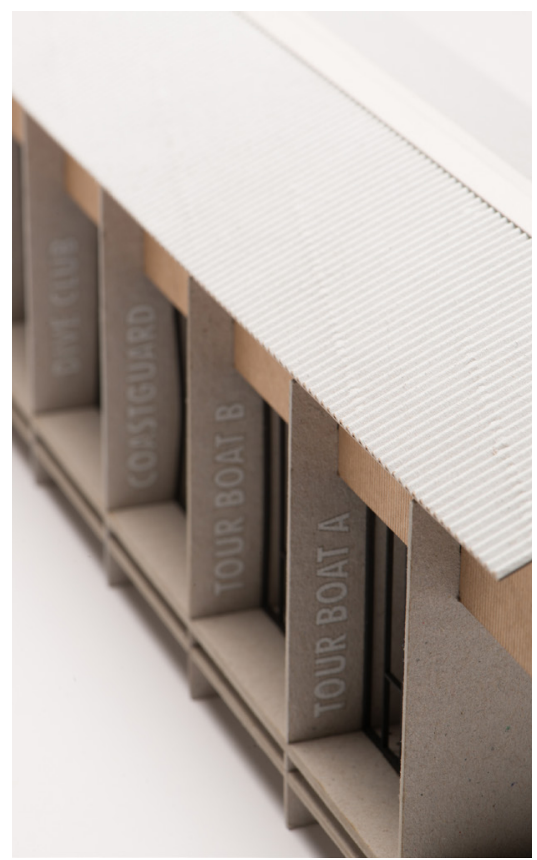

154. Boatshed signs. Boatshed Viewing Device 


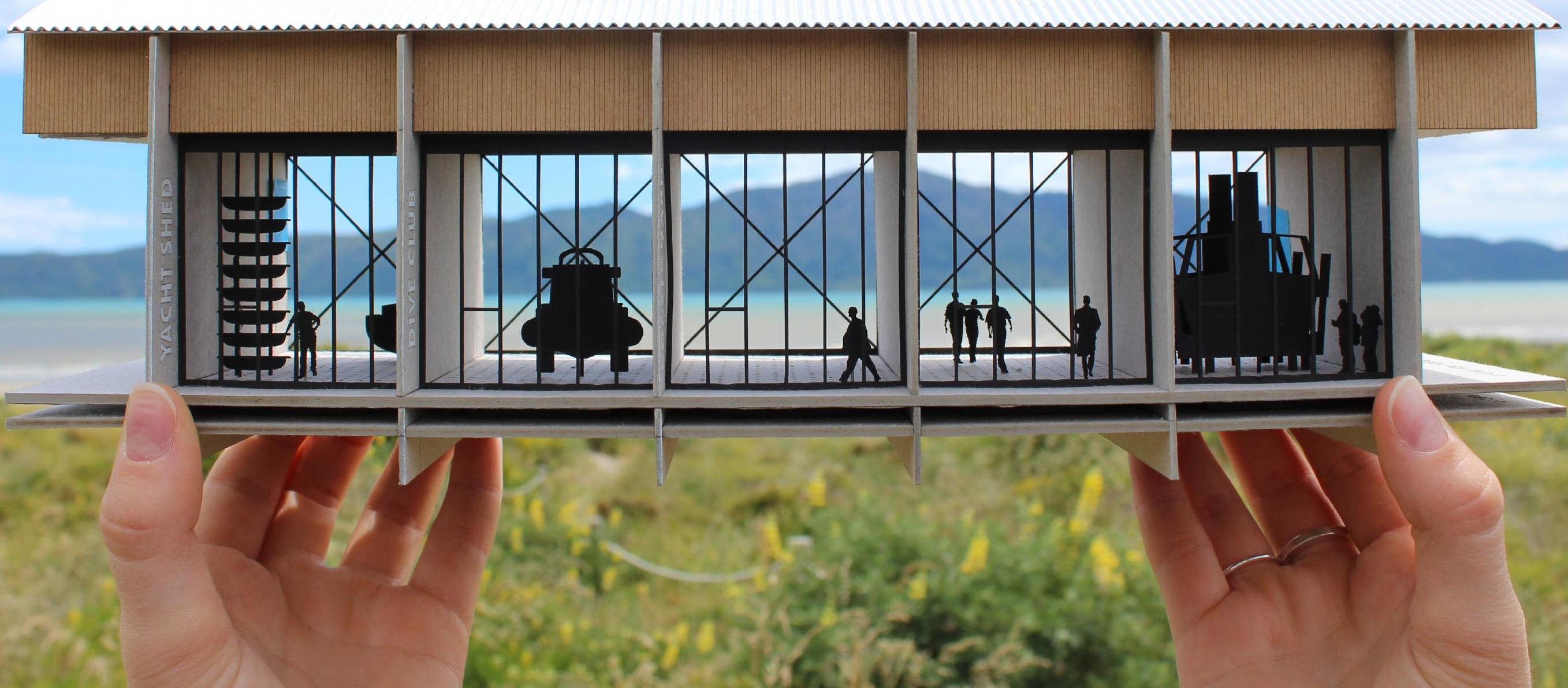




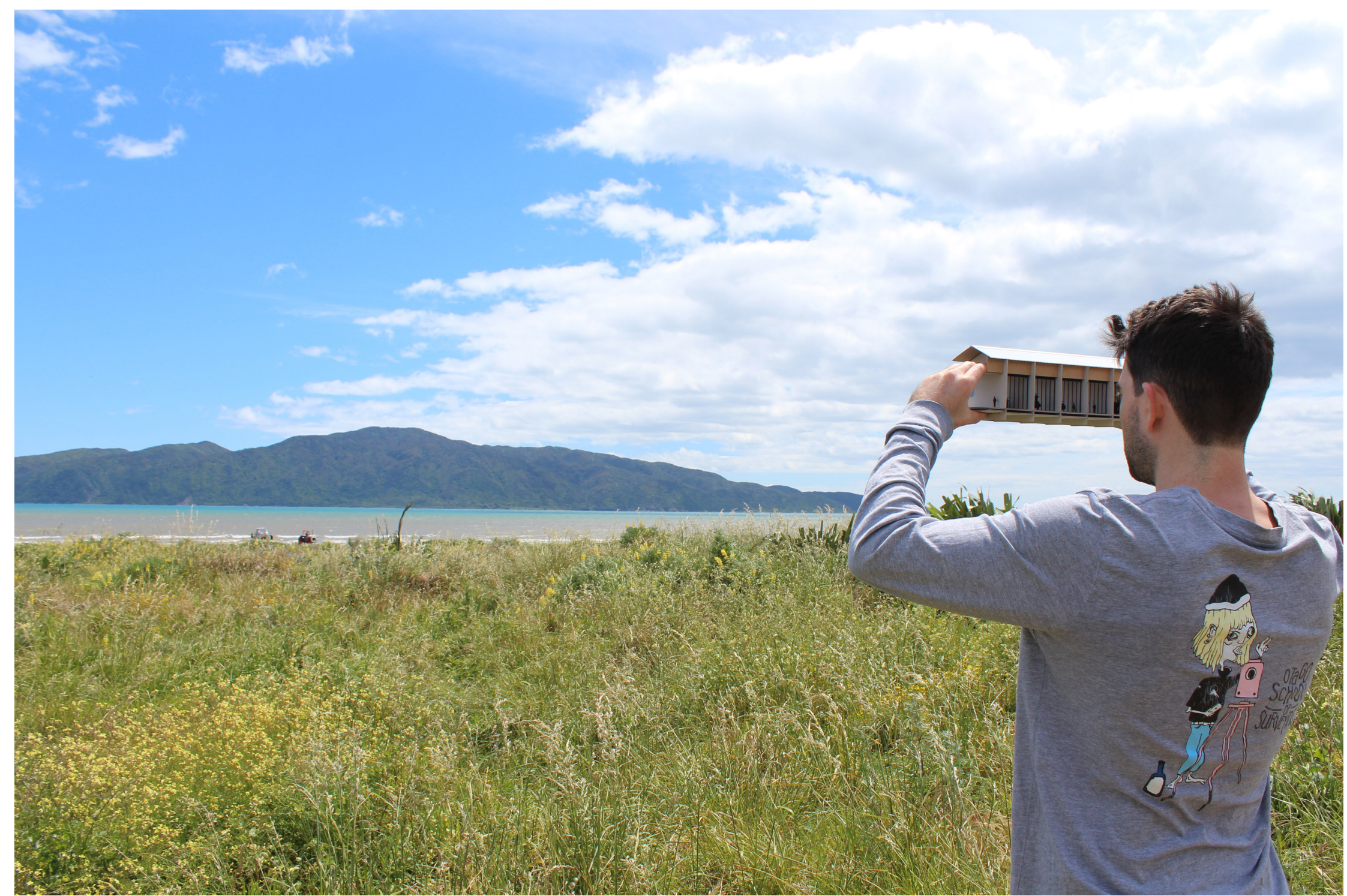



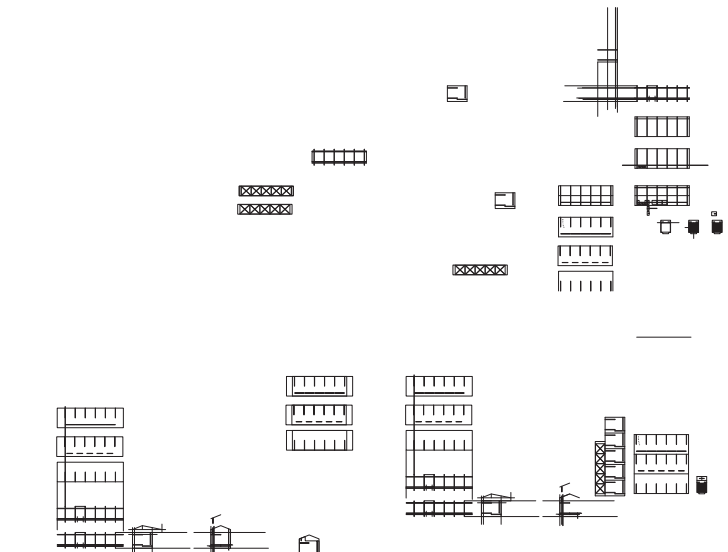

白

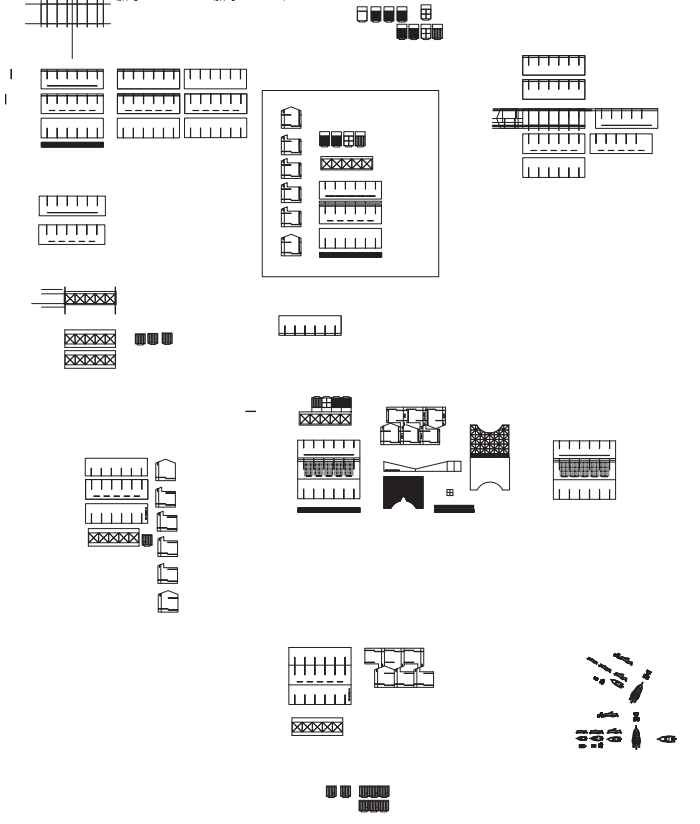

157. CAD design file. Boatshed Viewing Device

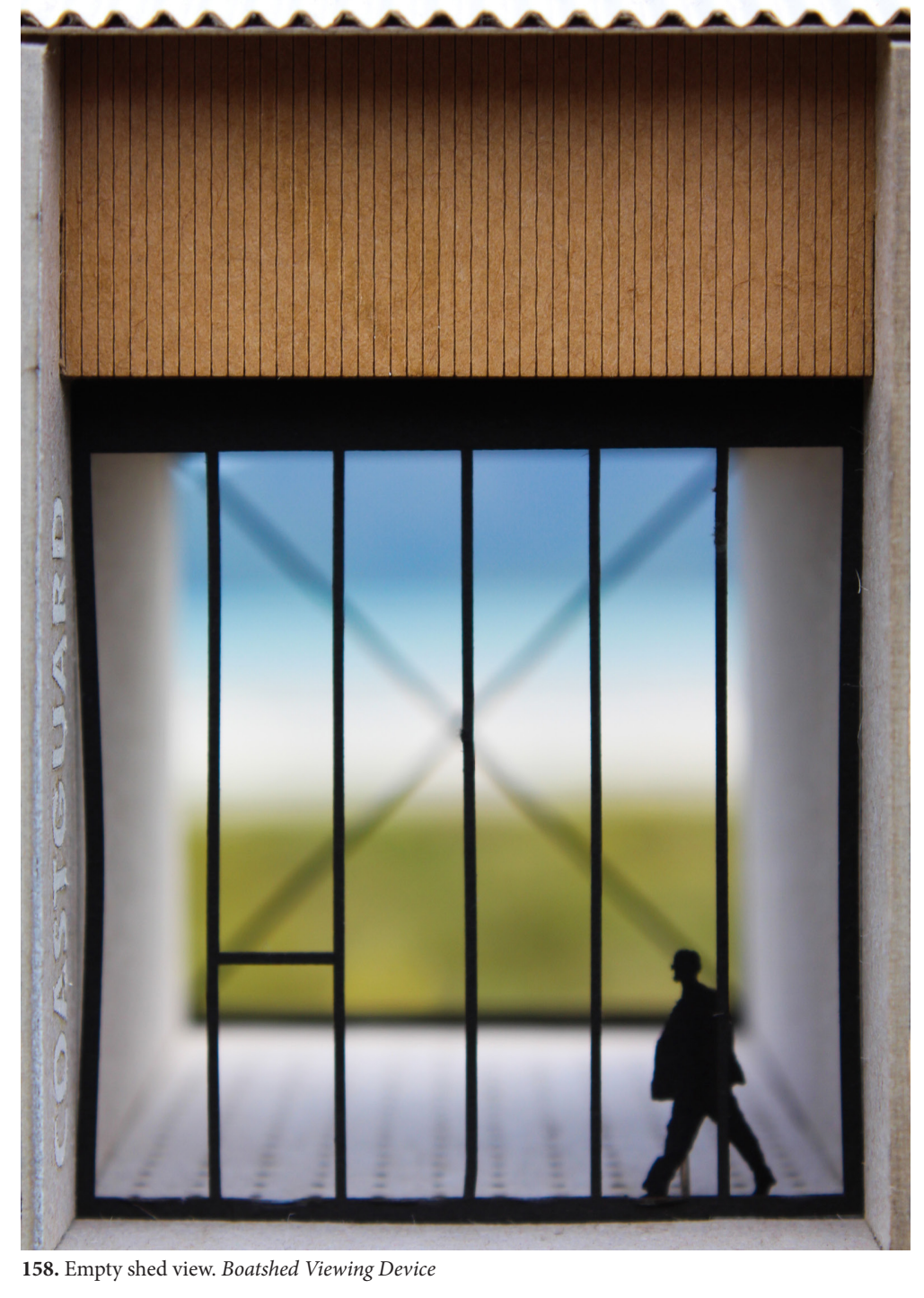

250 


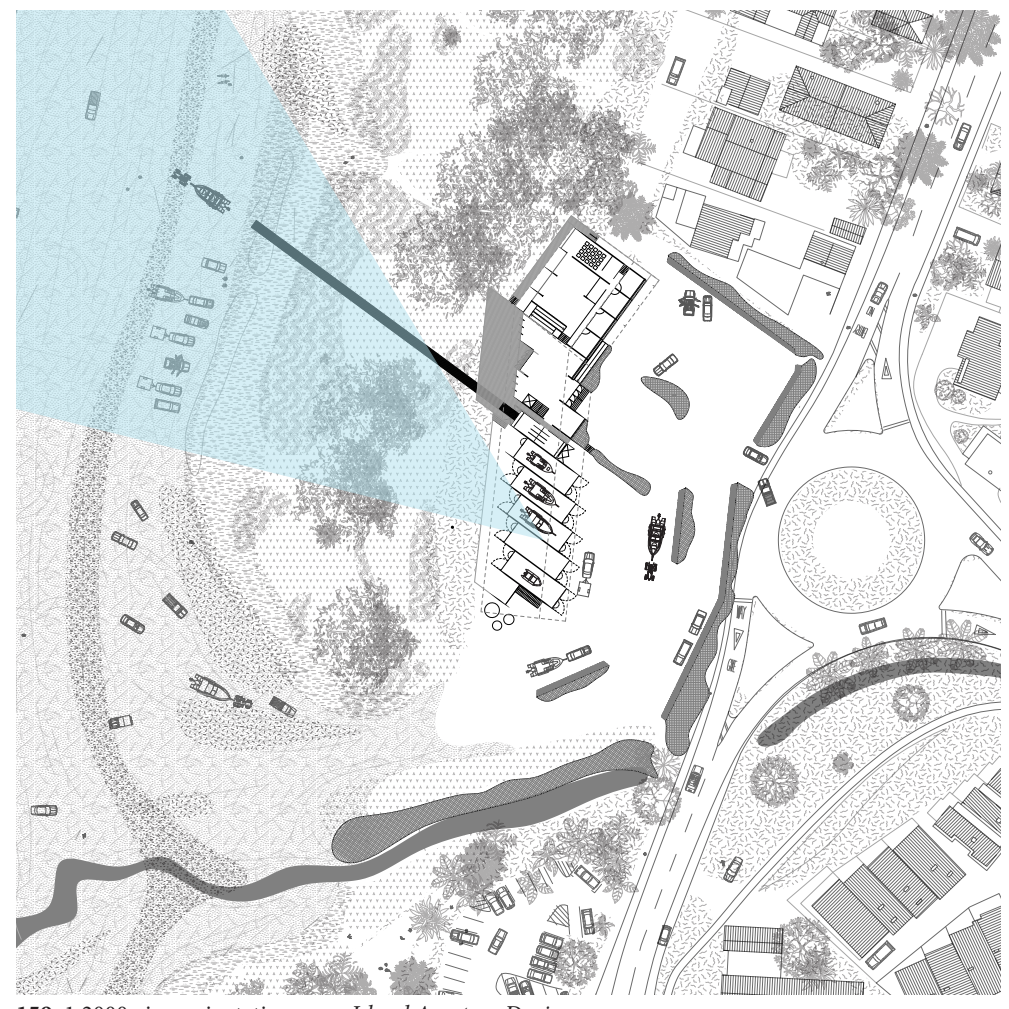

159. 1:2000 view orientation map. Island Aperture Device 


\section{Island Aperture Device}

Similar to the Boatshed Viewing Device, the Island Aperture Device explores how the view towards Kapiti Island can be effectively framed and cropped. This device considers the view from the top floor, looking out from the Boat Club main hall. Smout and Allen describe their 'panorama landmarks' to be "about the horizon and architecture - about the place of the horizon in architecture" (Superscape, 2013, p. 125). This device has a similar focus but also considers the Kapiti Island silhouette. Multiple prototype devices were developed to explore aperture dimensions and different roof forms. The final device, Island Aperture Device 03 represents the chosen attributes. Rather than offering tall glazing with a roof pitch opening to the view this device presents the opposite. Early device studies revealed the strength to a cropped view of the island which follows its long low form. This was created using full height $2.7 \mathrm{~m}$ tall glazing with large eaves pitched towards the beach.

Operation involved holding it up to the eyes while walking around and viewing the site. This was done mostly to compose the aperture dimensions in relation to the island. The ideal position and orientation were also recorded using GPS and compass.

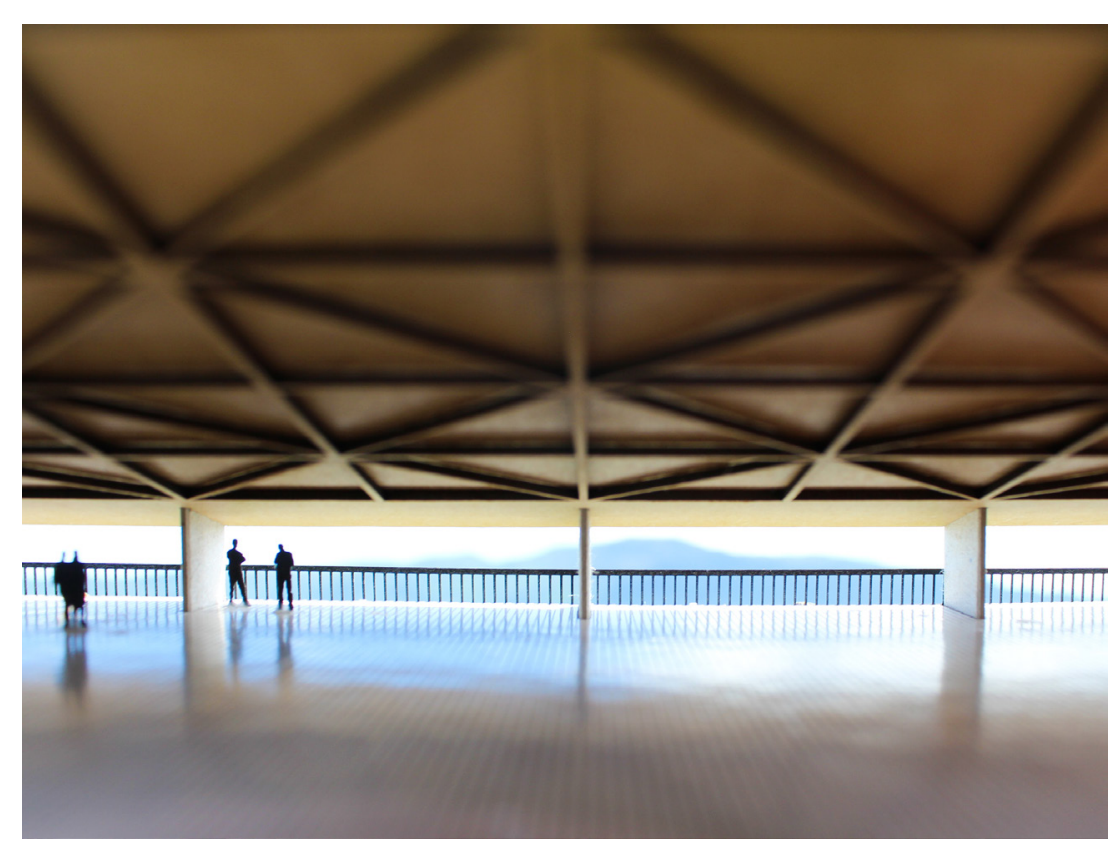

160. Kapiti Island as seen through the. Island Aperture Device 
besto

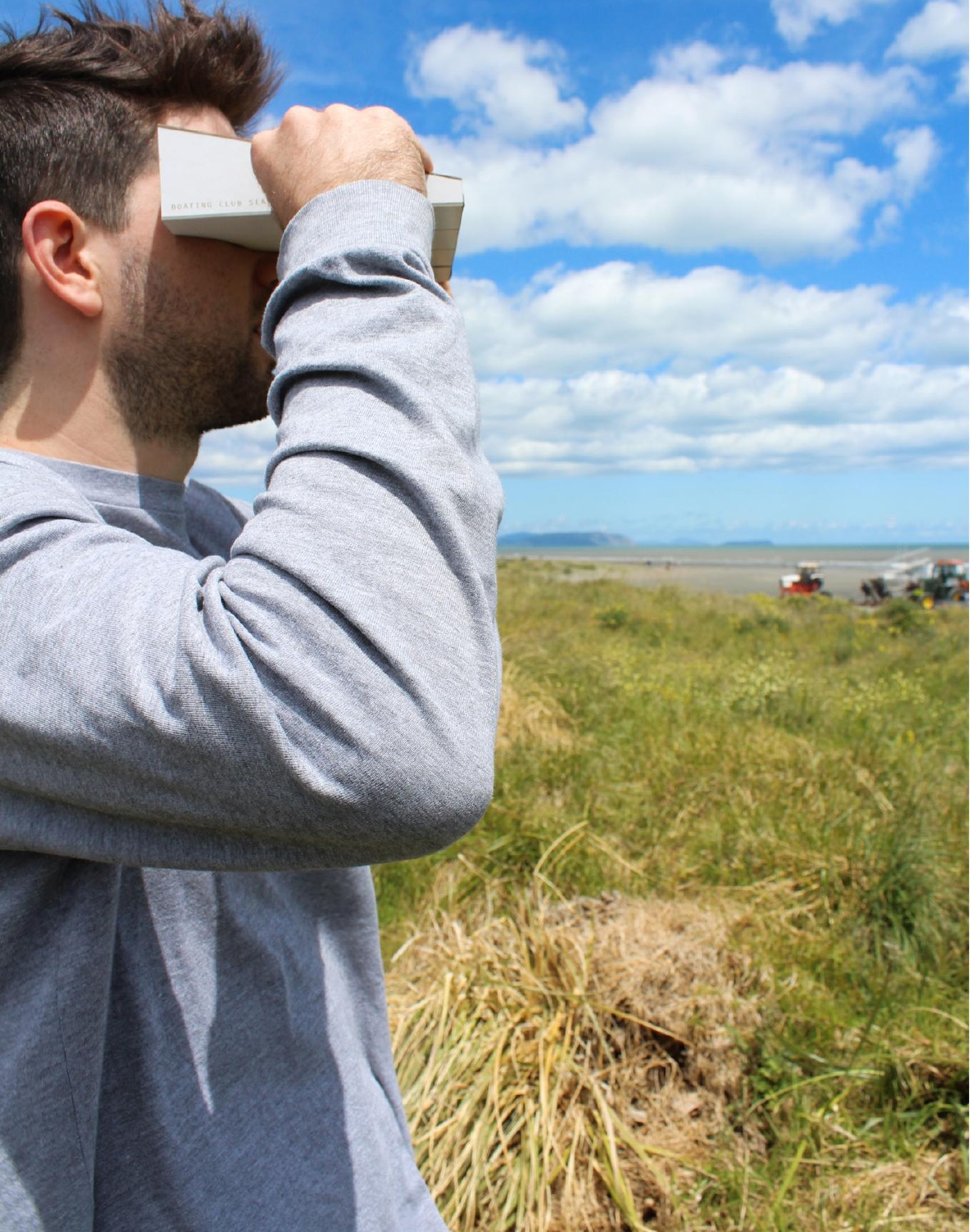

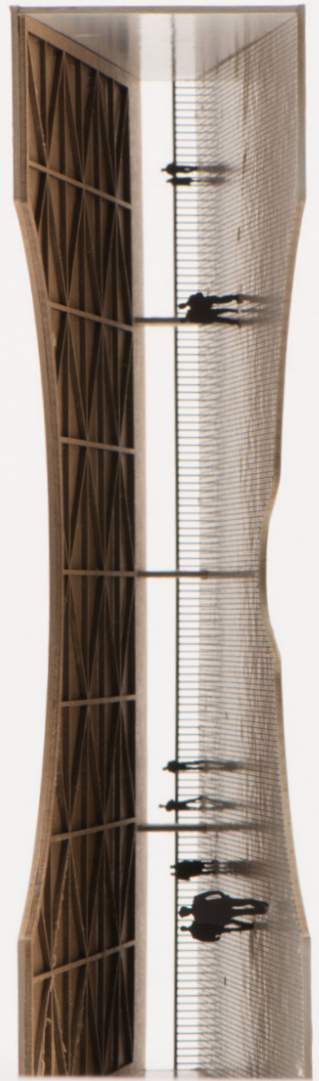

162. Device as an object. Island Aperture Device 


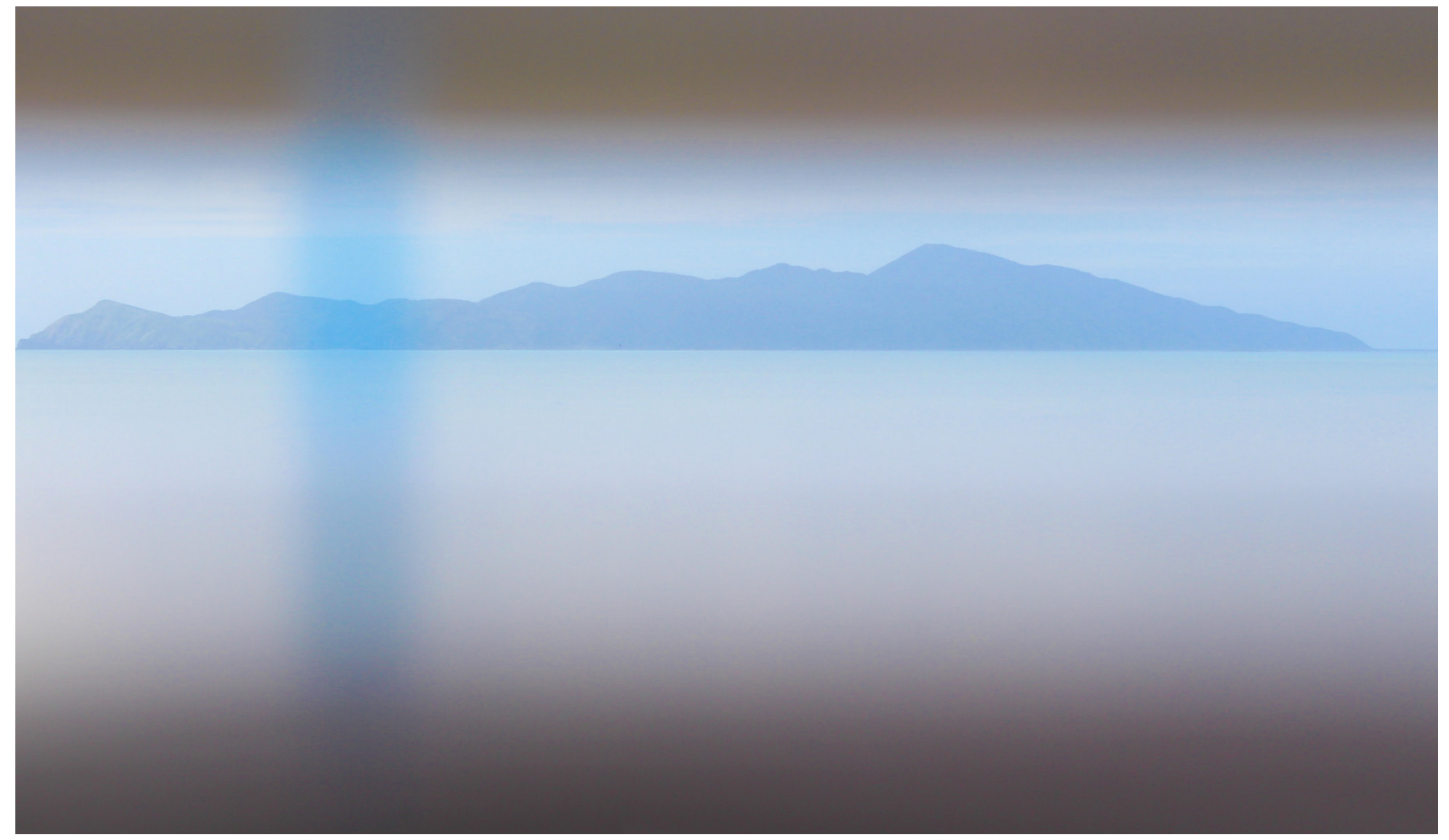

163. Kapiti Island seen through early aperture study. Island Aperture Device 


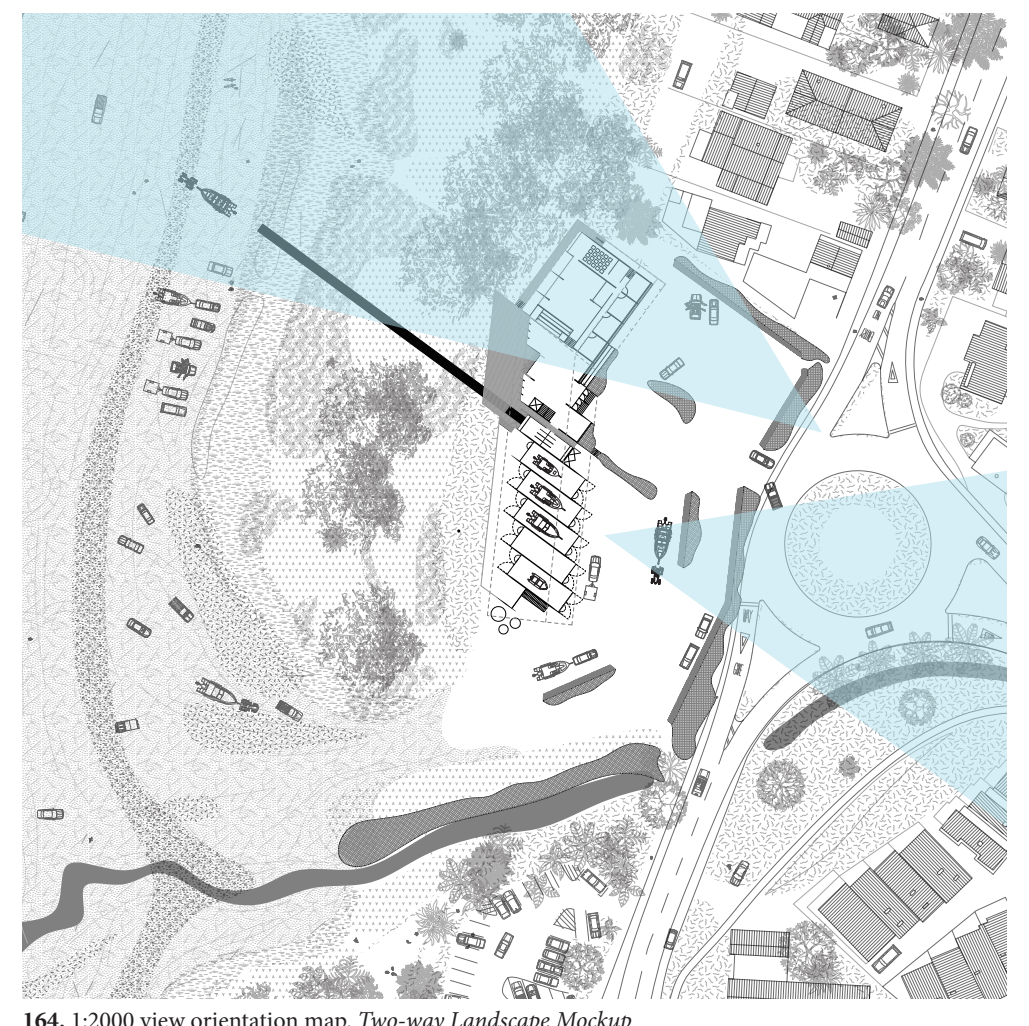




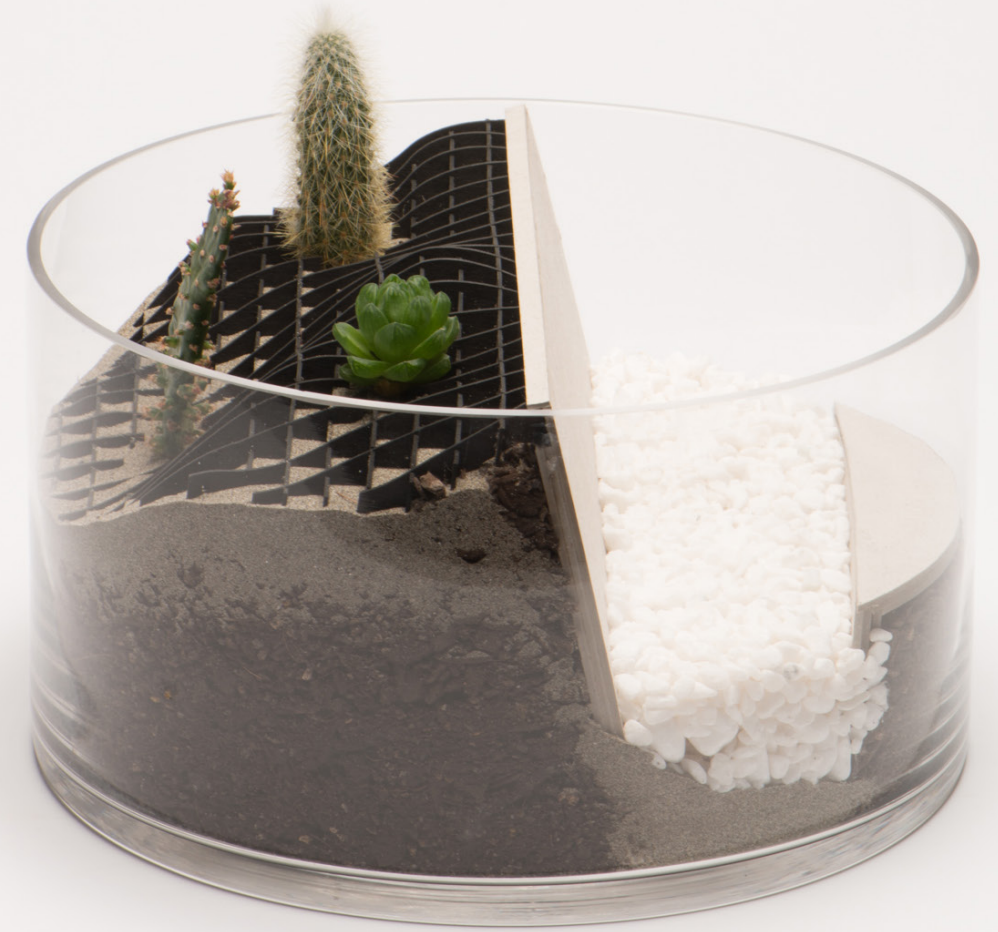

\section{Two-way Landscape Mock-up}

The Two-way Landscape Mock-up is a 1:20 marquette of a possible landscape design feature surrounding the Gateway complex. It depicts a berm $1500 \mathrm{~mm}$ high with two distinct sides. One side imposes a bare concrete retaining wall with a french drain at the bottom, designed to filter the carpark run-off. The other side displays a flowing grid structure which creates a static dune system. These contrasting sides were designed to sit in the foreground and extenuate existing views on site.

The design process involved photographing the marquette onsite in various orientations and locations. This helped determine its placement between the carpark and Marine Parade, blocking the views of the carpark from the street, placing the dune system in the foreground instead. This helped maintain the romantic outlook towards the island as the view is saturated with natural forms and colours. The flip-side looking from the carpark back towards Paraparaumu places a harsh concrete wall in the foreground. Only blocking low street views, the wall amplifies the urban backdrop. 


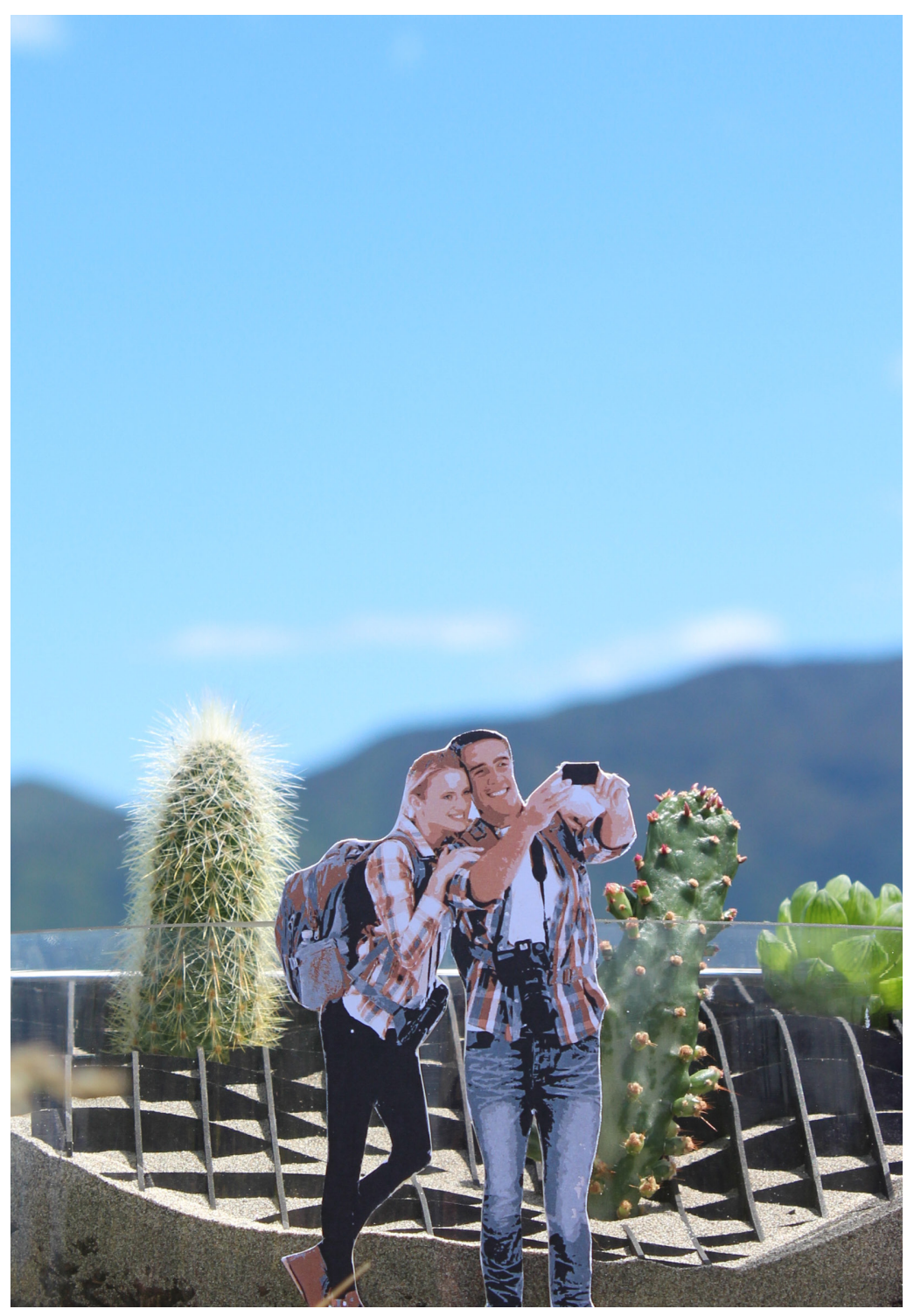

166. Romantic Kapiti Island view. Two-way Landscape Mockup

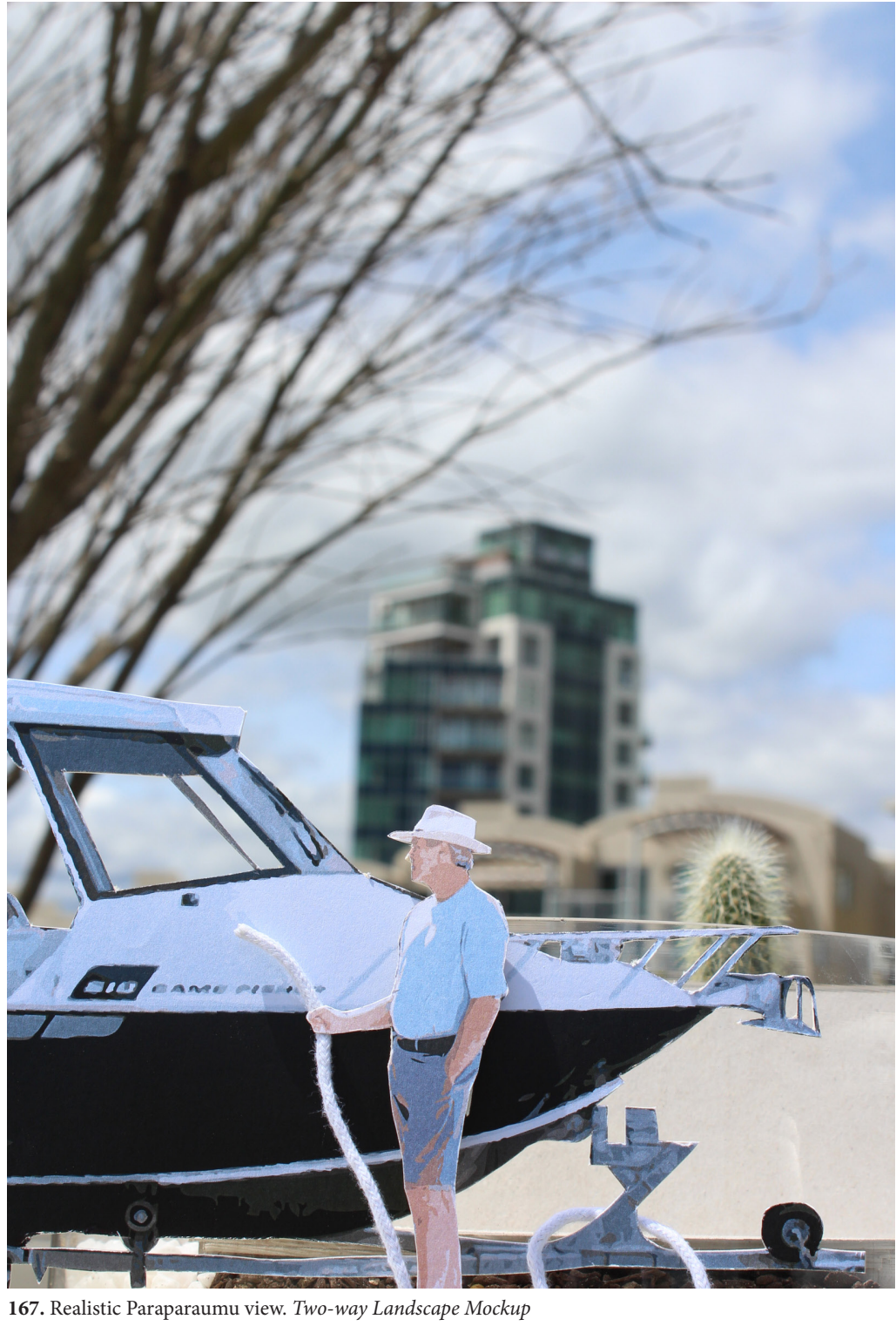

264 

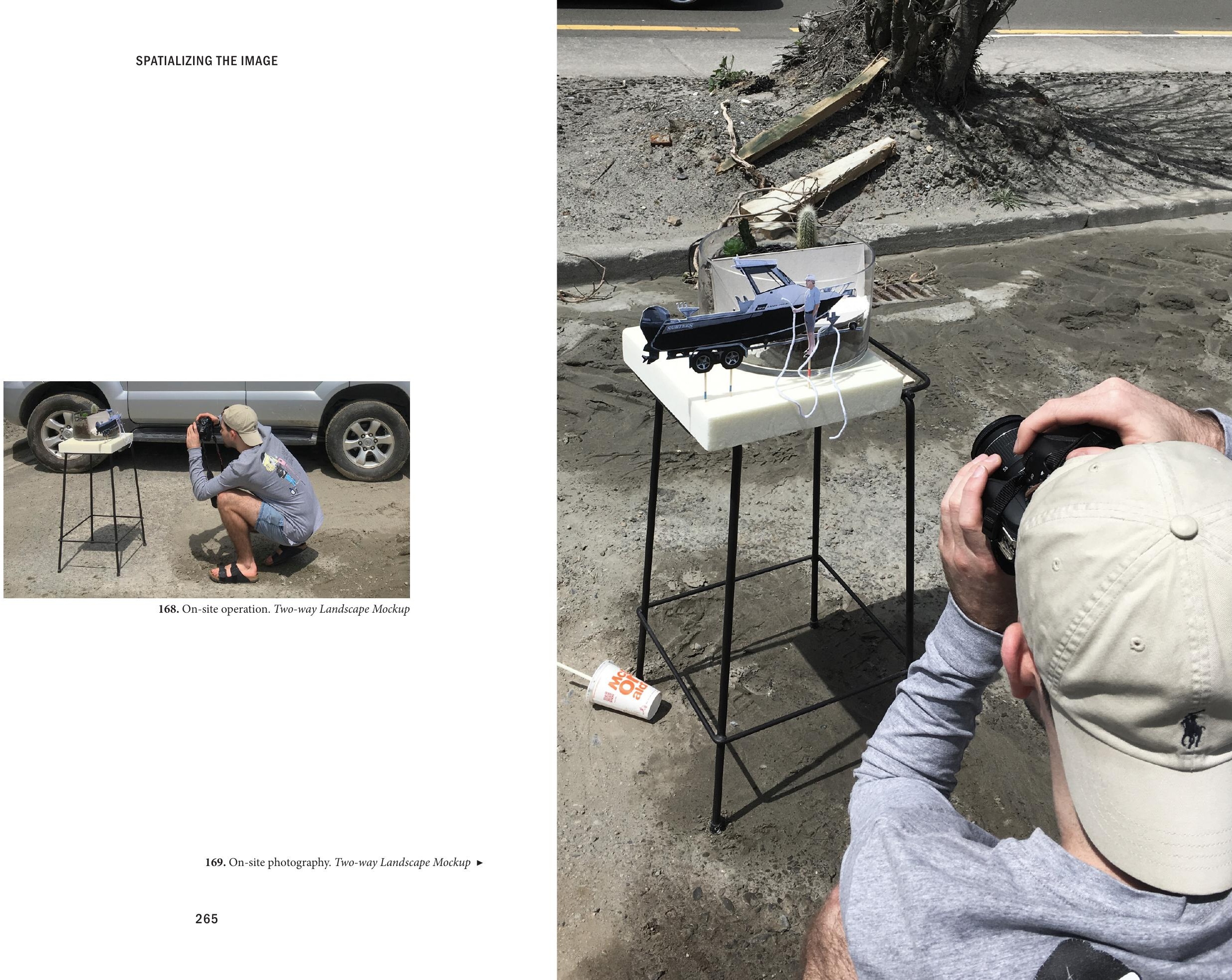


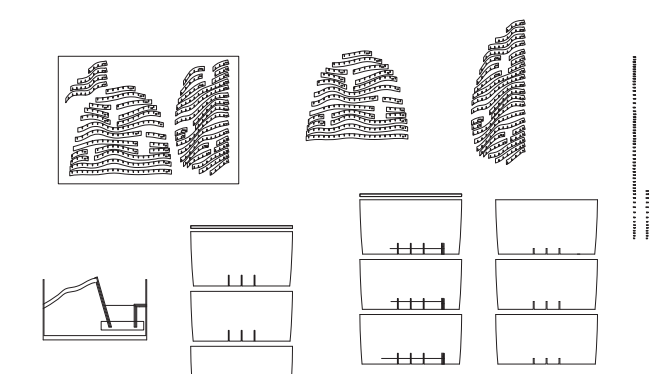

MV W
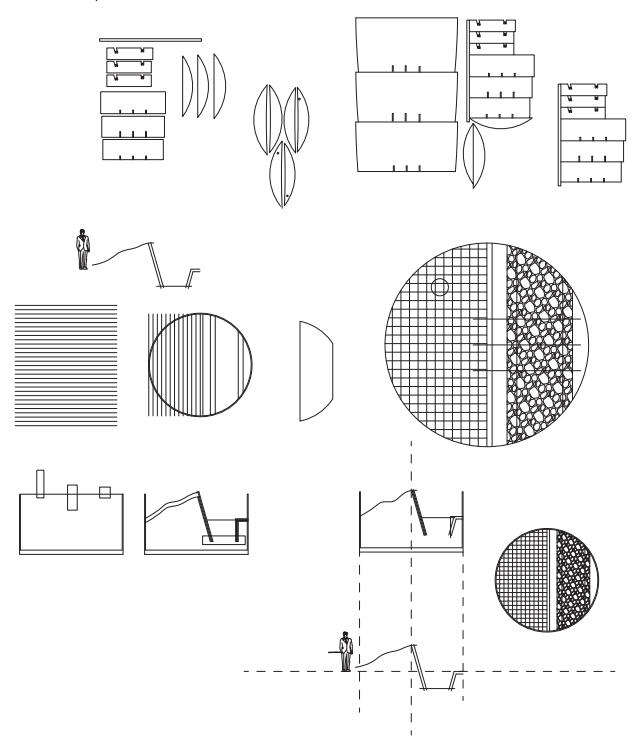

170. CAD design file. Two-way Landscape Mockup

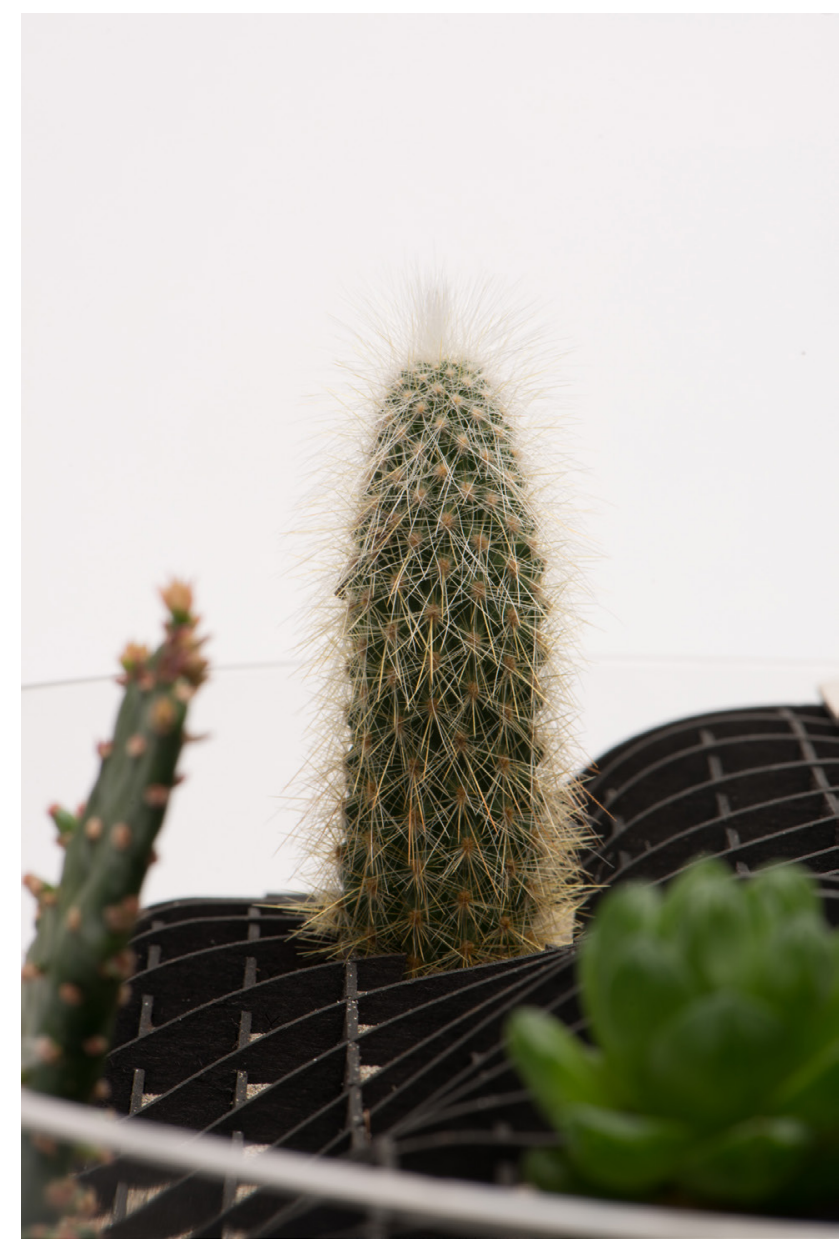

171. Dune close-up. Two-way Landscape Mockup 


\section{PEIR DEVICES}

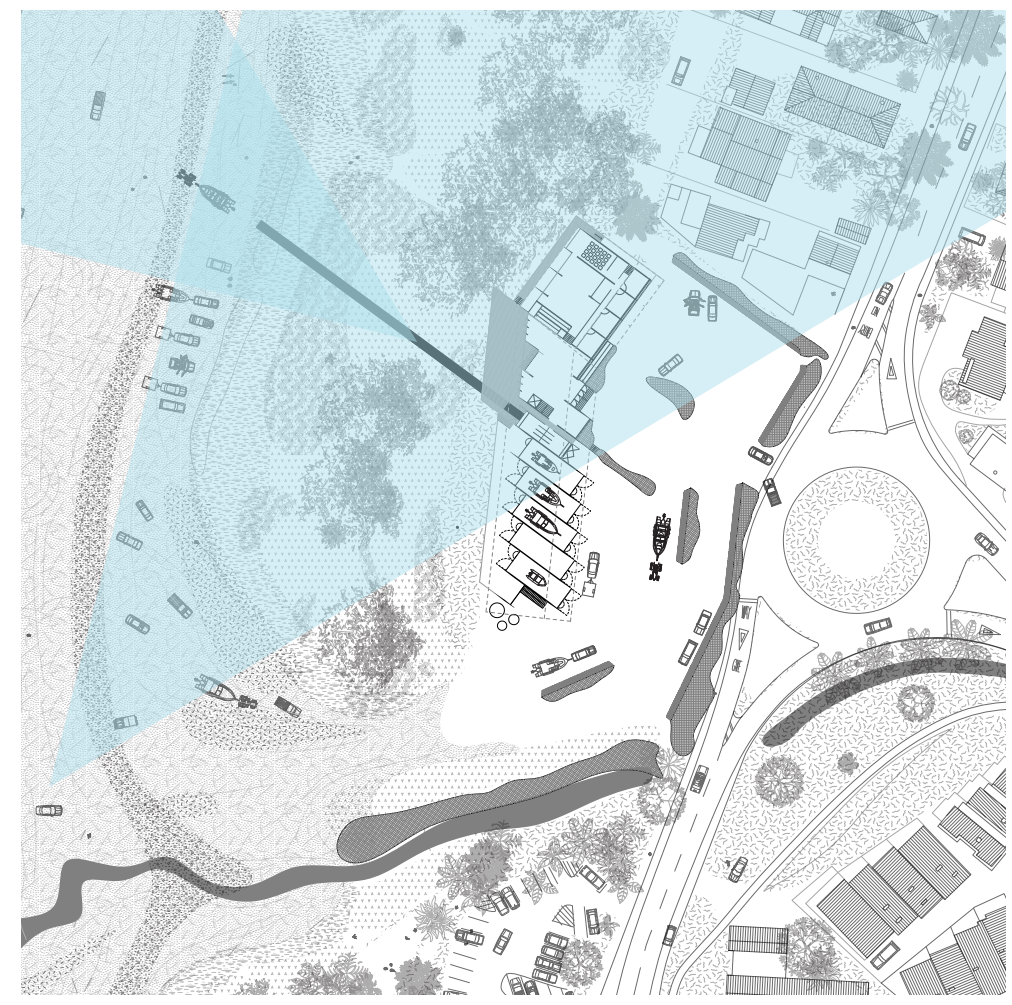

172. 1:2000 view orientation map. Pier Devices 
A series of devices were produced as tools for designing the pier which grants beach access over the fragile dune system.

\section{Enclosed Pier Mock-up}

The first model of the series was a mock-up at 1:50 to explore construction options. Using sand from site it was uncovered that many thin columns rather than a few wide ones were more aesthetic and stable. This model was also photographed on-site to check its suitability.

\section{Enclosed Pier Mock-up}

The Pier Orientation device is a clear piece of acrylic with a perspective drawing laser etched into its surface. This is operated in a similar manner to the Boatshed Device where it was held up to the eye to be used as a perception-altering optical device. The aim of the device was to position it in such a manner where the pier went seemingly all the way to the island. A figure placed in the foreground represents the likelihood of this being a photo 'hotspot' of the design. This tool aided in determining the pier orientation and height over the dunes.

\section{Pier Elevation Device}

Also constructed by etching a drawing onto clear acrylic, the Pier elevation device acts just like the Pier Orientation device but instead considers the perpendicular view. It was superimposed onto different views at site and used to examine possible heights and orientations.

Operating in perspective allows devices to exploit the phenomena of diminishing forms (apparent height $=$ actual height / distance). With careful arrangement components of the device will appear proportionate even if at different scales in real life. This allowed the site views to become an extension of the devices, and also allowed the use of large natural objects that would otherwise be too impractical to model with. When it comes to natural objects sometimes there is no substitute for the real thing.

A separate operation of this device explored the scenario of cladding the pier in driftwood. The 1:200 device and camera were set stationary on a nearby beach wealthy with driftwood. Behind the device driftwood was composed at roughly 1:20 to appear to clad the pier. The outcome wasn't entirely successful as the driftwood appeared too large and the background was confusing. This method of operation was refined later in the design of the Fernery Composition Diorama. 

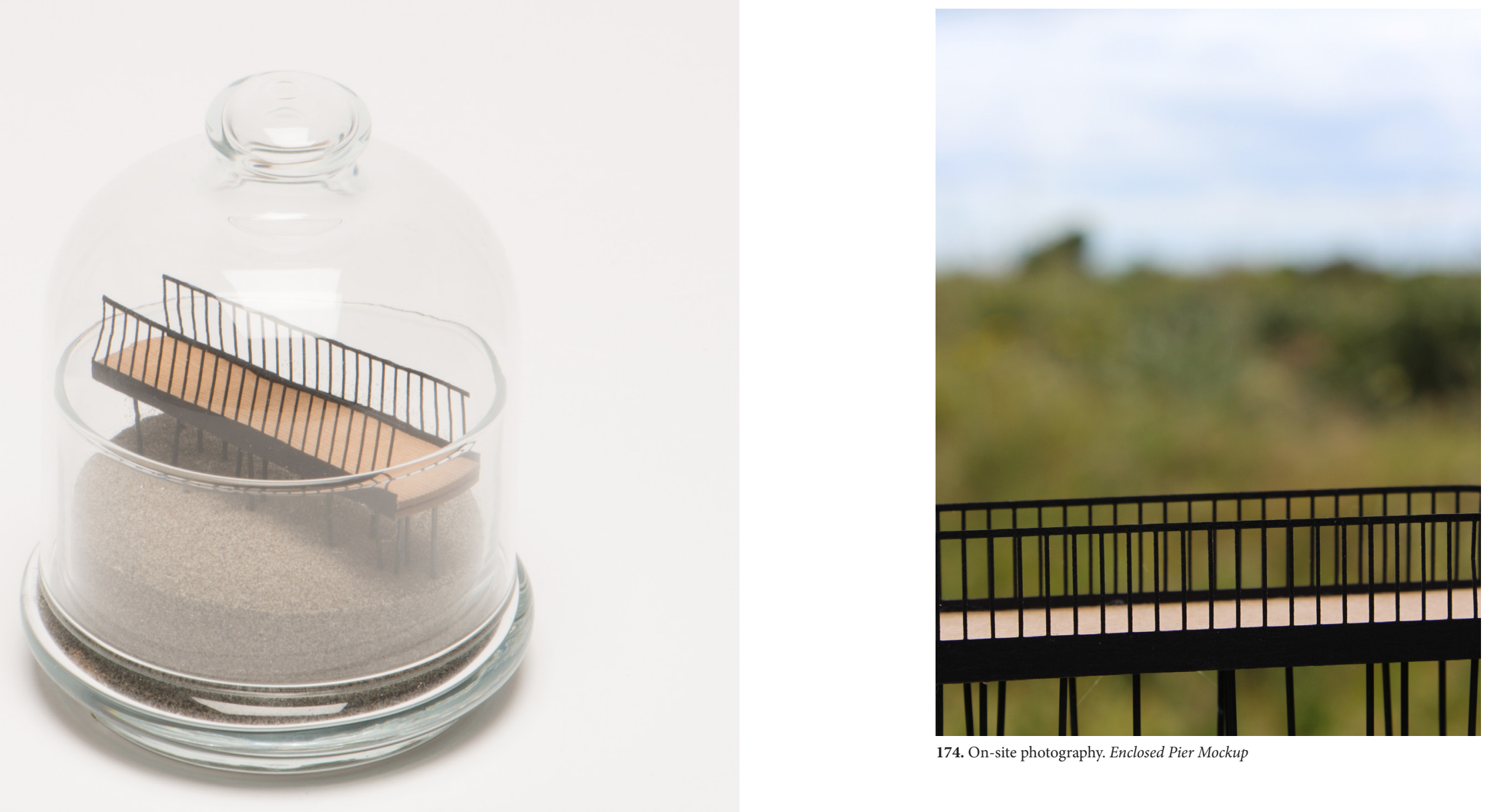

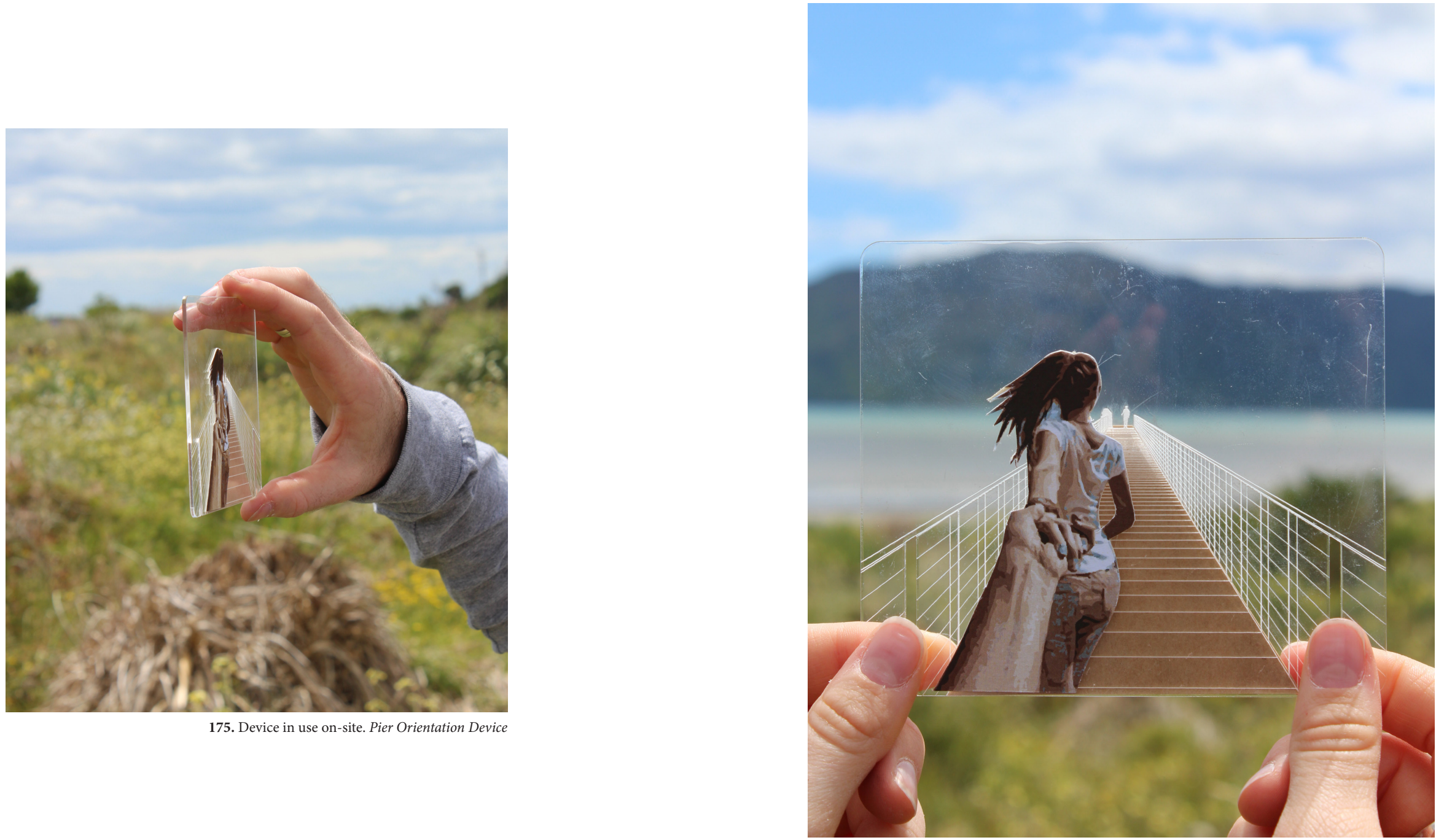

176. Final selected orientation. Pier Orientation Device 


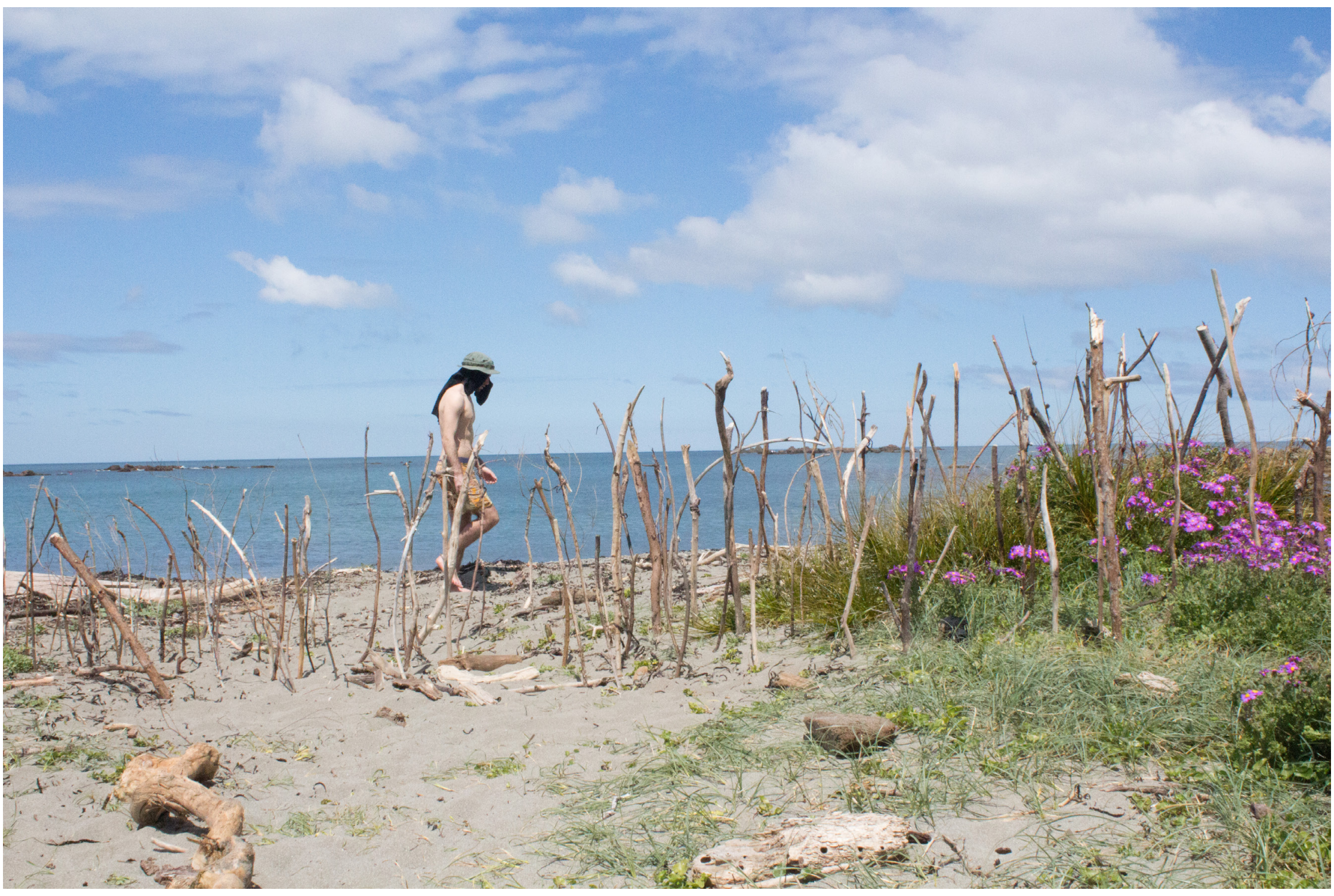




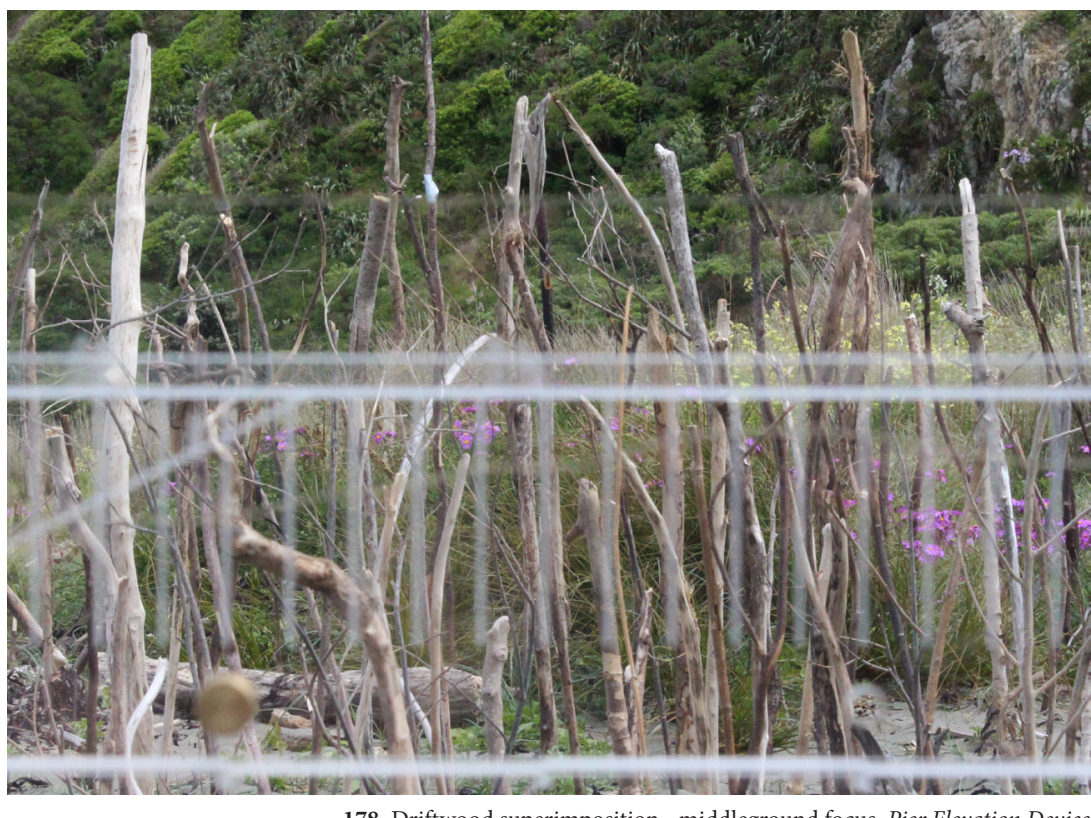

178. Driftwood superimposition - middleground focus. Pier Elevation Device

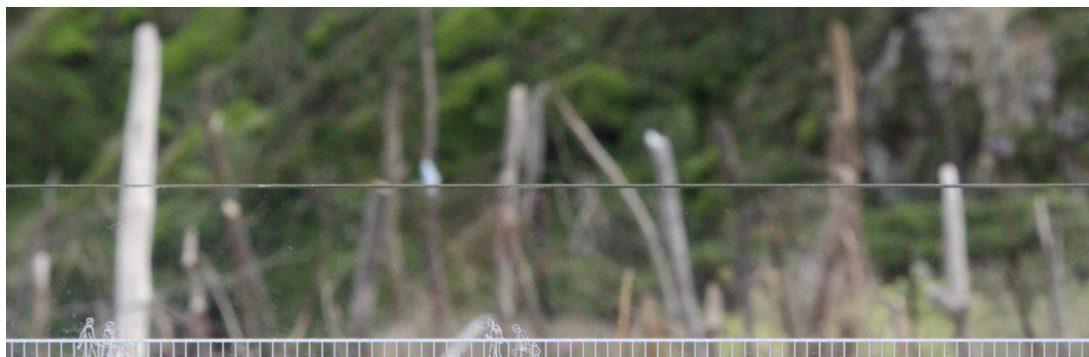

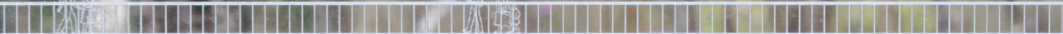

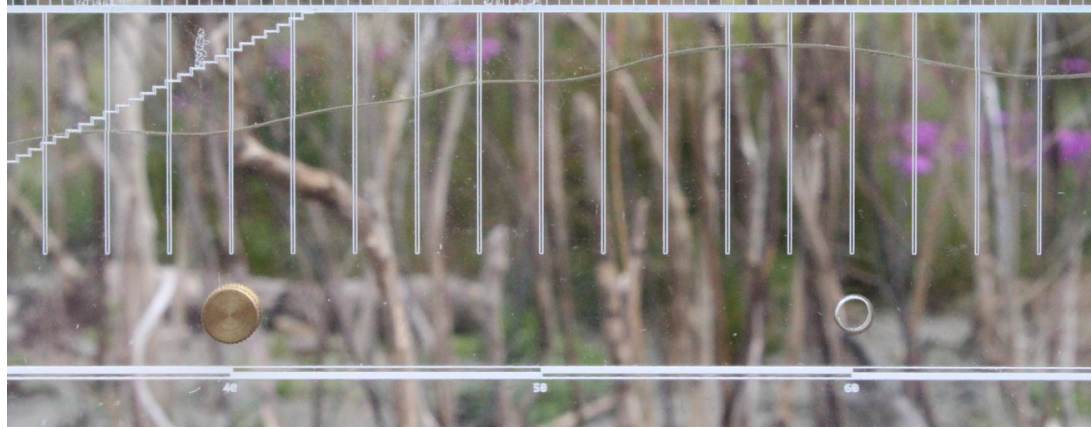

179. Driftwood superimposition - foreground focus. Pier Elevation Device 


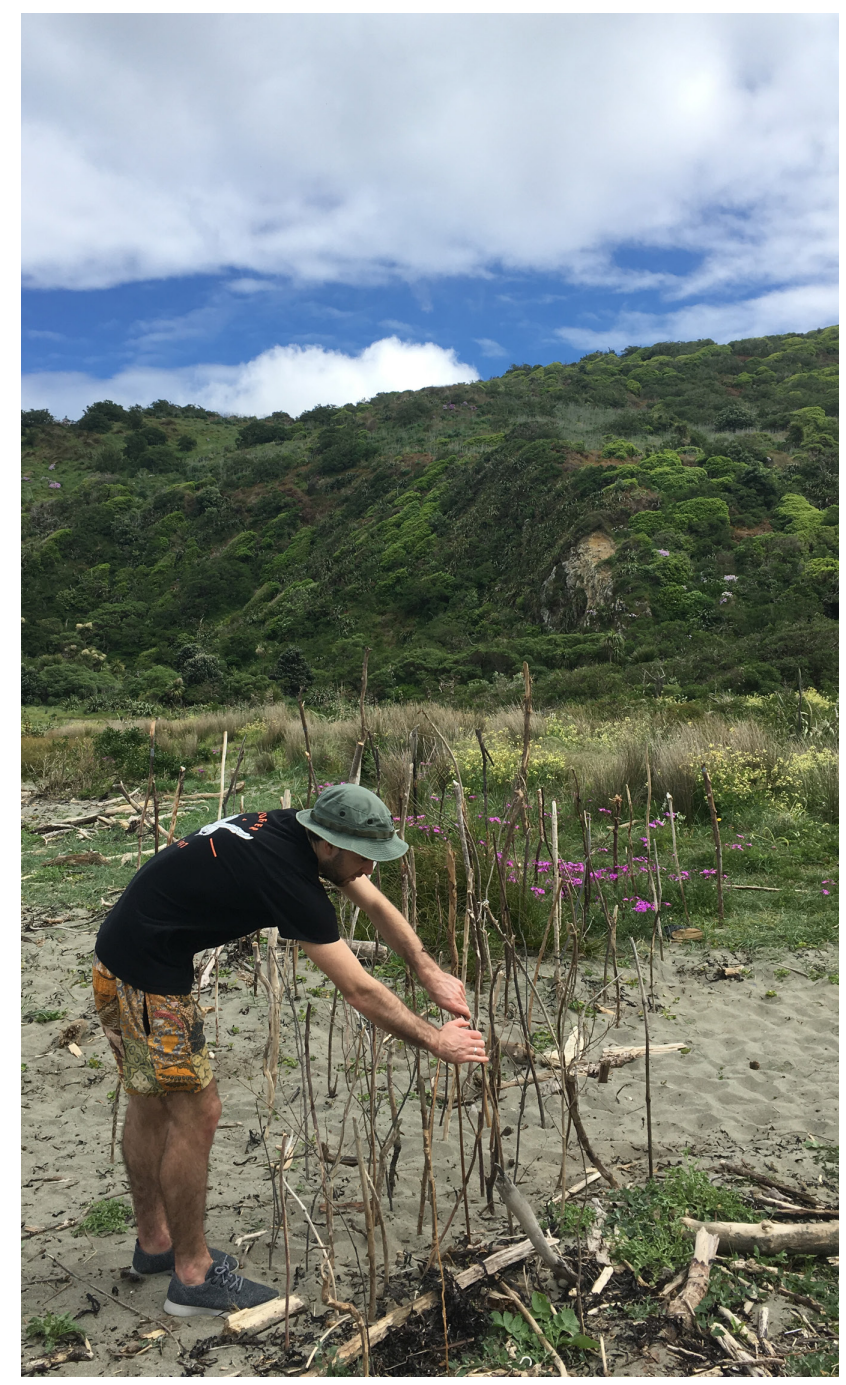

181. Composing driftwood structure within the field of vison. Pier Elevation Device 


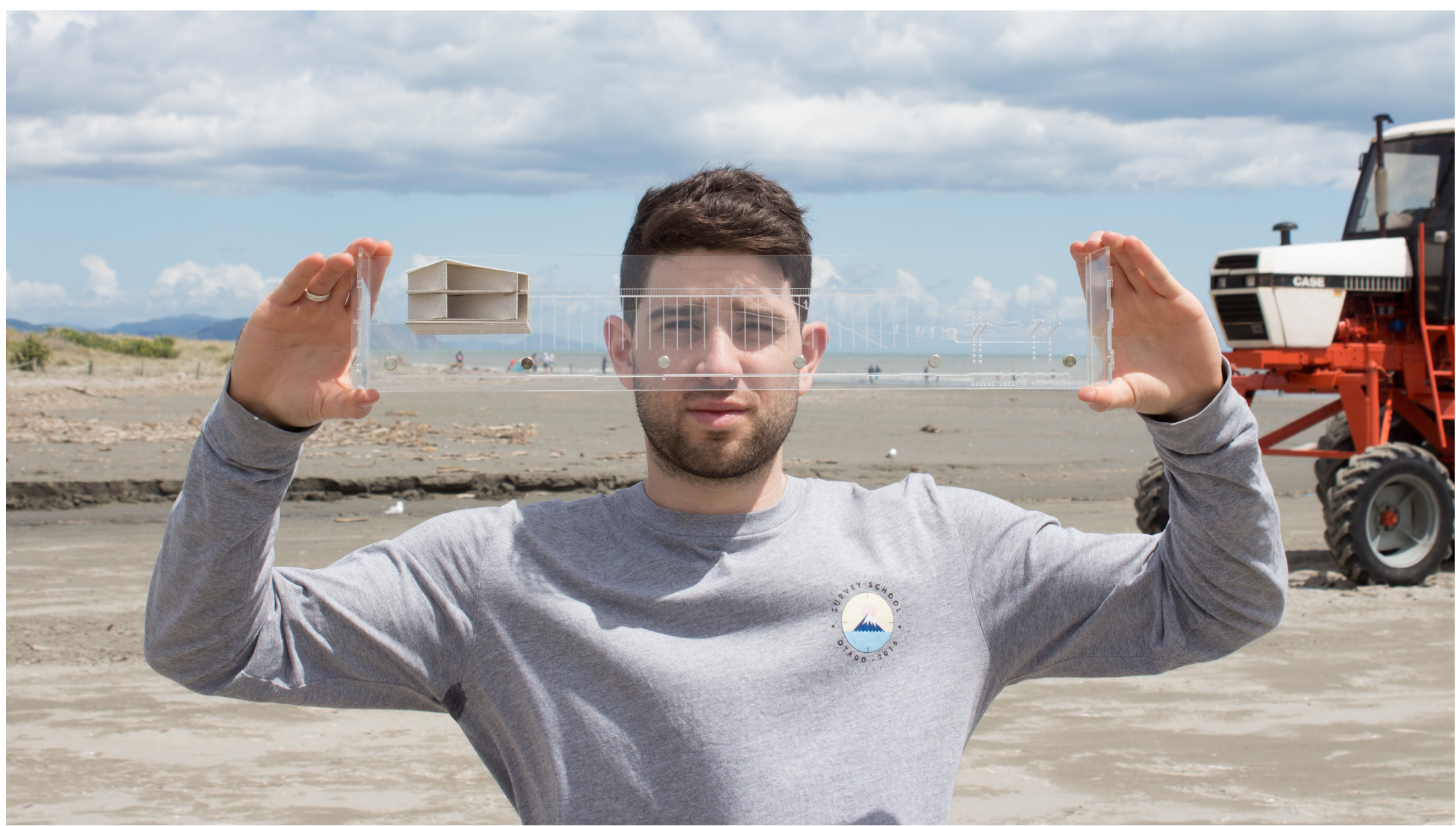

182. Device in use on-site. Pier Elevation Device 


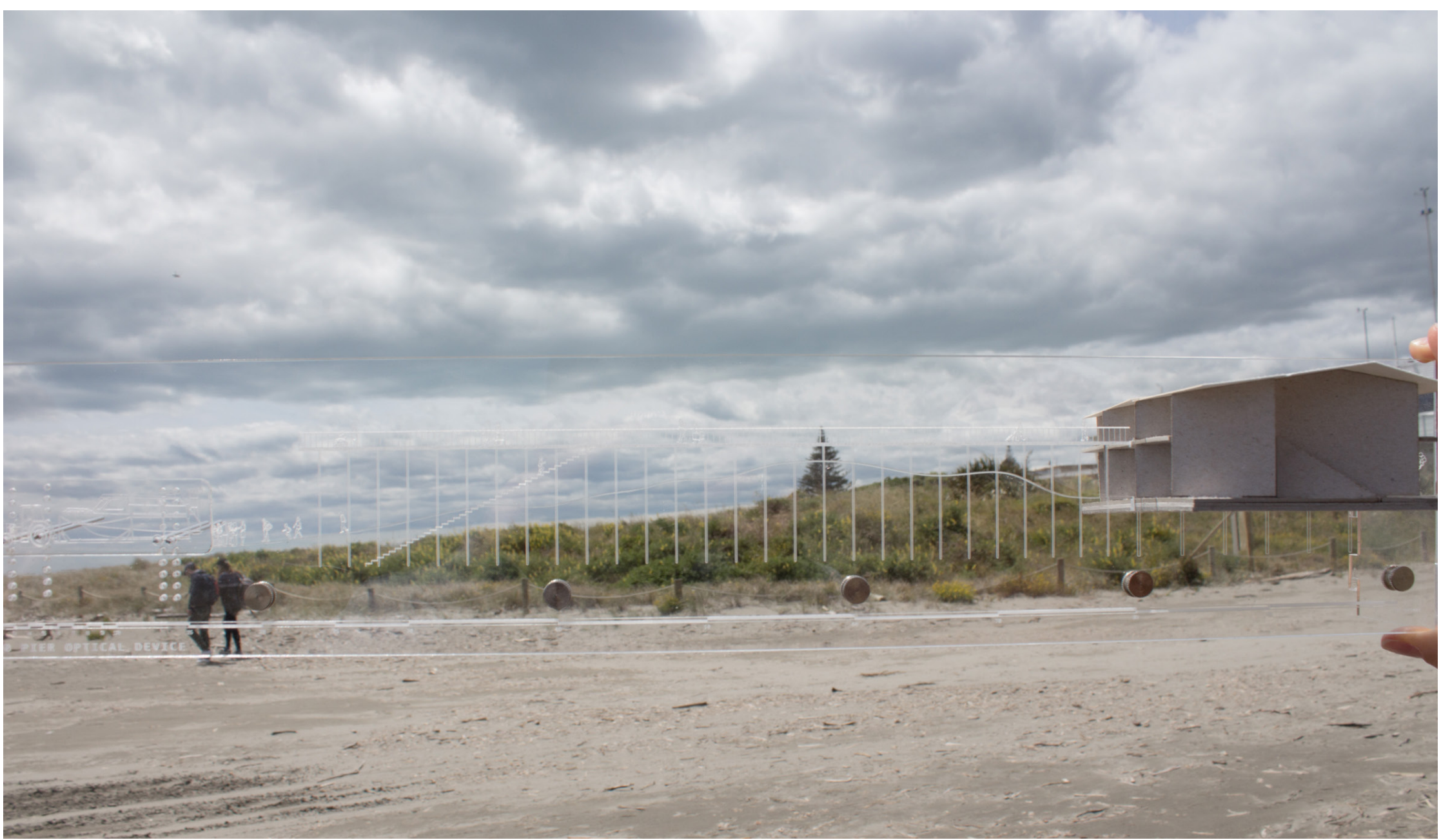

183. On-site view. Pier Elevation Device 


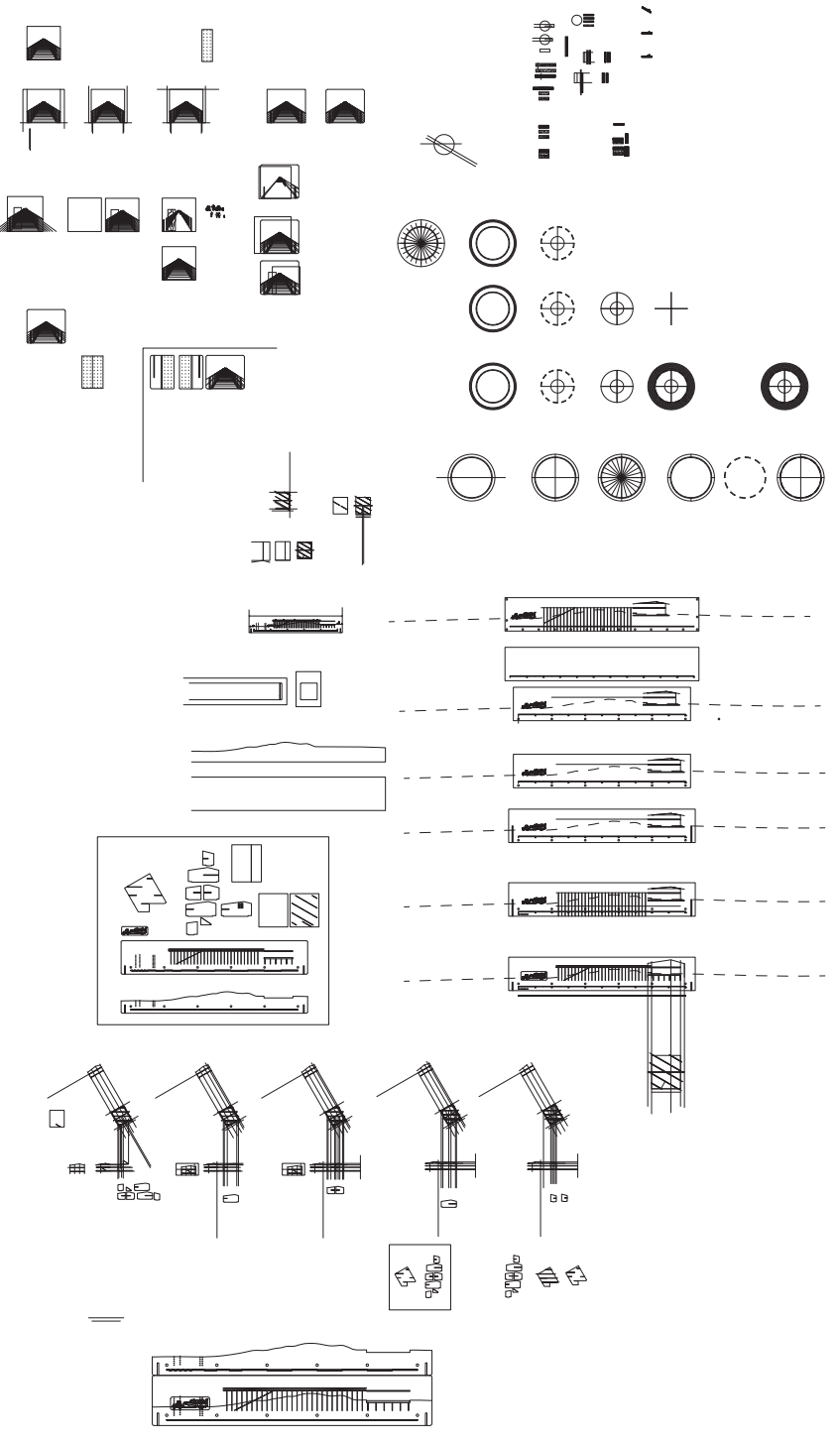

184. CAD design file. Pier Devices

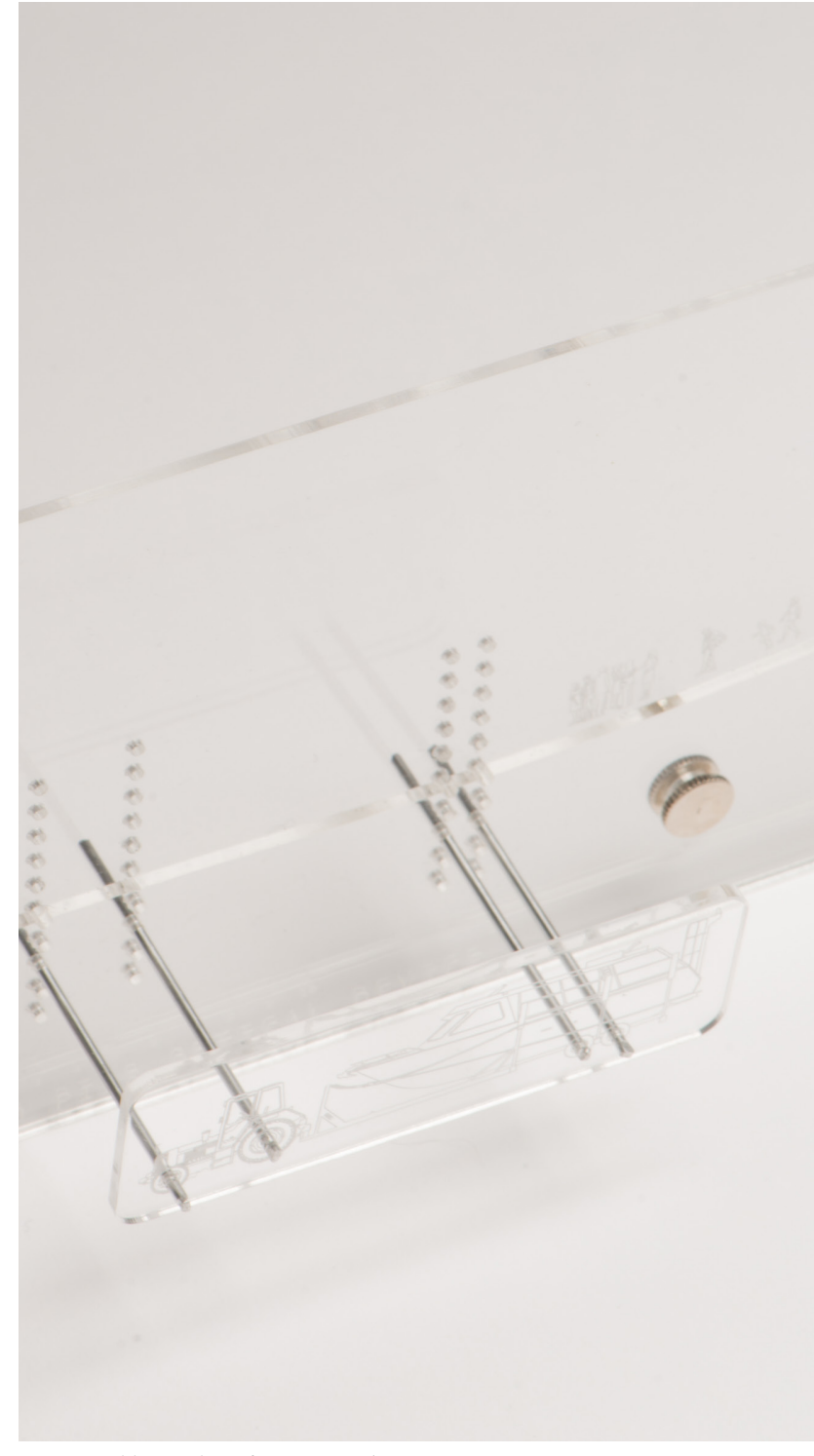

185. Movable tour boat figure. Pier Elevation Device 


\section{FERNERY COMPOSITION DIORAMA}

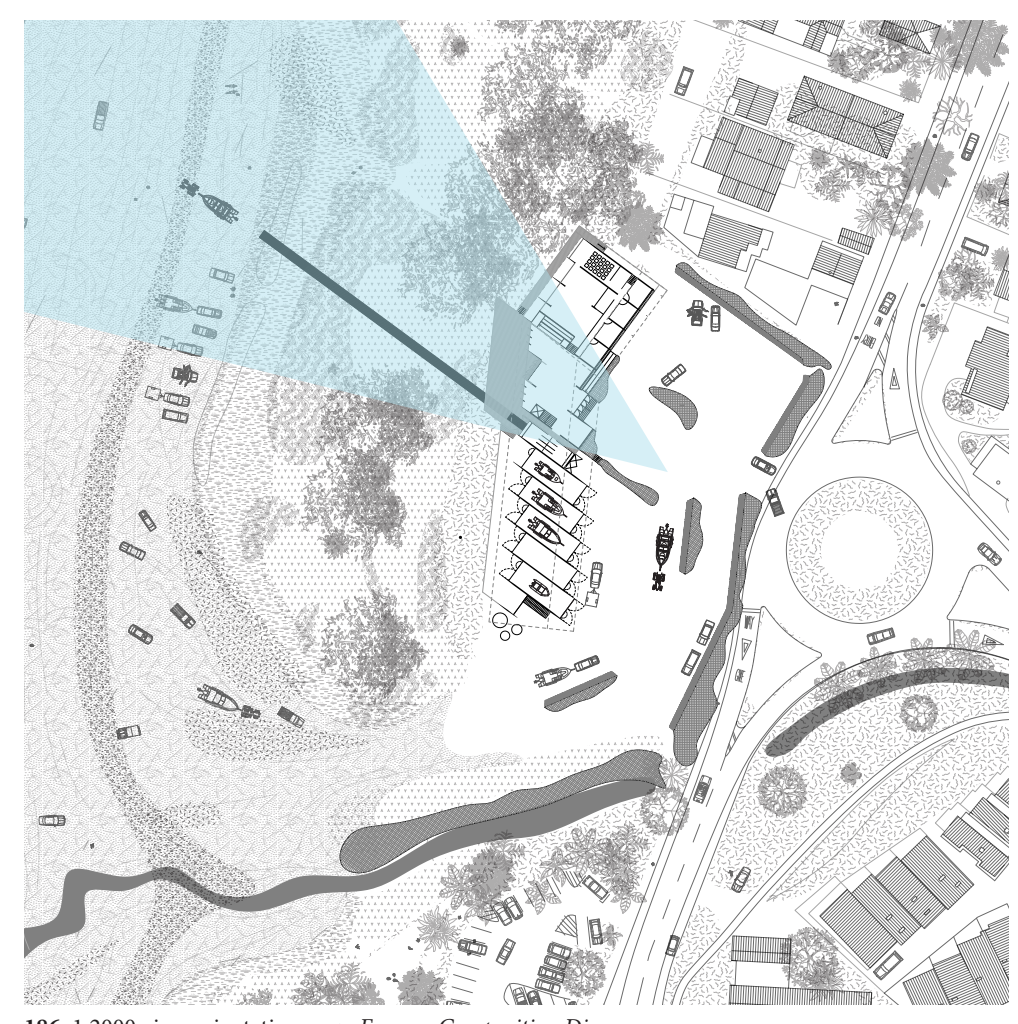

186. 1:2000 view orientation map. Fernery Composition Diorama 


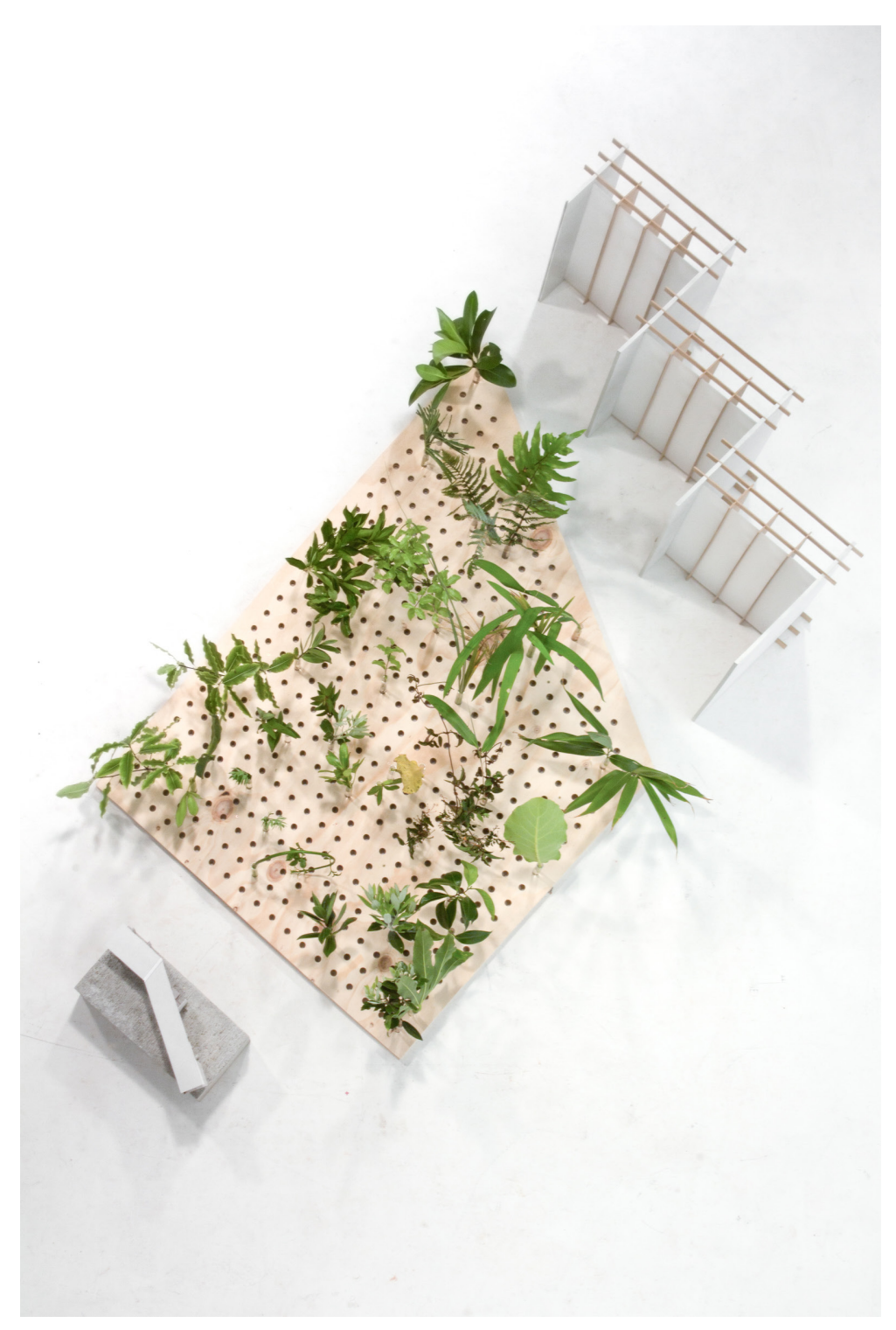

187. Top view. Fernery Composition Diorama

\section{Fernery Composition Diorama}

The Fernery Composition Diorama is a tool for designing the 'image' of the main entrance. As the primary thoroughfare and one of the first impressions for visitors it was essential to thoroughly design this scene. The diorama is composed of three main parts each built at a different scale, which are seen to be proportionate however when viewed from the designated perspective.

In the foreground the first component is a 1:100 section of the main entrance and eastern façade. The aperture of the entrance creates an optical device which defines the viewpoint of the diorama. The interior and mid-ground of the model represents the fernery/atrium. This is designed to be a meeting space containing native plants from Kapiti Island as well as bird feeders to invite native birds in. The aim of this space is to offer visitors an example of what is to be found on the island. Plant cuttings in test tubes forms the variable section of the diorama. The vases can be quickly and easily moved thanks to a plywood pin-board style base. Plant cuttings are only representative of full scale plants which would be used, nevertheless they are still detailed enough to represent colour, form and density of real life planting options. By looking through the optical device and shifting the vases around, the fernery design was able to be optimised for the 'image' seen upon entry. The resulting spatial implications of the composition were recorded through photography, and were then implemented into the design drawings. The background of the diorama is a 1:15 representation of the western façade. Comprised of full height translucent polycarbonate glazing with deep fin-like mullions. The diorama reveals a blurred silhouette of Kapiti Island which added to the considerations when composing the fernery. 

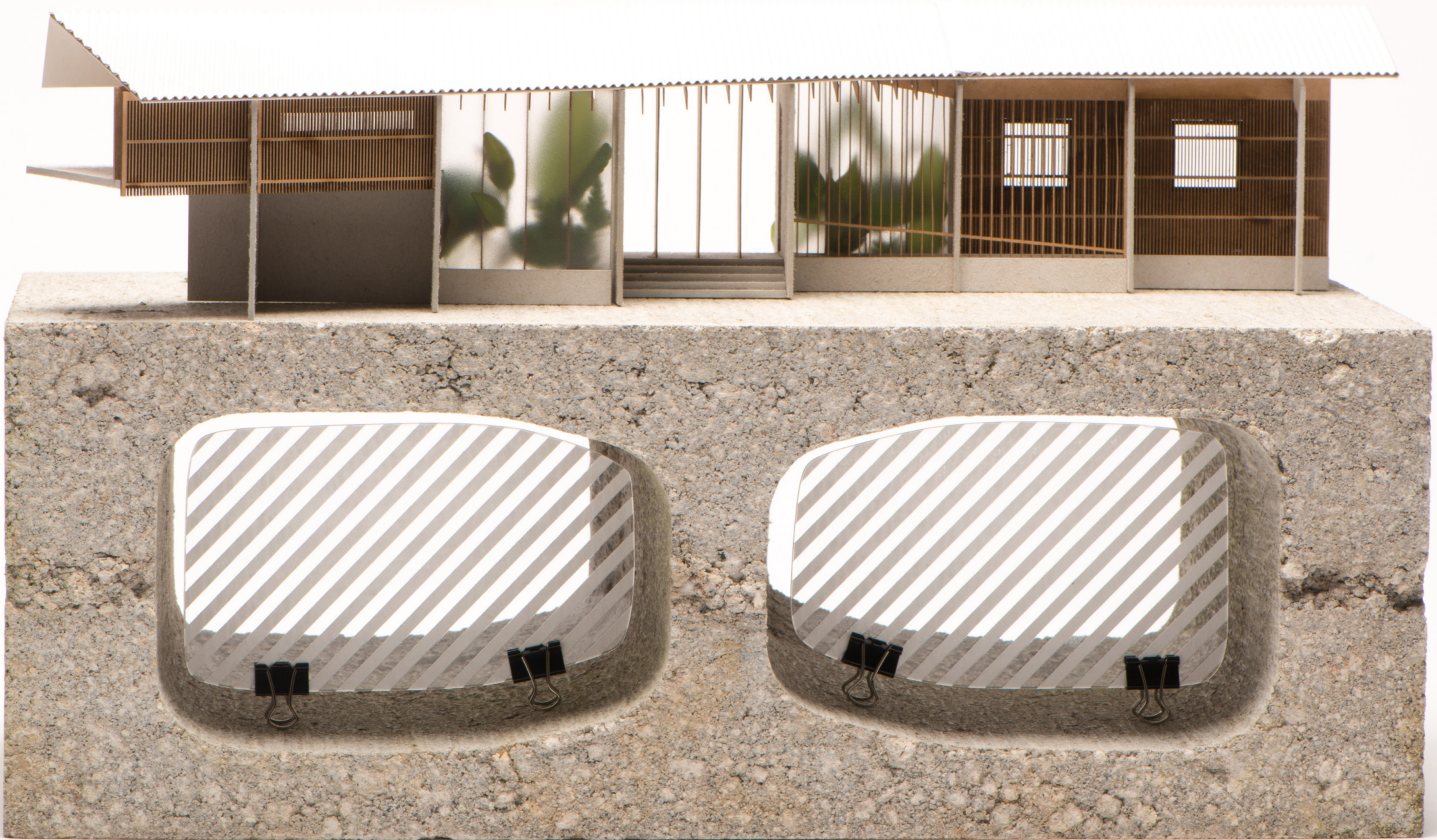

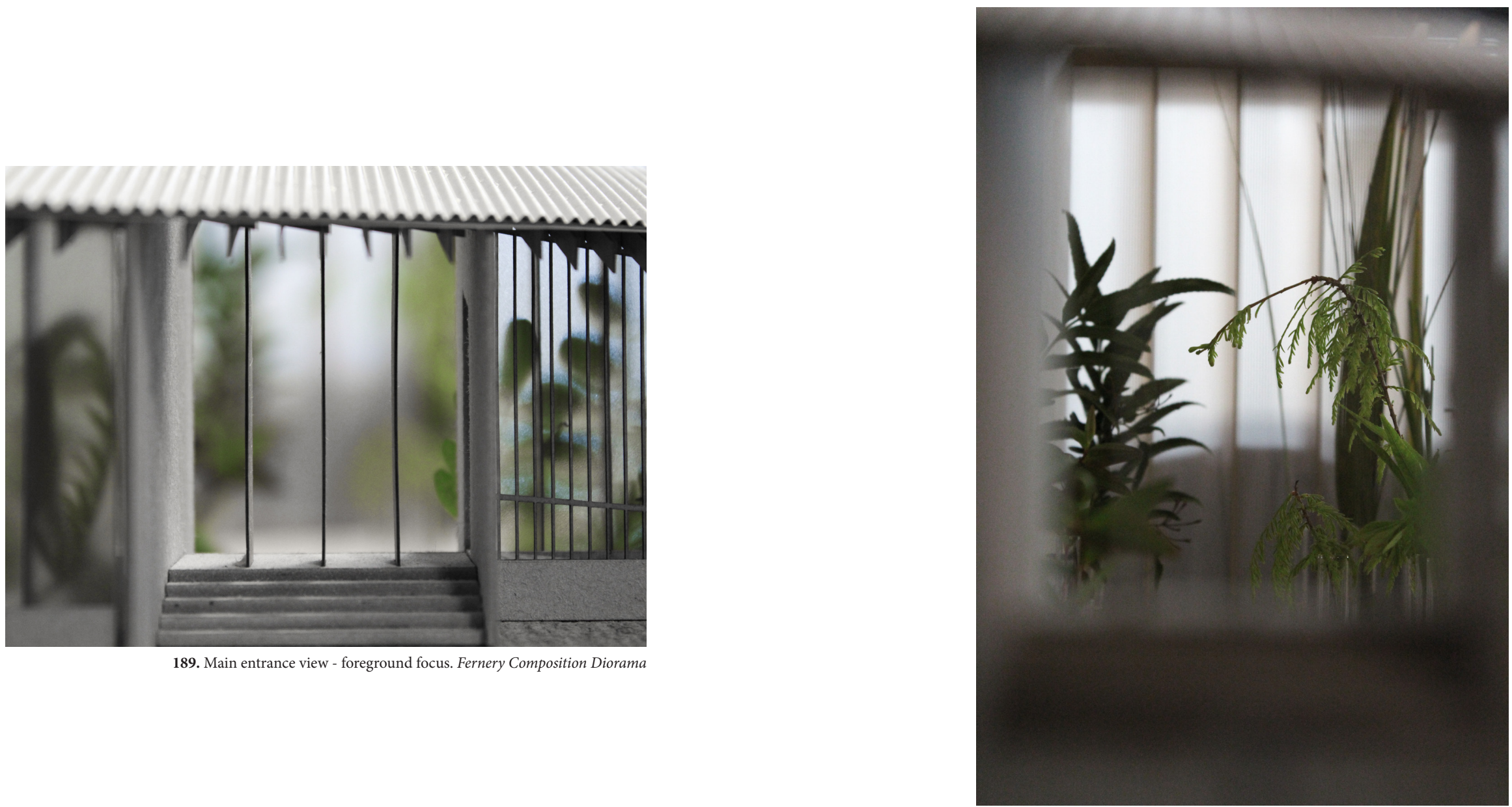


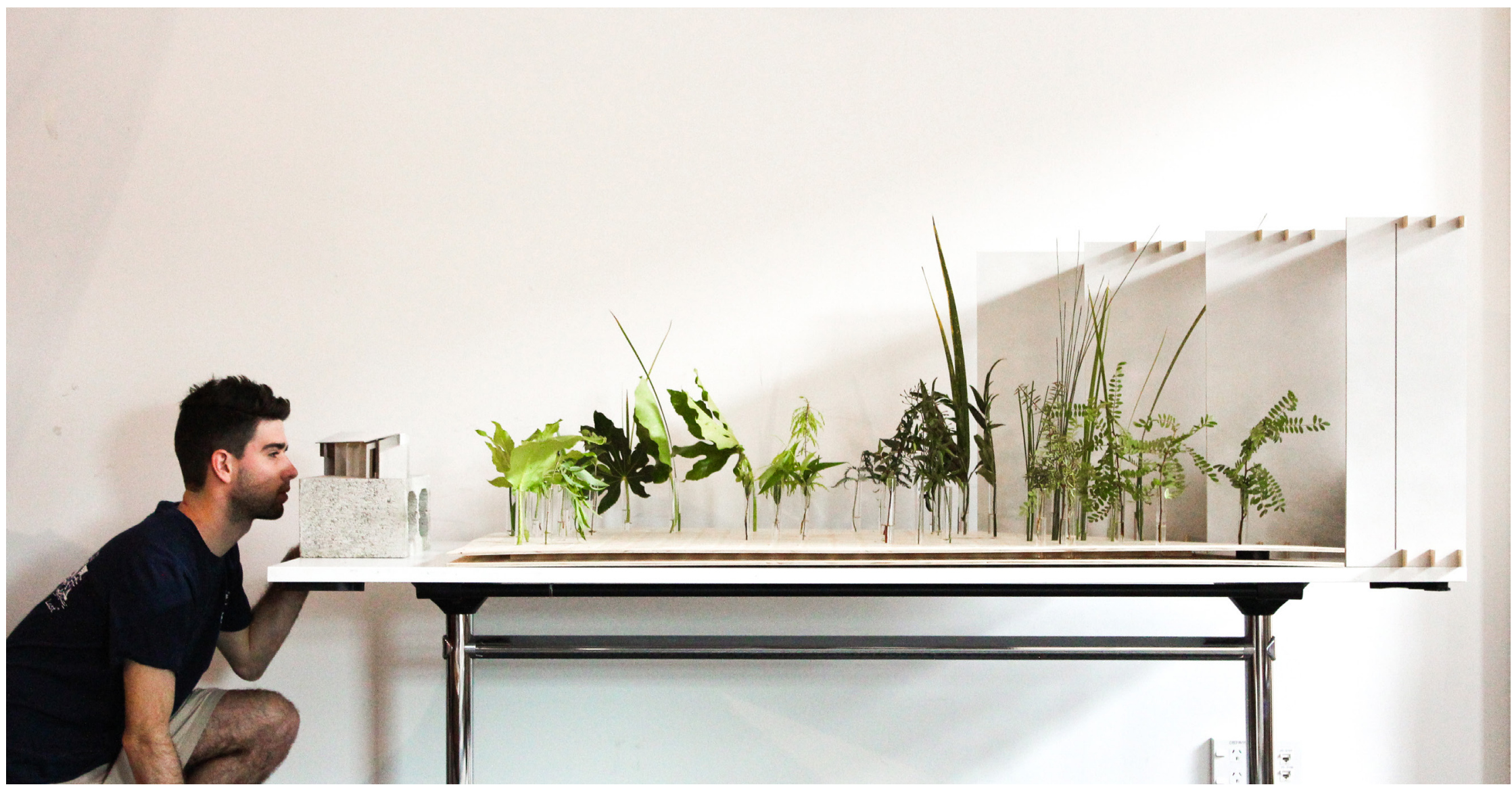




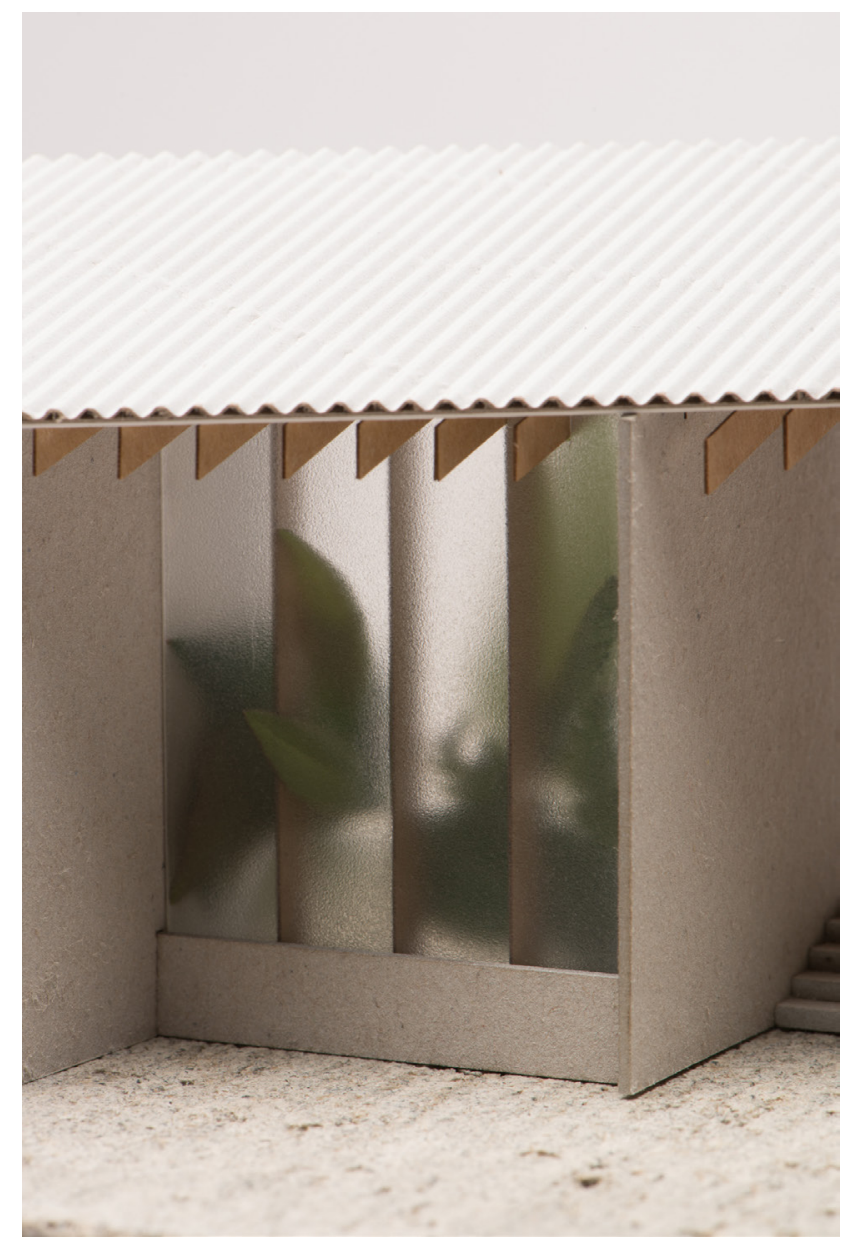

192. Optical device close up. Fernery Composition Diorama

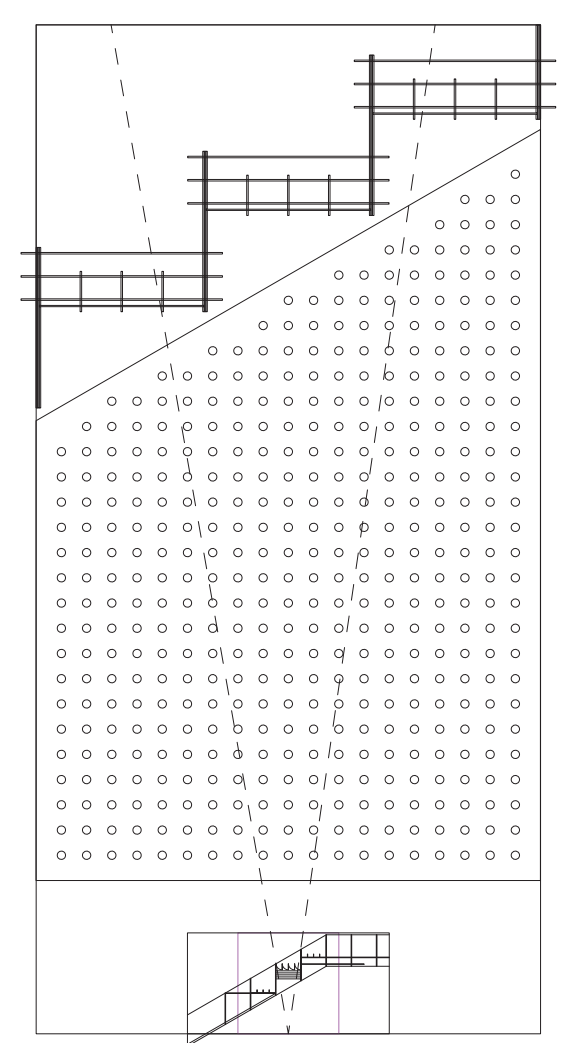

193. 1:20 plan. Fernery Composition Diorama 


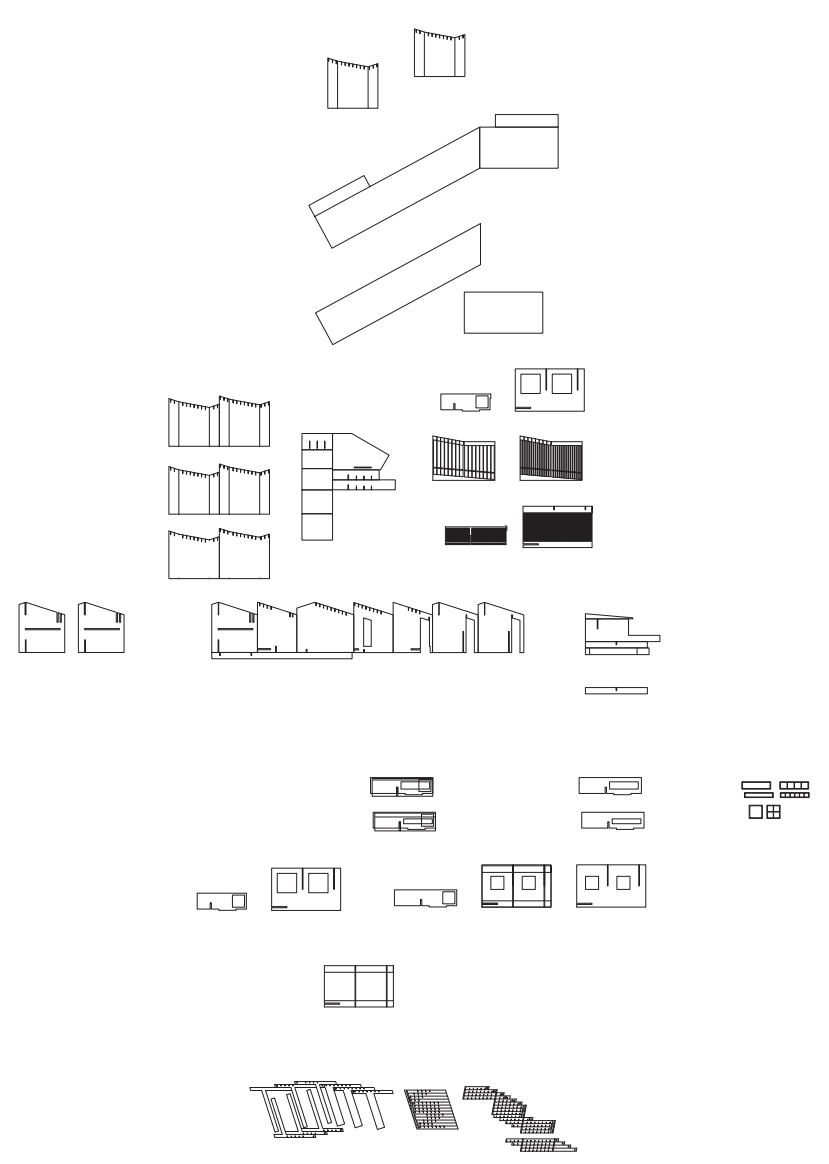

194. Optical device CAD design file. Fernery Composition Diorama

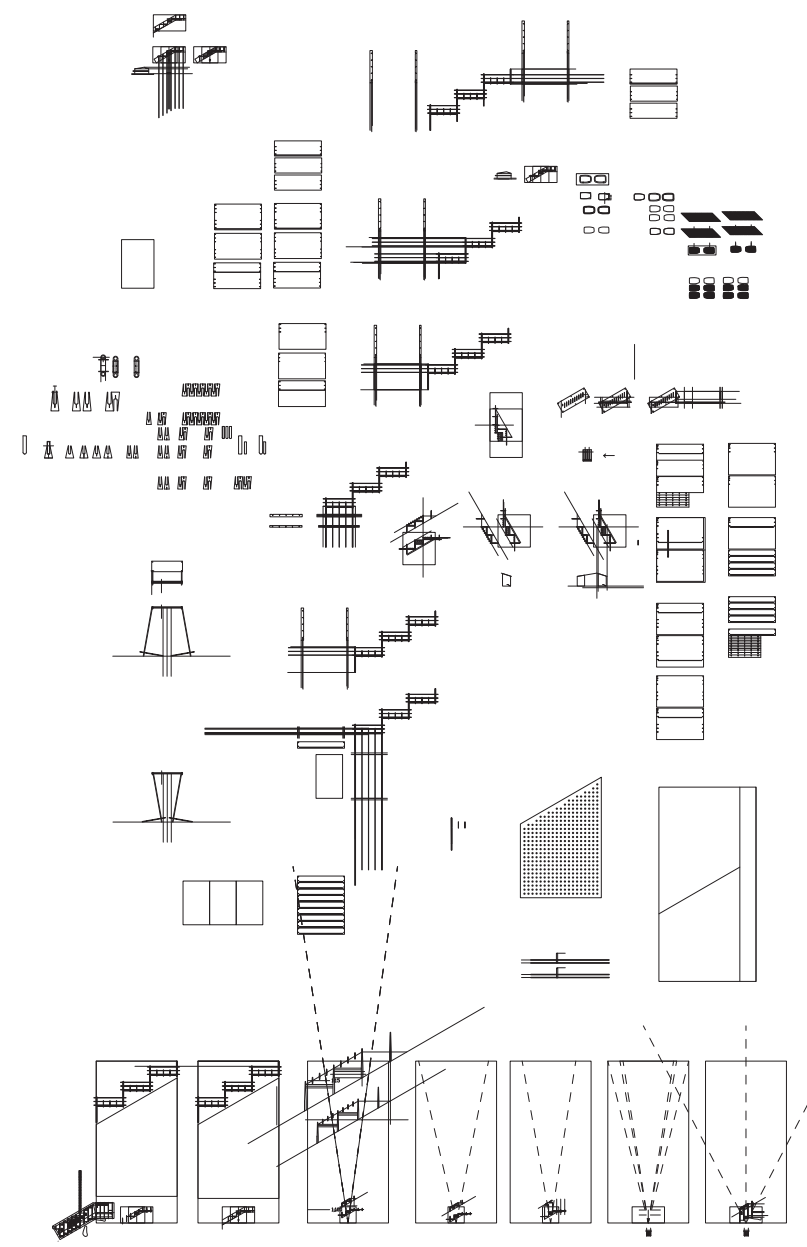

195. Fernery pinboard CAD design file. Fernery Composition Diorama 


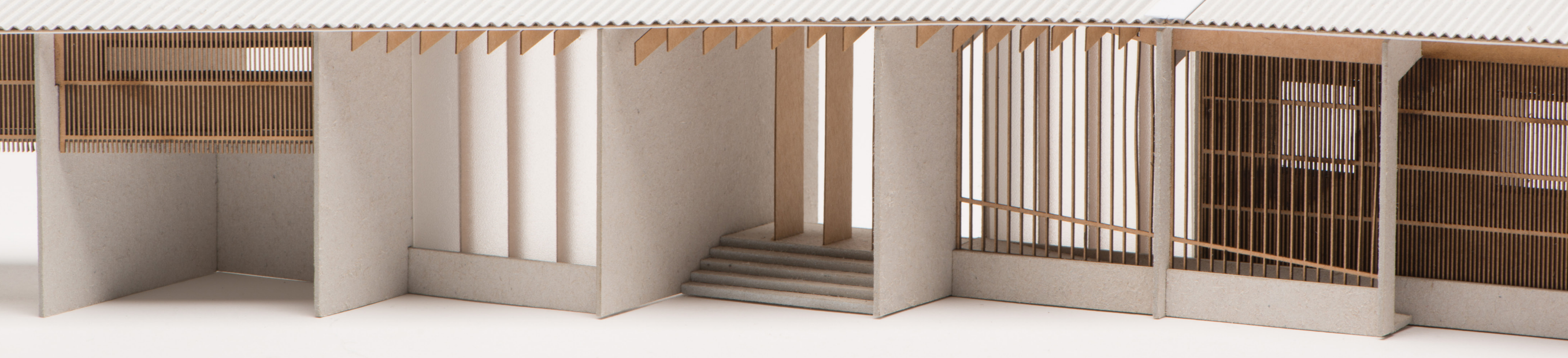


Chapter Seven

CONCLUSION 


\section{Device Based Process}

This research portfolio exhibits a range of architectural models built to investigate spatiality and image. Models began as simple scaled representations of possible space and in reaction to their photographic representations, developed into complex tools for design.

The final models are described as devices inspired by Bartlett lecturers; Nat Chard, Mark Smout \& Laura Allen. The term was adopted based on the fact that the models were designed to be operated. Smout \& Allen describe their models as "devices in the sense that they are supposed to be performative somehow" (Superscape, 2013, p.125). Like Smout \& Allen's devices, the devices in this portfolio implicate the viewer through a hands on experience. Each device is designed to compose a particular view of the proposed building in order to create photogenic moments. Although focusing on the image, the physicality of the devices implicate the spatial awareness of their operator, ensuring the architecture is understood in both two and three dimensions.

In an image saturated society it is important that architects practice with the medium of space. The physicality of making buildings demands an expertise that is familiar with the tactile and the physical (Sheil, 2005, p. 6). Renowned for the spatial qualities of his buildings Peter Zumthor describes how his design process "is based on a constant interplay between feeling and reason" (1988, p.19). Throughout the design process reason is integrated into each device. This included legally required dimensions and functional elements, while the overall composition is operated through feeling. Space is not often observed consciously so it makes sense to design it in the same way, intuitively.

The devices were designed in such a way that their operation would be a tool for designing architectural perspectives. However, in many cases the design of the device itself was just as, if not even more, enlightening into the qualities of perspective. This phenomenon has also been described about similar processes of Nat Chard and Smout \& Allen. Peter Cook remarks about Chard, "He produces machines that will observe, look, photograph, draw, compare: all of which become much more interesting and telling than the conditions or objects that are being observed" (2005, p. 2). While Smout \& Allen describe their own work, "They were not necessarily instruments that were meant to be used, in other words; the design of the instruments was itself the test (2013, p. 125). The device where this is most evident is the Island Aperture Device. Initial versions of the device included flimsy moving components such as the pitch of the roof. But by the time the final site ready version was made, the investigation into aperture was already complete. The final device ended up mostly tool for communication, offering a operational representation of the study. 


\section{Architectural Result}

Design processes are not just means to an end, they imbue the project with their nature. Chard remarks on this effect stating "Design medium is undoubtedly a contributing factor in the resulting architecture" (Drawing Instruments, 2005, p. 24). Just like the devices, the architectural product of this research could be described as an optical device through which the site is viewed and photographed. Smout \& Allen use the term instrumental architecture' to describe buildings of this manner. "Architecture that is the design, the landscape, the site, and the instrument that allows you to read all that, at once" (2013, p. 129). The resulting Bio-security centre design both blocks and offers views to draw inhabitants through each space to pre-determined perspective moments. These moments have been highly composed to exploit the qualities of perspective and create particular images. The building is composed in relation to the site, and in relation to itself. These moments, paired with strategic circulation designed in plan, result in a highly choreographed architectural journey.

For having an image focused design process, the building could be described as suprisingly humble. It attempts to highlight and compliment the surrounding natural beauty as opposed to drawing attention to itself. The majority of composed views focus outward, and the views towards the architecture aim only to make it more subtle in its context. The Dune Superimposition device resulted in deciding to shift the building back from the apex of the dune. This move was made in order to conceal the structure when looking east from the beach, and where there wasn't dunes to hide behind they were constructed, as demonstrated in the Two-way Mock-up. Resulting from the Boatshed Viewing Device the boatsheds were arranged to 'disappear' and draw attention to the island when seen from The prominent on-site perspective. The other remaining devices each in their own way also have an outward focus.
The design of the Biosecurity Gateway recognises and responds the nature of tourists and photography. Beautiful photo opportunities have been made easy for visitors as a result of compositions made in the design process. Kenneth Bayes describes a type of movement through space he calls the tourist where "the architecture is new, prominent and strange; one is exploring, open and receptive, moving and experiencing new things, investigating" (Porter, 2014, p. 44). In the design of the Kapiti Biosecurity Gateway this type of movement was heavily designed for. The designed journey is orchestrated as follows:

The first glimpse of Kapiti can be seen peeking over the roofline as you approach from Kapiti Road. Boating activity sits in the foreground making it appear as the place to go. Upon entering the carpark the subfloor fins encourage the viewer to align themselves where they are transparent. Walking up the staircase of the main entrance you enter the grand and spacious foyer filled with loca plants. Kapiti Island can be seen as a blurred silhouette through the polycarbonate back wall. The further you progress through the building the more of the Kapiti Island is revealed until you reach the dune pier, where it is displayed in its full glory. On the return journey back from the picturesque island visitors are faced with the harsh contrast and realities of urban sprawl. The image arranged as you exit the building is a composition of cars, parking, boating, pollution, stark concrete retaining, and an urban Paraparaumu backdrop. This journey acts as a narrative about the flaws of the image. For all their seducing benefits images can be problematic. Images can easily mislead viewers depending on how they are cropped and framed. The focus toward Kapiti Island forms the motif for the popular photographed romantic moments, while the Paraparumu view becomes the reminder that the genuine reality is not often how it is commonly presented in images. 


\section{Critical Reflections}

Murray Fraser explains that a crucial aspect of designled research is to "understand a method's preferences and limitations" (2013, p.2). The following section details a critical reflection on the final design process and the research portfolio as a whole.

The biggest flaw with the device based design process is that it is extremely time consuming. Because this is a process based research portfolio a decision was made to place huge emphasis and energy on developing a strong process over design resolution. As a result, the final design outcome is underdeveloped. In hindsight this was a mistake, as without a detailed design it is hard to fully evaluate the design process. A more fully resolved final design would have allowed for a more objective evaluation of each device.

The amount of different views in a building is near endless. I have no doubt that the design would have benefited from creating hundreds of devices to compose an equal quantity of views. However, because of the labour intense nature of physically modelling this is not feasible. This is where the more conventional method of $3 \mathrm{D}$ computer modelling shines as 3D computer software allows designers to quickly view digital models from any perspective.

While only a few perspectives were designed the spatial intuition central to the device operation was able to imbue the remainder of the building with a sufficient level of spatial quality. The views that were considered are of extremely high quality, and demonstrating a sophisticated manipulation of perspective qualities.
I believe the device based process is relevant to contemporary practice. It should however, be used sparingly unlike it was in this research. Used in moderation it could be very effective, designing street frontage for example, or any other demanding view. The process is effective at not only designing perspective but understanding the spatial implications. If I were to design using devices again they would only be supplementary to other methods. I would make a rough sketch device early on so the spatial implications could be felt. I would also build a final device in part to refine the composition, and also to demonstrate the concept to project stakeholders.

\section{Kapiti Island Biosecurity Gateway}

Alongside the process exploration, this research portfolio aimed to add to the longstanding conversation about the proposed Kapiti Island Biosecurity Gateway project. This project has been discussed for over twenty years, but only has a few feasibility studies to show for it. Project stakeholders are divided, meanwhile the biosecurity of Kapiti Island is put at risk daily. Informal chats and organised meetings were undertaken with stakeholders for both research and with the intention of sparking discussion. Two public exhibitions enabled me to share my work and hopefully capture and expand people's imaginations. 


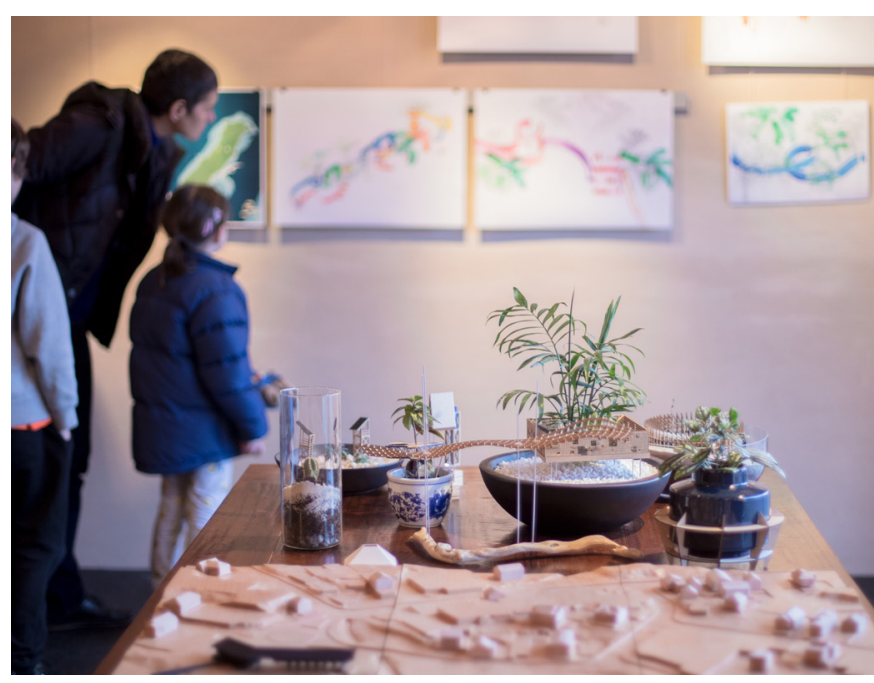

197. A selection of models sit next to the 1:500 site model. Kapiti Exhibitio

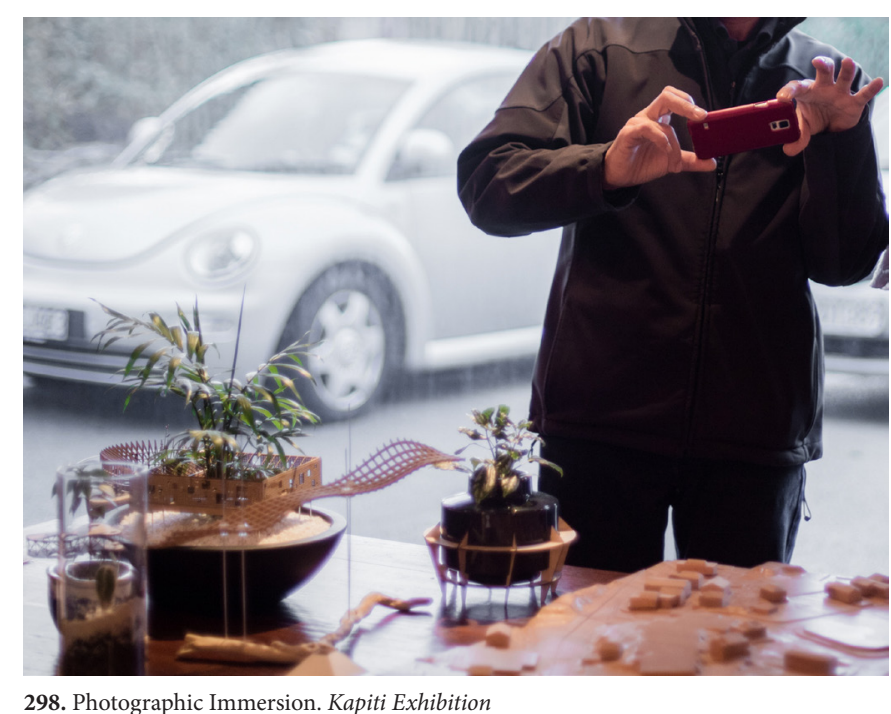

298. Photographic Immersion. Kapiti Exhibition 


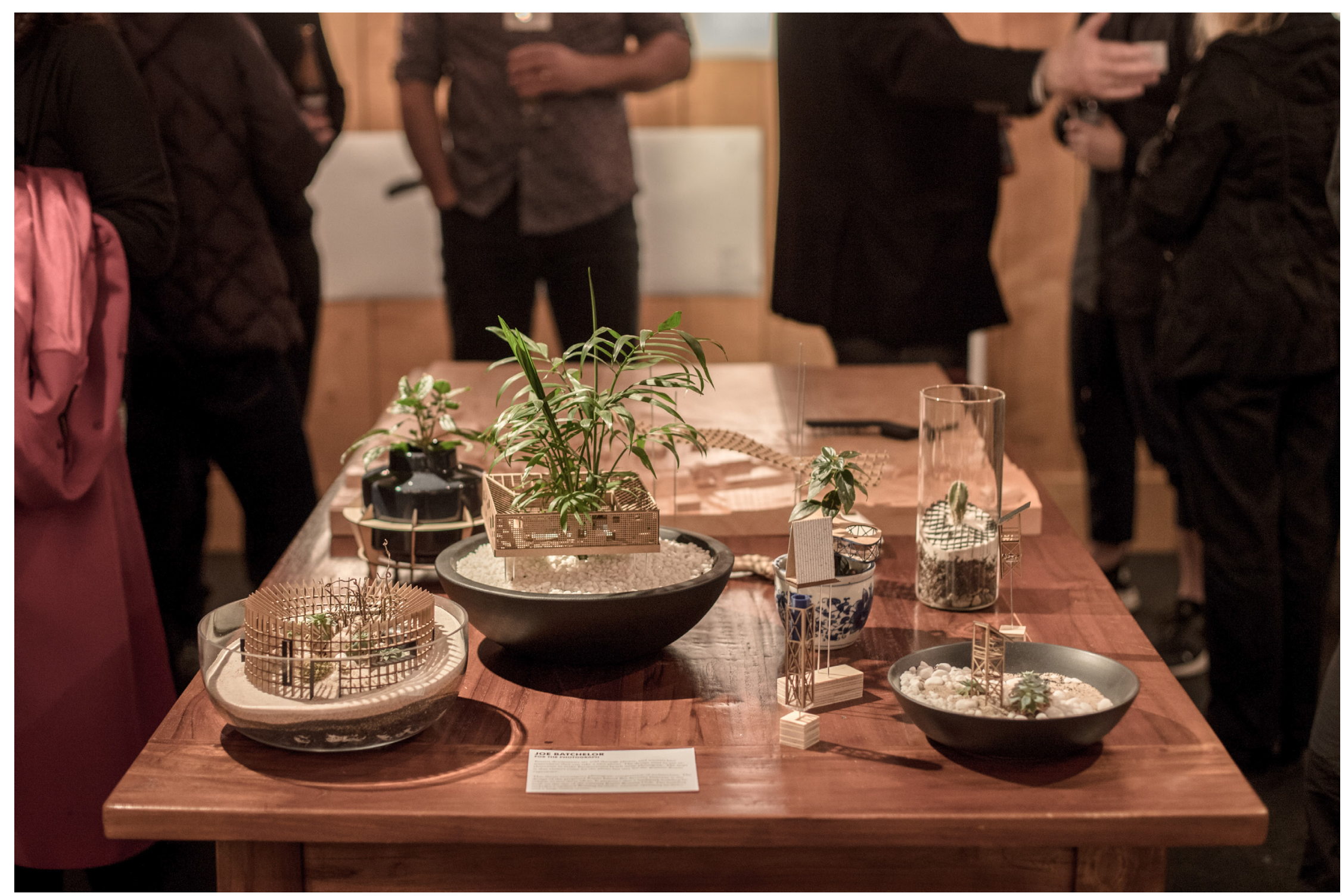


Allen, L., \& Smout, M. (2013). Superscape. (G. Manaugh, Interviewer) Spain: Ingoprint.

Chard, N. (2005, July/August). Drawing Instruments. Architectual Design, 75, 22-30.

Chard, N. (2011, Septmeber 16). Cold Bog Camera 1. Retrieved 03 01, 2018, from Nat Chard: https:// natchard.com/2011/09/16/cold-bog-camera-1/

Chard, N. (2015). Nat Chard: Drawing Indeterminate Architecture. Austria: Springer-Verlag/Wien.

Colletti, M., \& Sheil, B. S. (2009). Bartlett Designs; Speculating with Architecture. Sussex: John Wiley \& Sons Ltd.

\section{BIBLIOGRAPHY}

Cook, P. (2005). Introduction. In N. Chard, Nat Chard: Drawing Indeterminate Architecture (pp. 2-7) Austria: Springer-Verlag/Wien.

Debord, G. (1967). Society of the Spectacle. London: Rebel Press.

Department of Conservation. (2017, Feb). Kapiti Island Nature Reserve Brochure and Map. Wellinton, NZ: DOC National office.

Feireiss, L. (2010). In R. Klaten, \& L. Feireiss, Staging Space: Scenic Interiors and Spatial Experiences (pp. 2-4) Berlin: Gestalten. 
Fox, W. L. (2013). Dataland. In Manaugh, Landscape Futures (pp. 13-14). Spain: Ingoprint.

Fraser, J. (2017, March 29). Kapiti Island Tourism. (J. Batchelor, Interviewer).

Fraser, M. (2013). Design Research in Architetcure. Surrey: Ashgate Publisher Limited.

Gibson, R. (2006). Refractions; thought on aestheics and photogrpahy. Dustere: Steidl, Gottingen.

Haxton, D. (2016, August 23). Students to design Kapiti Island biosecurity hub. Retrieved December 2017, from New Zealand Herald: http://www2. nzherald.co.nz/kapiti-news/news/article.cfm?c_ $\mathrm{id}=1503789$ \&objectid $=11699327$.

Heidegger, M. (1977). The Age of the World Picture. In M. Heidegger, The Questions Concerning Technology and Other Essays. New York: Harper \& Row.

Hohauser, S. (1970). Architectual and Interior Models. New York: Van Nostrand Reinhold.

Kapiti Coast District council. (2017). Paraparaumu. Kapiti Visitor Guide. New Zealand: Kapiti Coast District Council.

Karssen, A., \& Otte, B. (2013). Model Making: Conceive, Create and Convince. Minnaepolis: Frame Publishers.
Levin, D. M. (1993). Decline and fall: Ocularcentrism in Heidegger's reading of the history of metaphysics. In D. Kleinberg-Levin, Modernity and the Hegemony of Vision. The University of California Press.

Lim, C. (2013, September/October). London Short Stories; Drawing Naratives. Architectural Design, 102-107.

Maclean, C. (1999). Kapiti. Wellintobn: Whitcombe Press.

Manaugh, G. (2013). Landscape Futures. Spain: Ingoprint.

Mills, C. B. (2011). Designing With Models. Hoboken: John Wiley \& Sons Inc.

Ockman, J., \& Fraustro, S. (2005). Architourism. Munich: Prestel.

Pallasmaa, J. (2015). The Eyes of the Skin: Architecture and the Senses. Chichester: John Wiley \& Sons Limited.

Pare, R. (1996). The Colours of Light. London: Phaidon Press LTD, 1996.

Porter, T. (2014). The Architect's Eye. Oxford: Taylor \& Francis.

Rendell, J. (2013). A Way with Words. In M. Fraser, Design Research in Architecture: An Overview (pp. 117-136). Surrey: Ashgate Publishing Limited.

Rousse, G. (n.d.). Biography. Retrieved Feburary 16, 2018 , from georgesrousse.com: http://www.georgesrousse. com/en/biography/. 
Schaik, L. v. (2008). Spatail intelligence; New Futures for Architecture. Chichester: John Wiley \& Sons LTD.

Sheil, B. (2005, July/August). Design Through Making, An Introduction. Architectual Design, 75, 5-12.

Smith, A. C. (2004). Architectual Model as Machine. Oxford: Architectural Press.

Smout, M., \& Allen, L. (2007). Augmented Landscapes. Pamphlet Architecture(28).

Smout, M., \& Allen, L. (2015). About. Retrieved December 12, 2017, from Smout Allen: http://www.smoutallen. com/about/.

Spiller, N. (2007). The Art of Touching the Ground Lightly. In M. A. Smout, Augmented Landscapes (pp. 4-5). Princeton Architectual Press.

TRC Toursim, Destination Planning Ltd, Pynenburg and Collins Architects Ltd. (2013). Kapiti Island Gateway Centre. Paraparaumu: Kapiti Coast District Council.

Zumthor, P. (1988). A Way of Looking at Things. Architecture and Urbanism, 6-26. 
02. LINZ. (2014). Wellington $0.3 \mathrm{~m}$ Rural Aerial Photos (2012-2013). Retrieved November 17, 2017 from https://data.linz.govt.nz

04. Instagram. (2017). Castlepoint, New Zealand. Retrieved July 03, 2017 from https://www.instagram.com/ explore/locations/263488446/castlepoint-newzealand/?hl=en

19. LINZ. (2014). Wellington 0.3m Rural Aerial Photos (2012-2013). Retrieved November 17, 2017 from https://data.linz.govt.nz

20. LINZ. (2014). Wellington $0.3 \mathrm{~m}$ Rural Aerial Photos (2012-2013). Retrieved November 17, 2017 from https://data.linz.govt.nz

\section{FIGURES}

54. Smout Allen. (2007). Pamphlet Architecture 28: Augmented Landscapes. New York, Princeton Architectural Press.

55. Smout Allen. (2015). Landmarks. Retrieved Feburary 22, 2018 from http://www.smoutallen.com/landmarks/

56. Chard, N. (2011). Nat Chard, Cold Bog Camera 1. Retrieved Feburary 22, 2018 from https://natchard. com/2011/09/16/cold-bog-camera-1/

57. Chard, N. (2011). Nat Chard, Cold Bog Camera 1. Retrieved Feburary 22, 2018 from https://natchard. com/2011/09/16/cold-bog-camera-1/ 
58. Chard, N. (2011). Nat Chard, Cold Bog Camera 1. Retrieved Feburary 22, 2018 from https://natchard. com/2011/09/16/cold-bog-camera-1/

59. Rousse, G. (2013). Georges Rousse in Rüsselsheim. Retrieved Feburary 22, 2018 from http://www. georgesrousse.com/en/archives/article/georgesrousse-in-ruesselsheim/

60. Rousse, G. (2013). Georges Rousse in Rüsselsheim. Retrieved Feburary 22, 2018 from http://www. georgesrousse.com/en/archives/article/georgesrousse-in-ruesselsheim/

Note: All unattributed figures belong to the author. 


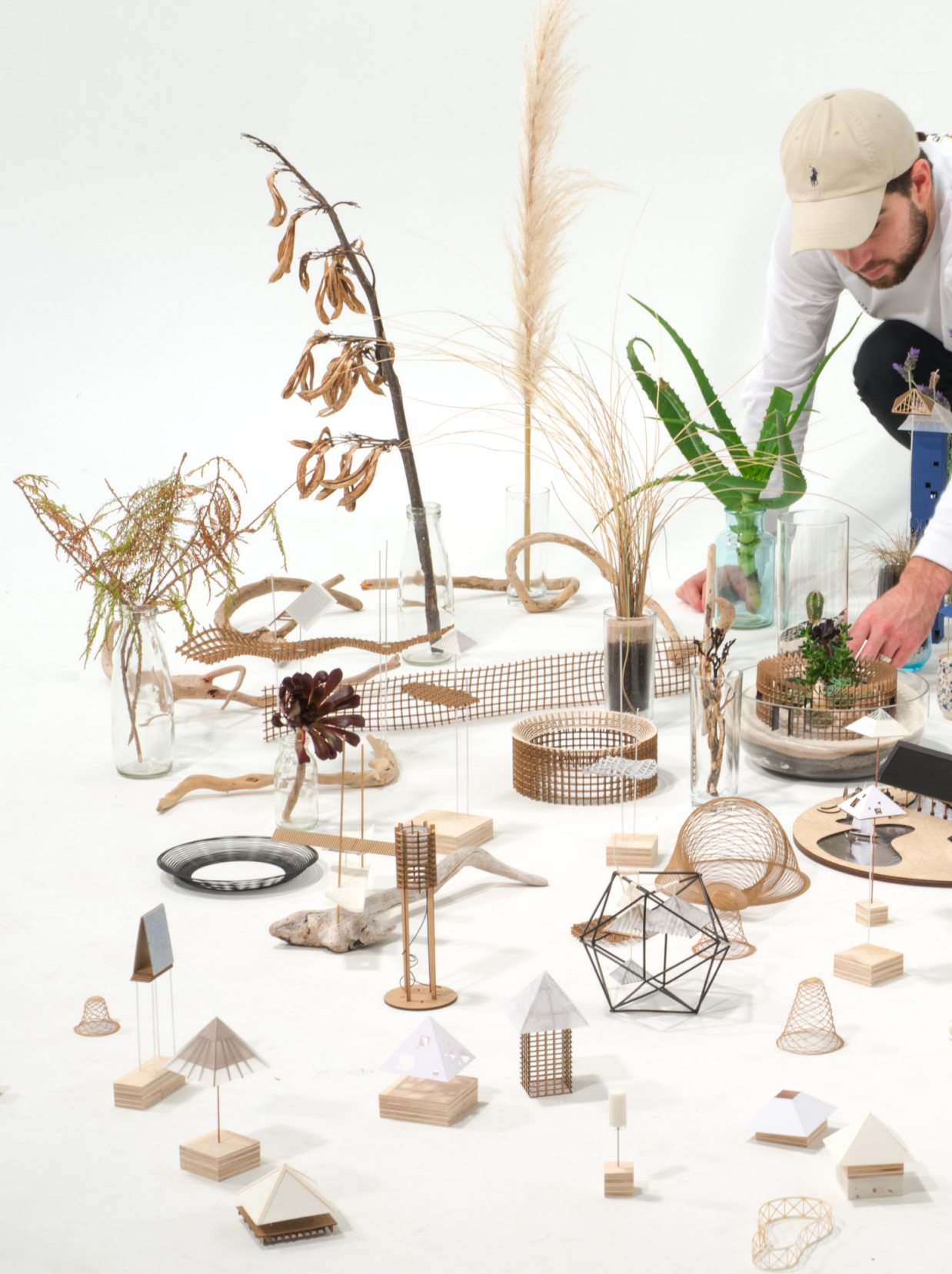

